\title{
ADAPTIVE MANAGEMENT OF TRADE ENTERPRISES: THEORY AND PRACTICE
}

\author{
The Monograph
}

Scientific editor:

Professor, Docor of Economics Viktoriia Hrosul

Kharkiv - Riga

2018 
Adaptive management of trade enterprises: theory and practice: monograph / V.Hrosul et. - Riga: RISEBA, 2018. - 171 p.

\section{Scientific Editor:}

Professor, Doctor of Economics Viktoriia Hrosul

\section{Authors:}

Balamut Hanna, Borysova Alina, Diadiuk Maryna, Fylypenko Olena, Kolesnyk Alina, Kruhlova Olena, Milash Inna, Muraviova Olena, Rachkovan Olha, Sinitsyna Halyna, Strazda Anna, Sukachova-Trunina Snizhana, Timchenko Olha, Zubkov Serhii

\section{Reviewers:}

Professor, Doctor of Economics Tatjana Vasiljeva (Latvia)

Associate Professor, Doctor of Economics Tatul Mkrtchyan (Armenia).

The text of this monograph was approved at the RISEBA University Scientific Committee meeting on October 2, 2018

RISEBA University of Business, Arts and Technology

Meza Street 3, Riga, LV-1048, Latvia www.riseba.lv

(C) RISEBAUniversity of Business, Arts and Technology, 2018

(C) Viktoriia Hrosul, Scientific Edition, 2018

ISBN 978-9984-705-41-5 


\section{CONTENTS}

PREFACE

CHAPTER 1. DEVELOPING AN ADAPTIVE MANAGEMENT SYSTEM OF TRADE ENTERPRISES, ITS THEORETICAL BASIS

1.1. Economic content of the category "enterprise adaptation"

1.2. Managing the process of trade enterprises adaptation

1.3. Adaptation strategy and its role in the system of adaptive management of trade enterprises

Conclusions to chapter 1

CHAPTER 2. METHODOLOGICAL BASES FOR THE FORMATION OF THE ADAPTIVE MANAGEMENT SYSTEM OF TRADE ENTERPRISES UNDER CONDITIONS OF THE EXTERNAL ENVIRONMENT DYNAMICS

2.1. Principles of forming adaptive management system of trade enterprises

2.2. The structure of the organizational and economic mechanism of adaptive management at trade enterprises

2.3. The toolkit for the formation of adaptive management system at trade enterprises

80

Conclusions to chapter 2

98

CHAPTER 3. METHODOLOGICAL SUPPORT FOR THE ADAPTIVE MANAGEMENT SYSTEM FORMATION OF TRADE ENTERPRISES

3.1. Competitive and financial potential as criteria of trade enterprise adaptation

3.2. Methodological approach to integrated assessment of the trade enterprise competitiveness potential

3.3. The methodology of the trade enterprise financial potential assessing during adaptation management system formation

Conclusions to chapter 3

CONCLUSIONS

APPENDICES 


\section{PREFACE}

The active development of trade in Ukraine during the last decade has led to an increase in its role in solving socio-economic problems. Creation of new workplaces and supplying of the state budget due to tax revenues depends directly on the efficiency of the activity of trade enterprises. Providing of the latter, in turn, is impossible without the timely adaptation of the industry to environmental changes. Ensuring a stable position of a trade company in the market, its sustainable development requires the development of an adaptation management system.

Domestic and foreign experience in providing sustainability and efficiency of operation of enterprises for a long time is the object of attention of scientists, specialists and entrepreneurs. The scientific bases of work are theories of adaptation of economic subjects of such researchers as G. Assel, B. Berman, O. Gradov, P. Drucker, M. Porter, J. Evans and others. The works of R. Acoff, O. Vihansky, M. Mescon, G. Mintzberg, N. Salomatin, A. Striklend, and others are devoted to the study of such problem as the environmental dynamism. Models, mechanisms, tools of adaptive management of enterprises are developed by V. Grinyova, A. Sapozhnikov, V. Shendrik, and others. Mathematical methods in management, the principles of system analysis, cybernetics, and synergetics are explained by L. Kontorovych, O. Vihansky, I. Gerchikova, G. Kleiner, and others.

Taking into account these achievements, it should be noted that the existing scientific papers do not cover the whole subject plane of the possible directions in the study of adaptive management through the discussion issues related to its conceptual adaptation management and the multifaceted criteria for evaluating its effectiveness. In addition, the matter of the research of methodical toolkit for the developing an adaptive management system that provides an increase in the efficiency of trade enterprises activity in a competitive environment hasn't been put into proper perspective.

The aim of the work is to develop theoretical and methodological principles and practical tools for the creation of adaptive management system of trade enterprises which are operating in a competitive environment. 


\section{CHAPTER 1}

DEVELOPING AN ADAPTIVE

MANAGEMENT SYSTEM

OF TRADE ENTERPRISES, ITS THEORETICAL BASIS 


\subsection{Economic content of the category "enterprise adaptation"}

Increasing the dynamism and uncertainty of the environment requires the mobility of enterprises, willingness to meet market needs, timely and adequate response to changes in the market situation. In the conditions of the unstable external environment of enterprises functioning and the increased level of its aggressiveness, which has recently been clearly manifested in the political, economic and social spheres, the horizon of strategic vision of any business entity is narrowing. It greatly complicates the implementation of the planned strategic goals and, accordingly, reduces the performance of many Ukrainian enterprises, adversely affects the "preservation of their presence" on the market.

Thus, according to the State Statistics Service [1], recently there has been a catastrophic decline in the net profit of Ukrainian enterprises and an increase in their losses, which in general leads to an increase in the number and proportion of loss-making business entities.

Under these conditions, special attention is given to increasing the efficiency and effectiveness of managerial decisions aimed at ensuring efficiency, competitiveness and development, which necessitates the use of adaptive management methods in modern management practice.

Recently, the interest in solving problems of adapting business entities to changes in the functioning environment has led to the expansion of the scientific field of research in this direction. Recently, many publications on the concept of "adaptation" have been published, while emphasizing the existence of significant differences in the definition of the essence of the concept itself, its place among other economic categories. The scientific discussion that unfolds on the basic concepts of the theory of adaptation is relevant to the present day.

Theoretical and methodological questions of enterprises adaptation are widely covered in the scientific works of domestic and foreign researchers: I. Ansoff [2], S. Alekseev [3], Zh. Krysko [4], B. Kleiner [5], O. Malyarchuk [6], A. Melnyk [7], I. Otenko [8], V. Yachmenova [9], V.Grosul [10], etc. However, despite of the undoubted achievements in the theoretical understanding of the essence of the investigated category, the continuous process of economic development and its current state require further research aimed at the creation of new modern approaches to the development of adaptive enterprise management system.

The current period of functioning of domestic trade enterprises is associated with a significant complication of economic conditions, which is due to the effects of crisis phenomena, which have long-term protracted nature. The global economic crisis, the negative consequences of which have not been overcome up to this day, has helped to increase the attention of scientists and practitioners to the problem of adaptation in the economy, in particular, enterprises adaptation to changes in the external conditions of their functioning. 
The processes of adaptation in economic management systems have been the subject of considerable interest by scholars and economists for a long time. And the transition of domestic enterprises to work in conditions of market relations has led to the fact that for most enterprises the nature of the external environment has been changed dramatically, as well as the nature of interaction with the environment. Thus, a surge of interest to the problem of adaptation in economic science took place at the end of the previous and at the beginning of this century [3; 11-21]. It was during this period that the problems associated with the activities of domestic enterprises under market conditions became more acute. This fact led to the emergence of a significant number of scientific works of predictive, programmatic and analytical orientation, which in some way were related to the problems of adaptation of Ukrainian enterprises to dynamic market conditions $[4 ; 7 ; 22-30]$.

Among the reasons that led to the need for the process of adaptation and management of this process, in addition to globalization and the global economic crisis, economists also called the following [31-36]: the emergence of technical and organizational changes, the volatility of the market situation, the instability of economic conditions in the country, the specifics of the resource and target components of the process of management decisions, the processes of management organization taking into account market regulation procedures, market nature of the processes of growth and development of market entities, intensification of the dynamics of globalization economic processes, excessive liberalization of market relations in conditions of outdated technologies, undeveloped organizational and economic mechanism of regulation of interaction between the participants of social and economic processes, changing organizational culture and business strategy, and others.

The word "adaptation" has a Latin origin. When translated from the Latin "adaptare" means "to adapt" [37], that is, adaptation is modification.

It should be noted that the concept "adaptation" refers to fundamental general scientific categories [38]. Thus, the problem of adaptation is the subject of research of a plurality of branches of knowledge, among which are biology, medicine, physiology, ecology, philosophy, psychology, sociology, cybernetics, economics, management, and others.

In our time, it is difficult to define a sphere of economy in which there would be no need for adaptation of objects and subjects of management. This, in turn, led to the availability of a wide and varied range of definitions of this category.

Thus, S. Ozhegov's thesaurus dictionary offers the following meanings of the term adaptation: "1) the process of change by which an organism becomes better suited to changing external conditions; 2) simplification of the text for the unprepared readers" [39, p. 27].

In the modern economic dictionary, is given the following definition: "Adaptation (from the Latin adaptatio - adaptation) - modification of the economic system and its individual subjects, workers, to the changing environment, production, labour, exchange, life. For example, in the transition from a centralized to a market economy there is an urgent need in enterprises adaptation and their employees to the market environment and to market relations" [40, p. 19]. 
The economic-mathematical encyclopaedic dictionary, under adaptation, suggests that it is "...the ability of the system to detect purposeful adapted behavior in complex environments, as well as the process of this adaptation itself" [41, p. 25].

In sociology, adaptation is "... active development by a person or group of a new for them social environment " [42, p. 21].

Corel L. V. argues that "... adaptation is an interdisciplinary term that is actively used in many areas of knowledge, such as natural sciences (biology, medicine, physics, cybernetics, etc.), as well as humanitarian (historical and social sciences) profile" [46, p. 63]. At the same time, the scientist notes that research papers about the problems of adaptation do not include a comprehensive approach, because each science studies adaptive problems autonomously [43].

Consequently, the analysis of literature shows that the term "adaptation" is polysemantic and is used in many ways. In various sciences there is a significant number of definitions of this concept and their modifications. Thus, in the scientific work "Philosophical problems of the adaptation theory", edited by G. I. Tsaregorodtsev, it was stated that "... the complexity of the problem of defining the concept of "adaptation" lies in the fact that, along with the distinction and consideration by each of the parties of the adaptation phenomenon, it is difficult to carry out synthesis and formulate such a definition of the concept from which it would be possible to deduce all the wealth of its forms" [44, p. 32].

Investigating the definition of "adaptation", Yu. A. Umantsev concluded that in its content and scope, the concept of "adaptation" is not only interdisciplinary, but also a rather complicated term [45]. By systematizing the definitions given in various encyclopaedias, the scientist identified certain inherent disadvantages [45]:

- circularity and lack of guidance on the essential and specific features that would contribute to the selection of adaptation itself;

- coverage by the definition of "adaptation" of, mostly, only one type of adaptation among the whole set of its existing types;

- due to this - lack of a correct definition of the category "adaptation" in general, and thus methodological developments on the possible ways of developing the doctrine of adaptation.

In turn, B. A. Efendiev [46] argues that the term "adaptation" is often viewed as:

- the system's ability to adapt to possible changes in operating conditions;

- the process of adapting the system to changes;

- a method based on the accumulation and processing of incoming data for achievement of a particular state by a system. In this case, the scientists objects of attention are the methods of adaptation and algorithms that use methods of adaptation; and the models built in this way are called adapted [46].

Chinese scientists Wang Yihua, Zhao Jianbo consider the term "adaptation" through the term "organizational immunity", which is a system that forms a protection mechanism based on the principle of "Detection - Protection - Remembrance" [47]. 
Foreign researchers Bruns Hille, Carlile Paul, Guettel Wolfgang, Konlechner Stefan, Karhade Prasanna, Shaw Michael, Subramanyam Ramanath, Miller Kent, Martignoni Dirk, Furneaux Craig, Tywoniak Stephane, Gudmundsson Amanda consider the process of organizational adaptation through the prism of the concept "routine", that is, special organizational knowledge, which is formed in the enterprise on the basis of its experience of functioning in the external environment [48].

Since adaptation, as a process of modification, is inherent in any system, adaptation is also characteristic for business systems (in particular, trade enterprises), which, from the point of view of economic theory, are open, and it makes it possible for them to interact with the external environment.

According to O. M. Kolodina, the term "enterprise adaptation" has a historically formed substantive content [49, p. 204]. In turn, a group of scientists G. V. Kozachenko, V. P. Ponomaryov and O. Lyashenko [23] investigated the history of this economic category establishment at different stages of development of domestic economic thought. Thus, the initial enterprise adaptation was interpreted as "the degree of enterprises involvement in market forms of management"; later, in the process of evolution in the views of scientists, it began to be understood as "survival, or rather, the maintenance of production afloat"; at the present stage, enterprise adaptation is interpreted as "the degree of development of "new rules of the game", new methods of production and financial activity of the enterprise in a completely different external environment" [23]. Gradual increase of the interest of scientists in the study of the problem of enterprises adaptation was accompanied by a variety of author definitions for this economic category (Annex A, Table A. 1).

In order to comprehensively examine and disclose the essence of the concept of "enterprise adaptation", we analyzed the works of economists in scientific and literary sources $[3-4 ; 7-9 ; 11-30 ; 38 ; 44 ; 49-62]$, which made it possible to systematize the definition of this economic category in five main key accents, the results of which are presented in Table. A. 1. (Annex A).

Among the main key accents of the interpretation of the category "enterprise adaptation" are the following (Figure 1.1):

1) enterprise adaptation as a process. 


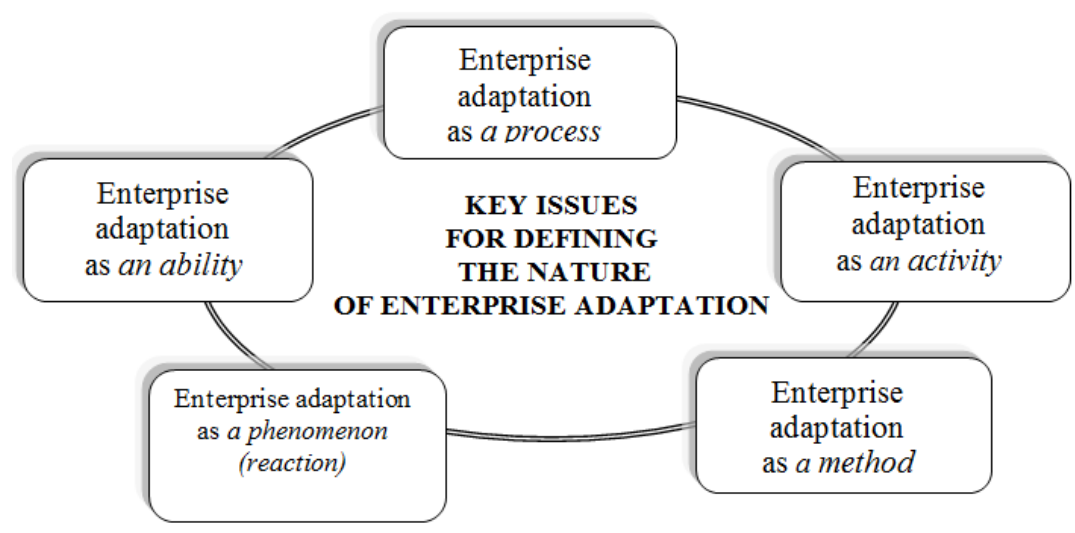

Figure 1.1. Key issues for defining the nature of category "enterprise adaptation" (author's development)

In this case, the term "enterprise adaptation" describes the process of its suitability to changing conditions of its operation. At the same time, adaptation can not necessarily be caused by crisis phenomena. It includes any changes in the external and internal environment that the enterprise interacts with. It should also be emphasized that the processes of adaptation at the enterprise are carried out constantly, accompanied by its functioning and development;

2) enterprise adaptation as an ability.

In this case, it is said about the ability of the company to adapt to changing environmental conditions. That is, the enterprise adaptation manifests itself in its ability to convert the options of the internal environment under the influence of the environmental options;

3) enterprise adaptation as an activity.

In this case, the key emphasis in defining the term "enterprise adaptation" is made on the activities of the company, aimed at changing certain key elements in its internal environment, as a response to environmental changes;

4) enterprise adaptation as a phenomenon (reaction).

With emphasis on this key point, the category "enterprise adaptation" is regarded as the phenomenon of economic entity reaction to the dynamic changes of the external environment and internal conditions of its activities;

5) enterprise adaptation as a method.

In this context, we are talking about revealing the essence of enterprise adaptation through its economic mechanism, that is, as a set of measures, forms, means, methods, actions, levers, procedures, etc., aimed at adapting the enterprise to change in its operating environment.

So, an analytical review of scientific and literary sources devoted to the problem of enterprises adaptation has allowed to reveal certain conceptual positions of the authors in approaches to the interpretation of enterprise adaptation, disclosure of its essence and substantive content, and also to establish the ambiguity of scientists`opinions about the 
content of the concept "enterprise adaptation". On the basis of the study, it was found that the overwhelming majority of scholars $[7-9 ; 11-13 ; 22-24 ; 29 ; 32 ; 38 ; 47-50 ; 57]$ tend to understand the enterprise adaptation as a process of adapting the parameters of economic entities to new, uncertain conditions of the environment, which provides an increase in the efficiency of their functioning. Also there is a fairly large number of supporters who consider the enterprise adaptation as a phenomenon of the system reaction to changing environment conditions $[17-21 ; 26-27 ; 44 ; 55-56]$ and activities to change certain key elements $[3 ; 15 ; 28 ; 53-54 ; 60-62]$. The perspective on adaptation as a set of suitability methods (or survival) of the enterprise $[14 ; 16 ; 49 ; 58]$ is less popular among the scholars.

In the context of focusing attention on "ability" while interpreting the essence of the category "enterprise adaptation" $[4 ; 25 ; 51-52]$, it should be noted that the developed level of quality of enterprise adaptive capabilities determines the direction of change in its adaptation to volatile environmental conditions. It is the adaptive capabilities which the enterprise possesses that allow to perform a qualitative analysis of changes and the timely detection of signals from the environment, according to which the balance of interests between the external environment and the enterprise should be ensured for the purpose of effective functioning and development.

In general, the study leads to the conclusion that, despite the difference in the author's position according to the refined focus on the interpretation of the essence of economic category "enterprise adaptation", each of them aims to adapt the enterprise based on the use of its dynamic properties and the final comparison of the goal of adaptation and its outcome.

In addition, surveys of the category "enterprise adaptation" and its content according to a plurality of literary sources provided the opportunity to identify the reasons for the lack of a single point of view on the essence of the enterprise adaptation among the researchers; it includes: insufficient consideration of adaptation time period in the process of enterprise activity; controversy about the purpose and result of enterprise adaptation; lack of sufficient study and specification of the level of management adaptation at the enterprise; the diversity of scientists' views about a clear list of processes that encompasses enterprise adaptation; the lack of a key property of the enterprise, which is the basis of effective enterprise adaptation.

Solving these issues in formulating the definition of "enterprise adaptation" should contribute to a deeper understanding of its content and a full understanding of the essence.

Thus, taking into account all of the foregoing and basing on the results of the study, in our opinion, the enterprise adaptation is a systematic process of its accommodation to the variability of the environment, implemented through a set of targeted adaptive measures and changes (reactions); it has a strategic nature, accompanies the entire life cycle of the company and is aimed at ensuring the effectiveness of its functioning and development [63].

In addition, the ability of an enterprise to adapt to changing environmental conditions is characterized by the notion of "adaptability", under which we propose to understand the ability of the enterprise to timely and competently determine the vector of necessary changes in its activities, in accordance with the environmental conditions, on the basis of combining their own adaptive properties and abilities. It is the company's ability to adapt that helps its development. We espouse the opinion that this ability is 
inherent to all enterprises, without exception. However, enterprises differ in their abilities to adapt. Adaptability of the enterprise may be different, depending on its capacity and ability to quickly respond to the changes that arise, by developing a special mechanism of adaptation that would allow the company to acquire new properties.

In order to determine how a particular company needs adaptation, it is necessary to obtain the characteristics of the environmental behaviour (complexity, dynamism and uncertainty) and assess the degree of the enterprise adaptability to each environmental parameter.

As a basis for the development of key adaptive properties and capabilities of the enterprise, it has been proposed to use business processes (basic, managerial, business processes of integration and development), which include business skills of the enterprise, on the basis of which the ability to completely determine the vector of the necessary transformational changes. It is this approach, in our opinion, that characterizes the ability of a particular enterprise to adapt to the conditions of the environment.

Based on this, the adaptability of the enterprise $\left(S^{A}\right)$ is determined by the following sequences of business processes:

$$
\mathrm{S}^{\mathrm{A}}=\left\langle\mathrm{BP}^{\mathrm{B}} ; \mathrm{BP}^{\mathrm{M}} ; \mathrm{BP}^{\mathrm{I}} ; \mathrm{BP}^{\mathrm{D}}\right\rangle
$$

where the $\mathrm{BP}^{\mathrm{B}} ; \mathrm{BP}^{\mathrm{M}} ; \mathrm{BP}^{\mathrm{I}} ; \mathrm{BP}^{\mathrm{D}}$ are a sequences of business processes (basic, managerial, business processes of integration and development), the quality of management which characterizes the degree of enterprise adaptability to the environmental changes.

The quality of a particular business process is determined by the sequences of the business skills of the enterprise, which allows monitoring and evaluating non-typical "signals" of the environment and implement unusual adaptive management solutions in time:

$$
\begin{aligned}
\mathrm{BP}^{\mathrm{B}}= & \left\langle\mathrm{bN}_{1}^{\mathrm{B}} \mathrm{bN}_{2}^{\mathrm{B}} ; \ldots ; \mathrm{bN}_{\mathrm{n}}^{\mathrm{B}}\right\rangle \\
\mathrm{BP}^{\mathrm{M}} & =\left\langle\mathrm{bN}_{1}^{\mathrm{M}} \mathrm{bN}_{2}^{\mathrm{M}} ; \ldots ; \mathrm{bN}_{\mathrm{n}}^{\mathrm{M}}\right\rangle \\
\mathrm{BP}^{\mathrm{I}}= & \left\langle\mathrm{bN}_{1}^{\mathrm{I}} \mathrm{bN}_{2}^{\mathrm{I}} ; \ldots ; \mathrm{bN}_{\mathrm{n}}^{\mathrm{I}}\right\rangle \\
& \mathrm{BP}^{\mathrm{D}}=\left\langle\mathrm{bN}_{1}^{\mathrm{D}} \mathrm{bN}_{2}^{\mathrm{D}} ; \ldots ; \mathrm{bN}_{\mathrm{n}}^{\mathrm{D}}\right\rangle
\end{aligned}
$$

where $\mathrm{bN}^{\mathrm{O}, \mathrm{y}, 3, \mathrm{P}}{ }_{\mathrm{i}}$ is a sequence of business skills of an enterprise that characterizes the ability to adapt to environmental changes in accordance with basic and managerial and business processes of integration and development.

In turn, business skills for each business process form a unique sequence of combinations $(\&)$ adaptive properties $\left({ }^{A} P_{i}\right)$ and abilities $\left({ }^{A} A_{i}\right)$ unique to a particular enterprise:

$$
\mathrm{bN}^{\mathrm{B}, \mathrm{M}, \mathrm{I}, \mathrm{D}}=\left\langle{ }^{\mathrm{A}} \mathrm{P}_{1} \&{ }^{\mathrm{A}} \mathrm{A}_{1} ;{ }^{\mathrm{A}} \mathrm{P}_{2} \&{ }^{\mathrm{A}} \mathrm{A}_{2} ; \ldots ;{ }^{\mathrm{A}} \mathrm{P}_{\mathrm{n}} \&{ }^{\mathrm{A}} \mathrm{A}_{\mathrm{n}}\right\rangle
$$


Considering that each business entity is characterized by an individual set and a combination of adaptive properties and abilities, the possibilities and results of enterprise adapting to the environmental changes are different for every particular enterprise.

Thus, summing up the available theoretical work on the subject of research, based on the study, the following conclusions can be made. The increase in competition, the development of globalization processes, changing consumer demand and benefits, determine the high level of environment dynamism. Ensuring the balance of economic interests between the enterprise and the external environment is possible on the basis of a timely solution to the problems of enterprises adaptation. Within the various theories of the enterprise, the essence and key aspects of adaptation are treated differently, which finds an appropriate reflection in the subject and object of adaptation. However, in general, the main goal of "adaptation" for each theory of the enterprise is to "resolve contradictions" or "adapt" the activities of business entities to the external environment. A key aspect of adaptation is the "ability" to determine timely and competently the vector of necessary changes in the enterprise activities in accordance with the conditions of the environment based on a skilful combination of adaptive properties and abilities. The proposed model of adaptive properties, their development and abilities contributes to the flexibility, mobility, and acts as the "guarantor" of the timely reaction of the enterprise to the "challenges" of the business environment.

\subsection{Managing the process of trade enterprises adaptation}

Nowadays, more and more attention of scientists and practitioners is paid to solving the problem of enterprises adaptation to dynamic market conditions, which determines the success of their economic activity and provides the basis for long-term development. At the same time, most modern scholars [16; 34; 64-67] believe that adaptation is not just a process, but a process that is constantly evolving. Accordingly, there is a need to manage this process. The market situation has changed - the mechanism of adaptation is included, and in the classical version it should work on the advance or synchronously [68].

At the same time, the experience of recent years shows that the vast majority of domestic trade enterprises are poorly trained to operate under the changing conditions of the market environment, and their managers do not, for the most part, possess the methods and practical tools of the struggle for survival in a dynamic competitive environment. In this regard, the theoretical and practical developments including the trade enterprises adaptation in a competitive environment, organization and management, aimed at maintaining the consistent matching of demand and supply of goods and services, is a topical issue of the present. This in turn causes the need for research and classification of factors influencing the adaptability of trade enterprises to dynamic market conditions.

The scientific papers of many scholars, including O. M. Avraamova, M. N. Budnik, Ye. S. Galushko, S. A. Galushko, S. M. Glagolev, G. I. Dibnis, E. V. Demyanova, A. V. Kozachenko, Yu. L. Stepanova and other [16; 23; 34; 64-67; 69] are 
devoted to the study of factors influencing the enterprises adaptability. At the same time, the study of factors influencing the adaptability of trade enterprises to the dynamic conditions of the market, taking into account their industry specificity, was largely left out of the scientists' attention.

In modern conditions, the process of trade enterprises adaptation to change in environmental conditions of operation should be active, because it is possible to operate in crisis conditions successfully only when the work community itself chooses and implements the tactics of intensive enterprise development, not just the tactics of survival. We associate the process of active adaptation to changing environment with the ability of the work community in the conditions of changed macroeconomic regulation to enter the regime of normal functioning, and thus help the enterprise achieve the level of expanded reproduction to the limits of sufficient profitability, which allows to recover the expenses, to execute an obligation to investors, state and work community.

Today, the task of ensuring the adaptability of trade enterprises in a changing competitive market environment requires a continuous search for new organizational approaches to its solution. At the same time, today the economic content of the task is to determine sufficient (minimum required) level of initial investment to launch the adaptation mechanism and further costs in support of the adaptive state of the trade system operating system in order to maintain the viability and development of the business entity in a competitive environment.

The goals of successful enterprises can be classified according to the current conditions in four types: development of new directions and areas of activity, building the capacity in the chosen field, survival and maximization of current profits. Accordingly, the first and second goals are strategic, and the goals of survival and maximizing profits are tactical. Consequently, survival characterizes the adaptive-passive line of development of a trade company, while maximizing profits is adaptively-active.

Concerning the definition and development of strategic directions of economic activity, the works of S. M. Glagoleva [65-66], in which, in particular, the concept of strategic management is considered, are of interest. Also, the emphasis is placed on the primary support of "economic growth based on a developed market economy" [65, p. 87]. And the efficiency of management is expressed in the fact that economic growth, as the main object of management, in the strategic long-term perspective allows us to more fully realize the set of economic goals and implement new large-scale programs [23].

Economic growth is determined by the influence of various factors and the ability to use them, in accordance with the specific conditions of the functioning of the economy as a whole and enterprises, in particular. These include: the quality of management at all levels of the hierarchy, the impact on the scope and scale of the technology used, the diversification of activities, the impact on the sale of goods (services), market laws, commodity exchange, etc.

The action of the above-mentioned factors can be traced to two levels:

- micro level - the implementation of the laws about operational activities, the implementation of the laws about commodity exchange, development (sources of funding, tax incentives) of matching of production opportunities with the needs of the market, etc.;

- macro level - factors of social development, level of state regulation of economic processes, level of development of productive forces, participation in the 
international division of labour, socio-economic and political stability, level of monopolization of natural resources, demographic factors, state investment policy (tax and credit policy, grants and subsidies, regulation of finance), etc.

The differences in the factors of macro- and micro-levels are due to the fact that economic growth at the state level, on the one hand, is a derivative function of economic growth in the enterprise, and on the other - depends on the state policy, on the economic mechanism used by it. Since economic growth at the state level is derived from the economic growth of each enterprise, the state must make a careful analysis of the development of productive forces, the rate and factors of economic growth, their features in order to have a real basis for practical activity. The state must at one time specify the specific problems of economic growth, the resolution of which requires its interference. Consequently, constant monitoring (observation) of adaptation processes under conditions of improvement and development of market relations becomes one of the main functions of the state.

Of course, the activity of any enterprise, ultimately, is aimed at profit. But this is an internal problem for each business entity. An enterprise is able to survive, adapt to the market only when it can satisfy a certain need of the environment. Therefore, when substantiating the strategy of the enterprise, in particular the strategy of adaptation, first of all, it is necessary to study the external environment.

The analysis of the environment means the process by which strategy developers control the external factors of the enterprise in order to identify opportunities and potential hazards. The study of the environment opens for the trade company the means of timely response to threats to the economic entity that appeared on the market and the ability to develop adaptation measures that are able not only to prevent these threats, but also to obtain favourable opportunities from the given situation.

The problem of survival is of the same importance - the definition of the internal capacity, strengths and weaknesses of any trade company. For this, it is necessary to consider the marketing activities of the enterprise, its financial status, to analyze the management of trade and technological processes and operations, personnel, the image of the enterprise, etc.

It should constantly be noted that the external environment is very active (multifactorial); it affects the state of the trade company. The latter constantly has to be adapted to it, at the same time adjusting its adaptive system (self-adjusting, selforganizing). In this regard, in our opinion, the mechanism of adaptation is an integral part of the organizational and economic activity of successful enterprises.

The socio-economic development of trade enterprises shows that the insufficient efficiency of business entities in the industry is related not only to unfavourable macroeconomic conditions, but also largely depends on their ability to navigate in a changing competitive market economy.

Now a top priority is adaptation of enterprises, in particular trade, to dynamic market conditions, the solution of which determines further prospects for our state development.

During the process of developing the adaptation measures for a particular trade company, we consider it necessary to take into account the main internal brand factors influencing the adaptability of trade enterprises, which are proposed to be combined into three main groups; each is required to apply appropriate adaptation measures. 
The first group - organizational and economic factors - includes: the use of techniques and methods for increasing the intensity of economic activity; solution of such complex problems as improving the trade enterprise size structure, rationalization and the choice of format among the trade enterprises, their commodity specialization; further development of specialization and cooperation; improvement of the labour organization, trade and technological processes; reduction of economic risk; improving the quality of business plans and forecasting; strengthening of labour motivation; professional development of personnel.

The second group - trade and technological factors that contribute to the competitiveness of the trade company, the prevention of bankruptcy, the adaptation of the trade company to the changing market conditions in economy - includes: improving the use of all types of resources, technical and technological potential of a trade company; improving the quality of goods and the level of trade services; reduction of resource and labour intensive trade activity; optimization of trade and technological processes, trade and technological structure of industry; introduction of effective technologies.

To the third group - social factors contributing to the development of mechanisms for adaptation, motivation and labour activity - can be attributed to the following: increase in wages; stimulating the development of creative abilities, innovation, creativity of personnel, managers, and specialists; reduction of income differentiation by groups of employees; increase in the rate of substantive work content; development of enterprise social infrastructure; improvement of working conditions and quality of life; changing the status of the hired employee; increasing the culture of trade services.

Trade and technological, organizational, economic and social factors contributing to the adaptation and increase of the trade business efficiency are closely interconnected. At the same time, it should be noted that only their systematic use ensures maximum synergistic effect.

In the course of study, we have identified general important measures that allow commercial enterprises to successfully adapt in a changing competitive market environment. Among them:

- advanced training of managers, specialists and a core staff in the direction of preparing them for work in a dynamic competitive environment;

- creation of subdivisions and services that meet modern market requirements (financial services, economic and legal work, monitoring, etc.);

- search, selection and involvement of specialists with the necessary knowledge and practical experience in the field of management, marketing, information technologies, financing and lending, securities, entrepreneurship, etc.;

- optimization of economic and financial activity of the enterprise in order to ensure the most effective level of realization of its resource potential, rational choice of commodity specialization within the trade enterprise;

- application of new techniques and modern technologies;

- updating of equipment and machines on the basis of leasing operations;

- creation of own shops and production units;

- development of commercial connections, expansion of the trade chain and stores;

- improvement and development in systems and forms of the enterprise personnel stimulation (expansion of the hiring contractual system and remuneration of specialists, introduction of modern insurance programs for the workers, etc.); 
- active cooperation with scientific and educational institutions, etc.

It should be noted that the main parameters that determine the success of trade enterprises adaptation to the external environment are: the period of the company existence on the market; the scale of its economic activity; material and technical level of the enterprise; the effectiveness of its activities; financial position; the development of economic and market infrastructure (consulting services, market information, etc.); relations with business entities and public administration bodies, which collectively form the external environment of a trade enterprise; the state activity regarding the creation of the environment for economic entities (legislation, infrastructure, etc.).

In today's market conditions, the ability to adapt to a constantly changing environment is a guarantee of enterprise survival. This issue is especially relevant for trade enterprises that operate on the consumer market and, along with adaptation to the general influence of dynamic environmental factors, are forced to constantly adapt to the variability of consumer demand and buyers' preferences in goods and services. This factor impedes the management process of trade enterprises adaptation significantly. In order to activate this process, it is necessary to identify the essence of the problem of managing the trade enterprises adaptation in order to identify the main directions in its solution, which, in turn, requires the study and revealing of the theoretical foundations in the system of adaptive management of industry enterprises [70].

Despite the fact that the problem of trade enterprises adaptive management, adequate to external and internal changes, is crucial for improving the efficiency of economic entities, nowadays they are underemphasized, because the management of the companies is forced to solve a multitude of current problems simultaneously, and it covers most of its time. At the same time, the reaction to the change of the market environment is situational and in many cases is belated, which ultimately leads to additional costs, both economic and psychological [71].

As it was noted above, the problem of enterprise adaptation to the dynamism of the business environment and its functioning has no interdisciplinary research constraints. In this connection, the research of adaptive management of enterprises was carried out by many scientists, among them V. Goncharov, Y. Kapitanets, P. Kulikov, A. Kucherenko, T. Landina, A. Melnyk, Y. Stepanova, I. Stets, Yu. Tkachenko [7-24; 28; 72-77] and others. Fundamental works and applied developments on the problems of adaptive management of enterprises were executed by these and other researchers and deserve a high praise.

At the same time, most papers are devoted to the study of the essence and content of adaptation process, as well as adaptive management of industrial enterprises. That is, in the context of sectoral specifics, there dominate papers dealing with research adaptation of production, but not trade enterprises. Trade enterprises are especially in need of adaptation management tools that are adequate to the current realities of the development of external environment, which in turn requires the formation of the theoretical basis in the system of adaptive management of trade enterprises.

Use of the system approach in the study allowed allocating functional subsystems of the trade enterprise, among which: trade and technological subsystem; financial and economic subsystem; subsystem of personnel; control subsystem and others. Quite often the literature distinguishes other functional subsystems, the appearance of which is due, in most cases, to the key features of a particular enterprise activity. 
Obviously, the adaptation management of these subsystems is complicated by the functional heterogeneity of control objects and causes the need for the development and use of various adaptation control tools.

According to world experience, adaptation management tools are a fairly large and diverse regulatory structure that is constantly changing and complemented with the aim of the most effective management of enterprise adaptation. All this is due to increased competition, the complication of business conditions, and, consequently, the emergence of new varieties and types of adaptation, which were ineligible to the previous conditions of enterprises operation.

When forming an adaptation management system at the enterprise it is necessary to take into account the principles of its development, implementation and functioning (realization).

It should be noted that to organize the system of adaptive management of the trade company, as well as any other management system, one should obey certain organizational and methodological principles. In this context, the principles in the system of adaptive management of the enterprise are considered to be divided into three groups:

1) general principles related to the entire system of management of trade enterprises;

2) private principles relating specifically to the management of the system of adaptation of trade enterprises;

3) specific principles expressing the individual (specific) features of the regulation of the processes of adaptation of trade enterprises.

The defined task requires the study of the private principles during the development of adaptive management system or of trade enterprises, which, on the one hand, determine the peculiarities of the internal organization and functioning of the system of adaptation management of economic entities in the industry, and on the other hand - fulfil the general principles of management of enterprises adaptation.

On the basis of the analysis of literary and scientific sources $[7 ; 24 ; 28 ; 72-79]$ we formulated the following principles of the development within the system of adaptive management of trade enterprises (Figure 1.2).

\section{The principle of a unified structural integrity into the system of enterprise adaptive management with general system of management.}

In this case, the subsystem of adaptive management is considered as the necessary structural element in the overall system of trade enterprise management, which increases the efficiency of its stable functioning. It should be emphasized that the subsystem of adaptive management is simultaneously special and relatively independent component of the overall managerial system within a trade enterprise, which is directly related to the general principles of development, adoption and implementation of organizational and managerial decisions. Consequently, on the one hand, the subsystem of adaptation management is aimed at the development of managerial decisions, but on the other hand, it performs the function of control over the implementation of the adopted decisions in the field of trade enterprise management and its adaptation. 


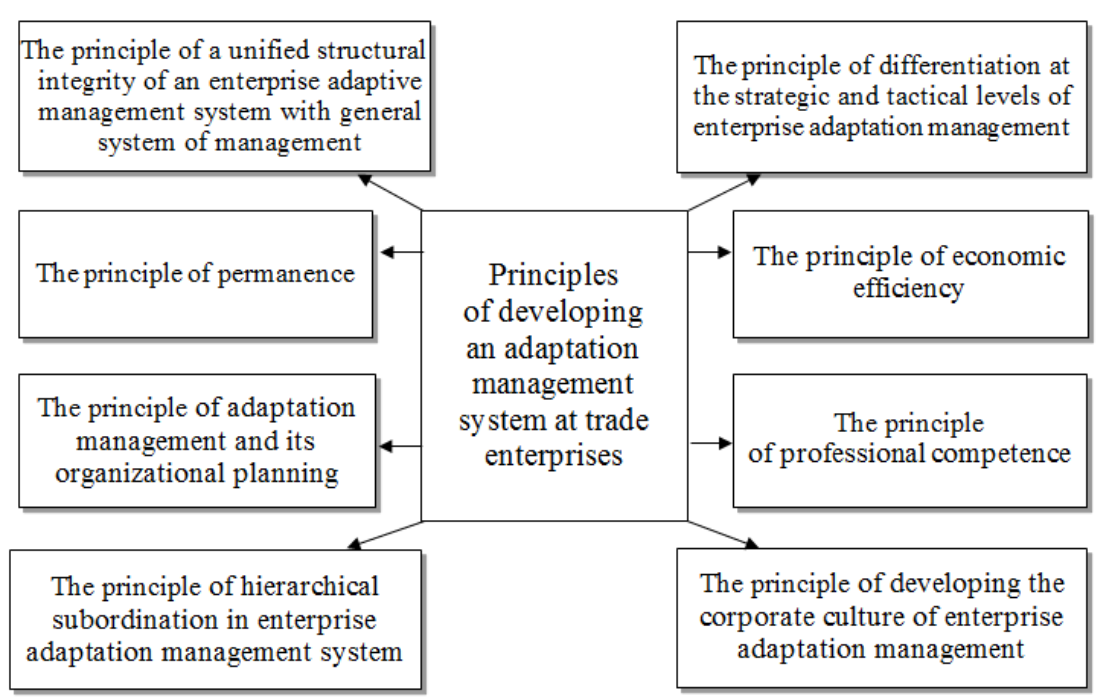

Figure 1.2. Principles of developing an adaptation management system at trade enterprises (on the basis of $[7 ; 24 ; 28 ; 72-79]$ )

\section{The principle of permanence}

This principle implies continuity of adaptation management process at the enterprise. Instability of the operation environment in a trade company, due to various factors and causes, requires the adoption of appropriate management actions and influences on the part of the economic entity. In essence, adaptation management should be considered as a set of concerted management actions for adaptation that is one of the most important functions of enterprise management.

In this context, the process of adaptation management can be represented as a continuous purposeful organizational and methodological process of the adaptation management system (as the subject of enterprise adaptation management) on the processes of enterprise adaptation (adaptation objects) in order to achieve competitive advantages of the enterprise and ensure the stability of its functioning in strategic perspective.

\section{The principle of differentiation at the strategic and tactical levels of enterprise adaptation management.}

The content of the formulated principle consists in the need to allocate adaptation management processes at the strategic and tactical levels of trade enterprise management. In our opinion, it should be noted that the structure and genesis of the enterprise adaptation at the strategic and tactical levels are significantly different. In this regard, there is a need in the segmentation of adaptation processes of strategic and tactical nature [80].

The main differences in the strategic level of enterprise adaptation from the tactical level are as follows. Firstly, strategic adaptation has a very high impact. Strategic adaptation which has not been implemented can lead to the exit of the company from the 
market, a significant loss of capitalization, etc. Secondly, the strategic enterprise adaptation has a significant time period. In strategic adaptation, the time span from the moment where we are located, to the point when it is realized, is much greater than that of the adaptation of another kind. Therefore, concentration only on tactical adaptation can lead to the fact that its management results will be unclaimed in the long run.

\section{The principle of organizational planning of adaptation management.}

This principle organizes the functioning of adaptive management system and allows each participant in the process to act logically, consistently, clearly fulfilling the responsibilities assigned to him and solving the tasks that are facing him. The activity on enterprise adaptation management is organized on the basis of a unified idea, which is incorporated into a comprehensive program and specific plans for particular areas and subsystems.

\section{The principle of economic efficiency.}

The proposed principle means that the system of a trade enterprise and its adaptive management must be constructed so that the means and money for its support are economically feasible, and the cost value is optimal and does not exceed the level at which the economic meaning of their use is lost.

\section{The principle of professional competence.}

This principle means that the management of enterprise adaptation should be carried out by professionals (specialists) who are fully aware of the essence and content of the problem, are able to timely assess the situation and justify the correct organizational and managerial decision.

\section{The principle of hierarchical subordination in enterprise adaptation management system.}

This principle defines subordination in the management system of enterprise adaptation at hierarchically dependent levels: organizational, coordinating and executive. At the organizational and coordinating levels the coordination of the work of various functional elements within the adaptation management system is carried out in accordance with the enterprise objectives. At the executive level, two tasks are realized: a) assessment of the actual level of enterprise adaptation; b) development and implementation of managerial decisions on the management of enterprise adaptation. Solving the tasks of this level is subordinate to the evaluation of the enterprise adaptive capacity in the process of implementation of decisions that have already been adopted, as well as during the preparation of the next important decisions for the enterprise.

\section{The principle of developing the corporate culture of enterprise adaptation management.}

Successful functioning of the adaptive management system of a trade enterprise depends on a number of factors, among which the corporate culture becomes of great importance, especially in the field of adaptation management, because it is the subject of economic activity. In this case, it is understandable that the culture of adaptive enterprise 
management is rather complex social phenomenon, which is associated with the awareness of the company's staff. These people know about the adaptation management and its objective need. From this position, the level of corporate culture development is in some way a criterion for the effectiveness of the enterprise adaptive management system.

The formulated principles of developing the system of trade enterprises adaptive management allowed to determine the general contours of the management model (which involves the adaptation of the trade enterprise) and to develop structural and logical scheme of trade enterprise management and its adaptation at the strategic, operational and tactical levels, presented in Figure 1.3 [81-83].

In the context of the proposed structural and logical management scheme for enterprise adaptation, it is advisable to highlight the following key points:

- inclusion of the subsystem of adaptation management into the general management system of a trade enterprise;

- development of a program for strategic and operational and tactical measures aimed at managing the enterprise adaptation, based on the decomposition of the strategy of a trade company operation 


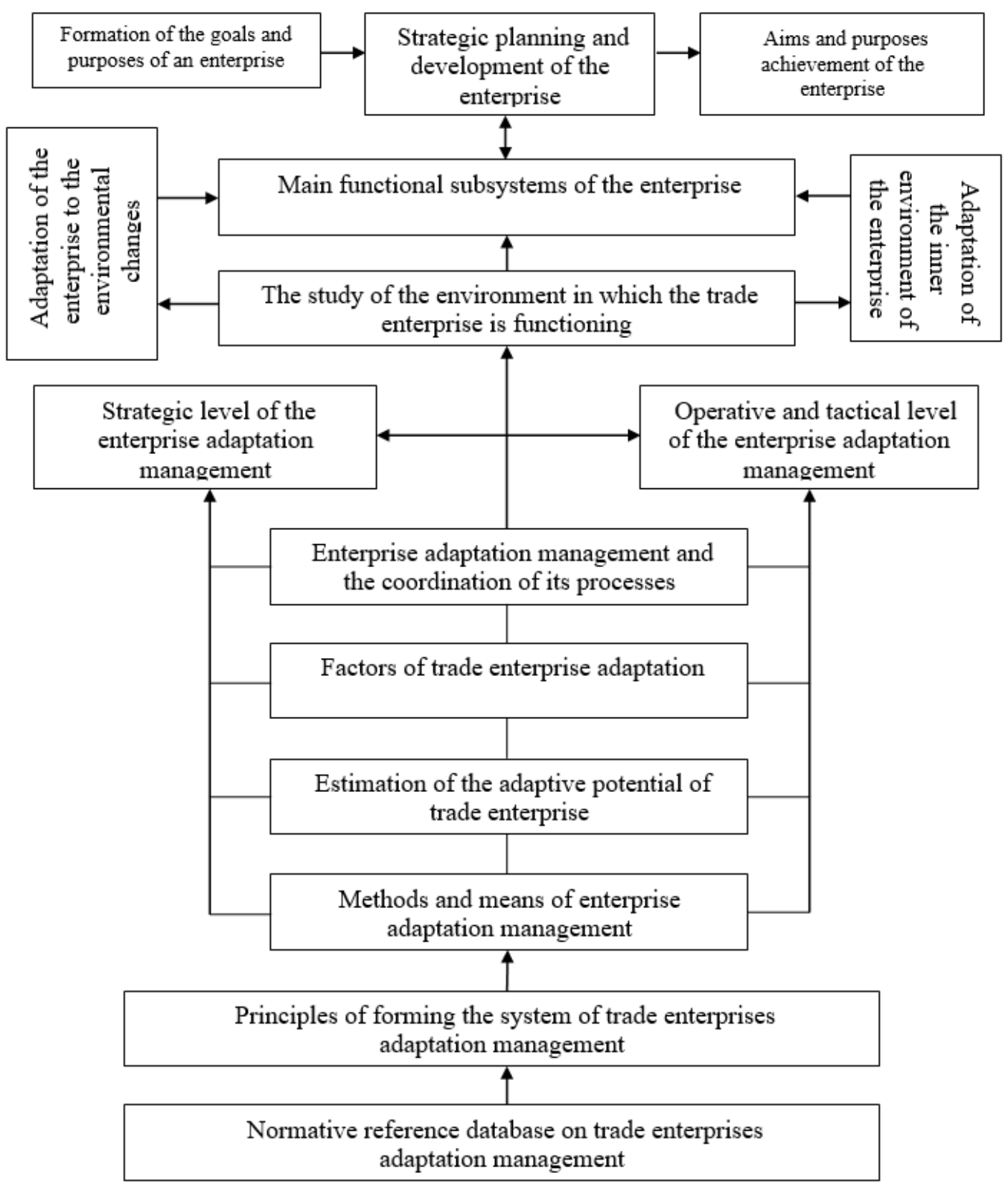

Figure 1.3. Structural and logical scheme of adaptation management system at trade enterprises on strategic, operational and tactical levels (authors' development)

- ensuring the obligatory performance of current tasks in the system of enterprise adaptation management;

- the existence of a feedback mechanism necessary for adjusting the methods and tools for adaptation management; 
- bringing the program of tactical measures on adaptation management and strategic management system in line with the basic transformations of the internal and external business environment of the trade enterprise operation;

- development of corporate culture in the system of management of the trade enterprise adaptation.

Management of enterprise adaptation in the developed structural and logical scheme is considered as a process of preparation and implementation of measures aimed at adapting the economic entity to the variability of the environment, the main purpose of which is to strengthen the financial and economic state of the enterprise and increase its level of competitiveness, which is ensured by minimizing possible negative consequences of developments in the process of implementation of approved organizational and managerial decisions.

Thus, the main purpose of the adaptive management system in the trade company is to formulate and implement a scientifically-based approach to the development of an adaptation strategy that is organically combined with the general concept of the trade enterprise development.

In our opinion, the process of managing the adaptation of a trade company should provide the following tasks:

- increase of the enterprise capitalization;

- increase of the enterprise competitiveness;

- ensuring the ability of the enterprise to minimize possible losses by its own means and funds without threatening the loss of financial and economic stability of the entity;

- providing cost-effective resource support for managing enterprise adaptation;

- reduction of unpredictable losses of the enterprise due to reduction of their occurrence probability, etc.

Thus, summarizing the conducted research, it should be noted that the management of the trade enterprise adaptation is an integral part of the overall system of organizational and managerial decisions, the goals and objectives of which must be consistent with the general strategy of the economic entity development, and ways of adjusting the adaptation have to be adequate in accordance with principles of entrepreneurial activity and its development. In this case, the formation of a strategy for its adaptation is an integral part of the strategic management system of a trade enterprise.

\subsection{Adaptation strategy and its role in the system of adaptive management of trade enterprises}

In a complex, modern, dynamic world, any enterprise, in order to provide a worthy place in the future, must strive to respond timely and flexibly to changes that take place, and adapt to them. This behavior corresponds to the main current and strategic goals of all levels of the organizational hierarchy of modern enterprises. Environmental changes, influenced by the processes of globalization in the economy, the growing integration, the 
rigidity of competition in national and international markets, require enterprises to predict and scale up major areas of activity increasingly. In the changing conditions of business management, the company constantly and steadily aspire to introduce the latest technologies and innovations in management.

Modern external challenges determine the need for development, adequate to the needs and conditions of the environment and internal management capabilities, methodical tools that ensure the establishment and implementation of competitive advantages. The most widespread concept, on the basis of which the successful accomplishment of this task is possible, is strategic management.

A strategic approach to management provides a long-term business success in a competitive environment, based on the assessment and use of its strengths and competitive advantages to confront external threats and risks, as well as the use of opportunities for development. It is strategic management that allows solving more complex problems of choosing promising business types under conditions of volatile environment.

The content of the process of adaptive strategic management is the development of a strategic adaptation mechanism as a set of elements that ensure the ability of enterprises to identify environmental changes in a timely manner, identify trends in their development, develop and implement a system of measures to eliminate or reduce the negative effects of its factors and the use of favorable conditions.

The adaptive strategic management tool is a strategy whose content depends on the chosen strategic management model. The internal content and architectonics of the strategic management model provide a justification of the strategy and mechanisms for its implementation by means that correspond to certain principal approaches and forms of manifestation.

The development of strategic management as an independent direction of economic theory begins in the 70 years of the twentieth century. One can find its theoretical basis in the works of A. Chandler, K. Andrews, I. Ansoff, P. Drucker, and others. Since then and until now, understanding of the company's strategy has undergone a certain transformation.

In the first scientific papers, a strategy was understood as a set of rules and techniques that achieved the main goals of the development of one or another system, and components of the strategy were considered as: market opportunities in the enterprise, overall competence and resources, values and needs. Understanding of the content of the company's strategy changed under the influence of the social economic development, the high level of competition and the dynamism of the environment.

In modern literature, it is possible to separate two main concepts of strategy philosophical, organizational and managerial.

The philosophical concept is related to the general meaning of the strategy for the enterprise. The strategy can be considered as a philosophy that can be guided by the enterprise. From this perspective, the strategy is:

- a position, a way of life, which does not allow to stay on the achieved, but focuses on constant development;

- an integral part of management that allows you to understand the future; 
- the process of thinking, intellectual exercises requiring special training, skills and procedures;

- a restored value, which makes it possible to achieve the best results by activating its staff [53].

The strategy can also be defined as the most important element of selfdetermination of the enterprise. In this context, it is closely linked to the characteristics and peculiarities of organizational culture, as a rule, has all its advantages and disadvantages, it enables to formulate social strategies and elements of social trends in other types of strategies in a more substantiated way [53].

Organizational and managerial concept of strategy is related to competitive actions, ways and methods of carrying out strategic activity at the enterprise [53]. From this perspective, the strategy is:

- general plans that are developed by the management in order to lead the organization in the future;

- an interconnected set of actions that an enterprise uses to achieve its goals, taking into account its own resource potential, as well as factors and constraints of the environment.

The research of scientific literature on strategic management leads to the conclusion that at this time there is no single approach to the definition of the concept of "strategy".

The analysis of the most well-known approaches to understanding the strategy provides an opportunity to imagine how accelerating the dynamics of changes in the business environment affects the strategic process of enterprises. The study of the gradual transformation of the category "strategy" gives an opportunity to understand the nature and essence of the strategic process of the enterprise (Table A.2).

The genesis of the definition of "enterprise strategy" indicates a gradual modification and complication of this category in terms of business tasks complexity and the acceleration of the dynamics of market environment change.

In the professional literature there is a set of definitions made by different scholars that do not contradict each other and emphasize on certain aspects and specifics of the enterprise strategy (Table 1.1). These characteristics form the systemic idea of the essence of the category "strategy".

Table 1.1

Approaches to the definition of the category "strategy"

(systematized on the basis of [53; 84-107])

\begin{tabular}{|l|l|}
\hline \multicolumn{1}{|c|}{ Author / Source } & \multicolumn{1}{c|}{ Definition of the concept } \\
\hline 1 & \multicolumn{1}{|c|}{ Strategy as a means of achieving goals } \\
\hline \multicolumn{1}{|c|}{ B. Carloff [84] } & $\begin{array}{l}\text { A generalized model of actions necessary to achieve the goals by } \\
\text { coordinating and distributing company resources }\end{array}$ \\
\hline D. Quinn [85] & $\begin{array}{l}\text { A plan integrating the main organizational goals, policies and } \\
\text { actions that can be combined into a single unit }\end{array}$ \\
\hline
\end{tabular}




\begin{tabular}{|c|c|}
\hline $\begin{array}{l}\text { A. Meskon, } \\
\text { M. Albert, } \\
\text { F. Hedouri [86] }\end{array}$ & Complex plan, formed for the mission and achieve its goals \\
\hline D. Hassy [87] & $\begin{array}{l}\text { The aggregate of means by which the organization is } \\
\text { approaching to achieve its long-term goals }\end{array}$ \\
\hline K. Bowman [88] & $\begin{array}{l}\text { A generalizing model of action needed to achieve the goals by } \\
\text { coordinating and distributing company resources }\end{array}$ \\
\hline O.S. Vihansky [89] & $\begin{array}{l}\text { A long-term, qualitatively defined direction of development of } \\
\text { the organization, concerning field, means and forms of its } \\
\text { activity, system of relations within the organization, as well as } \\
\text { positions of the organization in the environment that leads the } \\
\text { organization to its goals }\end{array}$ \\
\hline $\begin{array}{l}\text { Z.E. Shershniova } \\
\text { [53] }\end{array}$ & $\begin{array}{l}\text { A specific management plan of action aimed at achieving the set } \\
\text { of goals. It determines how the organization will function and } \\
\text { develop now and in the future, as well as which entrepreneurial, } \\
\text { competitive and functional activities and actions will be taken to } \\
\text { ensure that the organization has achieved the desired status. }\end{array}$ \\
\hline D. Campbell [90] & $\begin{array}{l}\text { Formation of long-term goals of the enterprise, establishment and } \\
\text { adoption of a course of action and allocation of resources } \\
\text { necessary for achieving the goal }\end{array}$ \\
\hline $\begin{array}{l}\text { R.A. Fatkhutdinov } \\
\text { [91] }\end{array}$ & $\begin{array}{l}\text { The program, plan, general course of the subject of management } \\
\text { to achieve strategic goals in any field of activity }\end{array}$ \\
\hline \multicolumn{2}{|r|}{ Strategy as a set of decision-making rules } \\
\hline 1 & 2 \\
\hline $\begin{array}{l}\text { Z.P. Rumyantseva } \\
\text { N.A. Salomatin [92] }\end{array}$ & $\begin{array}{l}\text { A set of rules, a comprehensive plan, designed to ensure the } \\
\text { implementation of the mission and achieve the economic goals of } \\
\text { the organization }\end{array}$ \\
\hline N.Tulenkov [93] & $\begin{array}{l}\text { A set of norms, guidelines, directions, spheres, methods and rules } \\
\text { of activity established for a sufficiently long period that ensure } \\
\text { the growth and high competitiveness of organizations, which } \\
\text { strengthen the position on the market, which increases the ability } \\
\text { to survive in a particular situation. }\end{array}$ \\
\hline K. Omah [94] & $\begin{array}{l}\text { A way that allows a corporation to successfully differentiate } \\
\text { itself from competitors by using its relative corporate strength to } \\
\text { better meet consumer needs. }\end{array}$ \\
\hline J. Kay [95] & Correspondence of its internal capabilities and external relations \\
\hline $\begin{array}{l}\text { V. Nemtsov, } \\
\text { L. Dovgan [96] }\end{array}$ & $\begin{array}{l}\text { The long-term qualitatively defined direction of the organization' } \\
\text { s development, aimed at consolidating its positions, satisfaction } \\
\text { of the consumer needs and achievement of the goals set. }\end{array}$ \\
\hline A. Gradov [97] & $\begin{array}{l}\text { A set of rules and techniques that help achieve the goals of } \\
\text { enterprise development }\end{array}$ \\
\hline I.A. Ignatieva [98] & $\begin{array}{l}\text { The long-term program of the organization' s activity, which is } \\
\text { constantly under control, is evaluated and corrected in the course } \\
\text { of its implementation. }\end{array}$ \\
\hline
\end{tabular}




\begin{tabular}{|c|c|}
\hline P.G. Clivets [99] & $\begin{array}{l}\text { A generalized activity program (action model) aimed at } \\
\text { achieving the desired stage, goal (status on the market, social and } \\
\text { economic indicators) by the enterprise through efficient } \\
\text { allocation, coordination and use of resources. }\end{array}$ \\
\hline \multicolumn{2}{|c|}{$\begin{array}{l}\text { Strategy as a model of interaction between the enterprise and the external } \\
\text { environment }\end{array}$} \\
\hline 1 & 2 \\
\hline $\begin{array}{l}\text { D. Johnson, } \\
\text { K. Scholes, } \\
\text { R. Whittington [100] }\end{array}$ & $\begin{array}{l}\text { The direction and scope of the organization for a long period of } \\
\text { time, enabling it to achieve benefits in a changing environment } \\
\text { by configuring resources and competences to meet the } \\
\text { expectations of the stakeholders }\end{array}$ \\
\hline E.A. Utkin [101] & $\begin{array}{l}\text { The firm's action plan for achieving market success and, where } \\
\text { possible, gaining a competitive advantage over rival firms }\end{array}$ \\
\hline $\begin{array}{l}\text { S. Hofer, } \\
\text { D. Shendel [102] }\end{array}$ & $\begin{array}{l}\text { A fundamental model for deploying existing and future resources } \\
\text { and interacting with the external environment, which shows how } \\
\text { the organization is trying to achieve its goals. }\end{array}$ \\
\hline $\begin{array}{l}\text { V. Gluck, } \\
\text { L. Jawack } \\
{[103]}\end{array}$ & $\begin{array}{l}\text { A unified comprehensive and integrated plan that correlates the } \\
\text { strategic benefits of the company with the challenges and } \\
\text { opportunities of its external business environment. It is built in } \\
\text { such a way that its long-term fulfillment ensures achievement of } \\
\text { the company' s goals }\end{array}$ \\
\hline B. Henderson [104] & $\begin{array}{l}\text { Intentional search for a plan of action that will help promote the } \\
\text { company' s competitive advantage and become an integral part of } \\
\text { it. }\end{array}$ \\
\hline $\begin{array}{l}\text { R. Kaplan, } \\
\text { D. Norton [105] }\end{array}$ & $\begin{array}{l}\text { The choice of such activities in which the organization will } \\
\text { achieve excellence, creating a stable competitive advantage in the } \\
\text { market }\end{array}$ \\
\hline $\begin{array}{l}\text { L. Fajey , R. Rendel } \\
{[106]}\end{array}$ & $\begin{array}{l}\text { A means by which the relationship between the organization and } \\
\text { its partners and competitors varies. Due to this it gets competitive } \\
\text { advantages }\end{array}$ \\
\hline $\begin{array}{l}\text { A.P. Mishchenko } \\
\text { [107] }\end{array}$ & $\begin{array}{l}\text { The basis for improving the company's competitiveness, strong } \\
\text { competitive position and the formation of such an organization, } \\
\text { which, through the improvement of the management structure } \\
\text { and the improvement of organizational culture, could work } \\
\text { successfully in difficult market conditions }\end{array}$ \\
\hline
\end{tabular}

Foreign and domestic theoretical developments indicate, and the practical experience of selecting and justifying the strategy of enterprise development confirms that the strategy is a logically consistent integrated decision-making scheme. The versatility and alternative approach to strategy definition, as well as a number of its essential features, are usually related to the specificity of the developing a national economic model characterized by historical traditions and the availability of professional experience in using strategic tools to achieve the goals set by the enterprise.

On the basis of the generalization of the scientific positions of the authors $[53 ; 84-$ 107] who were engaged in researching the essence of the strategy, as well as the process 
of its development, one can distinguish the fundamental approaches to the definition of the concept "strategy":

- $\quad$ strategy as the means of achieving goals - this concept of strategy reflects a targeted approach to its understanding and proceeds from the fact that in the process the definition determines the quantitative and qualitative parameters of the economic activity that the enterprise seeks to achieve in the long run, and the strategy determines how this goal can be achieved, with the help of which common alternative actions, that is, as a general algorithm, a system of measures, tools, decisions on the choice of an alternative model of enterprise behavior in the external environment, the implementation of which should ensure the company to achieve certain goals;

- strategy as a set of decision rules. This concept considers the strategy as a set of norms, guidelines, directions, areas, methods and rules for developing a longterm direction of movement and determining the scale of the company, that is, there are certain guidelines for the implementation of long-term intentions of the enterprise. The key to this approach is the recognition that no strategy, due to its essence, provides a detailed picture of the future, it is aimed at determining the overall, promising and qualitative direction of the enterprise from the present to the target future state;

- strategy as a model of interaction between the enterprise and the external environment. This concept of strategy reflects a process approach to its understanding as models of adaptive behavior, that is, one that deals with the most important, vital aspects and directions of activity and development of the enterprise in unstable and changing environment for the long-term perspective, should ensure its sustainable development.

In our opinion, the advantage of this concept of strategy is that it completely excludes determinism in the external environment, and the strategy involves adaptive freedom, taking into account the speed of the situation, predicts possible future changes and ensures preparation for them. This concept differs in specifying the key external factors of the company's success, and emphasizes that they should be at the center of the enterprise management strategy.

Modern authors, studying the essence and transformation of the concept "strategy", recognize that modern strategic management should be adaptive, and adaptation strategy is considered as a way not only for survival, but for the further sustainable development of the enterprise and give the following definition of the adaptation strategy.

R. Miles and C. Snow have the strategy of adaptation identified with the internal philosophy of the company for the integrated solution of three problems: entrepreneurial, engineering and administrative [108].

G.M. Sharapudinov understands the adaptive strategy as the measures and mechanisms of adaptation [109].

Yu.A. Maslodudov defines the strategy of adapting the enterprise to the uncertainty of the environment as a series of successive actions [110]. The same actions are also called an adaptation mechanism.

O.V. Taranova [111, p. 47] defines the adaptation strategy of the company as a combined program of methods of economic activity in the modern socio-economic conditions, aimed at achieving the set of goals, based on the enterprise potential. 
I.P. Siryk understands the "adaptation strategy of the enterprise" as a systematic plan of action for the development of a general concept, specific means and methods of protection against potential threats and / or active influence on the immediate environment on the basis of the analysis of the external and internal environment in conditions of incomplete definition of the economy environment in order to ensure a stable development [112].

K.E. Orlova believes that the strategy of adaptation is a long-term plan of actions and measures of the organization to ensure its adaptation to environmental factors, as well as to ensure balance of the state of the internal and external environment [113].

N.V. Yanchenko proposes to understand the adaptation strategy as the plan of actions that ensure compliance with the target directions of development and strategic changes to the requirements of stakeholders (stakeholders in the activities of the enterprise, representatives of the business environment) and the conditions for the functioning of business environments [114].

Analyzing the definitions of the enterprise adaptation strategy given above it can be stated that they all practically identify the adaptation strategy with the general corporate strategy of the enterprise, without identifying its differences and not distinguishing its essential characteristics.

The author's point of view for an adaptation strategy is based on the following: an adaptation strategy arises as a managerial response to changes in the business environment that can be predicted or foreseen due to the constant scanning of the external environment or the unexpected, aggressive challenges of the business environment. Therefore, if in the first case the reaction to system or predicted changes can be scheduled, then in the second case, the reaction should be prompt, so that as soon as possible develop and implement adequate organizational and economic measures to counteract the reduction of the enterprise operation efficiency.

According to the nature of the business environment challenges and the rate of compensation for the negative impacts of the time horizon, the strategy of adaptation can be both long-term (for strategic changes) and short-term - for an immediate response to unforeseen, unexpected changes.

The strategy of adaptation is developed within the framework of the overall corporate strategy, does not contradict its goals and objectives, but is its individual case for overcoming crisis phenomena. Implementation of the strategy of adaptation as a complex of organizational and economic management measures can keep the company on the path of sustainable development, adequately and quickly respond to changes in the external environment, providing operational restructuring of the enterprise. In view of the foregoing we can define these characteristics of corporate and adaptive strategies (Table 1.2). 
Table 1.2

Distinctive features of corporate and adaptive strategies (authors' development)

\begin{tabular}{|c|c|c|}
\hline Kind of a & Corporate & Adaptive \\
\hline Differences & \multicolumn{2}{|c|}{ Characteristics } \\
\hline Rates & General & Particular \\
\hline Goals and tasks & $\begin{array}{l}\text { Aims and tasks of } \\
\text { functioning }\end{array}$ & Aims and tasks of adaptation \\
\hline Reaction rate & planned & $\begin{array}{l}\text { planned and/or } \\
\text { fast }\end{array}$ \\
\hline Time period & long-term & $\begin{array}{l}\text { long-term and/or } \\
\text { short-term }\end{array}$ \\
\hline
\end{tabular}

In view of the selected differences and the essential characteristics of the company's adaptation strategy, we will formulate a generalized definition of the research concept.

In our opinion, the strategy of adaptation can be interpreted as a combination of the long-term and short-term goals, actions and decisions that are being made to adapt the company to new opportunities for obtaining competitive advantages and new threats to weaken its competitive position in the existing business environment.

Thus, the proposed definition of an adaptation strategy reveals its content and role in the process of strategic management of the enterprise.

The goal orientation of the adaptation strategy necessitates the justification of the goals system, reflecting the overall strategic direction of the trade enterprise. Goals are needed to ensure survival and successful long-term operation. If the goals are bad or incorrectly defined, it can lead to unwanted negative consequences for the business entity.

In the theory of management, key requirements have been formulated, which should meet well-formulated goals: reach, flexibility, dimensionality, concreteness, compatibility, acceptability and time-orientation [53, 86, 89, 91, 115].

Goals should be achievable. Of course, there should be a challenge for employees. They should not be too easy to achieve. But they also do not have to be unrealistic, beyond the limits of the performers. The purpose, which exceeds the ability of employees, causes them indifference to the outcome of work, leads to a reduction in the rate of return and deterioration of the results of the enterprise.

Goals should be flexible. It is expedient to formulate goals with a certain reserve, so that the ability to change their direction adequately changes the conditions of activity. There must always be the possibility of transforming certain goals, as a reaction to the positive or negative externalities of the environment; otherwise the enterprise may get an undesirable result.

Goals should be measurable. If the goals are expressed in concrete measurable forms, then the enterprise has a clear basis for making subsequent decisions and assessing 
the fulfillment of tasks and achievement of goals. Otherwise, there may be difficulties at the stage of evaluating performance, which may lead to conflict situations.

Goals should be specific, that is, to have the necessary characteristics in order to determine in which direction the movement of the enterprise should be carried out. The goal should clearly indicate what needs to be done as a result of the activity, what time frame it should be achieved and who should achieve it. The more specific a goal, the easier it will be to develop a strategy for its achievement. If the goals are set specifically, the implementers will understand the necessity and expediency of their work, then they will be able to find more perfect ways to achieve goals.

Goals must be compatible. Compatibility suggests that there is a close connection and interconnectivity between all objectives, which allows them to be seen as a system of enterprise goals. Its composition includes goals of different levels, defined at different periods of time, different in terms of content, purpose, sphere of influence, etc. Requirements must be met so that actions and goals for achieving one goal do not interfere with other goals, such as profit-oriented goals and sales-oriented goals, goals for creating high-quality goods, and cost minimization purposes.

Goals should be acceptable to the main actors of influence, which determine the activities of the enterprise, and, first of all, for those who will have to achieve them. When formulating goals it is very important to consider desires and needs of employees. Taking into account the interests of owners occupying a leading role among the subjects of influence on the enterprise and interested in receiving profits, management should avoid trying to develop the purpose of targeting large short-term profits. It should strive to establish such goals that would provide more profit, but it is desirable in the long run. Buyers are the subject of influence on the company; they play a key role for the organization's survival, that's why, when setting goals, managers must take into account their interests, even if they lead to a reduction in profits by decreasing the price or increasing costs to improve product quality.

Also, when setting goals, it is necessary to take into account the interests of society, such as, for example, the development of the local environment, etc. [89].

Goals should be timed. A specific prediction horizon is another characteristic of effective goals. It is worth determining exactly what the company wants to accomplish, but also when the result should be achieved. Goals are usually set to short or long time intervals [86]. The first is aimed at the immediate achievement of the desired results, and the second - makes you think about what needs to be done now to strengthen the firm's position and improve performance over the long term [115].

Strategic goals make you think about what you need to start now to strengthen the company's position and improve performance over the long term. They are aimed at providing higher growth rates than the average within the industry, increasing the market share, improving the quality of products and services rendered in comparison with competitors, achieving low costs, and improving the reputation of the company. The penetration of foreign markets, the use of advanced technologies and the development of various growth opportunities are also strategic objectives [115].

Objectives serve to develop the activities and progress of the enterprise. Defining specific goals helps to move from the general formulation of the strategic direction to individual work plans that can be used to succeed. The set goal contains a number of desired results, which require certain efforts and organized actions to achieve. 
The commitment to move from the existing position to the desired makes the enterprise be more inventive, improve its financial performance and business reputation. It needs to concentrate all the capabilities. Complex, but achievable goals help the company to protect itself from fluctuations, intra-firmness disorder and provide a balance in work [115].

Each enterprise develops its own system of goals, unique in characteristics, since it reflects the desired future state of the enterprise and takes into account the nature of its strategic orientation, the state and degree of instability in the business environment, the characteristics of the industry.

An analysis of existing publications on the subject under research $[53,86,89,91$, 115 and others] showed that today in the theory and practice of management several persistent ideas dominate in relation to the specific content of the enterprise objectives. It can be reduced to the following areas:

1. Income of the enterprise;

2. Work with consumers;

3. Welfare and needs of employees;

4. Social responsibility [89].

However, the formulation of goals (goal definition) is a logical process, where you can only systematize the procedure, but not formalize it, and moreover, do not define it unambiguously. This is an art based on the experience and intuition of senior management. Therefore, it is impossible to give recipes for all occasions in the field of goals development; we can only offer a fundamental approach to this process, paying attention to aspects that are typical for enterprises of any organizational and legal form and areas of activity [116].

We have researched the plurality of the authors' opinions on strategic objectives and took into account the essential characteristics of the adaptation strategy. In our view, the strategic focus of adaptation (strategic vision) is ensuring the viability and efficiency of trade operation in the long run. It is based on a dynamic balance with the business environment.

Taking into account the strategic vision, the process of adaptation of an economic entity in the field of trade can be aimed at achieving three main objectives (support on the basis of corrective effects):

a) survival, b) a stable position on the market, c) a sustainable development and effective functioning in the long run.

At the same time, as it has been already noted, survival - or (for the economic entity) a way out from the crisis and the creation of prerequisites for further stabilization in any environmental change; stable state - is the achievement of dynamic equilibrium, characterized by counteraction of different directed and balanced influences (external and internal). Sustainable development is a balanced growth of long-term nature, that is, a dynamic process that determines the possibility of an enterprise transition into a new, more complex state; it is aimed at achieving leading competitive positions.

In the future, in the context of the proposed strategic vision, the objectives are specified into the sub-goals, which, in turn, address the respective tasks of adapting the enterprise as an answer to the challenges of the environment that were identified during 
the diagnosis. We realize that it is impossible to take into account all the diversity of environmental changes, and, consequently, the diversity of responses to them. That is why the authors developed the system of goals for the company's adaptation strategy and possible sub-targets, which will contribute to their solution (Table 1.3).

Table 1.3

The strategic framework of trade enterprises adaptation

\begin{tabular}{|c|c|}
\hline $\begin{array}{c}\text { Objectives of the } \\
\text { adaptation } \\
\text { strategy }\end{array}$ & Underlying strategies for adaptation \\
\hline Survival & $\begin{array}{l}\text { - ensuring of self-sustainability (zero net revenue); } \\
\text { - } \text { optimization of the product mix; } \\
\text { - maintenance of the market share; } \\
\text { - } \text { providing competitive advantages; } \\
\text { - } \text { high-quality maintenance of the consumers needs; } \\
\text { - ensuring financial stability of the enterprise; } \\
\text { - maintenance of the market value of the enterprise; } \\
\text { - } \text { providing a positive image of the enterprise. }\end{array}$ \\
\hline $\begin{array}{l}\text { Stable position on } \\
\text { the market }\end{array}$ & $\begin{array}{l}\text { - maintaining the growth rate of profit; } \\
\text { - } \text { optimization of the product mix; } \\
\text { - maintenance of the market share; } \\
\text { - support of sustainable competitive advantages; } \\
\text { - high-quality maintenance of consumers needs; } \\
\text { - support of financial stability of the enterprise; } \\
\text { - support of the market value of the enterprise; } \\
\text { - support of the the enterprise image. }\end{array}$ \\
\hline $\begin{array}{l}\text { Sustainable } \\
\text { development } \\
\text { and effective } \\
\text { functioning }\end{array}$ & $\begin{array}{l}\text { - maximization or achievement of target profit; } \\
\text { - expansion in the products; } \\
\text { - increase of the market share; } \\
\text { - ensuring sustainable competitive advantages; } \\
\text { - improvement of the quality of consumer needs; } \\
\text { - increase of financial stability of the enterprise; } \\
\text { - maximizing the market value of the enterprise. } \\
\text { - improving the image of the enterprise. }\end{array}$ \\
\hline
\end{tabular}

The proposed system of goals should ensure the ability of the trade company in the short run and its effective functioning in the new environment.

In addition, the strategic goals should vary significantly depending on the stage of the life cycle where the enterprise is: creation, growth, maturity or decline (negative output). Therefore, taking into account the strategic direction of the enterprise and using the analysis of the business environment, the authors developed the goals and 
corresponding adaptation tasks, as a response to the possible challenges of the environment and the stage of the company's life cycle (LCC).

At the stage of creation, any company aims at:

- finding the necessary funds for the organization and start of business;

- entering the markets;

- establishing business relations with partners (suppliers, etc.);

- surviving.

For the growth stage, priority is given to goals that reflect its successful positioning in the market and satisfactory financial results [117]. The following goals can be distinguished in their own right:

- achievement of profitability and stability of business;

- expansion of activities and markets;

- $\quad$ supporting the growth of new financial sources;

- involvement of professionals, improvement of the enterprise management structure.

At maturity stage, the following goals may be prioritized:

- the use of competitive advantages, which are provided by high growth rates and scales;

- development of the enterprise image;

- financial control;

- organization, use of new methods and control systems (by objectives, quality, control, etc.).

At a stage of decline, entire enterprises can address the following issues:

- $\quad$ suspension of activities and, as a consequence, - dismissal of personnel and sale of property;

- $\quad$ sale of the enterprise and its subsequent adaptation to the stage of the life cycle of a new enterprise.

So, summing up the research, its results can be presented as a system of goals and objects of adaptation strategy of a trade company (Figure 1.5).

The proposed target system includes objects of adaptation strategy, because according to their state and properties we eliminate or prevent all the negative influences of the business environment.

Strategic resource management involves the process of their formation, namely, the definition of their needs, their structure, in accordance with the goals of the strategy and the impact of the business environment, the sources of their involvement, and the process of their consumption, namely, their distribution, in accordance with the objectives of the strategy and the impact of the business environment and use, which should meet the requirements of effective adaptation management.

Capacity management involves the process of identifying the enterprise needs in certain abilities of the chosen adaptation strategy, comparing them with the existing level of abilities, their formation and choosing the necessary measures to bring it in line. Management of the company's capabilities involves the processes of their formation, stimulation of the phenomenon and development. Formation of capabilities provides the 
company with the necessary capabilities to implement an adaptation strategy. Stimulation of the phenomenon is necessary, because the formed abilities will not be useful if the staff who owns them is not interested in effectively implementing them. The development of abilities to implement the strategy of enterprise adaptation involves continuous improvement of the existing abilities, which is realized through professional training.

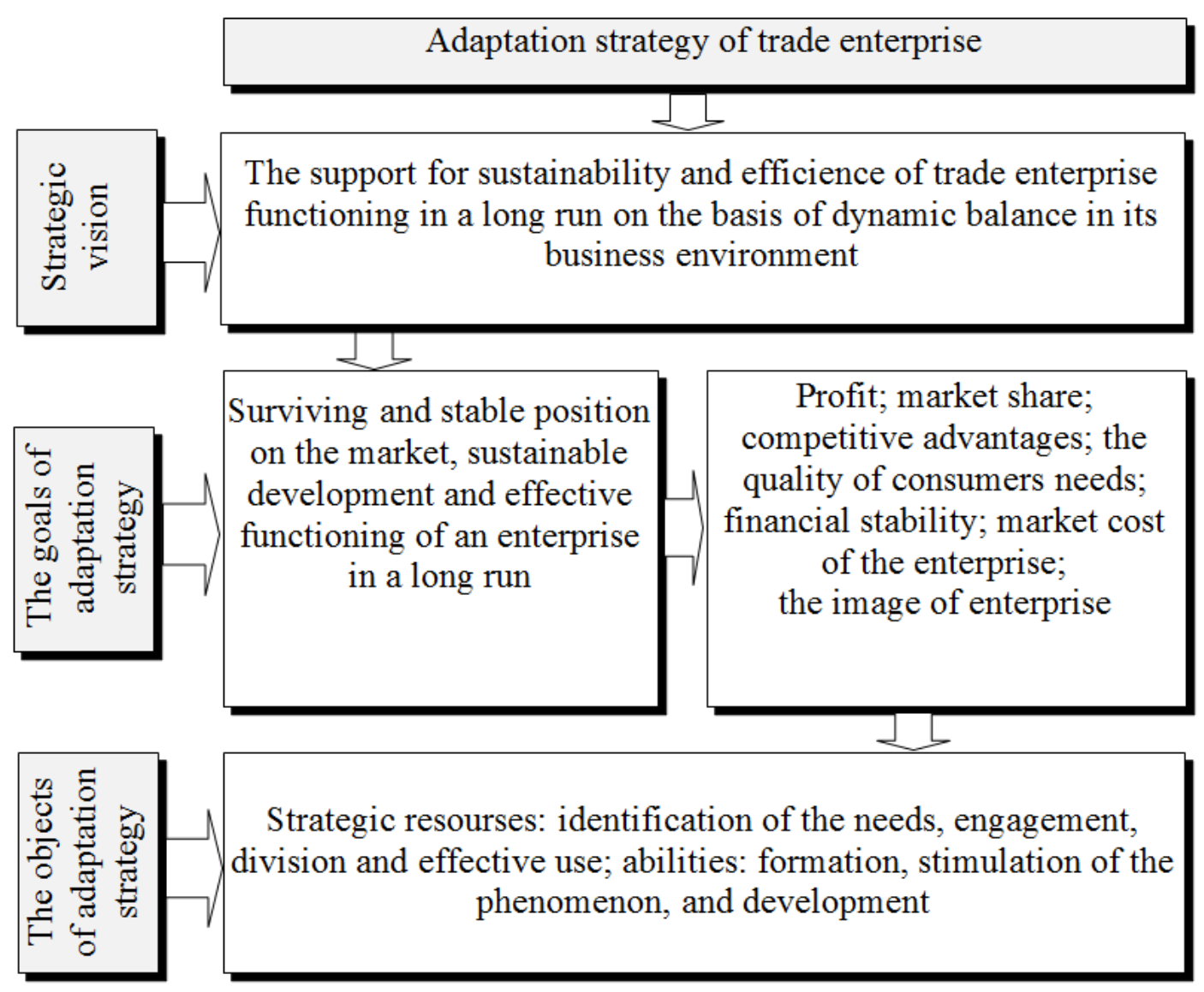

Figure 1.5. Strategic vision, goals and objectives of the adaptation strategy of trade enterprises (author's development)

Thus, the proposed system of goals and objects of the enterprise adaptation strategy provides a comprehensive understanding through the directions of adaptation solutions. It is the basis for defining a set of measures for influencing these objects of adaptation management. 


\section{Conclusions to chapter 1}

1. Taking into account the study of invariant interpretations of the economic category "enterprise adaptation", the key accents were identified with regard to the definition of the concept, among which: adaptation as a process, adaptation as ability, adaptation as activity, adaptation as reaction (process), and adaptation as a method. The defined characteristics indicate the complexity of the "enterprise adaptation" concept and the ambiguity of its content. In the process of the critical analysis of scientific sources on the definition of the enterprise adaptation, it was concluded that its generally accepted definition is absent.

2. Taking into account the results of the conducted research, it has been proposed to adapt the enterprise for understanding the systematic process of its adapting to the variability of the environment, implemented through a set of targeted adaptation measures and changes (reactions). It has a strategic nature, accompanies the entire life cycle of the enterprise and is aimed at ensuring the efficiency of its functioning and development. It is proved that the ability of an enterprise to adapt to changing environmental conditions is characterized by the concept of "adaptability", which suggests to understand the ability of the enterprise to timely and competently determine the vector of necessary changes in its activities, in accordance with the environmental conditions, based on a skillful combination of their own adaptive properties and abilities.

3. Based on the critical analysis of scientific sources, the principles of development of the adaptive management system of trade enterprises were formulated. It allowed developing a structural and logical scheme of adaptation management of the trade enterprise at the strategic, operational and tactical levels. It is suggested to manage the enterprise adaptation as a process of preparation and implementation of measures aimed at adapting the enterprise to the variability of the environment, the main purpose of which is to increase the efficiency and level of competitiveness of the enterprise, which is ensured by minimizing the possible negative consequences of the course of events in the process of implementing approved organizational and managerial decisions.

4. Based on the study of the genesis and systematization of approaches to the interpretation of the company's strategy essence, the peculiarities and distinctive characteristics of the corporate strategy and the strategy of adaptation by characteristics have been substantiated: the ratio, goals and objectives, reaction rate, time period. It has been proposed to be understood in accordance with the trade company "strategy of adaptation" , e.g. the combination of planned goals, actions and solutions of long-term and short-term nature of enterprise adaptation to new possibilities and obtaining a competition rental advantages and new threats to weaken its competitive position in the existing business environment.

5. In order to ensure the purposefulness of forming the adaptation strategy of the trade company, the strategic vision of the adaptation process, within which the system of objects and goals of the adaptation strategy, which is in line with the principles of the goal definition of the management theory, is specified, and the directions of decisions adaptation are specified. 


\section{CHAPTER 2}

METHODOLOGICAL BASES FOR THE FORMATION OF THE ADAPTIVE MANAGEMENT SYSTEM OF TRADE ENTERPRISES UNDER CONDITIONS OF THE EXTERNAL ENVIRONMENT DYNAMICS 


\subsection{Principles of forming adaptive management system of trade enterprises}

The works of foreign and domestic scientists are dedicated to the study of problems of the theory and practice of strategic management, management of changes that became the starting point in the field of adaptive management and formation of adaptive management system at the organization: R. Acoff, M. Albert, M. Meskon, F. Hedouri, I. Ansoff, G. Mintzberg, B. Milner, I. Markina, T. Burns, T. Davenport, T. Peters, R. Waterman, T. Haroutyunyan, S. Bay, A. Gradov, I. Adizes, M. Green, E. Cameron, G. Kleiner, N. Lepi, A. Nalyvayko, O. Rayevneva and others.

Such domestic scientists as Vlasova N.O., Ligonenko L.O., Petrovych YM, Grybyk I.I., Tereshchenko O.O., Kharchenko V., Chernysh I.V., Yanchenko N.V., Alekseev S.B., Stasyuk V.P., Solomakha S.A. and foreign scholars: Kristensen K., Fomin V. N., Hammer M., Hall R. H., Sheer A., Fererman M. I. et al made a significant contribution to the formation of the adaptive management concept in economic and technical systems, analysis of socio-economic systems adaptation to modern conditions of management. [3; $6 ; 114 ; 118-133]$.

However, the author's presentation of the material and a certain fragmentation of research results in the lack of a unified view of the main components of an integrated system of adaptive management at the enterprises. This makes it impossible to create a holistic methodological basis for effective adaptation of enterprises and, correspondingly, their ability to purposeful adaptation with the account of specific conditions of functioning depending on the sphere of entrepreneurial activity.

The basis of the development of methodological foundations for adaptive management of trade enterprises is a complex of scientific approaches: systemic, situational, process, dynamic, and others. Due to the use of analytical features and advantages of each of them, a purposeful formation of the organizational and economic mechanism of adaptive management with regard to the peculiarities of functioning and interaction with the environment of the systems under research - business entities in the field of trade, and adequacy of links between the components of the adaptive management process is ensured.

Based on modern approaches to management, the methodology of management includes purpose and tasks, principles, laws and regularities, functions and methods of management [89; 134-143]. As it was fond in the process of studying economic content of adaptation of trade enterprises and its conceptual characteristics (paragraph 1.1), the purpose of adaptive management is its adequate timely response to changes occurring in the external environment of their functioning. The most important tasks of the adaptive management system of the organization include: securinng high flexibility that allows to change rapidly all elements of organizational and economic mechanism of the enterprise; mobility in the adoption of managerial decisions and their implementation in business management; adequacy to the current situation with the account of external conditions of functioning and competition; recognition of risks associated with the uncertainty of the environment and the dynamics of change and development.

Achievement of the objectives and performance of the tasks of adaptive management becomes possible only if managerial influences are based on certain rules 
that are consistent with mental models of the reality of the relevant society. Generalization of empirical experience in scientists' theoretical conclusions contributed to the emergence of a number of managerial principles that are the quintessence of scientific thought about the way in which management should be conducted and how to build an effective managerial system.

Principles of modern paradigm of management are the starting point, precondition and central concept of the scientific system of adaptive management at trade enterprises, since they reflect its deep regularities and preconditions for further development.

The science of management in its evolution at various historical stages determined various priorities in functioning and development of the organization, according to which the principles of management evolved, ranging from classical rationalist approach to the organization of production processes, and the ideas about effective management in the era of globalization and information technologies [141].

"One-dimensional" doctrines focus on solving only one particular management problem: tasks, people, organization of managerial activities, etc. [144]. Classical management areas are among the most prominent doctrines in this group: schools of scientific management and administrative management, behavioral doctrine, school of rational bureaucracy, administrative school of management.

F. Taylor was the first who scientifically substantiated management. He pointed at the necessity to adhere to certain rational requirements in managing production processes and the subordinates. This scientist and his famous followers G. Hunt, F. and L. Gilberts, G. Emerson, G. Ford represent the first wave of synthesis in scientific management characterized as a process of combining physical resources or technical elements of organization with human resources to achieve main goals of the organization $[143 ; 145$ 146]. Technologically, F. Taylor's scientific approach was aimed at the analysis of the existing business practices for standardization and rationalization of the use of resources. On the human resources part, he sought the highest degree of individual development and rewards by reducing fatigue, scientific selection, matching the worker's abilities to the work he performed, and stimulating the worker.

The basic principles of the scientific management of F. Taylor are as follows: development of science is the development of optimal methods of work on the basis of scientific study of the cost of time, movements, efforts, etc; absolute compliance with the developed standards; recruitment, training and placement of workers at those jobs and tasks where they can be most useful; payment for the results of their work (lower results lower payment, higher results - more payment); use of functional managers who oversee specialized areas; maintaining friendly relations between workers and managers in order to ensure the possibility of scientific management.

The basis of the search process for determining specific principles of adaptive management of trade enterprises and their systematization is the position of F.Taylor concerning the neessity to use principles in the complex, without allowing the allocation of the most important among them, since only their combination is considered as scientific management.

Further development of the scientific principles of management was obtained in the studies of F. and L. Gilbretts, who focused their attention on the study of production operations, while standardizing the workers' time based on the most rational way of their implementation. This allowed to increase control over the length of production processes, 
and reasonably plan the number of workers, their wages, thereby increasing productivity of labor personnel.

It was G. Emerson who considered the issues of revealing regularities in the management of production processes to improve their efficiency. He singled out 12 basic principles: precise formulation of goals; substantiation of the activity with the account of prospects; competent advice; discipline; fair treatment to staff; fast, reliable, complete, accurate and continuous accounting; dispatching; norms and schedule; normalization of conditions; transaction valuation; written standard instructions; performance reward. G. Emerson first considered the question of the efficiency of production in the broad sense.

Consequently, the school of scientific management facilitated the transformation of management into an independent science, determined management as an independent sphere of activity at the enterprise, substantiated the necessity and principles of improving the use of working time and methods of work execution.

The purpose of classical school of administrative management was the creation of universal management principles [147-148] One of the main aspects of developing governance principles was the creation of a rational system of managing the organization through its division into subdivisions or working groups, which carry out certain functions: technical (implementation of the production process; commercial (the purchase of everything necessary for the creation of goods and services and sales of finished products), financial (attraction, conservation and efficiency of using cash, accounting (statistical observation, inventory, drawing up of balances, etc.), administrative (impact on employees) and protective (life, health, property, etc.), which are characterized as main managerial functions. A. Fayol presented management as a universal process consisting of several interrelated functions, such as planning, organization, management, coordination, control, motivation. Management should be based on 14 principles, which still retain their significance.

Distribution of labor. The purpose is to increase the volume and quality of production through the unchanging efforts.

Powers - Responsibility. The head manager is entitled to give orders and force to obey. Powers are combined with the responsibility. Each employee must possess the delegated authorities sufficient to be responsible for the performance of the work.

Discipline. Employees must comply with the terms of the agreement concluded between them and the management; managers should apply fair sanctions to those who offend order.

Unity of management. An employee receives orders from only one direct supervisor and reports only to him.

Unity of actions. All actions with the same purpose should be grouped and executed according to a single plan.

Subordination of private interests to general. Interests of employees or a group of employees should not be higher than the interests of the enterprise.

Staff remuneration. The remuneration of staff for the performed work should be fair and satisfy the staff of the company and its employer.

Centralization. Determination of the level of centralization, which is the most favorable for the enterprise. 
Hierarchy. All orders are transmitted and implemented in accordance with the communications between all levels of the hierarchy.

Order. It is a well-known formula of material order: a certain place for every thing in its place is projected on the content of social order: a certain place for each employee, each employee is in his place.

Justice. It is necessary to treat the staff with kindness in order to encourage them to perform their duties with full zeal and dedication; justice is the result of a combination of benevolence with justice. All employees at all levels of the hierarchy should observe the established rules.

Staff stability. The staff turnover is simultaneously the cause and the consequence of the problems at the enterprise. The installation for long-term work in the organization is implemented because high fluidity reduces its effectiveness.

Initiative. Encouragement of the employees to making independent judgments within the limits of the authorities delegated to them.

Corporate spirit. Coherence between the interests of the staff and the organization ensures unity of the efforts.

Each of these principles makes a definite contribution to improving the quality of management, however, in our opinion, these principles are to be considered as recommendations for the organization of management. These principles should lie in the basis of the system, generalizing phenomena of that field of knowledge from which they are abstracted.

A. Fayol emphasized the universality of the management principles without restricting their application only to the sphere of production. V.I. Knoring in his work "Theory, Practice and the Art of Governance" refers to the principles of management [149-150] suggested by G. Kunts and S. O'Donnell concerning the fact that principles cannot always be formulated as a legitimate judgment. In this regard, criticism of such interpretation of the principles of governance is fair. They are to be interpreted as follows: if the work is performed in accordance with a certain principle, the result achievement of the goal will be more effective.

Representatives of the school of administrative management G. Kunts and S. O'Donnell give the following description of the principles of management in the fundamental study of management organization, specialization of managerial functions, their contents and procedures related to the implementation of these functions "Management: system and situational analysis of managerial functions" : "If we use the principles to explain managerial behavior, they should be formulated in such a way that results can be foreseen" [149, p. 12-15]. The authors consider the degree of the achievement of the goals defined as the results. Therefore, the principles of management should contribute to effective and resultative achievement of the goals of the enterprise or subdivision, irrespective of their essence - economic, political, social, etc.

The authors define appointment of the principles for managing an organization, in our opinion, directly relate to our research: "support of the enterprise organization as an effective form of group activity for a certain period of time, i.e., ensuring survival of the group until the main objectives are achieved. In most enterprises, these goals are steady and designed for such a long period of time, which means endless survival. Thus, a commercial enterprise can set the production of goods or services which people 
constantly need and which they are able to buy ... as a continuous goal "[149, p. 13-15]. Principles of management organization by G. Kuntsom and S. O'Donnell are grouped in the following directions:

- principles of the formulation of goals: concreteness, measurability, perspective, reach, unity;

- principles of the requirements to organize: the range of management; scalar; delegation of responsibility and authority according to personal, functional, organizational and disciplinary aspects; absolute responsibility; parity of authority and responsibility; united command; level of authority;

- principles of the division of functions: division of labor, functional definition, distribution of control;

- principles of implementating organizational process: equilibrium, flexibility, and management optimality.

In their studies, the scholars of scientific and administrative management schools also considered some aspects of socio-cultural problems of management without emphasizing basic attention on this, which further developed into a humanistic direction represented by schools of human relations, human resources, and behavioral school.

Moving the emphasis in managing production tasks and processes to a person is the main characteristic of E.Mayo school of human relationships. Unlike the statements of scientific management, the focus of attention is transferred from the tasks, operations or functions performed by the workers, to the system of relationships, to a person who is perceived not as a machinne, but as a social phenomenon. The ideas of the school of social systems developed and supplemented various behavioral management theories V.D. Scott, M.P. Folette, A. Maslow, D. M. Gregor, and others. [151-152]. F.Taylor focused on the best performance of tasks, operations and functions, but the scientists of the behavioral school of management were looking for the solutions of problems of the nature of relations in a team, the motives of human activity, conflict science, etc.

In the following decades, the theory of management was supplemented by the principles from the scientific works by John Moon, A. Reilly and L. Gulick L. F. Urwick, M. Weber, and G. Church. Their attention was focused on the fundamental elements of management - planning, organization, motivation, control.

J. Mouny and A. Reilly in their work "Principles of organization" defined the concept of organization as one of the forms of people associating for the achievement of a common goal [153]. Without the goal definition, no organization can function effectively, including the business sector. Achievement of a common goal requires consensus, so the leadership of the organization should first of all consider its main task of creating favorable climate and direct all efforts of the workers toward this. In order to fulfill this main task, the principles of creating a system for coordinating activities according to hierarchical principles were formulated:

- $\quad$ scalar (the hierarchy of power);

- functional (division of labor according to functions);

- coordination.

M. Weber, who developed the theory of bureaucratic construction of the organization and, in particular, the system of management, worked on the problem of 
organizing the work of business entities as machines. In his opinion, the basic principles of constructing an organization should be the following:

- division of labor with the account of functional specialization;

- hierarchy of the levels of management;

- definition of rights and obligations of employees based on the system of rules and norms;

- definition of the system of rules and procedures in specific situations;

- absence of personal background in interpersonal relations;

- admission to the organization based on the competence and needs of the organization;

- promotion within the organization based on the competence and broad knowledge of the organization that come with the years of employment;

- $\quad$ strategy for "lifelong" recruitment of employees;

- concise career system;

- managing administrative activities through written instructions on internal activities of the organization.

The theory of organizational culture - V. Sate, E. Shine, T. Parsons, R. Quinn, J. Rorbach and others. [154] depicts organizational culture as a powerful tool that enables them to target all divisions of the organization and its individuals on the achievement of common goals, mobilize employees' initiatives, bring up allegiance to the organization, improve communication, and adjust behavior, thereby increasing adaptability of the organization. The main principles of the theory of organizational culture are:

- individual autonomy in a degree of responsibility, independence and opportunities for the initiative;

- regulation - establishment of a set of rules, regulations and definition of the degree of control over the employees' behavior; interaction of employees and management;

- $\quad$ purposefulness - formation of goals and prospects of the activities;

- integration - implementation of coordinated activities;

- managerial support - providing clear communication links by managers, assisting in duties performance and support of their subordinates;

- support - the subordinates' assistance to their leaders;

- stimulation - establishment of the ratio of reward depending on the results of work;

- identification - identification of employees with the organization as a whole;

- conflict tolerance - control of the degree of conflict in relations between employees, their willingness to be honest and open;

- risk management - encouraging employees to engage in activity, innovations, and assumption of a certain degree of risk;

- comparison - establishment of employees' appropriatness to their duties.

Principles of the humanistic concept of modern management should be reflected in the complex of principles of adaptive management at trade enterprises. For this purpose, in our opinion, the principles of functioning of the mechanism of adaptive management should be characterized in two directions: organizational, technical and social. The social component should integrate the principles on which the interaction of higher managers with personnel is built. 
The principles of a new managerial paradigm are formulated in modern "synthetic" management doctrines. The scientific flow of "synthetic" approaches to management is characterized by management judgment as a multifaceted, complex, variable phenomenon whose characteristic feature is numerous connections to the internal and external environment of the organization. It considers management of the organization in all its diversity from the point of view of the system approach. Its main characteristic is recognition of the systemic effect, which is expressed in the fact that the whole always qualitatively differs from the simple sum of its elements.

For some managerial doctrines in this area, it is characteristic to shift the emphasis on a separate component or direction of the organization's activities - goals, external environment, structure, etc. However, their fundamental difference from "onedimensional" doctrines is that they all support the thesis of multi-dimensional organization and its management, and the necessity of taking into account the influence and interaction of external and internal factors that have a direct and indirect influence on its functioning.

Systemicity principles consider a modern organization, first of all, as a socioeconomic system, which has specific, proper peculiar features. Basic principles of the situational approach are discussed in detail in the monograph of Bekh Yu.V. [155].

Basic statements directly proceeding from the system doctrine:

- the principle of unity - joint consideration of the system as an organic whole and as a set of elements;

- the principle of connectivity - consideration of any part of the system, in conjunction with other parts and with the environment. When considering connectivity, special attention is paid to feedback in the system;

- the principle of development - taking into account variability of the system, its ability to develop, replacement of parts, accumulation of information, dynamics of the environment is also taken into account, change of the system interaction with the environment.

Those that determine rational, purposeful approach to the consideration of the structure and functioning of the system:

- the principle of the ultimate (global) goal: particular responsibility for choosing a global goal. All activities of the system must ultimately be subordinated to the achievement of its global goal. The purpose of the organization is defined as a state of the organization, which is necessary and desirable to reach up to a specific point of time, having spent on it certain resources limited from above. Any decision may simply be meaningless without a clear understanding of the goal. The uncertainty of choosing the purpose is connected with the presence of a set of goals and a set of criteria in complex systems, and, possibly, the ambiguity of the dynamics of the environment. The uncertainty in predicting the state of the environment, it must be necessarily taken into account during the formation of a set of goals and development of the ways for their achievement;

- the principle of functionality: joint consideration of the structure of the system and functions with functions priority over the structure - the change of functions entails a change in structure;

- the principle of decentralization: a combination of decentralization and centralization. 
Complex systems with full centralization adapt more slowly to environmental changes. Information channels in such systems are overloaded that leads to delays in the information processing, emergence of errors and, in the end, reduction in the quality of management. High degree of centralization results in the lack of initiative and irresponsibility at the lower levels of the management hierarchy - reduction of the "internal activity" of the system. However, at a high degree of decentralization, coordination of the decisions, their focus on the global goal achievement is complicated. To ensure purposeful activity of a highly decentralized system, there is a need for special regulation mechanisms in the system that do not allow individual elements of the system to deviate the main purpose of the system. Optimal combination of centralization and decentralization is conditioned by the following statements: the lower levels of the hierarchy should get all the tasks whose solution at these levels is possible, freeing up higher levels of the hierarchy for solving strategic problems; a system of delegating powers for all levels of the management hierarchy should be developed and adopted; there must be mechanisms of control that exclude acceptance of the decisions at the lower levels of hierarchy, which contradicts the achievement of global goals by the system;

- the principle of modular construction: allocation of modules and consideration of the system as a set of modules. A module (block, subsystem) is a group of elements of the system, described only by its input and output. The partition of the system into interacting modules (subsystems) depends on the purpose of the research and may have material, functional, algorithmic, informational and other diverse bases. The partitioning of the system on the modules contributes to more effective organization of the analysis and synthesis of systems, since it is possible, abstracting from minor details, to find out the essence of the basic relations existing in the system and determine the consequences of the system;

- the principle of the hierarchy - the whole is divided into parts and the relation of subordination or the entry of parts into a whole is introduces, the parts are ranked. The hierarchy is inherent to all complex systems;

- the principle of curtailing information: the information is curtailed and enlarged when moving from the bottom to the top of the hierarchy;

- the principle of uncertainty: is one of the main principles of the system approach. Quite typical are the cases when the problem has to be solved with the incompleteness or uncertainty of knowledge about the system under study. This happens due to the limited possibilities of science at this level of its development, and fundamental limitations of human knowledge. At the same time, it is often impossible to get any reliable information about the future, to envisage all possible variations of the environment.

Modern empirical school of management is represented by scholars who combine development of the theory with the study of management practices based on the synthesis of the ideas of classical school and the school of human relationships. The leading representatives of the empirical school include: P. Draaker, A. Sloan, R. Davis, E. Ploumen, A. Chandler, L. Newman, D. Miller and other scholars [156].

The most famous theoretical scientific work of P. Draker is the concept of "management according to the goals". General characteristic of management by the goals using the principles of systemicity is reduced to three of its most significant elements: the definition of clear strategic goals; involvement of all employees to the process of defining the goals; evaluation of the effectiveness based on the results obtained. 
Since the focus of managers was previously concentrated on functions and processes, P. Draker's idea concerning the fact that management should start with the development of goals, and then move on to the formation of functions, the system of interaction and the process of management influences, changed the logic of management. Principles of management by P. Draker:

- unity of the purposes;

- commitement to the achievement of purposes outside the organization;

- ability to joint actions;

- connection with culture and traditions;

- the ability to develop and implement needs;

- individual responsibility;

- assessment of activity.

U. Ouchi attempted to formulate the best approach to managing any organization. The starting point of his concept is that the person is the basis of any organization and the success of the organization depends primarily on it. The author formulated the main statements and rules of human management, based on which one can achieve effective management:

- long-term hiring of personnel;

- group decision-making;

- individual responsibility;

- slow assessment of staff and their moderate advancement;

- indefinite, informal control by clear methods;

- non-specialized career;

- overall care for employees.

The theory of "7-S" elaborateded by T. Peters, R. Waterman, R. Pascal and E. Atos is the most wide spread among the modern system management concepts. Based on the principle of systemacity, the researchers concluded that an effective modern organization is formed on the basis of seven interrelated elements, the change of each leads to the change of six others [157]:

- strategy;

- structure;

- system;

- common values;

- composition;

- symbolism of behavior;

- amount of skills.

The principles of a new managerial paradigm, which form the basis for improving management of the organizations, include the principles of a situational (case) approach. Its relevance in the context of our research lies in the fact that it allows to adapt the enterprise to changing conditions and unique situations, choosing the most effective strategy according to them.

The background of situational approach to the organization is the concept of situation - a specific set of variables (circumstances), which affect functioning of the organization in a specific period of time [138, p. 17]. According to situational approach, there is no single best way to manage an organization, the most effective method in a 
particular situation is the one that most corresponds to it. An organization is considered as a complicated, complex and multilevel system, which incorporates adaptive principles (that is, the possibility of rebuilding in a situation change). The task of situational theory is to study the dependence of management methods on the situation and unique conditions of the organization that applies them.

The situational theory of governance was started by R. Mokler, who in his article "Situational Management Theory" expressed the idea of the lack of existence of principles of management, designed for general application. At it best, it is possible to develop conditional or situational principles useful in certain specific business situations. The other founders of the situational approach are T. Burns, G. Stalker, P. Lawrence, J. Lorsch. who claimed that a more stable and formal organizational structure is consistent with the stable environment than the changing one. The main theorists of the situational school are K. Knight, M. Star, D. Miller, who developed methodology of the situational approach.

Situational approach is not only in the understanding that in each particular situation it is necessary to act according to the circumstances, but most importantly - in striving to build a theoretical model of the organization in which external factors are represented as a set of variables, and establishment of the relationship between these variables and elements of the internal environment of the organization.

Theoretical and applied research of situational approach are closely connected with the development of the theory of systems, according to which, depending on the degree and nature of the interaction of organizations with the environment, isolated and open systems are distinguished $[158$, p. 36]. It is obvious that in this concept, an organization is considered an open system, which is in close relation with the external environment, which affects the situation in which it operates.

Situational theory of management assumes that the main task of the manager is his ability to interpret the situation correctly based on the analysis of variables, the main of which are the size of the organization, dynamics, uncertainty and complexity of the environment and technological features of the production process [159]. Thus, the objects of the analysis in the framework of the investigated approach are situational variables that form unique managerial situations.

Basic principles of situational approach to management are as follows.

1. There is no universal approach to management. Each situation is unique, different problem situations require different approaches to their solution.

2. The task of the researcher is to interpret the situation correctly, determine which factors are most significant in this situation, evaluate the consequences of a decision and choose the methods that will be most effective in this situation. Situational probabilistic factors are taken into account in strategies, structures and processes.

3. Each of the management techniques has its strengths and weaknesses. The researcher should be able to anticipate possible consequences of applying a particular technique or concept in a particular situation.

4. The situational approach is based on the study of interaction between the external and internal environment of the organization, impact of external and internal factors on the organization. 
5. Because each organization and each situation are unique, the results of one and the same management decisions can vary significantly.

6. There is more than one way to achieve the goal. Application of situational approach in the management of organizations is based on the situational analysis technology.

According to the situational approach principles, dynamism of the organization, predetermined by numerous variables of the internal and external environment, denies the possibility of applying a universal method of effective management, that is, the most effective is the method, which corresponds to a particular situation to the greatest extent. Thus, this approach is aimed at the development and practical application of tools for the analysis of potentially possible or already existing situations and making management decisions on this basis.

Conceptual statements and principles of system and situational approaches are the the starting point for identifying the principles of adaptive management of trade enterprises, in particular, we consider it expedient to emphasize the following criteria:

- conceptual principles of adaptive management, predetermined by its specific properties and scope, which are universal for all components of the adaptation process;

- principles of adaptive management associated with the dynamics of the environment are divided into two subgroups based on the degree of friendliness of environmental functioning: preferential treatment of the environment (development strategies) and its aggressiveness (problems in complying with the target parameters of functioning);

- principles on the basis of which the organization and functioning of adaptive enterprise management system are organized, namely: principles of the management process and the formation of management mechanism.

The need to improve substantive and functional-oriented approaches to management, (application of the first in relation to socio-economic systems is to improve the existing objects (systems), and the second is based on the hierarchical organizational structure of the enterprise), led to a widespread use of a more progressive functional process-related - approach. Intensive implementation of the process approach at the enterprises initiated research works of Sheer A. and continued in the works of Hammer M., Champi D., Davenport T. et al. [126; 136; 160-161].

Principles of the process-related approach to management determine basic rules for managing effective business operation aimed at the final result. The first principle: the implementation of business processes, subjected to mandatory regulation or formal description, defines vision of the company activity as a set of business processes. That determines new culture of perception of the organization in the process-related approach, since the company's activity is considered as a set of business processes.

The second principle: every business process has an internal or external client and the owner (the person responsible for the outcome of the business process) is based on the fact that allocation of the business process is always linked to the identification of the client or consumer of the process result that costs something. Besides the client, each business process has an owner - an official who possesses necessary resources, manages run of the business process and is responsible for its results and efficiency. The owner of the business process is an official, a formal leader, so he has all necessary powers, the 
resources required for the process implementation, manages run of the business process and is responsible for its result. These advantages guarantee high performance of the organization, which is a process-oriented management.

The third principle: each business process is characterized by the key indicators describing its implementation, the result or impact on the overall performance of the organization as a whole.

Process-oriented management allows qualitatively change the organization's activities at the operational, interfunctional and inter-organizational levels of its integration. Functional integration ceases to be a source of inter-functional conflicts that are difficult to solve. As a result, manageability of the organization increases, influence of the human factor and cost price of products and services reduce. All this leads to a change of the organization quality itself and formation of a process-oriented organization, in which the entire team is a conscious participant in a continuous process of activity associated with the end result of production or service provision. Comparative analysis of functional and process-related approaches to management, performed by K.S. Bezgin and I.V. Gryshyna [162], convincingly proves advantages of the latter.

The latest scientific and practical trends concerning organization of the research in management based on a process-oriented approach are characterized and consolidated in numerous international standards: ISO 31000: 2009, ISO / IEC 31010: 2009, ISO/IEC 31010 , etc. For example, the principles of COSO standard regulate the requirements to management systems, TQM standard - to the overall quality management system; PIQS Quality Management Systems integrated with business processes; WFMS - process control systems; ERP - integrated planning and resource management system [163].

Regarding the application of the principles of the process approach to adaptive management of trade enterprises, its following distinctive features attract special attention: adaptive organizational structures oriented towards innovations, orientation of the result of work to the consumer, high adaptive ability, capability to take into account the peculiarities of conomic environment, such as negative impact of macroeconomic shifts (crisis), uncertainty and variability of needs or positive impact of macroeconomic changes. We support the authors' opinion that opposition of process-related and functional approaches as phenomena in different areas of organizational and managerial reality is incorrect. In our opinion, the system of adaptive management by trade enterprises should not discard the advantages of functional approach - simplicity of the organizational structure, possibility of saving on overhead costs due to the centralization of functions, specialization of officials in a certain direction, resulting in the improvement of their professional skills, elimination of managerial functions' duplication, high competence of the specialists responsible for the implementation of specific functions, reduction in the requirement for broad profile specialists, etc., and use it in complex with modern approaches to management: process-related, value, structural, design, and their combinations.

Integration approach is the development of process-related, situational and other approaches. At the integration approach, different management situations are considered, decision-making processes are described with the use of logical forms, methods, and laws. Integration is aimed at deepening the interaction of the subjects of management, their association, strengthening of interaction and relationship between the components of the system. Integration provides deepening and specification of interconnections between individual subsystems. For example, the managing subsystem of the organization, based 
on the market research, brings to its subdivisions precise indicators on the quantity and quality of products produced, resource costs, terms of works execution, based on which the defined goals are achieved. Such coherence provides an opportunity to ensure the efficiency of management and rationality of the use of material, labor and financial resources of the organization, introduction of innovative and intensive production technologies, improve control over the implementation of the decisions made, which makes it necessary to use principles of the integration approach in the system of adaptive management of trade enterprises.

The peculiarity of modern management lies in its focus on ensuring rational management of the economy under the conditions of resource shortages and achievement of high final results with minimal costs, optimal adaptation of the organization to changing market conditions.

Market conditions of management require revision, improvement and addition of the existing management principles, because classical principles reduce their efficiency in the conditions of modern business structures. Modern scientific developments in the theory and practice of management offer author's vision of management principles, which can partly be applied in the system of adaptive management of trade enterprises.

In the work of V.I. Knoring "Theory, practice and art of management " [150] on the basis of critical rethinking of A. Faiol principles, the author describes the most important principles of management, which, in his opinion, reveal patterns of a controlled system formation: its structure, methods of influencing the personnel, shaping motivation of the behavior of the staff, taking into account features of technology and technical equipment of managerial work:

- $\quad$ principle of purpose. Each action must have a clear and specific purpose. This principle applies to all types of human activities: from state and production management to tactics of a person's behavior at the domestic and interpersonal levels. Not knowing the purpose and the results, which can be expected in the conditions of its achievement, any action is doomed to failure or can cause a significant conflict. In management, the problem of purpose is central, it defines and regulates actions and is a basic law, a complex algorithm of behavior conquering all aspects of control influence. Constant commitment to the general purpose of the enterprise and control of the achievement of local goals is characteristic of Japanese management and many firms in America and Europe. However, the method of managing the goals will not be effective in the case of high centralization of management and weak motivation of labor;

- the principle of legal protection of managerial decision. Entrepreneurship is always associated with certain risk, and especially in Ukraine after its entry into competitive market relations and for imperfect legal norms. Interaction between the producer and the consumer, between the seller and the buyer depends on many legal constraints. New laws are constantly born, the components of the Commercial Code are changing. It is difficult to foresee the direction and effect of certain laws, decrees and regulations, but it is necessary to contend with them. This principle requires managers of enterprises to understand the current legislation and the adoption of management decisions only with the account of the compliance of these decisions with existing legal acts;

- principle of management optimization. Timely processing of information concerning internal processes in the system and its comprehension allows to take 
precise managerial decisions, to improve internally system connections, to increase efficiency of interaction with the external environment. Optimization of management allows to improve structure of the controlled object and increase its functionality, which in the end leads to weakening or complete elimination of internally system negative processes. Thus, optimization of management improves efficiency of the managed system. Optimization and simplification of complex production systems is a prerequisite for more effective use of everincreasing amounts of information that determines the progress of these systems. The principle of optimization lies at the bakground of any organizational structure, regardless of whether it applies the criteria of optimality and whether the systems of restrictions work;

- the principle of delegating authority. Its main contents is the transfer of the head office functions of their subordinates without active interference in their activities. The main practical value of this principle is that the top manager frees his time of less complex everyday cases, routine operations and can concentrate efforts on solving the problems of more complex management level. At the same time this method is a targeted form of upgrading of employees, facilitates their motivation to work, manifestation of initiative and independence;

- the principle of conformity. The basis of the principle of conformity is the work that is to be performed should meet intellectual and physical capabilities of the performer.

Up to date, in the principles of management, the main attention is paid to human (social) aspect of management: management is directed towards a person, in order to make people capable of joint actions, to make their efforts more effective. Management is inseparable from culture, based on honesty and trust in people; management forms communication between people and determines individual contribution of each employee in the overall result. Ethics in business is a golden rule of management.

These modern trends in the development of the theory and practice of management are characterized by American scientists T. Peters and R. Waterman in their work "In search of effective management" [157, p. 29-30], who, having studied activities of the best firms in the world, formed a group of priority principles of modern business:

1. Orientation to action, to achievement of success. In a number of advanced companies, the standard procedure looks like this: "Do it, decide it, check it out."

2. Face to the consumer. These companies learn from the people they serve. They offer high quality, service and reliability. They are thriving in the individualization of the most progressive goods. Many of the pioneering companies have drawn the ideas of their best products from consumers. To do this, they carefully and constantly listen to the public.

3. Independence and entrepreneurship. Companies inclined to innovations contribute to the organization's leaders and innovators.

4. Productivity comes from the person. Exemplary companies consider ordinary staff as the main source of achievements in quality and productivity.

5. Relationship with life, value leadership.

6. Fidelity to the lifework. Chances for high efficiency are much better for the companies that stick to the very thing they know. 
7. Simplicity of the form, modest management staff.

8. Freedom and stiffness at the same time. Model companies are both centralized and decentralized at the same time.

The most important task of Japanese management is to establish close relationships with employees, to develop their attitude towards the corporation as a family, to form understanding of the fact that employees and managers have one share.

Principles of management developed by K. Tateisi [164] determine organizational behavior in decision making, assessment of the performance of modern business. These principles form perceptions of the market, consumers, competitors, technology and trends in their changes, determine advantages and weaknesses of the organization and sources of its profits.

The main statements of the Japanese control system are as follows:

- employees should be satisfied depending on the vertical connection density in the organization;

- the main task of the manager is to support employees in obtaining all necessary information and in the procedures for implementing main goals of the group;

- for group decision-making, all members of the team should contribute to achieving the goal to the fullest extent possible;

- inside a collective formed on an ambush of attachment to one common cause, a sense of unity is provided by the emotional participation of all members, which enhances group solidarity;

- in order to ensure solidarity in the team it is expedient to use the clan model, according to which the hierarchical system remains constant, and in part - the concept of the contract, which presupposes the possibility of entering and leaving the team;

- use of the sense of cosmological gratitude characteristic for the Japanese for controlling them in all spheres of social and cultural life;

- the manager should pay the greatest attention to personal qualities of each employee;

- in the process of managing, the manager should rely on the understanding that the Japanese have a strong sense of interdependence;

- the manager should maximum time be at his working place during the working day;

- employees who have knowledge are the "know-how" of the company;

- employers applying innovations, raising productivity and quality should be constantly encouraged to feel that they are listening to their demands and considerations.

Kadzum Tateyisi laid the following techniques to the fundamentals of the philosophy of management that relate to the organization's activities:

- definition of the firm credo;

- the ratio of company goals to the behavior of its employees (human factor);

- distribution of income;

- corporate spirit and joint activity;

- general interest policy;

- a promising market; 
- original technologies.

According to K. Tateyisi, an effective leadership should be based on three principles (management lines) [164]:

- $\quad$ studying needs of a buyer;

- assessment of the virtues of each employee;

- encouragement of the competition spirit.

Essential attention in the philosophy of K. Tateyisi is paid to the technology of "three K": computers, communications and control [164].

The European scientific school of social-oriented management is represented by the German system of "13 Mortal Sins of a Manager" by Wolfgang Hoyer [165]. This system is based on the principles of rejecting unjustified and ineffective actions, that is, the manager must organize his work and influence people in such a way that the latter perform the work entrusted by the organization according to its mission and objectives, namely:

- not abandon personal responsibility;

- not interfere with the improvement of qualifications and the growth of subordinates' talents;

- not oppress the subordinates;

- not take the wrong position;

- not forget about the importance of profit;

- not manage all subordinates the similar way;

- not focus on goals, but focus on problems;

- not be a boss but be a friend;

- adhere to the general rules;

- not abuse the employees;

- be attentive;

- not evaluate highly the work of the just punished employees;

- not manipulate people.

Scientific and theoretical approaches to the socially-oriented leadership of the Ukrainian economist V. Tereshchenko [123] are concluded in the fact that, in his opinion, the task of the leader (manager) is to direct, to select good staff, to develop organizational structure of the enterprise, to choose general direction of its activity, to coordinate all work, to fight unproductive loss of time. And the most important tasks as this scientist thinks is to learn to work intensely and improve quality of the work.

Thus, according to the main feature of modern management paradigm, which is humanization of the society, in modern management, the humanistic concept, according to which no human lives for production, but production exists for a human, is becoming more and more relevant. With the introduction of the developed society into its informational stage, a new individualist-informational direction comes into the direction of changing traditional movement in management. Characteristic of certain organization business principles should be known and understandable for the personnel. They should always be in the center of the organization's leadership, be tested and updated in accordance with the actual conditions in which the organization operates.

The essence of the new philosophy of management is determined by the following principles: 
- self-realization of a person (in contrast to the economic and human social person);

- awareness of the value of material and technological base of modern production and service provision;

- democratization of management;

- increased participation of ordinary employees in the distribution of profits (ownership of a certain share of ownership) and the implementation of managerial functions;

- strengthening the international nature of management;

- constant renewal of enterprises and constant desire to adapt to external factors, the main of which is a consumer.

In the collective scientific and methodical work of Ukrainian scholars under the editorship of A.A. Mazaraki [141] management principles are studied in the context of achieving the goal of the organization. The authors singled out general and partial (local) principles. General principles define the rules of managerial activities that are vested in the organizations of different types and kinds, which should be followed by managers at all levels and services of the organizational hierarchy when making appropriate managerial decisions. They are based on the laws of the development of nature, society and business, objectively reflect the essence of phenomena and real processes of management, undeniably recognized by the society. Individual areas and directions of the manager's work relate to the principles that reflect the specifics of a particular activity and are a continuation of the general principles, specifying them in accordance with the purpose and objectives of functional managers: personnel management, production, finance, innovation and marketing activities, etc. These include the principles of labor division, unanimity, balance of authority and responsibility, justice, remuneration for work performed, discipline and order, which, by virtue of their universality, objectively fit into the system of adaptive management of trade enterprises.

The system characteristic of enterprises under the market conditions of management is the necessity to develop, modify according to the requirements of the dynamic functioning environment. Therefore, principles of adaptive management, in addition to the tasks of providing specific functions of adaptive management, should determine the philosophy of doing business, organizational behavior, form ideas about consumers' markets, competitors, technologies and their changes, etc. They should rely on strengths of the firm and take into account weaknesses, outline areas of activity, and identify clear development benchmarks, allow them to adequately assess the results of their activities and formulate new goals in a timely manner.

Dynamism of the external environment determines continuous development of the organization and the necessity to maintain general equilibrium at each stage of this development. Numerous variables of the environment can be both favorable and threatening to operate the enterprise. Given this, due to the favorable environment changes (friendly environment), the principles of adaptive management of trade enterprises have common features with the system of strategic management, especially with the principles of developing and implementing situational and competitive strategies.

Aggressiveness of the environment leads to problems in adhering to target parameters of functioning, therefore, the principles of adaptive management have common features with the principles of anti-crisis management and risks control. 
Fundamentals of modern methodology and theory of strategic management were laid down by I. Ansoff, P. Drucker, J. Quinn, G. Mintzberg, D. Peters, M. Porter, G. Simon, A. Strickland, A. Thompson, and other [139; 115; 166-167] foreign scholars. From their works on the principles of adaptive management, it is important to state that during the strategy formation it is impossible to predict all the possibilities because of incomplete and inaccurate information concerning various alternatives; the goals of a particular strategy cannot be achieved without feedback.

Conceptual studies of strategic management of enterprise development in modern conditions are presented in various modern scientific works, in which a large number of provisions concerning the principles of strategic management are proposed and considered. Thus, V. Kharchenko [127] proposed author's development of a set of scientific principles for the formation of a strategic management system for the development of an industrial enterprise, which is based on the synthesis of modern publications on this problem. The author distinguishes basic and additional principles, singles out the principles corresponding to managerial actions according to the development stages from the formation of the development purpose to its achievement; principles of the system formation according to its components are distributed, depending on the functional purpose of each subsystem.

Basic principles:

- flexibility as the ability of the system to anticipate, confront and adapt to changes in the environment (for each controlled element), ability to resolve managerial decisions regarding the development of a business entity in the changed conditions of operation;

- complexity as a combination of all managerial decisions in the integrated system, which allows to determine priorities in managing economic activity, ensure interconnectedness and mutual influence of decisions in the process of their implementation;

- optimality is manifested in providing optimal choice between the priority of the tasks for each element of management system and inside each element;

- effectiveness implies, based on the application of system approach to managing the achievement of costs minimization of resources, processes, types of activity in time and volume, as well as maximizing incomes by sources of their occurrence for each controlled element of the strategic management system for the development of industrial enterprises;

- performance means obtaining positive (necessary and sufficient) results on the evaluation indicators (on the basis of absolute and relative indicators of evaluating quantitative and qualitative characteristics) in managing controlled elements of the strategic management system for the development of the industrial enterprise, as well as positive results in the process of managing production subsystem and sales products, subsystems of financial and resource status.

Additional principles:

- rationality manifests itself in a reasonable, harmonious, coordinated management of all elements of the system, in achieving effectiveness of the enterprise development, in the justification of managerial decisions concerning the tasks of managing elements of the system; 
- compliance, which is manifested in the correct definition of economic situation in the country, industry, directly at the industrial enterprise; taking into account global trends in the markets of goods, resources, financial and stock markets; in related industries both inside the country and abroad; in defining competitive positions both among domestic and foreign producers of industrial products;

- dynamism, the content of which lies in the necessity to take into account the state of the environment, i.e., indicators of the subsystem of the external state (economic, political, market, social, environmental), when implementing the development goals under the subsystems of the internal state, which are under the influence of various factors;

- control is continuous monitoring of the implementation process of managerial decisions at all levels of management, for all functional services, taking into account the need for adaptation to changes in the internal and external environment of the enterprise.

The principles of forming subsystems in the system of strategic management of the development of an industrial enterprise are presented in relation to the adoption of managerial decisions: optimality, rationality, control. Principles of efficiency and effectiveness in the author's presentation characterize the summary of the work of all components of the system.

Based on the generalization of scientific and methodological developments on strategic management, we believe that specifics of adaptive management of trade enterprises conform principles of the strategic management, presented by M.M. Martynenko and I.A. Ignatieva [168, p. 22-23]:

- priority - determines the necessity to prioritize achievement of goals and priorities of these strategies implementation;

- heredity - characterizes logical transition from dominant signs of existing potential to the desired potential;

- adjustment - characterizes the necessity for constant changes of goals and strategies for their adaptation to the current conditions of the enterprise;

- concentration of efforts - determines that during the strategy choice, it is necessary to concentrate efforts on the priority areas of activity;

- the balance of risks puts forward requirements for the equilibrium of possible risks through the development of alternative strategies;

- creation of a strategic reserve;

- comparison - determines the technology of conducting long-term analysis; the principle of synergy determines rules of the mechanism formation implementation of the strategies of the enterprise.

It is important to note that the use of strategic management at the enterprise is possible only if the enterprise is strategically oriented. This means that the management possesses strategic thinking, the company uses the system of strategic planning, and daily activities of the company are subordinated to the achievement of the defined strategic goals.

Key principles of competitive strategy are highlighted and characterized in scientific works of domestic and foreign scientists: [118; 169-171]. Namely: purposefulness, systemicity, resource constraints, complexity, alternative, optimality, consistency, manageability, flexibility, efficiency [169, p. 68]. Common specific 
principles of both adaptive and competitive strategic management are: continuity and accumulation of experience; sequence of the executed steps (stages); periodicity.

Success of a competitive strategy lies in the fact that the company even before the strategy development is to analyze previous experience, to find out what actions had a positive impact in the competition and check their relevance at the current moment. In addition, study of the past experience will allow the company to avoid old mistakes when developing a new strategy.

The sequence is caused by the dependence of the next stage on the results obtained in the previous one. To implement this principle, an algorithm of the steps to be taken for strategy development is required to avoid inconsistency of the competitive strategy and market situation, errors that occurred in the past, to evaluate the results obtained in the course of strategy implementation.

The periodicity of competitive strategic planning is manifested in the fact that the results of the implementation of a competitive strategy must be analyzed and taken into account during the subsequent development of strategies, because the competitive strategy is constantly adapting to a competitive environment.

Management principles similar to the previous ones, which are specific in the process of ensuring competitiveness of the enterprise are described in the scientific and methodical publication "Fundamentals of Management", ed. by A.A. Mazaraki [141]:

- adequate assessment of business environment of the organization (economic, scientific and technological, institutional aspects, state and forms of competition, type and structure of market, existing ways of forming consumer preferences, etc.);

- clear definition of the mission of the organization with an emphasis on the positions that will become the basis of competitiveness and formulation of relevant goals and objectives;

- focusing on the "key competencies" of the organization that will form the potential required to carry out its mission (market opportunities, technical leadership, etc.), which will help to determine which area is to be improved to maintain leadership;

- identification of main management approaches (rules) that are principally essential for achieving strategic goals of the organization and bringing them to the whole staff, improving and updating them according to the requirements of the time.

The urgency of these principles may vary depending on the purpose of the organization and the environment. Therefore, they integrate organically with the system of adaptive management of the organization, ensuring its long and effective functioning.

New philosophy of management is based on the system-situational approach, according to which main preconditions for success do not lie inside, but outside the firm $[121 ; 123 ; 172-174]$. The effectiveness of adaptive management depends, first of all, on how timely and adequately to the circumstances, the enterprise adapts to the external environment. Given that in the adaptive management, the predictions of the future state of the environment are of high relevance, the principles of strategic management should be integrated to the system of principles of adaptive management. 
The most significant systemic principles that define general requirements for anticrisis management presented in the scientific works of domestic and foreign researchers [172-174] include:

- the principle of objectivity, use of which involves taking into account the essence and mechanisms of occurrence and deepening of crisis phenomena, orientation of managerial influence not only on external manifestations of the crisis, but also on the root causes of the emergence of crisis phenomena with a view to their localization (blocking) or elimination;

- the principle of complexity, which determines the necessity for system thinking, development of anti-crisis solutions in all areas of the enterprise, types of resources used, functional subsystems of the enterprise;

- the principle of conformity, the essence of which is to study and typify the conditions of the operation of a specific enterprise-object of crisis management, to identify specific conditions and trends in its development, taking into account the life cycle stage and the existing competitive advantages of the enterprise, time constraints inherent in the anti-crisis process, especially at the stage of the crisis deepening;

- the principle of control, which presupposes continuous monitoring of the implementation of management measures in order to permanently adapt to the conditions of the internal and external environment of the enterprise, changing in time;

- the principle of optimality, which involves optimization of methodical tools for researching problems of the enterprise and diagnostics of the threat of its bankruptcy, the optimal ratio of operational, tactical and preventive anti-crisis measures, taking into account the stage of the crisis, the probable period of occurrence of the bankruptcy situation, causes and factors that led to the emergence of crisis phenomena;

- the principle of the key link, the use of which orientates on the search and primary solution of the main problem (catalyst of the crisis), increasing attention to the sphere (direction) of the activity, which causes emergence and spread of the crisis or in which further deepening of the crisis most negatively influences the functioning and viability of the enterprise in general;

- the principle of legality, which presupposes knowledge and use of legal framework governing the conduct of entrepreneurial activity in the interests of the enterprise-object of anticrisis management, the introduction and consideration of a bankruptcy case, determine the possibilities for financial rehabilitation of enterprises;

- the principle of effectiveness, the essence of which is to maximize the possible use of the potential of the object and subject of management to form a sound program of anti-crisis actions, minimizing time, material and financial costs associated with/or an exit from the crisis state of the enterprise.

The specific principles of crisis management are differentiated in terms of the mechanism, process and management system. The mechanism of crisis management is considered as a set of tools and methods of influencing the object of management - the crisis phenomena. These principles include:

- reliance on anti-crisis consciousness - understanding of negative consequences of the emergence and deepening of the crisis for all entities of the crisis; the most 
important characteristics of consciousness are the interests, values and motives of the activity on which achievement of the goal depends;

- anti-crisis motivating activities - the predominant use of motivation tools aimed at solving crisis problems (administrative or organizational measures are not supported by economic and moral-ethical motivation, as a rule, ineffective);

- bias in solving problems - the speed of deepening crisis phenomena at a certain stage goes out of control, the changes become irreversible, so the mechanism of crisis management should be focused primarily on preventing the emergence and deepening of crisis phenomena;

- multivariate development of possible anti-crisis procedures with the account of the uncertainty and risk of implementing individual planning measures, the necessity to develop alternative measures is conditioned, firstly, possible lack of the efficiency, and secondly, the probability of changes in the external environment, internal capacity, goal identification of the owners of the enterprise, resulting in the developed version of anti-crisis actions will be recognized as inappropriate or impossible for the implementation;

- the principle of realism in the assessment of the situation, success or failure; assessing the possibility of overcoming the crisis must be based on objective reality. Information about any positive developments taking place and resulting from anti-crisis measures should be disseminated among the staff. Failures should not be taken as fatal, but it is necessary to focus on the study of reasons for low efficiency or inefficiencies to prevent the repetition of such errors in the future.

The process of managing in crisis management is determined by researchers as a sequence of actions which should be implemented, and form managerial influence [121; 123; 173-175].

The main thing in the organization of the anti-crisis management process is to adhere to the following principles:

- $\quad$ strategic (target) - anti-crisis management cannot be effective if it is carried out without a specific purpose or clear objectives when there is no crisis management strategy;

- sequence of problem solving - in the course of crisis management, it is necessary to rank the tasks and problems by the degree of their importance to reach the ultimate goal, taking into account their influence on the solution of further tasks and the speed of anti-crisis transformations;

- timely adoption of managerial decisions, the implementation of which requires continuous monitoring of the state of the economic system, early detection of signs of the crisis situation, rapid response to them by the appropriate anti-crisis measures. Ignoring this principle can have fatal consequences, since it is well known that removal of the system from deep crisis requires much more effort and cost than preventing its occurrence;

- flexibility, maneuverability, adaptation to rapid changes in the internal and external environment of the enterprise; despite the expediency of developing a typical scheme of the crisis, the specifics of a particular enterprise can specify the content and tools of work to be carried out at each stage, rank their significance, to change the procedure; 
- assessment of positive and negative consequences of the decisions taken, taking into account their influence on vital functions of the enterprise in the short and long term.

A set of functions and responsibilities that are necessary for managerial influence, including the anticrisis is understood as the control system. The system of crisis management should be based on the following basic principles:

- functional integration - anti-crisis management cannot be effective if it relies only on solving operational and tactical tasks; all management of the enterprise needs all its functions to be oriented towards preventing the crisis, and in case of the emergence of signs of a crisis state, their localization;

- professionalism that provides special training of those persons who assume responsibility for the effectiveness of crisis management, the acquisition of certain knowledge and skills for the direct conduct or management of this work; only professional training ensures effectiveness of anti-crisis transformations, prioritization, proper ranking of tasks, makes it possible to save time, save funds, and sometimes ownership;

- responsibility for the consequences of the decisions made; it is this functional subsystem of management that requires a well-developed and balanced system of responsibility for the consequences of the implementation of the anti-crisis program, primarily financial ones; in the developed countries such system of responsibility has been formed and tested by time; in Ukraine, the formation of its principles and mechanisms is one of the top priorities to be solved;

- optimal correlation of centralism and decentralism in making appropriate decisions, maximum involvement of the personnel of the enterprise in a crisis situation, in the development and implementation of anti-crisis measures. Only under these conditions one can hope for maximum speed and efficiency in achieving the target result. The described principles of the crisis management, complementing and specifying each other, can and should act only within the system.

O.A. Osadcha's vision of the main principles of crisis management [175] is based on the following principles:

- the principle of preventing solution of the problems, which involves creation of mechanisms for preventing the emergence and neutralization of crisis phenomena;

- the principle of creating favorable opportunities, which is concluded in the search of the ways for overcoming the crisis by creating necessary conditions, for example, the search, concentration and cost-saving use of resources, minimization of labor, material and financial costs;

- the principle of marketing orientation of manufacture, aimed at measures of the enterprise on the use of resources for the production of only competitive products, which can provide a significant economic effect at a specific time;

- the principle of time constraints, directed towards the implementation of anticrisis measures in the period specified by the legislation for crisis management before the beginning of liquidation procedures;

- the principle of objectivity and realistic assessment of the situation as an opportunity to self-overcome the crisis; 
- the principle of optimal correlation of centralism and decentralism in the taking managerial decisions, which presupposes involvement of staff to the development and implementation of anti-crisis measures;

- the principle of multivariate and permissible risk, the observance of which requires the development and evaluation of a large number of alternatives to take into account possible risks, and determine effectiveness of the specific activities;

- the principle of personnel policy, which consists of the formation and preservation of a unique personnel potential through selection, training of qualified specialists capable of taking non-standard, risky anti-crisis measures in the conditions of the crisis;

- the principle of motivation, which is to use the means of motivation, in particular, stimulation and encouraging personnel, aimed at anti-crisis consciousness to solve crisis problems.

The author added the developed principle of the Crisis Policy, which envisages the search for the main problem (catalyst for the crisis), identifies prime causes of the crisis and necessary concentration of legal, financial, material and labor resources required for the solution of this problem. In our opinion, the Crisis Policy is nothing more than the principle of the mainstream known from the special literature, so its use will duplicate the existing principles.

Specific principles of crisis management are presented on the Web-portal "Front Management" [176]:

- prejudice in solving problems - involves taking into account mechanisms for preventing the emergence and neutralization of crisis phenomena;

- maximization of the opportunities, which means to find the ways out of the crisis on the basis of unique conditions for the enterprise, in accordance with this, to concentrate resources during the process of identifying specific conditions of the enterprise development, taking into account all stages of the life cycle and the availability of competitive advantages. This principle presupposes efficiency not through solving the problems, but through the use of opportunities via minimization of labor, material and financial costs;

- concentration of production aimed at the efforts of the enterprise to concentrate resources on a small number of competitive products, which can provide a significant economic effect;

- time constraints - it is the time specified by the legislation that is available to the anti-crisis manager before the start of liquidation procedures;

- the principle of the key link, which involves the search for the main problem (catalyst for the crisis), determines prime causes of the emergence of crisis phenomena, concentrationof effort in accordance with this (legal, financial, material, labor) to solve this problem;

- the principle of objectivity and realism in assessing the situation, the possibility of overcoming the crisis, based on objective reality;

- the principle of optimal balance of centralism and decentralism in making managerial decisions - presupposes maximum involvement of personnel to the development and centralized adoption and implementation of anti-crisis measures; 
- the principle of multivariateness and riskiness, the observance of which requires the nomination and evaluation of rather a large number of alternatives to take into account the risks of inefficiency of individual measures;

- the principle of personnel policy - preservation and formation of unique personnel potential through selection, training and retraining of qualified specialists able to accept non-standard, risky anti-crisis measures, to be stressresistant in the conditions of crisis;

- the principle of motivation is concluded in the use of the means of motivation (incentives for staff, increase of the share participation in profit), aimed at the increase of anti-crisis consciousness of personnel and solution of crisis problems.

The principles of anti-crisis management technology are described in the article of S.M. Yesh "Perfect technology of crisis management as a factor of business entities' success " [177]. The author proposed the principles of creating technology for anti-crisis management, which, in her opinion, are capable of ensuring success in the development of business entities, namely:

- time saving - the principle related to the efficiency and timeliness of making management decisions;

- normative use of resources, which presupposes to determine efficiency of resource allocation by operations and the stages of anti-crisis management process development by means of management technology. Such stages are: definition of goals; identification of the situation in which differences between the situation and goals are clarified; forming a crisis-related problem and measures which can overcome it, etc. This principle also involves the principle of intensifying the construction of anti-crisis management technology, which involves full use of resources, reducing their losses and rationalizing stock volumes;

- integration within the framework of the overall functioning of the crisis management system. The factors for achieving integration are the methodology and management organization, distribution of functions in the system of crisis management, the system of personnel motivation, the strategy of management, use of computer technologies, etc.

Comparative analysis and grouping of the principles of the above-mentioned anticrisis concepts, as well as points of view on this issue by such economists as: Shtanhret A.M., Bychkova Ye.A., Sviridova N.D., Gryaznova A.G., Dovgan D. A., Shcherban I.O., Bazarova G.Z. and Buriy S.A., presented in the scientific article by Chernysh I.V. [129, p. 176] on the basis of identity gave us the opportunity, by eliminating lexical and substantive repetitions, to concentrate on the numerous principles of anti-crisis management which should be reflected among the specific principles of adaptive management in the following group:

- information support for the implementation of the concept on the basis of facts monitoring;

- adequacy of the solutions of the crisis situation;

- identification of priority problems, goals and ways of their solution;

- control over the achievement of goals;

- organizational and personnel support of the management process;

- mobilization of internal capabilities and resources; 
- urgency and timeliness of responding to the situation taking into account the dynamics of the external environment of the entity's operation.

The system of principles of adaptive management will be incomplete if it does not take into account the principles of solving the problems of the effectiveness of economic decisions, because decision-making ensures functioning and solving business problems. The following categories are the main principles for solving the problems of the effectiveness of economic decisions [178-179].

Systemicity. This principle implies the necessity to consider the place of activities which are evaluated in a multi-level planning and management system. Improvement of indicators at a lower level of the hierarchy should be accompanied by the improvement of the corresponding characteristics at higher levels. However, for such indicators as profitability, return on assets, productivity, these properties may not be available. Here it is important to take synergistic effects into account.

Complexity. In accordance with this principle, a comprehensive analysis of the consequences of the consideration of the measure in all areas where its influence is required. It is also important to combine calculations of absolute and comparative effectiveness. The chosen option should be, firstly, positive, and secondly, it is necessary to ensure full account of economic and social outcomes (both external and internal).

Dynamism. It must be borne in mind that all the basic indicators of socio-economic nature (volume of production, capital investments, current costs, etc.), as a rule, change over time. Moreover, disposable (non-synchronous) costs and results are economically uneven.

Principles directly related to the specifics of adaptive management of business structures have initial definition of adaptive structures provided by T. Burns and D. Stalker [180, p. 105] as their source, which emphasized the following fundamental differences in adaptive management from the traditional bureaucratic hierarchy: "higher flexibility, less relevance to rules and norms, use of group labor organization as a basis". Further development of scientific thought has allowed to substantially supplement the list of properties and principles that characterize adaptive structures of management: management decisions are made on the basis of discussion, not based on authority, norms, rules or traditions. The key to decision-making is trust, not power, belief, and not power; work on the realization of the purpose, and not for the purpose of carrying out job description [181].

Studying the works of domestic and foreign authors, we come to the conclusion that adaptive management, having common features with the overall system of management at the enterprise, strategic and anti-crisis management, is a flexible management that allows adaptation to changing environmental factors in the conditions of lack of information about it. Author's vision of the principles of adaptive management is given by G.M. Aubakirova [182]: systemality, multiplicity, efficiency, humanization, flexibility, hierarchy, adaptability, feedback, diversity and inconceivable solutions.

R.L. Lupak and V.O. Romanyuk [183] noted that for effective performance of administrative functions assigned to it, use of economic mechanism of adaptating to the competitive environment at the enterprise should be based on the following principles of introducing adaptation processes at the enterprise: 
- specialization - exact distribution of adaptation measures according to the corresponding production and organizational directions;

- proportionality - material and technical capabilities of the enterprise cover demands for the implementation of adaptation measures;

- parallelism - involves simultaneous use of individual measures, the aggregate implementation of which will lead to the final result, rational differentiation of adaptation measures will enable to reduce the time of the implementation process;

- continuity - requires absence of breaks in the implementation of successive adaptation measures;

- planning - the work of all units should be carried out with the same rhythmicity that will ensure uniform workload of workplaces, will allow to use production capacities more fully and to avoid production downtime;

- flexibility - provides operative adaptation to changes in organizational and technical conditions with lower costs and without losses in a short period of time, provides susceptibility to innovations;

- correction - presupposes such organization of the adaptation process, which would allow to conduct adjustments at each stage due to unpredictable changes.

L.I. Fesik examining evolution of the concept and providing essential characteristics of the adaptive management emphasizes the necessity to adhere to the following principles [184]: timely response of the object to the signals of the environment; collection and analysis of information to assess the situation; coordination of the signals of the environment; development of a realistic goal and its transformation into internal motives; creation of adaptive (variant) models of activities in which general parameters and criteria are made by the managerial bodies, and adaptation to local conditions and peculiarities is carried out by the performers through the selection of criteria of the second level; directed self-organization to perform tasks by selecting and implementing adaptive models in co-operation and coordination of target functions; current process tracking by the executor with self-analysis and self-regulation (selfmonitoring of the process); determination of the task performance by the manager based on the comparison of the state of affairs before and after its execution (by the model "input-output"); prognostic regulation through a joint (manager-executor) forecasting of further development on the basis of external analysis and self-analysis of the result and making changes to the existing model of activity in accordance with the identified reserves.

Summing up these ideas about the principles of creating adaptive management system, we believe that the principles of the adaptive system for managing enterprises under the conditions of dynamic environment must ensure fulfillment of its functions, which are regulated by the basic principles of modern scientific management, such as: forecasting and planning; organization of work; activation and stimulation; coordination and regulation; control, accounting and analysis, on the other hand, should be deduced from the algorithm of managerial process on an adaptive basis, taking into account specifics of trade enterprise functioning.

The difficulty in classifying the principles lies in their amount, in close relationship, semantic and meaningful similarities of individual principles, in the fact that the classification directly depends on the point of view and goals pursued by the 
compilers. This leads to inaccuracies and discrepancies in the classifications and types of principles.

To develop a scientifically grounded non-contradictory approach to the systematization of the principles of adaptive management of trade enterprises in the conditions of dynamic environment that allows them to be rationally and consistently classified in the context of achieving its goal and the effectiveness of the implementation of management functions, the following principles of grouping were used:

- compliance with the goals (creation of an integrated management system for adequate response to dynamic changes in the environment of the organization functioning);

- reflection of the essential characteristics of adaptive control; systematic; possibility of practical application.

Based on these requirements, we have identified the principles of adaptive management on the following criteria:

- conceptual principles of adaptive management, stipulated by its specific properties and scope, which are universal for all components of the adaptation process;

- the principles of adaptive management are related to the dynamism of the external environment, which were divided into two subgroups based on the degree of environmental friendliness of functioning: environmental friendliness and aggressiveness of the environment (problems with respect to target performance parameters);

- the principles, on the basis of which the organization and functioning of adaptive enterprise management system are organized, namely: principles of the management process and formation of management mechanism.

According to the modern paradigm of management, subgroup of the principles of constructing mechanism of adaptive management has focused on the social aspect (Figure 2.1). 
The group of conceptual principles of adaptive management included systemic and universal principles that were selected by the authors on the basis of research and critical analysis of the principles of classical school of management, modern paradigm and modern theories of management.

These are the principles of informatization, goals, scale, balance, priority, dynamism, flexibility, maneuverability, adaptability, integrity, adequacy, reactivity, uncertainty, diversity, etc.

A number of modern principles have been introduced to this group, at which domestic researchers often do not pay attention, although their effectiveness is confirmed by the world practice of management, namely: priority, integration, emergence, consumer orientation, action orientation, success, diversity (Ashby's principle), perfection, cyclicity and concretization.

A number of principles belong to the group of principles inherent in the dynamic characteristics of a supportive environment (development strategies) and have common features with the principles of organization development $[119 ; 127 ; 185]$ : definition of prospects, taking into account strategic opportunities, multiple-level system, compatibility, openness to innovations and transformations.

Principles of adaptive management in the conditions of the environment aggressiveness, which causes problems in observance of the target parameters of functioning and have common features with the principles of crisis management and risk management $[121 ; 156]$ combine the principles of: preventive, proactive, the key link (weak link), reliance on collective consciousness, problem motivation of activity, taking into account the uncertainty of the future as strategic threats, taking into account risk, urgency of responding to threats, internal mobilization.

The group of principles regulating the process of adaptive management and corresponding to modern management tendencies is based on the following principles: the principle of managing change, realism in evaluating the situation of functional integration, relationship and interdependence, target direction of action, continuity of the experience problem solving, the principle of ingress.

From the authors' point of view, the developed classification should find a reflection of the humanistic concept of modern management, so the group of the principles of implementing adaptation processes in the enterprise in the mechanism of adaptive management contains two subordinate levels: organizational, technical and social components. The social component combines the principles on which the interaction of managers of different levels of management with the personnel is created and personnel is stepped up. For example, according to the principles of ARCU management code [186] (Accomplishing - creation, embodiment, completion, achievement, Regulating - regulation, systematization, administration, Creating creativity, creativity, Uniting - association, integration, measurement).

Thus, use of the scientific principles of classification allowed to develop an integrated approach to the classification of the principles of adaptive management of trade enterprises, which corresponds to the tasks of applied research and to improve the process of developing a comprehensive integrated system of adaptive management of trade enterprises under the conditions of dynamic environment. The principles, grouped according to the proposed features of the classification are specified and expanded by incorporating the principles generated by the modern management paradigm. This makes 
it possible, on the basis of classification, to implement adaptive management more thoroughly and perform its tasks and functions more effectively.

\subsection{The structure of the organizational and economic mechanism of adaptive management at trade enterprises}

The structure of the organizational and economic mechanism of adaptive management of enterprises, in particular trade, is presented as follows. At a given time the enterprise is in a certain outgoing and/or optimal state, which corresponds to a certain state of the environment. There is a two-way connection between the enterprise and the external environment. During the transition of the external environment to another state, conditions of the enterpris functioning objectively change. The company also goes into a different state, which is very likely beyond the optimal one.

Under the adaptive system of managing a trading company an adaptation mechanism that provides economic entity with the possibility of adapting to new environmental conditions must operate in such a way that, under these conditions, the enterprise is able to function optimally, providing target parameters of competitiveness in the market.

The system of adaptive management principles is the initial system-forming element of the conceptual model of the integrated system of adaptive management of trade enterprises (Figure 2.2).

Trade is an industry characterized by a high degree of dependence on the state of the environment in view of the tasks and functions that it performs. The specificity of trade enterprises activities are manifested primarily in the fact that the effectiveness of their functioning largely depends on the state of the consumer market, which is very variable in nature because of a high level of demand and supply elasticity. High dynamics of the competitive environment and rapid development of competition facilitate increase of the level of environmental impact. 


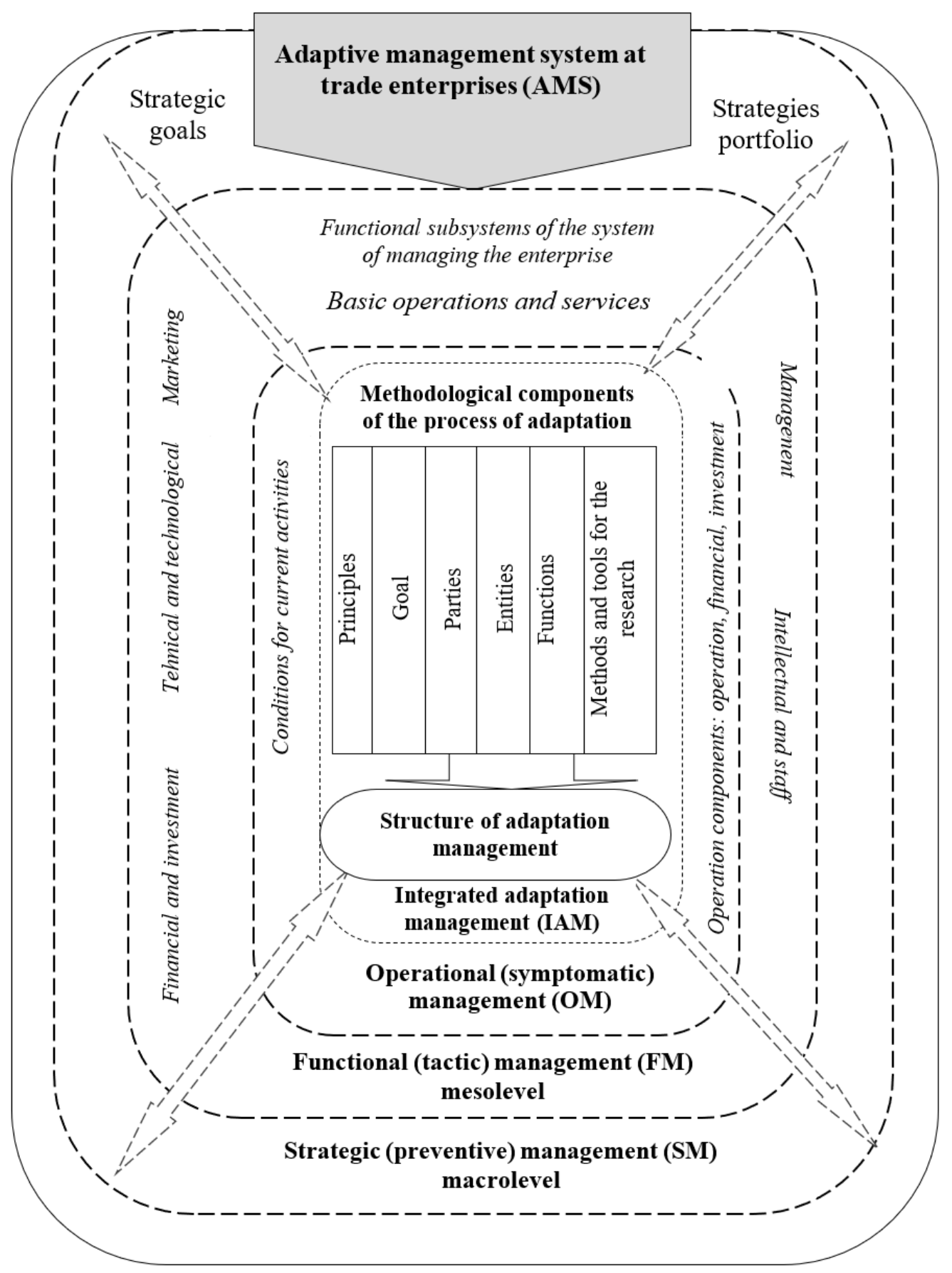

Figure 2.2. Conceptual model of the integrated system of adaptive management of trade enterprises in a dynamic external environment (author's development) 
Dynamic territorial and quantitative development of a network of trading enterprises of different formats, a large degree of uncertainty due to fluctuations in price and market conditions, rapid changes in the needs and tastes of the population are the specific features of the competitive environment of trade enterprises that promote the dynamics of operating conditions [187, p. 28, p. 144, p. 172; 188-192].

The degree of uncertainty of the conditions of trade enterprises' functioning, as an integral part of the economic system of the country, is largely enhanced by the effect of such specific factors as a deep socio-economic crisis, lack of clarity in the legislative framework and its frequent changes, instability of economic, political and social development, inequality of inflation rates, insufficient use of modern technologies and equipment, low payment discipline, ineffective management and marketing.

Thus, management of the activities of trade enterprises in the periods of global instability should be more flexible than during the periods of steady growth of the world economy.

Central component of the integrated system of adaptive management of trading enterprises in the conditions of dynamic environment, its task and target benchmark should be the provision of a permanent adaptive ability. This concept refers to the continuous ability to withstand adverse situations associated with the aggressiveness of the environment or the ability to use prospects that open under favorable environmental conditions, as in the spatial aspect - at the meso-level, micro-level and directly in operational activities, and in the dynamic aspect - at the strategic, tactical and operational levels of management. The main integration factors are the mission and strategy of enterprise development.

We have identified three levels of the integrated system of adaptive management of trade enterprises (Figure 2.2): strategic (preventive) management (contour SM), functional (tactical) control (contour FM) and operational (symptomatic) control (contour $\mathrm{OM}$ ), aimed at providing effective sectoral adaptation at macro- and meso- levels.

Central element of the model is the system of adaptive management of trade enterprises in the conditions of dynamic environment (contours ADM), which indirectly provides the preconditions for the effectiveness of the adaptation process through the functional connection of its spatial, functional and time components.

The main purpose of the proposed integrated management system is to ensure the sustainability and integrity of the activity of trading enterprises in the conditions of volatility and ambiguity of the environment. The sustainability of activities is ensured, on the one hand, by the coordination of actions on strategic, tactical and operational control, on the other hand, by regulatory influences of adaptive management, when the given direction is maintained despite constantly changing circumstances. As I. Actashkina, B. Mishin [193] noted, the enterprise management system is an independent system, but cay enter the systems of higher order, at that, composition of the elements of each subsystem of the enterprise management system is diverse and depends on the specific content of the organization's system. Regarding the system of adaptive management - the mandatory precondition for its effectiveness is the integration into all levels of management systems and subsystems of the enterprise. In view of the above, integrity of the activity is ensured by the fact that the system of adaptive management does not contradict general organization of the management system, and organically integrates with it. 
Like any system, the integrated system of adaptive management of trade enterprises consists of the elements joined together for functioning, at that the subject and object of management and the main elements of the control system are distinguished. Each element must correspond to its purpose to ensure integrity of the management system.

The system of managing enterprise includes such elements as management functions, organizational structure of management, management personnel, technical means of management, information, management methods, technology, finance, managerial decisions. Methodological components of the process of adaptation are presented by the system of principles (see Figure 2.1).

The purpose of functioning of the adaptive management system in trade enterprises in the conditions of dynamic environment is the development and implementation of managerial influences or decisions for the formation of the required behavior of the controlled system (or object of management) in the conditions of various environmental influences for the achievement of the formulated objectives.

The structure of parties and objects of adaptive management, referring to professional sources concerning the issue under research $[3 ; 114 ; 131-132]$ includes:

- $\quad$ parties - founders (owners), shareholders, managers, staff, potential investors;

- objects - processes occurring in the external environment of trade enterprises functioning and their impact on the system of trade and economic activity at a certain time period on the macro-, meso-micro levels.

The research of such an element of the proposed integrated system of adaptive management as a function is of great practical importance, since it determines organizational structure of this type of management, as discussed in the article "Management Functions" [194]. At the same time, the system of adaptive management is based on the general management functions required for the success of any organization, and present at all integration levels of our proposed system - planning, marketing, entrepreneurship, finance, organization, innovation, information and social development, motivation and control. It has specific management functions determined by the object of management.

Specific functions of adaptive management of a modern enterprise, as noted by Alekseev S.B., Solomakh S.A., Stasyuk V.P. [3; 131-132], include:

- formation of management focus on the sustainability of the development according to the criteria of adaptability or stability;

- control of the characteristics of environmental changes;

- management of personnel development to reconcile personal goals with the goals of the enterprise development;

- formation of sustainable development strategies;

- coordination of basic and special functions and subfunctions of management in the field of stability parameters of development;

- formation and regulation of technical and technological basis;

- adjustment of the balance of financial characteristics of sustainable development management;

- formation of orientation of internal communications on the stability of the development process; 
- formation and regulation of the style of leadership aimed at sustainable development;

- formation of the conditions for the compliance of the structures of environmental factors and goals of sustainability of the enterprise development.

The developed model of the integrated system of adaptive management of trade enterprises in the conditions of dynamic environment creates conceptual preconditions for the development of an independent system of adaptive management, which represents a unified regulated set of elements and actions forming a closed management system.

The model of organizational and economic mechanism of an independent system of adaptive management of trade enterprises in the conditions of dynamic environment, which is depicted in Figure 2.3 was created in compliance with the conceptual principles of adaptive management due to its specific properties and scope, as well as the principles of the construction and operation of adaptive management system of the enterprise (see Figure 2.2). Scientific basis for the development is represented by the combination of system, functional, process, integration, marketing, dynamic and integrated approaches, which should ensure the effectiveness of practical implementation of the developed management system. 


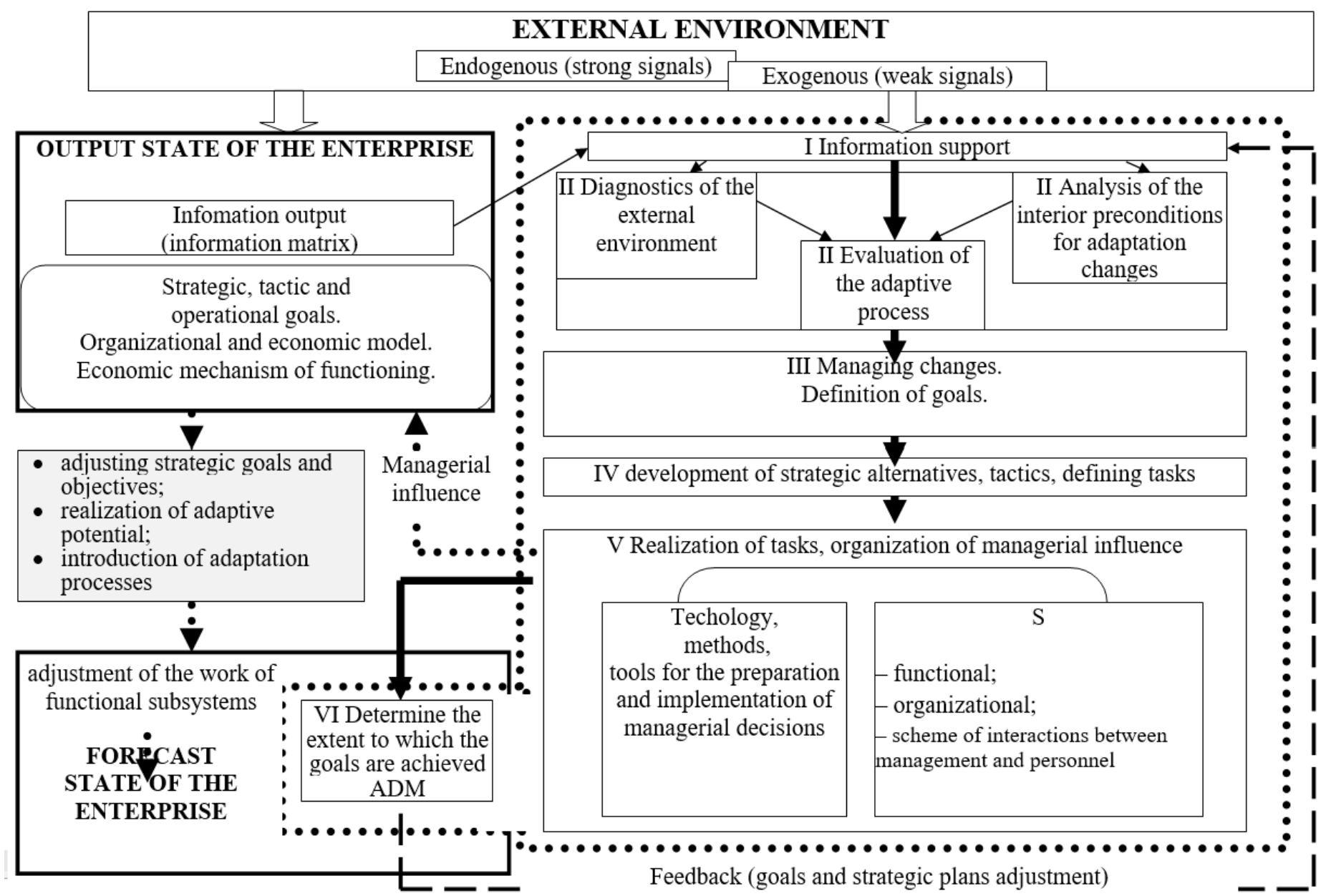

Figure 2.3. The structure of the organizational and economic mechanism of trade enterprises' adaptive management under external environment dynamic (author's development) conventional signs: - loop of the adaptation management process technology 
Based on the theories of modern management, the creation and operation of effective organizations, modern concepts of strategic management, the theory of "selflearning systems" (P. Sandj et al.), etc. [195-196] we have developed a scheme of organizational and economic mechanism of adaptive management of trade enterprises under dynamic conditions of the external environment. Conceptual content of the system of adaptive management can be characterized as a holistic system of views on the development of trade enterprises by adequately responding to external perturbing influences. Influence of management is aimed at achieving its own adaptation of the enterprise in order to timely react and prevent negative impact of the environment on its efficiency and effectiveness. The primary task is to recognize the basic environmental factors, the managed application of which allows to manage the enterprise with greater efficiency and effectiveness.

Consideration of the enterprise as an object of management, which functions in a dynamic economy, has led to the interpretation of adaptive management of trade enterprises as a function of the state of the environment and the starting point, concerning which the adaptation process is carried out and managerial decisions are made. Since the specific feature of trade enterprises functioning is that the external environment dominant influences not only on the nature of their activities, but also on their internal organization, the enterprise for the development within the established strategic tasks must be prepared for dynamic changes of the environmental factors.

From the point of view of adaptive management of trade enterprises, it is appropriate to focus on weak signals from the external environment: this is incomplete information about the possible changes in the external environment, connected with early and inaccurate signs of the onset of important events. Such signals are characterized by a very low level of awareness. Under the current conditions, trade enterprises in Ukraine are in such state of ignorance.

The sources of weak signals are global trends (global instability, international events, relations between countries, etc., any sphere of the economy that undergoes constant changes as a result of sector specifics (high-tech industries, information technologies, emergence of new materials, etc.); political events (results of elections to state authorities, legislative initiatives, etc.).

Managing by weak signals in the system of adaptive management allows the company to know in advance about the dramatic changes in the external environment; respond timely to events that are difficult to predict; in the early stages of potential dangers or new opportunities to take measures in response to specific measures aimed at preventing the elimination of danger or effective use of the created opportunities. Mnagement by weak signals in the opinion of I. Ansoff is based on the fact that favorable and unfavorable phenomena in the activities of entities do not appear unexpectedly, but are preconditioned by the appearance of practically impenetrable "weak signals" from the external and internal environment [197, p. 53-57].

For successful organization of the process of adaptive management, timely perception of signals about the changing trends in the external environment is an objective necessity to ignore which can turn into a devastating threat or lost opportunities for business. Models, methods, tools for modeling development of the system by weak signals are discussed in detail in the scientific works of Rudensky R. A. and V. Ashley [198-199]. 
A prerequisite for ensuring effectiveness of the adaptive management process by "weak signals" in trade enterprises is the ability to change in time, adapt to new changes in market conditions, economic and political factors. It is practically impossible to specify all possible variants of signal, since it is impossible to take into account the variety of circumstances that form the state of the environment. However, the most significant sources and nature of signals must and can be identified.

To provide the timely reorganization of the system of trade enterprises functioning, upon the condition of changing the environment of functioning, in the system of adaptive management a system of indicators consisting of aggregated factors of the environment are to be applied, which determine the conditions of trade enterprises functioning, and are external signals about the occurrence of negative changes ofthe initial state of the enterprise with further detalization by the types and economic content. A set of such signals in the conditions of the environment aggressiveness is presented in table 2.1 [200].

Table 2.1

External signals of possible changes in the status of trading company in the process of adaptive management (developed on the basis of [197; 199])

\begin{tabular}{|c|c|c|}
\hline \multicolumn{2}{|c|}{$\begin{array}{l}\text { Factors of the environment, } \\
\text { which determine conditions of } \\
\text { trade enterprises operation }\end{array}$} & $\begin{array}{l}\text { Signals about the emergence of initial } \\
\text { economic phenomena in the state of the } \\
\text { enterprise (signals about the increasing } \\
\text { threats to perform mission of the enterprise) }\end{array}$ \\
\hline Aggregated & Detailed & Economic content \\
\hline 1 & 2 & 3 \\
\hline \multirow{2}{*}{ 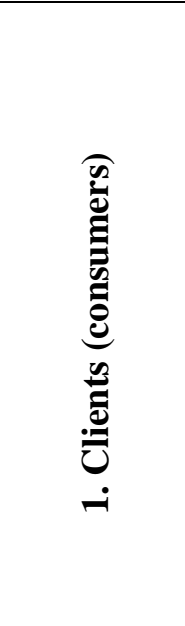 } & $\begin{array}{l}\text { Size of demand } \\
\text { and consumers' } \\
\text { economic } \\
\text { potential }\end{array}$ & $\begin{array}{l}\text { - negative dynamics of commodity turnover per } \\
\text { capita; } \\
\text { - negative dynamics of the population; } \\
\text { - negative dynamics of commodity turnover per } \\
\text { capita; } \\
\text { - reduction of incomes and consumer expenses } \\
\text { per one household; } \\
\text { - reduction of purchasing power of the population }\end{array}$ \\
\hline & $\begin{array}{l}\text { Dynamics and } \\
\text { stability of demand }\end{array}$ & $\begin{array}{l}\text { - negative dynamics of the turnover (size of } \\
\text { demand) of the enterprise; } \\
\text { - growth of goods turnover (size of demand) of } \\
\text { competitors; } \\
\text { - increased fluctuations in demand and profits of } \\
\text { the enterprise }\end{array}$ \\
\hline & $\begin{array}{l}\text { Elasticity of } \\
\text { demand }\end{array}$ & $\begin{array}{l}\text { - increasing the demand elasticity } \\
\text { on services and products of the enterprise }\end{array}$ \\
\hline & $\begin{array}{l}\text { Segmentation of } \\
\text { the consumers of } \\
\text { the enterprise } \\
\text { commodities }\end{array}$ & $\begin{array}{l}\text { - in all segments of the served market, interest to } \\
\text { the services and goods of the enterprise is lost }\end{array}$ \\
\hline
\end{tabular}




\begin{tabular}{|c|c|c|}
\hline & $\begin{array}{l}\text { Demographic } \\
\text { changes }\end{array}$ & $\begin{array}{l}\text { - lower birth rates and increased mortality; } \\
\text { - unforeseen negative migration processes; } \\
\text { - increasing social tension; } \\
\text { - sharp change in the sexual and age structure of } \\
\text { the population as a result of military, social } \\
\text { conflicts and other force majeure circumstances }\end{array}$ \\
\hline \multirow{5}{*}{ 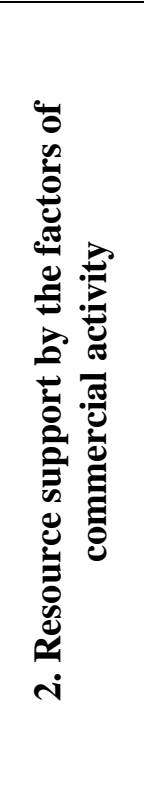 } & $\begin{array}{l}\text { Commodity } \\
\text { markets condition }\end{array}$ & $\begin{array}{l}\text { - reduction of goods supply; } \\
\text { - narrowing the range of a product offer; } \\
\text { - increase in prices for goods from manufacturers } \\
\text { and intermediaries }\end{array}$ \\
\hline & $\begin{array}{l}\text { Condition of } \\
\text { labor resources } \\
\text { markets }\end{array}$ & $\begin{array}{l}\text { - reduction of sources for the replenishment of } \\
\text { labor resources; } \\
\text { - growth of the level of labor remuneration due to } \\
\text { inflation }\end{array}$ \\
\hline & $\begin{array}{l}\text { Condition of } \\
\text { financial } \\
\text { resources markets }\end{array}$ & $\begin{array}{l}\text { - raising interest rates on loans from commercial } \\
\text { banks; } \\
\text { - falling stock of own shares }\end{array}$ \\
\hline & $\begin{array}{l}\text { Condition of } \\
\text { markets of trade } \\
\text { means }\end{array}$ & $\begin{array}{l}\text { - reduction of supply of trading activities; } \\
\text { - growth of prices for means of trading activity }\end{array}$ \\
\hline & $\begin{array}{l}\text { Innovation } \\
\text { activity } \\
\text { development }\end{array}$ & $\begin{array}{l}\text { - increase in the cost of licenses for the use of } \\
\text { inventions and discoveries; } \\
\text { - strengthening the conditions for obtaining grants } \\
\text { and government orders for R \& D }\end{array}$ \\
\hline \multirow{3}{*}{ 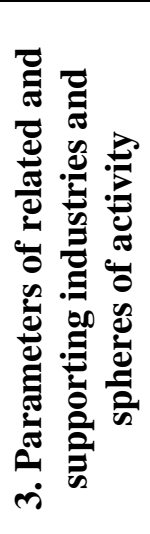 } & $\begin{array}{l}\text { Logistic } \\
\text { infrastructure }\end{array}$ & $\begin{array}{l}\text { - breaking the development of the road network; } \\
\text { - reduction of warehouse space }\end{array}$ \\
\hline & $\begin{array}{l}\text { Advancement of } \\
\text { supporting } \\
\text { industries and } \\
\text { spheres of activity }\end{array}$ & $\begin{array}{l}\text { - rising prices for supporting industries and spheres } \\
\text { of activity }\end{array}$ \\
\hline & $\begin{array}{l}\text { Using } \\
\text { achievements of } \\
\text { the related } \\
\text { industries }\end{array}$ & $\begin{array}{l}\text { - unacceptability of the achievements of related } \\
\text { industries for the purposes of the enterprise; } \\
\text { - impossibility of using achievements because of } \\
\text { their high cost }\end{array}$ \\
\hline 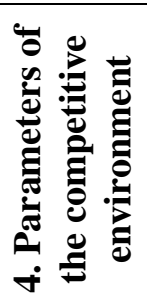 & $\begin{array}{l}\text { Business- } \\
\text { environment }\end{array}$ & $\begin{array}{l}\text { - significant increase in the number of competing } \\
\text { enterprises; } \\
\text { - increase in the share of state and local taxes and } \\
\text { fees in their total; } \\
\text { - increase in the number, lengthening of the terms } \\
\text { of obtaining permit documents }\end{array}$ \\
\hline
\end{tabular}




\begin{tabular}{|c|c|c|}
\hline \multirow{3}{*}{ 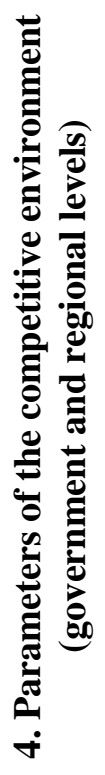 } & $\begin{array}{l}\text { Market } \\
\text { saturation }\end{array}$ & $\begin{array}{l}\text { - increase in the share of modern enterprises in } \\
\text { their total number; } \\
\text { - increase of concentration of trade - increase of } \\
\text { the market share of leading trade enterprises }\end{array}$ \\
\hline & $\begin{array}{l}\text { Competitive } \\
\text { forces that arise as } \\
\text { a result of the } \\
\text { threat of the } \\
\text { emergence of new } \\
\text { competitors }\end{array}$ & $\begin{array}{l}\text { - favorable conditions for entry of new } \\
\text { participants; } \\
\text { - companies operating on the market are loyal to } \\
\text { newcomers }\end{array}$ \\
\hline & $\begin{array}{l}\text { Competitive } \\
\text { forces that arise as } \\
\text { a result of the } \\
\text { economic } \\
\text { potential and } \\
\text { trading ability of } \\
\text { suppliers. }\end{array}$ & $\begin{array}{l}\text { - economic potential of suppliers is high due to } \\
\text { their significant share in the portfolio of suppliers } \\
\text { of the enterprise; } \\
\text { - suppliers - parties of the market of perfect } \\
\text { competition }\end{array}$ \\
\hline$\stackrel{\mathscr{U}}{\sharp}$ & Taxation policy & $\begin{array}{l}\text { - increase of tax rates; } \\
\text { - removal of tax breaks from the goods of the } \\
\text { enterprise; } \\
\text { - introduction of new taxes }\end{array}$ \\
\hline 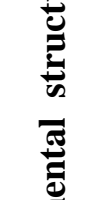 & Monetary policy & $\begin{array}{l}\text { - increase of the discount rate; } \\
\text { - unfavorable change in the exchange rate of the } \\
\text { national currency; } \\
\text { - rigid policy of financial stabilization }\end{array}$ \\
\hline$\sum_{0}^{0}$ & Customs policy & $\begin{array}{l}\text { - unfavorable change of export and import customs } \\
\text { duties }\end{array}$ \\
\hline 苍 & $\begin{array}{l}\text { Legal } \\
\text { environment }\end{array}$ & $\begin{array}{l}\text { - changing civil and commercial law; } \\
\text { - introduction of permissive order }\end{array}$ \\
\hline is & $\begin{array}{l}\text { Price and income } \\
\text { policy }\end{array}$ & $\begin{array}{l}\text { - introduction of control over prices; } \\
\text { - introduction of taxation, which stimulates } \\
\text { reduction of incomes depending on the dynamics } \\
\text { of prices }\end{array}$ \\
\hline & $\begin{array}{l}\text { Force majeure } \\
\text { circumstances }\end{array}$ & $\begin{array}{l}\text { - the company is located in a region, systematically } \\
\text { exposed to natural disasters }\end{array}$ \\
\hline 言 & $\begin{array}{l}\text { Foreign policy of } \\
\text { foreign states }\end{array}$ & $\begin{array}{l}\text { - aggressive and unstable; } \\
\text { - reliability of the investments is not guaranteed }\end{array}$ \\
\hline $0 \frac{2}{2}$ & $\begin{array}{l}\text { Scientific and } \\
\text { technological } \\
\text { breakthroughs }\end{array}$ & $\begin{array}{l}\text { - sale of new discoveries and inventions by } \\
\text { competitors, increasing their competitive status }\end{array}$ \\
\hline
\end{tabular}


In the developed structure of the organizational and economic mechanism of adaptive management of trade enterprises in the conditions of dynamic environment, we take the fact that the enterprise is in a certain initial condition, which can be characterized by organizational and economic model, economic mechanism of functioning, whose activities are managed and aimed at the achievement of strategic, tactical and operational goals. Deterministic characteristics of the initial state of the enterprise are presented in the information matrix.

The proposed adaptive managementtechnology as an independent unit in the higher order system consists of the following stages.

Stage one. Information support. D. Yampolkaya, M. Zonis [201] note that managerial information should not only be correlated due to the tasks of a manager, but also be adapted and combined with the applied models of processes, with significant information, that is, influencing the decisions made. Since adaptive management based on prediction is not isolated, but occurs as a part of higher levels of the overall management process, based on such information about the current and past state of the enterprise, as a socio-economic system and predictive values of indicators concerning the prospects of its environmental impact, the preconditions are created for a complex of diagnostic procedures, with the purpose of interfering in the process of development of events and control over it.

Analytical procedures of the second stage are grounded in three steps aimed at solving the problems of the environment diagnostics, analysis of the internal prerequisites of adaptation changes and assessment of the adaptation potential. They are based on various computing methods and tools. Monitoring of the external and internal environment of an enterprise is carried out for active search for potential opportunities and/or threats that arise in adaptation processes.

Stage three. Managing changes [202]. At this stage, identification of the current state of the enterprise is planned based on the results of comprehensive diagnostics of the second stage. A level of flexibility and responsiveness to the determined changes is determined, the conclusion on the external adaptive capacity and internal adaptive capacity required to respond to external influences. On this basis, the priorities of the adaptive management tasks are determined, they are determined by the type of reaction to changes - reactive or interactive, the way of adaptation is chosen - active, passive, proactive, and the goals of adaptive management are defined.

The system of adaptive management should be consistent with general objectives of the operation of management system at the enterprise. In the context of the possible frequent changes in the scenarios of the development of economic activity systems in order to adhere to the principle of integrity, which ensures permanent consistency, the focus on a single result of all levels of the hierarchy, the purpose of adaptation must be consistent with the strategic goal of the enterprise and the main tasks of its achievement. It should be emphasized that each particular company must have its own exclusive system of the adaptive control, formed by its management, based on exclusively actual problems and tasks.

At the forth stage, the objectives of adaptive management should be specified by developing strategic alternatives, identifying priorities for adaptive management, setting objectives and developing tactics of managerial impacts. Localization and neutralization of threats and negative influences from the external environment; 
development and strengthening of external opportunities; establishment of control over the current situation and preparation for future transformations can be the specific tasks of adaptive management.

The key moment influencing efficiency of the process of adaptive management is the generation of strategic alternatives, since the very choice of optimal alternatives determines the degree of conformity of the adaptive management to its main task - to provide flexibility of the management system.

Implementation of the tasks of adaptive management, organization and implementation of adaptation processes, which are the content of the fifth stage is carried out by the participants of the organizational structure of adaptive management by means of technology, methods and tools for the preparation and implementation of managerial decisions with the help of the identified methods of adaptive management and resources involved.

The purpose of performing administrative influence on the company's initial state is to provide achievement of the adjusted strategic goals and tasks by introducing adaptation processes and implementation of adaptation potential. The methods and results of managerial influence characterize the process of adaptation and allow to assess how effectively the trade enterprise performs its main task - ensuring harmonious interaction between individuals, their needs and external environment in broad sense.

In case of effective managerial influence, the corrected work of functional subsystems will ensure achievement of the objectives of adaptive management, which will be reflected in satisfactory parameters of its predictive state.

Determining the degree of achievement of the objectives of adaptive management at the fifth stage is designed to make the conclusion on the effectiveness of the cycle of adaptation changes and establishment of the following prospects. During the solution of the tasks of determining the degree of achieving the objectives of adaptive management, indicative parameters of the forecast state of the enterprise should be compared with the criteria of adaptation, which are defined in the process of preparation and implementation of management decisions at the fifth stage.

Adaptive management is a feedback management with a unit of goals adjustment, strategic plans, which allows, under conditions of poor satisfaction, according to the results of the analysis of the degree of achievement of adaptive management objectives, to implement changes aimed at eliminating identified deficiencies.

Thus, during the research it was established that the main task of adaptation in the dynamic external conditions of functioning is the formation of a flexible control system capable of self-organization and restructuring. The developed structure of organizational and economic mechanism of adaptive management of trade enterprises in the conditions of dynamic environment is a hierarchy of circuits of circulation and transformation of information in the process of implementation of management concept, and is able to fit into specific organizational and legal forms, types of economic activity and the specifics of management of enterprises in the industry. Its introduction into the practice of trading enterprises activity in the conditions of dynamic environment and crisis processes occurring today in Ukrainian economy will ensure the survival, stability, performance of the operation, thus improving macroeconomic situation and ensuring macroeconomic stability. 
Adaptive managementwill be effective and resultative, provided that "weak signals" of the destabilizing influence from the environment are systematically monitored and that an adequate response is immediately received to these signals. Use of management tools for "weak signals" in the system of adaptive management of trade enterprises will help not only to counteract the dangerous changing realities of the market faster and better than the competitors, but also under condition of timely response to them, organizationally, financially, psychologically prepare for their perception.

\subsection{The toolkit for the formation of adaptive management system at trade enterprises}

The toolkit for the formation and maintenance of the functioning of the adaptive management system at trade enterprises is presented in modern scientific literature by a wide spectrum of analytical tools for the collection, processing and analysis of information, diagnostics and forecasting of economic processes and phenomena occurring in the organization and in the environment, as well as administrative and managerials tools. In order to ensure practical effectiveness of economic instruments, it should be based on modern scientific achievements in management, general and special methods of economic analysis, forecasting, and evaluation of the effectiveness of managerial process. By the content, functionality and purpose, the tools of adaptive management of trade enterprises can be grouped by the following features: tools of the methods for collecting and analysis of primary information; tools for processing and analysis of information; administrative and managerial tools, and modern tools for managing an enterprise (Figure 2.4).

Informational provision of the process of adaptive management of trade enterprises at the first stage of adaptive management technology (see Figure 2.3) requires the use of methods for collecting and analysis of primary information:

- synthesis (synthesis of the result of the influence of various factors on the identified trends and indicators of trade and economic activity) and structural, analytical, simple and combination groups (selection by certain features of characteristic groups among the phenomena studied, distinguished: (by productivity, level of mechanization, structure); 
Tools used for the formation of adaptive management system of trade enterprises

\begin{tabular}{|c|c|c|c|}
\hline $\begin{array}{c}\text { Tools of the } \\
\text { methods of } \\
\text { collecting and } \\
\begin{array}{c}\text { analysis of primary } \\
\text { information }\end{array}\end{array}$ & $\begin{array}{c}\text { Tools for the } \\
\text { information } \\
\text { processing and } \\
\text { analysis }\end{array}$ & $\begin{array}{c}\text { Administrative and } \\
\text { managerial tools }\end{array}$ & $\begin{array}{c}\text { Modern tools for } \\
\text { managing an } \\
\text { enterprise }\end{array}$ \\
\hline
\end{tabular}

Figure 2.4. Tools for the system of adaptive management at trade enterprises (author's development)

- absolute (characterize the size of economic phenomena of indicators, used as the basis for calculating aveage and relative values) and relative values (used to analyze dynamics of phenomena, changes in the indicator, phenomena in time, reflect the level of the implementation of planned tasks, compliance with norms, terms of growth, structure, specific weight);

- average values (used for the generalized characteristics of massive, qualitatively homogeneous economic phenomena, indicators, processes, types: average arithmetic, average geometric, weighted average, mod);

- dynamic rows (reflect changes in the values of indicators in time);

- solid and selective research, studying all totality of phenomena that characterizes specific direction of production and economic activity of the enterprise and provide the study economic activity of the enterprise on the basis of typical representatives of phenomena, processes, for example, based on methods of the theory of probability;

- detailing (decomposition of the generalizing (final) indicator into separate parts to determine the impact of each of them) and generalization (determine the relationship between parts of the whole and their impact on the overall results).

The tools for processing and analysis of information for the solution of the tasks for diagnosing the environment, analysis of internal prerequisites for adaptation changes and assessing adaptive potential set at the second stage of adaptive control technology (see Figure 2.3) are classical and modern methods of analysis.

The method of comparison that allows one phenomenon to be considered in relation to another for establishing similarities or differences, advantages or disadvantages between them. The method makes it possible to compare the reporting indicators and indicators of the previous period, data of the leading enterprises, data of the industry, etc., to evaluate the work of the investigated trade enterprises, to identify deviations from the comparative indicators, to identify causes, adaptation opportunities and reserves. The main types of comparisons used during the analysis are: index, balance method, method of chain substitutions, graph-mathematical analysis.

The index method is based on the operation of relative indicators, expressing the ratio of the level of this phenomenon to its level in the past, or to the level of a similar phenomenon, taken as the base. The balance method makes it possible to compare the interrelated indicators of economic activity, with the aim of assessing their mutual influence, determining the reserves for improving efficiency of production. In the case of using the balance method, the relationship between individual indicators is expressed in the form of equality of the results obtained in the process of various comparisons. 
The method of chain substrates is used to calculate the influence of individual factors on the corresponding common indicator or function. Due to this method, it is possible to obtain a number of intermediate values of the generalizing indicator by successively replacing the basic values of the factors with the actual ones. Graph-mathematical methods, such as grid charts, "decision trees", etc., serve as a means of illustrating business processes, calculating a totality of indicators, and designing results of the analysis. Factor analysis involves establishing the force of influence of factors on a function or a performance trait that aims to rank factors in order to develop a plan of organizational and technical measures to improve the function.

Broad analytical capabilities of information and analytical provision of various aspects of the adaptive management of trade enterprises are based on such economic instrument as functional and cost analysis (FCA), as the efficiency of adaptive management increases with the regular use of forecasting models to obtain forecasts of processes and developments in the management object [203]. An analyst is abstracted from the actual design and focuses on the functions that must perform goods, services, process, and other objects for analysis. During the functional-cost analysis, as a rule, they construct functional models of the investigated object, depicted in the form of circuits, graphs, tables (matrices) or in another form. On the basis of the model, extra and duplicate functions are distinguished; function costs are determined in parallel. Exception from the functional sphere of the object of the analysis of extra and duplicate functions reduces the cost of its maintenance.

Stages of FCA:

- preparatory (popularization of the method, training of specialists in FCA fundamentals, selection of the object of research and definition of the objectives for the analysis, working group formation, drafting a plan for the analysis of a specific object);

- information (collection and systematization of object documentation, identification and formation of functions: construction of the scheme of interconnection of components, determination of costs for the creation and functioning of the object, its components, identification of areas of the greatest concentration of costs);

- analytical (analysis and refinement of functions; definition of basic, auxiliary, identification of unnecessary functions in an object and its components; delimitation and analysis of costs associated with the implementation of functions of the object, cost of their implementation with the analogues; formulation of tasks for search; new ideas and options for optimal solutions);

- creative (clarification of the direction of the task of searching new technological solutions and the choice of methods of research; organization and holding of meetings on the promotion of ideas; processing and systematization of the results of creative meetings for the evaluation of the proposed ideas);

- research (exclusion of obviously unfeasible proposals and examination of the selected proposals; research and experimental verification of various possibilities of performing functions in the proposed variants; assessment of the possibility of realizing selected proposals to determine the cost and efficiency of performing functions for different solutions; ranking options and choosing an optimal one); 
- recommendation (registration and agreement with the interested services of recommendations concerning the implementation of the proposals of final decisions chosen by the clarification of efficiency calculations, discussion of the recommendations submitted by the committee of the FCA and decisionmaking, drafting and approval of the plan-schedule of the implementation of recommendations, their transfer to the relevant services);

- stage of implementation (coordination of the schedule for the implementation of FCA recommendations with other levels of management hierarchy, organization and monitoring of the implementation of recommendations, report on the work performed).

The matrix method refers to objective analytical tools in the system of adaptive management of trade enterprises. The method implements the selection of a better solution from the totality of alternatives based on a compromise between the signs (criteria) reached by the parties concerned. A compromise can be reached between two, three or more interested parties, then the matrix of attributes can be two-dimensional, three-dimensional, etc. The simplest matrix is a two-dimensional matrix of the type "target-means", "problem-provision". The database should contain a number of alternative solutions and different criteria. The manager's task is to coordinate the values of the criteria and establish their priorities. The matrix gives a lot of options for the solution, combinations of problem solving, but in itself does not give any method to evaluate these options. The applied aspect of the using this method is presented in the scientific research of Gurzhii N.M. [204].

Special tools for strategic analysis, including SNW, PEST, VMOST, GAP, SWOT-analysis, Ansoff matrix, ADL / LC matrix are presented in Table. 2.2.

Table 2.2

Essential characteristic of special analysis tools

(compiled based on [205])

\begin{tabular}{|l|l|}
\hline \multicolumn{1}{|c|}{ Tools } & \multicolumn{1}{c|}{ Essence of the method } \\
\hline SWOT-analysis & $\begin{array}{l}\text { Identification and classification of information according to the } \\
\text { criteria for attribution to the external or internal environment, as } \\
\text { well as the nature of the influence - positive or negative }\end{array}$ \\
\hline SNW-analysis & $\begin{array}{l}\text { Analysis of information concerning the internal environment of } \\
\text { the subject of management; classification of information } \\
\text { according to the criteria of strengths, weaknesses, compliance } \\
\text { with averaged indicators; maximization of key factors }\end{array}$ \\
\hline PEST-analysis & $\begin{array}{l}\text { Analysis of the distant environment. Ability to detect structural } \\
\text { relationships vertically at different levels of management }\end{array}$ \\
\hline
\end{tabular}




\begin{tabular}{|l|l|}
\hline $\begin{array}{l}\text { VMOST- } \\
\text { analysis }\end{array}$ & $\begin{array}{l}\text { Interconnection of factors of the internal and external } \\
\text { environment between the subject of management and the } \\
\text { priorities of development, construction of the system of goals, } \\
\text { strategy and tactics of service implementation; clear structuring } \\
\text { of goals and objectives }\end{array}$ \\
\hline GAP- analysis & $\begin{array}{l}\text { Detection of "white spots", "gaps" between the existing situation } \\
\text { and the assumed vision of the subject of management }\end{array}$ \\
\hline mDL/LC & $\begin{array}{l}\text { The service, like a separate business, as well as a separate } \\
\text { branch; the branch of economy can be found at one of the } \\
\text { definite stages of the life cycle, therefore, analysis should be } \\
\text { carried out taking into account stage of the development of the } \\
\text { object under research }\end{array}$ \\
\hline I.Ansoff matrix & $\begin{array}{l}\text { Analysis of qualitative characteristics of the provided service } \\
\text { while simultaneously assessing market opportunities }\end{array}$ \\
\hline
\end{tabular}

Mathematical methods accelerate the analysis, contribute to a more complete account of the influence of factors on the results of activities, increasing accuracy of the calculation. Application of mathematical methods in the process of adaptive management of trade enterprises requires: systematic approach to the research of the object, taking into account relationship with other objects (enterprises, firms); development of mathematical models reflecting quantitative indicators of the systemic activity of employees, processes taking place in trade enterprises; improvement of the information system with the use of computers.

Classical methods of mathematical analysis are used independently (differentiation and integration) and within other methods (mathematical statistics, mathematical programming).

Statistical methods are the main means of studying mass repetitive phenomena in the process of adaptive managing trade enterprises. To study one-dimensional statistical aggregates the distribution law, the variation series, the sample method are applied. For multidimensional statistical aggregates, correlation-regression, dispersion, covariance, spectral, component, factor analysis types are used.

Economic methods are based on the synthesis of three branches of knowledge economics, mathematics and statistics. Their basis is the economic model in the form of a schematic representation of economic phenomena (processes), their characteristic features through scientific abstraction.

Methods of mathematical programming are used as the main means of solving problems of optimization of trade and economic activity. Due to these methods, the tensions of current activity, scarcity of resources, etc. are estimated.

Methods of investigating operations (methods for solving linear programs, inventory management, game theory, decomposition theory, mass maintenance theory, network planning methods) are aimed at quantitative estimation of decisions and choice of the best of them, it is possible to determine the combination of structural 
interdependent elements of the system that is the largest measure the best economic performance.

Economic cybernetics with the use of system analysis, simulation methods, simulation methods, teaching methods, business games, image-spatial methods analyzes economic phenomena and processes as complex systems from the point of view of management laws and information movement in them.

Processes and phenomena investigated during the adaptive management of the enterprise are complex and cannot be limited by the methods of a certain onedisciplinary science. Therefore, under these conditions, modern methods of complex and functional analysis, systemic and historical approach are of particular importance. Thanks to their application, there is the possibility of the most complete, deep and comprehensive study of the problems of adaptive management.

Use of comprehensive approach allows to gain new knowledge about the organization through the study of this phenomenon in the interdisciplinary aspect at the junction of various sciences. Research of the organization from the standpoint of the system approach gives the opportunity to reveal its properties, such as integrity, systemicity, organization, describe the laws of the relationship between its elements, internal organization relations and relations with the external environment.

Application of a functional approach makes it possible: to study the manifestation of purposefulness and activity of the organization; determine its place in economic and social processes; to find out interaction of the organization with other system and non-system entities, relationship between the individual components within the system.

The system-historical approach determines, integrates the initial state and movement of the organization, takes into account growth rate of the development, allows to establish laws of transition from one state to another, organically combines genetic and predictive interpretation of objects.

To some extent, analytical tasks of adaptive management put forward in the third (managing changes) and fourth (development of strategic alternatives) stages of adaptive control technology (see Figure 2.3) are solved using economic-mathematical modeling, since it is oriented towards prediction of economic phenomena and processes [131-132].

For the formalization of each model in the process of adaptive management, a certain set of means is used, among which the following are most commonly used.

1. An algorithm for the solution that depicts alternatives to actions and financial implications of each alternative. Considering the probability of each variant of the development of events, it is possible to analyze the results of decision-making or a number of decisions.

2. Ishikawa method (diagram of fish skeleton), which helps to understand the relationship between cause and effect. It is especially useful in the situations where the causes of problems or crises are difficult to find out. The diagram gives the opportunity to: take a look at the problem as a whole, rather than on its separate parts; find more than one possible cause of the problem; to give proper attention to small causes of the problem; to see more clearly links between causes; discuss the problem with a team or group; to develop new ideas; to appreciate the idea of collective decision-making. 
3. Block diagram (block diagram) - graphical representation of the current information, ideas or components of the system. This is the best way to explain or understand what's going on inside a locked system. In business, flowcharts illustrate the process (physical process of production, management process), through which the solutions are brought to an end.

4. Mapping ("the first coat") is a way in which you can accurately depict the process through interviewing people who work on an individual site in order to understand main directions of their activity, information sources and contacts between them.

5. Implicit schemes is a way to represent many different components of a complex problem, tools for conveying complex ideas to others. Schemas give an opportunity to break the traditional ways of reasoning over the problem, to approach the problem literally from a blank sheet of paper, to prevent people from following the previous logic

6. The method of $\mathrm{ABC}$ and color coding are the main means of forming priorities and relevant in the process of informing the processes of adaptive management, since unplanned changes in the environment and the internal realities of the enterprise require the business entity to make many decisions, but the lack of time and resources makes it impossible to implement these solutions at the same time. Therefore, the decision maker must determine which types of work or decision to give preference. The ABC method is a way of defining the hierarchy of tasks and solutions through placement according to their importance: the problem of the highest priority; important tasks with less priority, but one can get it very quickly; tasks that will sooner or later attract attention, but now can be postponed and tasks that can generally remain unfulfilled, they can simply be discarded. Color coding is used to indicate the priority of the solutions.

Author's methods of assessing the readiness of enterprises for transformation are based on expert selection of criteria and corresponding indicators of readiness, and further, on expert methods of establishing the level of readiness. Part of the approach focuses only on aspects of staff readiness for change. These approaches are presented in the works of Cohen D. S., Kulikova P. N., Faerman M. I. et al. [132; 206-207].

Integral indicator of the actual state is formed on the basis of 54 valuation indicators that characterize 9 key aspects of the enterprise's activity: finance, personnel, strategic management, marketing, organizational structure, production, information system, organizational culture, quality management. The financial and economic component of readiness is taken into account in works by Ermolenko L.I., Pavlova A.V., Usik S.P. and others. [208-210]. The method proposed by Guseva O.Yu. allows to calculate four integral indicators of readiness, three of which relate to the readiness of staff at different levels of the hierarchy, and one - financial and economic readiness [211].

At the fifth stage of adaptive mnagement technologies (see Figure 2.3), the implementation of tasks, the organization of management influence is carried out by means of administrative and management tools which are intended to solve specific problems [212].

Economic management methods make it possible to influence the staff, based on economic mechanisms of motivation and stimulation of activity, stimulating economic 
interests of performers. Among the economic methods of management, the method of economic stimulation is used, the basis of which is the formation of incomes of enterprises and organizations, as well as employees, depending on their personal contribution.

Economic stimulation is based on the following basic principles: the relationship and consistency of the objectives of economic stimulation with the goals of the organization (trade enterprise); the differentiation of economic stimulation, aimed at implementing the necessary changes in the structure of production; a combination of economic incentives with other methods of motivation; a combination of economic incentives with economic sanctions that imply financial liability of organizations and individual workers.

A special place in the system of methods of organizing managerial influence Organizational and administrative managerial methods. They include methods of influencing the subject of management on the object of management based on the power of the authorities. Organizational-administrative methods of management are based on the system: legislative acts of the state, normative documents of the higher management structures, plans, programs, tasks of operational management, developed in the organization, firm, etc.

Organizational and administrative management is carried out in the following main types:

- direct administrative instructions, which are mandatory, addressed to specific managed objects or individuals, affect the specific situation;

- establishment of rules governing activities of the subordinates (normative regulation), development of standard procedures for administrative influence;

- development and implementation of recommendations for the organization and improvement of certain processes subjected to organizational and administrative influence;

- control and supervision of the activities of organizations and individual employees.

Socio-psychological methods of management in the process of adaptive management provide an opportunity to influence social and individual consciousness, social activity of personnel in order to increase effectiveness of the activity of the controlled object. They include specific techniques of influencing the process of formation and development of the team, on the processes occurring within it. These methods are based on the use of socio-psychological mechanism in the collective, which includes formal and informal groups, the role and status of an individual, the system of relationships, social needs and other socio-psychological aspects.

The most important motivational methods in the process of implementing the objectives of adaptive management are the methods of persuasion, aimed at inducing the object of management to the desired for the subject of action. These include: induction, rejection, encouragement, suggestion, imitation, method of personal example, engagement, condemnation, informing, etc.

The method of inclining means that the subject of management with the help of various kinds of arguments and facts convinces the performer in the expediency of the task and inclines it to act in exactly the way proposed by the subject. The main form of implementation is the recommendation, i.e., managerial influence, based on the 
consciousness of the performer, his moral responsibility and performance discipline, experience and professional qualifications.

The method of induction carries in itself even more than the previous method, a motivational charge, since it involves inducing the performer to certain actions not so much because of the interests of the subject of management, but on the own needs of the performer. Forms of the implementation of this method are advice and request.

The methods of encouragement are intended to provide a clear link between the results of labor and its stimulation. Methods of encouragement include knowledge of the leaders of the psychological characteristics of workers, focus on the development of their needs for self-realization, creativity.

The method of informing involves the targeted management influence of the subject of control on the object of management to obtain the desired result by selecting, processing and disseminating information, the required object for better orientation in the situation and the choice of the optimal way of action to achieve the result.

Psychological methods of management are aimed at regulating relations between people through optimal selection and placement of personnel. These include the methods of manning small groups, humanization of work, professional selection and training, etc .;

Depending on the stages and elements of the process of adaptive management, the following special and specific management methods can be distinguished:

- special: influence on managed objects; organization of the control system itself; information management support; development and decision making; control, evaluation, analysis, etc :;

- specific: problem-organizing; functional; program-target; organizational analysis; organizational regulation; organizational valuation; organizational design, etc.

Among the methods of performing management functions that are associated with solving problems facing the subject of management in the process of its impact on the object on the way to the intended purpose, we note the specific ways of planning, organization, coordination, control and motivation of the activity.

Methods for the acceptance of management decisions are a totality of steps and procedures necessary to solve a particular problem that occurs before a management subsystem. At the stage of the problem statement, the leading role is played by the methods of collecting, storing, processing and analyzing information, methods for fixing the most important events, describing and evaluating them, analysis, analogy, modeling, etc. The problem solving stage is also related to the application of information collection methods. In addition, at this stage, information technology is actively used as a computerized method of analyzing decision-making processes. At the stage of choosing a decision, first of all, the method of optimization is applied. At the stage of implementing the decision, along with the methods of direct influence (order, etc.) indirect methods of management - material and moral stimulation, formation of social and psychological readiness of the workers to the realization of tasks are used. At the control stage, such specific methods as diagnostic, corrective, and others are used.

Determination of the degree of goals achievement in the final stage of the adaptive management technologies is possible with the use of both traditional statistical and logical information processing tools (comparisons; absolute, relative and averages; 
grouping; balance, graphical, tabular, series of dynamics), and tools of deterministic factor analysis (chain substitutions, absolute differences, indexes, integral indicators, etc.), deterministic complex estimation (method of sums, sums of places, geometric meanings, distances) and financial mathematics.

Figure 2.5 presents a generalized scheme of calculation and analytical tools for adaptive management of trade enterprises with the definition of priority directions of their application at the stages of the technology of adaptive management process.

The expressive direction of the processes of adaptive management of trade enterprises for the future puts forward specific requirements regarding the methodical tools for conducting analytical procedures and calculations. Modern enterprise management tools, suitable for use in the process of adaptive management of trade enterprises, are used by many international, and some Ukrainian enterprises. These are the systems of support and management decisions: MPS, SIC, MRP, MRP II, ERP, etc. [213, p. 142]. At the same time, it is believed that "the most elaborate integration system that combines the approach to managing economic and noneconomic indicators is a balanced system of indicators" [214, p. 255]. This system is not only the most popular in international business practice, but also quite well theoretically disclosed in the domestic economic literature. 


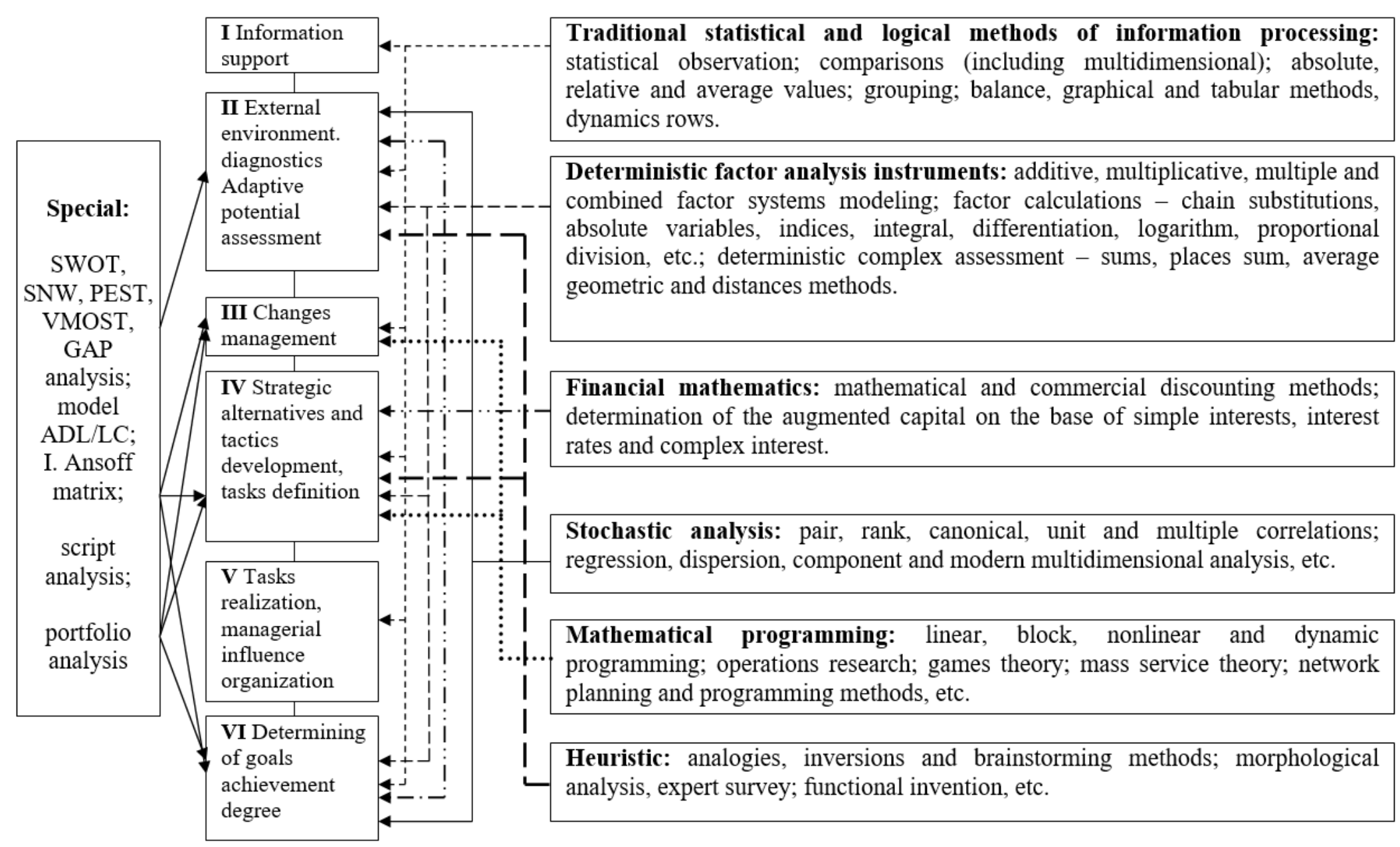

Figure 2.5. Computational and analytical tools of trade enterprise's adaptive management (author's development) 
The research toolkit of a predictive-adaptive approach, in terms of its application in the adaptive management of trade enterprises, will provide an opportunity to provide it with flexibility through a system of economic levers that affect all business processes in a forward-looking way.

Such an approach to the situations of aggressive influence of the environment will not allow negative tendencies to develop into threatening crisis phenomena in the activity of the enterprises of trade, and, given the favorable coincidence of external circumstances, will provide an opportunity to take advantage of the potential for strengthening of competitive positions and implementation of development strategies.

In the conditions of solvent demand, limited income, hard competition, constantly increasing requirements for the quality of trade services, with the addition of problems of the crisis state of the economy of Ukraine, management of trade enterprises to ensure sustainable operation and effective development, it is necessary to use qualitatively new instruments of adaptation management. Progressive means of proactive management are best suited to the requirements of adaptive management, since proactive management is relevant both in the stable functioning of the economy and during crisis phenomena.

Use of the concept of proactive management by the management in real time is a guarantee of the survival of their enterprises in the current business environment, when, according to B. Gates, "business with the speed of thought" has ceased to be the privilege of individual companies, so proactive management acts as the basis of effective adaptation management of trade enterprises in modern conditions [230]. Newstrom D.V. and Davis K. in the book "Organizational Behavior" define the proactivity in management as follows: proactivity is the prediction of events, the initiation of change, the desire to "keep in their hands" the fate of the object of management [216, p. 343].

The basic principles of proactive management include: to anticipate and prevent consonant with the purpose and direction of adaptive management. Proactive management is aimed at recognizing and analyzing errors, implementing corrective influences on the results of analysis, freedom of choice, self-learning ability, strong corporate spirit. Proactive management means the ability to predict problems and plan further actions in such a way as to prevent or mitigate the effects of undesirable effects. The basis of the proactive management technique is the analysis of information about problems. Successful analysis allows to get knowledge - clear understanding of what happened, what to expect in the future and what to do today.

By efforts of domestic and foreign scientists proactive management tools are created. They are used in natural science research, management of production processes, various functional areas of management [204; 217-224]. Information technologies, capable of implementing proactive management [225], technologies for preventing potential threats [226-227], and others have been developed.

However, methodological and practical tools of proactive management did not find proper distribution in the management of trade enterprises.

To implement proactive management at the enterprise today, such techniques as BPR (business process reengineering), KPI (key performance indicators), BSC (balanced score card - balanced system of enterprise performance indicators), 
budgeting, modeling based on IDEF0, IDEF3, SADT, UML and many other standards. [228].

G.O. Chornous according to the results of her scientific research, in details described the methodology, mathematical tools and software tools, as proactive management tools [223] able to combine the power of information technology and the complexity of analytical research procedures. In particular, these are statistics, profiling, pattern recognition, behavioral analysis, time series analysis, predictive modeling, visualization, causality analysis, etc. Various proactive management tools can be used to solve a number of tasks at different stages of the implementation of its processes. Proactive management tools are presented as classical quantitative methods of forecasting and modeling, and methods based on the use of psychological concepts, and, most importantly, on the intellectual data analysis:

- quantitative methods of forecasting and modeling: economic and statistical methods, econometrics, economic dynamics, theory of choice and decision making, research of operations in economy;

- methods based on the use of psychological concepts: neurolinguistic programming, reflexive management, methods of information influence in social networks;

- methods of data mining: Data Mining, Visual Mining, Text Mining, Process Mining, Real-Time Mining, Web Mining. Use of these tools improves support of management processes in companies and improves their competitiveness.

Among the contemporary analytical technologies, the author of the article highlighted the technology of intellectual approach to business management "Business Intelligence" (BI) [229] as a promising direction for solving the pressing problems of management. The tools of information analysis in BI are supported by OLAP technologies, interactive visualization, predictive modeling and intelligent data analysis.

Datamining, one of the most important components of BI technology, is information analysis technology used to improve decision making, as well as a set of tools used to extract data from important information system. Powerful technology of intelligent data analysis allows: to classify objects; to determine the hidden dependencies of output quantities on certain parameters, to build predictions on their basis; to conduct clustering of objects on the basis of determining their coherence according to certain criteria; to identify associations, that is, the laws between the related affairs; determine sequential patterns; to discover the facts of the events timing; to analyze deviations and to identify non-characteristic and repetitive ones among them. Thus, the means of datamining can be carried out by classification, clustering, association, consistency, forecast. The main tools for obtaining such information are arguments for precedents, neuro-computing, intelligent agents, etc. [230].

Datamining processes use many methods, some of which are borrowed from the tools of artificial intelligence, some from classical statistical methods, and the rest are innovative methods generated by the latest advances in information technology [231]. Methods of datamining, corresponding to the tasks of the analysis of proactive management processes, are presented in Table. 2.3. 
Table 2.3

Characteristsics of datamining methods according to the tasks of proactive management (composed on the basis of [223])

\begin{tabular}{|l|l|l|}
\hline $\begin{array}{c}\text { Proactive } \\
\text { management } \\
\text { process }\end{array}$ & $\begin{array}{c}\text { The class of } \\
\text { datamining process }\end{array}$ & \multicolumn{1}{c|}{ Method of datamining } \\
\hline Causal link & $\begin{array}{l}\text { Revelation. } \\
\text { Analysis of } \\
\text { anomalies }\end{array}$ & $\begin{array}{l}\text { Fuzzy queries and analysis. Rules. Trees } \\
\text { of solutions. Statistical methods. Genetic } \\
\text { algorithms. Neural networks. Cross } \\
\text { tabulation. Visualization. Clustering. } \\
\text { Considerations by analogy }\end{array}$ \\
\hline $\begin{array}{l}\text { Decision } \\
\text { making }\end{array}$ & $\begin{array}{l}\text { Modeling } \\
\text { predictions }\end{array}$ & $\begin{array}{l}\text { Clustering. "The closest neighbor". } \\
\text { Considerations by analogy. Trees of } \\
\text { solutions. Statistical methods. Genetic } \\
\text { algorithms. Neural networks. } \\
\text { Visualization }\end{array}$ \\
\hline Plan analysis & $\begin{array}{l}\text { Revelation. } \\
\text { Modeling } \\
\text { predictions. } \\
\text { Analysis of } \\
\text { anomalies }\end{array}$ & $\begin{array}{l}\text { Fuzzy queries and analysis. Rules. Trees } \\
\text { of solutions. Statistical methods. Genetic } \\
\text { algorithms. Neural networks. Cross } \\
\text { tabulation. Visualization. Clustering. } \\
\text { "The closest neighbor". Considerations by } \\
\text { analogy }\end{array}$ \\
\hline $\begin{array}{l}\text { Overview of the } \\
\text { situation }\end{array}$ & $\begin{array}{l}\text { Revelation. } \\
\text { Analysis of } \\
\text { anomalies }\end{array}$ & $\begin{array}{l}\text { Fuzzy queries and analysis. Rules. Trees } \\
\text { of solutions. Statistical methods. Genetic } \\
\text { algorithms. Neural networks. Cross } \\
\text { tabulation. Visualization. Clustering. } \\
\text { Considerations by analogy }\end{array}$ \\
\hline
\end{tabular}

During the implementation of proactive management inside the corporate environment, episodic, strategic or permanent datamining can be used. An episodic datamining can be used to analyze data from the standpoint of a specific episode in the process of causation, decision-making and analysis of the plan. Strategic datamining involves analysis of a broader range of corporate data and is most useful in causative analysis, plan analysis and, most importantly, review of the situation. In reviewing the situation, permanent (non-continuous) datamining is important because it allows to draw attention to changes in the corporate environment over a period and to identify a number of problems associated with these changes. From the point of view of adaptive management by trade enterprises, actual characteristics of datamining are the ability to act ahead of events and to identify problems long before they become apparent.

Datamining technology can increase the efficiency of management and decision making, providing the ability to quickly and objectively output valuable aggregate content from a large amount of data, presented in a convenient and understandable 
form. According to the concept of proactive management of the overwhelming majority of business tasks, it is possible to reduce to a number of stages realization, from which virtually any management solution is formed: plan-factor analysis (data visualization), forecasting (regression problem), risk management (regression, clusterization, classification), stimulation of population (clusterization, association), identification of customer preferences (sequence, clusterization), etc. These tasks are solved by the methods of intellectual data analysis, and the vast majority of modern corporate systems have appropriate means in their arsenal [232]. Information-analytical systems capable of implementing datamining and providing data warehousing, business analysis, index charts, textmaking, decision support, budgeting, planning, data integration, ETL technologies are offered by such manufacturers as IBM (Cognos, SPSS, Applix, Celebrity, Data Mirror, Adaytum, Frango, ILog, AptSoft), Infor (Epiphany, Extensity, GEAC, MIS), Oracle (Hyperion, BEA, Sunopsis, Haley), OutlookSoft, Pilot Software, Armstrong Laing, FirstLogic, SRC Software) SAS (DataFlux).

One of the main problems is the availability of IT technology at the level of small and medium-sized businesses, which has become widespread in trade business. Companies of this class need cheap analytical tools, and this can be helped by the use of so-called "managed spreadsheets." BI-tools and Excel spreadsheets can be integrated. For small businesses, the development of analytical applications presented in the form of Service Software as a Service, SaaS is very important. SaaS, Web 2.0 and a number of other technologies are part of Cloud Computing technology (so-called "cloud computing", computing on the Internet).

The example of successful implementation of the proactive management toolkit, which was passed by practical testing, was proposed by N.S. Busheva using scientific foundations of matrix technologies, the author created mechanisms for the formation of the development programs and their monitoring on the basis of proactive management, implemented in the form of a software shell and the corresponding information technology in the Microsoft Excel environment [233].

Durel Rigby, director of Bain \& Company (Boston), in the analytical research "Management Tools 2003" [234], provided a comprehensive description of the best tools for managing a company.

Analytical review includes information on the use of modern management tools and their satisfaction in the practice of 708 companies from five continents: North and South America, Europe, Asia and Africa. The relevance of the research is $95 \%$.

The best management tools of the new millennium are the following.

Activity-based management: tracks overall and indirect costs across all processes and attaches them to specific products and clients, allowing more accurate distribution of costs and more legitimate solutions.

The balanced scorecard: transforms mission and vision into quantitative measurements and monitors whether management achieves the planned results.

Benchmarking: compares costs and productivity with internal and external reference points. The company's best practices are being implemented to achieve its goals.

Key Competence (Core Computation): separates and invests in special skills or technologies that create a unique value for customers. 
Venture Capital (Corporate venturing): investing in new products or technologies through business financing inside or outside the company.

Customer Relationship Management: Collecting information to better understand customers in order to acquire, retain, and create the most profitable ones.

Customer Satisfaction Measuring (Client Satisfaction Measuring): collecting information from clients in order to measure their satisfaction, identify key needs.

Customer segmentation: divides markets into customer groups that share common features in order to create a special product or marketing proposal.

Cycle time reduction: reduces the overall time from conception to product and process readiness.

Growth strategies: direct resources to profitable growth opportunities.

Knowledge management: the development of systems and processes for the identification and dissemination of intellectual property of the company.

Market disruption analysis: identifies early signals of possible changes in market trends and new technologies that can turn the market situation.

Merger integration teams: teams of senior executives from two merging companies aiming at finding synergies in sales and production.

Mission and vision statements: a codified definition of the company's business, goals, approaches and desired position in the future.

Personized marketing: organization of extensive and systematic communication with an client to personalize the dialogue with him and provide individualized products and services.

Outsourcing: use of a third party to perform work that is not the main task.

Pay-for-performance: ties managers' compensation to measurable and monitored goals.

Real options analysis: analysis and investing in real assets (such as production, people and products) as in options, just as financial managers analyze and invest in financial options in the stock market.

Reengineering: radical change in key business processes to achieve significant productivity and quality improvements and reduce time costs. decisions.

Scenario planning: identifying several options for the future for strategic

Shareholder value analysis: Measurement of the ability of a company or unit to receive higher returns than the value of the attracted capital. Provides a framework for assessing alternatives to raising shareholder value.

Strategic alliances: agreements between firms; each allocates resources to achieve a common set of goals.

Strategic planning: comprehensive process for determining what business should become, and how to allocate resources to achieve this goal.

Supply chain integration: synchronizes efforts of several parties (suppliers, manufacturers, distributors, dealers and customers) to achieve continuous exchange of information, goods and services across the organizations' boundaries. 
Total quality management: binds demands of customers for products and services, the goal is zero-level marriage.

Given the current crisis situation in Ukraine, attention should be paid to governance tools recommended for "difficult times." So, Durle Rigby notes that the economic downturn has caused companies to turn their own crises into a win. This is manifested in the choice of management tools. Managers of companies with a significant advantage have given preference to tools that help to sharpen strategies and prepare managers for the hard way ahead and up. Instruments such as strategic planning and key competencies, as well as tools that help businesses define markets and improve customer relationships, have proved useful, as companies have been trying to maximize profits from already existing customers. By the degree of popularity - from $89 \%$ to $70 \%$, crisis management tools are as follows:

- strategic planning;

- benchmarking;

- mission and vision statements;

- customer segmentation;

- outsourcing;

- customer surveys;

- customer relationship management;

- corporate ethics code;

- growth strategies;

- payment for results;

- core competence;

- contingency planning.

Noting that management tools should be tailored to the management system and not vice versa, since each business is unique and the tools must fit the specifics of a particular organization, Durle Rigby provides practical guidance on choosing effective management tools:

- before using the tool, it is necessary to gather facts in order to have realistic expectations and not to make common mistakes: how does it work? How much will it cost for proper use? How satisfied are his colleagues from other companies?

- Do not be confused with tools and strategy. Tools are not goals, they only help in work (in particular, in the implementation of the strategy).

- Right tools should be chosen for proper work, that is, tools must be consistent with the research objectives and be based on an adequate information base. No tool is universal for any circumstances.

- Do not expect too much from the tool. No tool will solve all the problems. In management, there are no universal laws.

- Build communication at all levels of the company, explaining how and why the tool is used. It is important to attract the right people and make sure they understand the importance of the tool.

- Results of the tools should have deterministic look. Success requires tangible goals and ongoing monitoring. 
The choice of specific analytical tools in the formation of the system of adaptive management of trade enterprises depends on the tasks of specific research and the possibilities of information provision of their application. Their complex use will give the greatest effect.

The choice of specific analytical tools is influenced by: the scale of the tasks under solution (global and local); long-term solutions (operational, tactical, strategic); conditions (informational situations) of research (certainty, risk, uncertainty).

Definition of the specific toolkit during the formation of the system of adaptive management of trade enterprises should be carried out in view of the following criteria: practical applicability; balance of this tool with the others; cost of use; probability, efficiency and stability of application.

Practical applicability is determined by the possibilities and conditions that characterize use of the specific tools. So, if we apply linear programming, then the functions used should be linear. Other important constraints are time constraints and the lack of qualified specialists - system analysts. The balance is the necessity of using the interdependent methods at different stages of the adaptive management technology. For example, if you use insecure information, it's inappropriate to use complex, costly methods for its processing. The cost of research tools should be less than the magnitude of the effect of their application. In the cases where the problem solution promises a particularly high return, it may be desirable to use expensive but more accurate methods. The probability is that you need to know how big the mistakes in this study are. Given this, it might be reasonable to give preference to settlement tools that are less effective but more possible. The effectiveness is characterized by both individual and aggregate indicators with a mandatory check on the absolute performance indicator. Stability of application is determined by the length and frequency of the use of analytical tools. If frequent and long-term use is envisaged, more money can be invested in its development and more skilled professionals are involved.

Thus, study of modern tools for conducting scientific research has allowed to provide grounded scientific and practical recommendations on a set of calculation and analytical tools that should be used in the formation of the system of adaptive management of trade enterprises. For the increase of the effectiveness of analytical procedures for adaptive management, a wide use of modern management tools is recommended: proactive management, Balanced Scorecard, Benchmarking, Customer Relationship Management, Cycle time reduction), Growth Strategies, Knowledge Management, Market Degradation Analysis, Reengineering, Scenario Planning Scenario planning and others. 


\section{Conclusions to chapter 2}

1. Managing adaptation of trading enterprise is an integral part of the overall system of organizational and managerial decision making, the goals and objectives of which must be consistent with the general strategy of the development of the economic entity, and ways of regulating adaptation should be adequate to the principles of the formation and development of entrepreneurial activity.

2. The model of the integrated system of adaptive management of trade enterprises under the conditions of the external environment dynamics is substantiated, which creates conceptual preconditions for the development of an independent system of adaptive management, which is a unified ordered set of elements and actions forming a system of closed management. The model of the organizational and economic mechanism of an independent system of adaptive management of trade enterprises in the conditions of dynamic environment is developed in compliance with the conceptual principles of adaptive management, due to its specific properties and scope, as well as principles of construction and operation of adaptive enterprise management system. Scientific basis of the development is based on the combination of system, functional, process, integration, marketing, dynamic and integrated approaches, which provides the effectiveness of practical implementation of the developed management system.

3. The main task of adaptation in the dynamic external conditions of functioning is the formation of a flexible control system capable of self-organization and restructuring. The developed structure of the organizational and economic mechanism of adaptive management of trade enterprises in the conditions of dynamic environment is a hierarchy of circuits of circulation and transformation of information in the process of implementing the concept of management, and is able to fit into specific organizational and legal forms, types of economic activity and the specifics of management of enterprises in the industry. Its introduction into the practice of trading enterprises in the conditions of dynamic environment and crisis processes occurring today in the Ukrainian economy will ensure the survival, stability, performance of the operation, thus improving the macroeconomic situation and ensuring macroeconomic stability.

4. Adaptive management is effective and efficient provided that "weak signals" of the destabilizing influence from the environment are systematically monitored, and receive an immediate, adequate response to these signals. The use of managerial tools for "weak signals" in the system of adaptive management of trade enterprises will help not only faster and better than competitors to counteract the dangerous changing realities of the market, but also provided timely response to them, organizationally, financially, psychologically prepare for their perception.

5. The study of modern tools for conducting scientific research has allowed to provide grounded scientific and practical recommendations regarding a set of calculation and analytical tools that should be used during the formation of the system of adaptive management of trade enterprises. For the increase of analytical procedures effectiveness for adaptive management, a wide use of modern management tools is recommended: proactive management, Balanced Scorecard, Benchmarking, Customer Relationship Management, Cycle time reduction ), Growth Strategies, Knowledge 
Management, Market Degradation Analysis, Reengineering, Scenario Planning Scenario planning and others. 


\section{CHAPTER 3}

METHODOLOGICAL SUPPORT FOR THE ADAPTIVE MANAGEMENT SYSTEM FORMATION OF TRADE ENTERPRISES 


\subsection{Competitive and financial potential as criteria of trade enterprise adaptation}

It is generally accepted that the basis for providing reliable prerequisites for the implementation of the strategy for the development of any enterprise, including trade, is its economic potential and competitiveness increasing. The domestic enterprises development in the trade sector is connected with the solution of the problem of economic entities competitiveness, which has many-sided nature and is common to all sellers of goods and services.

Market conditions make trade enterprises to stir to activity, overcome the difficulties which are generated by the uncertainty of the business environment of their operation. As a result, the struggle for economic resources and benefits in the markets, for consumers of goods and services intensifies. «Market competition is system of relations between economically independent producers (sellers) of goods and services. It only takes place when producers and sellers are able to respond to changes in market conditions; to those or other actions of their competitors ... Enterprises enter into competitive struggle, eventually, for getting a profit. Therefore, market competition is effective only when commodity producers and sellers are actually interested in profit increasing» $[235$, p. $67-68]$.

In general, the market mechanism can be defined as a mechanism for enterprises adapting to the uncertainty of the business environment, and the products which they offer (supply) to the consumers requirements (demand) [236, p. 48]. The main driving force of the market economy is competition between commodity producers and sellers.

«Competition» translated from Latin means a collision as a result of any actions. It is defined as economic competition, competition in the struggle for the consumer, for the best conditions of production and sale of products (goods and services) [237, p. 251; 238, p. 311]. Market competition is defined as a system of relations between commodity producers (sellers), as a struggle between them for economically favorable conditions of production and sales of goods in order to obtain the greatest profits. According to Y. Shumpeter, there is no equilibrium in competition [239].

The ultimate aim of trade enterprises adapting is victory in the competition for the consumer, markets, which is logical result of its integrated efforts to implement the organizational and economic system of adaptation. Competition is form of mutual competition between business entities. The subject of competition is goods (services), and the object is consumers and buyers [236, p. 51]. According to V.L. Lunyov [240], the distribution of the «subject» and «object» of competition points to two spheres of influence in competitive struggle: the product (subject) and the consumer (object), which causes difference as in competition methods, and in ways of the competition level assessment. Competitive relations have double character: under constant competitiveness of sellers in the markets, their competition is needed as a base for the development of the economy and democracy of society as a whole. The double essence of competition is represented in the most important characteristic namely in the competitiveness. The focus on the market economy model deepens the crisis in the state, the overcoming of which is inextricably connected with providing of high level of domestic enterprises competitiveness. Many leading specialists in the field of strategic management adhere to this position [236; 241-245]. 
According to R. A. Fatkhutdinov, «the competitiveness is the main factor of success under conditions of market relations. However, this tendency is not enough elaborated till now» [91, p. 66].

Efforts for competitiveness improving should be an effective means of overcoming the crisis of the domestic economy and its further development and prosperity. V.L. Lunyov proposes to choose competitiveness as an integral indicator of the state economy development, which is also condition for full-fledged and effective entry into the world economic system [240].

Professor Yu. V. Husiev believes that the market conditions in which the trade enterprises operate «... make them to carry out a large number of changes and, as a rule, these changes have strategic nature; ... to pay a lot of attention to strategic management of competitiveness...» [243, p. 73]. Currently, domestic trade enterprises are in crisis, so their goal is providing their own competitiveness [243].

As A. Seleznov notes, «today commodity markets competitiveness becomes the problem of national (state) security» [246, p. 9].

H. L. Azoev is convinced that «a modern entrepreneurship must effectively solve a great number of main tasks, which include the competitiveness management» [241, p. 13].

Such important role of competitiveness is determined by the complex conditions of the present stage of economic development, the uncertainty of the business environment of trade enterprises, the functioning in which involves certain adaptation changes for providing the life activity and competitive advantages of goods and services sellers. It is indicated by businessman Kadzuma Tateisi, who believes that in order to provide the enterprise's survival during the rapid changes «... it should adapt all its business activity to changes in the environment» [164, p. 60]. I. Ansoff connects the enterprise's success with how well it «adapts to its external environment - economic, scientific and technical, social and political, etc.». [2, p. 60]. Foreign scholars M. Meskon, M. Albert, F. Khedouri argue that «... organizations are forced to adapt to their environment in order to survive and maintain their effectiveness» [86, p. 175].

Consequently, each trade enterprise must quickly adapt, maintain high competitiveness and business value for providing the competitive positions. This position is supported by M. Porter, who argues that the competitiveness and financial strength of the enterprise are the main factors which determine its strategic position in the modern business environment [247].

Adaptive capabilities of the trade enterprise (competences) allow responding to changes which occur in its business environment. The strategic orientation of the adaptation processes management of the trade enterprise can be ensured only on the base of effective competitive and financial potential management, which requires the selection of these indices as local criteria of the strategic adaptation model and their quantitative determination (assessment).

The author's attitude regarding the selection of one of the criteria for enterprise's adapting in the form of such indicator as the competitiveness potential fully coincide with the approach of L.V. Sokolova, who considers that «the main criterion for the adaptation of enterprises to market conditions is the level of competitiveness» [248, p. 59]. The views' coincidence takes place regarding the main factors of competitiveness (the place of the enterprise in the market, the level of its trade activity, the measure of 
channels' development of goods distribution, the efficiency of the promotion systems use, etc.).

It is impossible to disagree with the opinion of professor Z. A. Vasylieva, who believes that «the single conceptual and methodical machinery, which allows assessing the competitiveness of each market entity should be formed for the coordination of the actions of various producers (sellers) and different management levels during the development and adoption of managerial decisions about the mechanisms of economic growth» [249, p. 37].

The problem of the quantitative expression (assessment) of the competitive and financial capacity of trade enterprise - the local criteria for its adaptation to the uncertainty of the business environment did not find its final solution in the scientific literature. Therefore, the analysis of theoretical and methodological approaches to their definition and development modern assessment methods is essential tendency of its solution.

Modern market conditions of the activity of domestic trade enterprises increasingly sharpen the problem of economic entities competitiveness providing, moreover it is not only the goods and trade services competition, but the organization and management methods competition also reaches new frontiers. At the same time, strategic management is considered as the most promising way and effective means of increasing the competitiveness of Ukrainian trade enterprises.

We consider starting to study this issue with the consideration of competitiveness as one of the key concepts of the theory and practice of economic science and in particular the economy of the enterprise.

Under developing the essence of the trade enterprise competitiveness, the features of this economic category should be taken into account [250, p. 7], which are as follows:

- competitiveness is determined by the existing enterprise potential and the efficiency of its use;

- trade enterprise is mediated bearer of the competitiveness property through goods and services, which is determined by the dependence of the results of the enterprise's activity on the reaction of buyers to its goods and services;

- the competitiveness of the trade enterprise as a characteristic of its activity in the market is relative indicator, where similar indices of enterprises-competitors competitiveness are the base for comparison;

- the trade enterprise competitiveness is dynamic category, external and internal (managed) factors cause its changes.

Thus, the competitiveness of the trade enterprise is an integral characteristic of its activities, which expresses the ability to successful operation in the market and withstand competition from sellers of similar goods and services. It is a set of properties of an economic entity which determine the development of the opportunities of the enterprise and allow it to compete with other enterprises, survive in the sectoral and general markets with an acceptable risk for it and satisfy consumers with goods and services.

The following problems related to providing the competitiveness of domestic trade enterprises can be distinguished [251]: 
1) legal: imperfection of legislative support; the implementation of new regulations which outgoes the ability to adaptation of the majority of enterprises; insufficient efficiency of work of human rights bodies; the existence of unnecessary administrative barriers for the enterprises development, etc.;

2) trade and technological: low level of mechanization of trade and technological processes; uneven workload during the working day (week), which depends on the stream of customers and commodity specialization of the trade enterprise; low quality of goods etc.;

3) Organizational: lack of strategic management, which provides stable development of enterprises; weak automation of management processes; inconsistency of the enterprises' management structure with market conditions, etc.;

4) financial: lack of the system of financial and investment support for the operation and development of enterprises; high cost of bank loans; inefficiency of the financial payments control system, etc.;

5) economic: high cost of renting buildings; imperfection of the economic mechanism of enterprises' operation; low cost management; investment deficit; inefficient use of resources; imperfection of the methods of prices' calculating of goods and services, etc.

It is possible to offer a number of known in the literature ways for competitiveness improvement on the base of the problems list for providing the competitiveness of domestic trade enterprises: adaptation of the regulatory system to the real possibilities of enterprises; developing of innovation-oriented management system; attraction of sufficient volume of investment resources for strategic development of enterprises; the formation of the adaptive management system with strategic orientation, etc.

In our opinion, the lack of strategic management system which provides stable development of enterprises and low management quality are the most important problems at present for the domestic trade enterprises. At the same time, the most promising way of trade enterprises' competitiveness increasing is the formation and implementation of the adaptive management system with strategic orientation.

The topicality of these two problems is grounded by those market conditions which already fully have formed abroad and which domestic trade enterprises still continue to adapt.

Globalization of the economy creates favorable conditions for the business systems globalization; in this connection the internationalization of elements and conditions of business systems under the simultaneous globalization of business processes takes place. Deep changes in the content of the business entities activity occur in the new conditions. In addition, the globalization of the economy changes the traditional conceptions of the quality of goods and services, the costs level, labor productivity, etc., which requires from trade enterprises adaptation to global conditions of competition, searching for global competitive advantages.

The single economic space significantly changes the conditions of competition. Under the common resources market (labor, financial, material, in particular, commodity resources, etc.) the competitive advantage can be achieved by creating and developing some distinctive quality which has demand among customers (consumers) 
on the base of distinctive abilities of the trade enterprise, but not on the base of its resources and factors.

Classical statements about the fact that enterprise's profits and wealth of nations are generated by competition [167] should be checked today. Since in our time it is not the competition, but cooperation and collaboration of enterprises is the base of their business success, prosperity and development.

Under such conditions, the competitiveness of trade enterprise depends directly on competently provided strategic management and the formation of the adaptive management system by enterprise. Future competitiveness is not determined by the current rules. It is determined by the ability to break and modify these rules [247]. As the analysis of the current market conditions shows, the success of trade enterprises is determined not only by the speed of reaction to the existing conditions, but also by the ability to form them.

The market economy system requires from trade enterprises constant increasing of their competitiveness. In turn, the competitive advantages of the enterprise start formation already at the stage of setting goals and developing strategy that is considered in many studies. Because strategic management methods allow concentration on those types of activities where the enterprise is leader, that is, it has stable competitive advantage. Successful business strategies of enterprises base on the stable competitive advantage.

Undoubtedly, the development and implementation of the strategy are the main management functions. Among the entire set of manager actions of just very few not actions provide such significant impact on the trade enterprise operation as the choice of long-term trends of the economic entity development, the elaboration of effective strategic actions, the strategy implementation which allows obtaining the desired results.

Now the debate is not scientific assertion Statement that the competition is prerequisite for the transformation of the enterprise's potential in its competitive potential doesn't provoke discussion now among scholars. However, researchers' opinions about formulation the competition essence and explanation of its effect mechanism on the market participants potential which are trade enterprises as well differ.

Thus, the works of many domestic and foreign scientists are devoted to the study of the theoretical and historical conditions of competition and practical aspects of enterprises' competitiveness managing. At the same time, the works of A. Smit, D. Rikardo, A. Marshall, I. Ansoff, Y. Shumpeter, M. Porter are considered classical works on the competition and competitiveness. The works of modern scholars such as H. Azoiev, L. Balabanova, Yu. Ivanov, S. Klymenko, L. Kobyliatskyi, S. Savchuk, R. Fatkhutdinov, A. Yudanov and others are based on the researches of these scientists. However, despite the existence of a large number of scientific works, the problem of the structuring of the categorical apparatus of the competition theory still isn't explained enough. It complicates the practical questions of determining the place of the enterprise's competitive potential in the system of basic concepts of competition theory.

The study of economic literature allow finding out that there are several economic categories in the competition theory, which in general in varying degrees characterize the enterprise's competitiveness [252]. The analysis of competition and the 
explanation on this base of the competitive potential and competitive strategy in the aggregate competitiveness relations is the methodological basis for the study of the laws of the market economy formation and functioning. In the context of this, the definition of the relationship between the basic concepts of competition theory will allow identifying the place of competitive potential and determining the sequence of planned measures for achieving of the competition desired result.

So, in the process of theoretical research, we identified the following basic elements of the categorical apparatus of competition theory, namely: competitiveness, competitive environment, competitive stability, competitive strategy, competitive potential, competitive advantage, etc.

The concept «competitiveness», as one of the most well-known and fundamental economic categories, is widely investigated by specialists in the field of goods and services, sectors of the economy, spheres of life activity and economic entities [253].

The determined multiplicity of implementation and research methods characterizes the complexity of «competitiveness» concept from broad to narrow its understanding. Enterprise's competitiveness is one of the criteria for assessing the effectiveness of its activities and development. In a broad sense, competitiveness can be defined as the ability of an enterprise to achieve its own goals under counteraction to competitors. It is in this aspect the social elements of the external environment are of particular importance: historical traditions which are peculiar to territorial formation, within which the target segment of consumers is concentrated, ethical norms, type of outlook and moral principles.

It is the need to focus the attention of enterprises on the presence of elements of the environment which causes such concept as «competitive environment» in the competition theory; it is possible to characterize and assess the competition at the macro level on its base. The competitive environment describes the conditions under which business entities should operate trying to achieve maximum economic returns with the most efficient use of their own resources by implementing measures which will help in the long-term perspective to attract more customers than competitors.

There are two types of competitive environment of direct and indirect influence according to which the enterprise can both directly or indirectly interfere and influence the course of its development. Traditionally, the elements of the macro environment of indirect influence include the so-called PEST-factors which manifest themselves through political, economic, social and technical and technological factors. In turn, the competitive environment of direct influence includes «5 forces» which were firstly generalized by M. Porter [247]. They include the assessment of such components as barriers to entering the market, the number of suppliers, the presence of competitors, the activity of consumers and the quality of substitute goods, which, as a rule, have significant impact on the investigated enterprise and must necessarily be taken into account in the process of competitive analysis.

The concept «competitive environment» closely correlates with the category «competitive strategy» which determines competitive stability and competitiveness. Quite often, these concepts are identified in the literature, but it is inadmissible because of various functions which differentiate these categories.

The concept «competitiveness» should be considered through the prism of its components, namely competitiveness and sustainability. According to the literature 
analysis, competitiveness is often considered as the system of interconnected factors, which allows business entity withstands competitors effectively through the intensive use of existing competitive advantages on the base of rational use of resources. With taking into account that sustainability is certain ability of the system to resist changes in the environment in the long term perspective under maintaining the possibility of further development, the competitiveness category (with taking into account the competitive strategy influence) is an integral part of competitive stability [252].

In fact, it is advisable to determine competitiveness «... as characteristic of effective implementation ... of enterprise processes under the long-term perspective competition, which is determined by interconnected and interdependent components (by competitiveness and sustainability of the enterprise), the obligatory complex of which provides the solution of the corresponding functional tasks» [254, p. 5].

The competitive strategy plays key role in competitiveness, and hence competitive stability providing, its first substantial understanding was created by the work of M. Porter in the form of «taking of stable and favorable position which allows organization to withstand the pressure of those forces which determine the competitive struggle in the industry» [247, p. 25]. At present, the enterprise's competitive strategy should be defined as «... the set of measures on the base of competitive advantages and which is implemented by the organization in order to achieve and maintain advantageous competitive position and neutralize the influence of competitive forces» [255, p. 95].

Thus, it is determined that it is the competitive strategy, through providing longterm sustainability forms the competitiveness of the enterprise, which, in turn, is substantiated the level of achieved enterprise competitiveness, and determining component of which is competitive advantage.

The concept «competitive advantage» was firstly formulated by M. Porter [247]. He means the set of certain factors of the enterprise's activity (from low costs to goods differentiation) under the concept «competitive advantages»; these factors determine success of the enterprise in the competition. F. Kotler has somewhat different point of view, he characterizes this economic category, as an advantage, «which is achieved by the subject over competitors by offering greater value or goods and services at lower than the competitors' prices, or providing consumers with greater benefits, which sufficiently compensate higher prices» [256, p. 417]. Unlike Porter, F. Kotler relates the competitive advantage with the definitive characteristics of individual products are proposed by enterprise but not with the enterprise and its potential. The view of domestic researchers group presents the most comprehensive definition of the «competitive advantage», they consider that the competitive advantage is «...concentrated expression of the advantages over competitors in the economic, technical, organizational spheres of activity which can be measured by economic indices (additional profit, higher profitability, market share, etc.)» [257, p. 104].

Successful functioning and development of enterprises in modern economic conditions necessitates the definition of an appropriate approach to the identification of competitive advantages. In our opinion, it is the competitive advantages form the competitive potential of objects and business entities, which, in turn, involves the need to determine the role and significance of the competitive potential of the enterprise activity. 
The study of economic literature on this issue shows that the definition of the «competitive potential» concept is significantly changed: from its definition as combination of resources and opportunities [258] and «the part of the general potential» [259], to understanding the competitive potential as the set of key success factors [260] and components which have properties of innovation and adaptability [261].

We determine during summarizing the results of the research of the essence of the «competitive potential» or «competitiveness potential» concepts that many scholars in their definitions emphasize the following criteria of its identification:

1. Availability of the resource component, which is the base for the enterprise potential formation and its availability.

2. Availability of methods for the transformation of potential in competitive advantage.

3. Comparative analysis of potentials of competing market subjects.

4. Accounting of the effect of external forces and, in this regard, the ability of the enterprise to changing market conditions adapting.

5. Relation with enterprise's competitiveness.

Thus, as the analysis shows, the main categories of competition theory are closely interconnected and form the essence of competition in the competitive environment at the micro level. If the level of competitiveness as relative indicator, first of all, presents the possibility of use the competitive potential for further identification of the main tendencies of the enterprises competitive strategy. If competitiveness is potential, competitive advantages are the levels of this potential use. Hence it turns out that the level of competitiveness of the enterprise forms on the base of the competitive potential and can not be higher than it. If in the certain competitive environment under full use of the competitive potential, the enterprise does not possess sufficient competitive advantages, then, first of all, it is necessary to develop measures for the competitive potential increasing and its implementation [262].

The visual representation of the relationship between the main categories of the competition theory and the position in it of the competitive potential (competitiveness potential) is shown in Figure 3.1. 
Integral part of the aggregate
activity planning system

Effectiveness of the actions on

the consumer market

Dominates of the resource component

Properties of the enterprise, which show up in the competition

The field of objective interconnections

Set of actions of the consumer

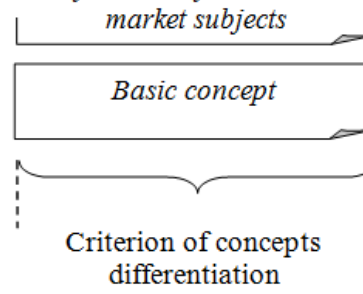

differentiation
Competitive strategy VII

Competitive stability $\quad V I$

Competitiveness potential $\quad$ V

Competitive advantages $\quad$ IV

Competitiveness. Competitive environment III

Competitive relations II

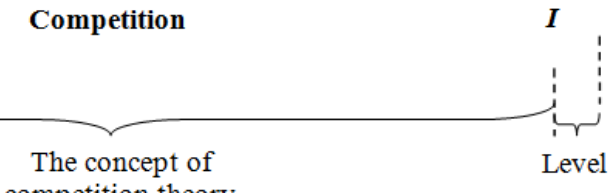

Figure 3.1. Hierarchy of concepts of the categorical apparatus of the competition theory (author's development)

Thus, the main criteria for differentiation of the competition theory main concepts are identified with taking into account the internal orientation of each of them on the base of the study of the categorical apparatus of the competition theory. The structuring of the categorical apparatus of the competition theory allows more qualitative solution of such basic practical tasks as studying the requirements of the consumer market and the requests of potential consumers; market monitoring in order to collect information about the conditions of sales of goods (services), enterprisescompetitors and products-competitors; creating of the generalized model of competitive potential management with taking into account a number of factors which effect on the achievement of the competitiveness target level; determining the main target tendencies of trade enterprises activity according to the competitiveness criterion.

Trade enterprises are forced to adapt to changes in the needs of target markets and respond to the actions of competitors under the influence of competition. They need the abilities and opportunities for it which will provide economic entities with increased competitiveness. On this base it is possible to make conclusion that in the competitive environment, the enterprise potential must transform into the competitiveness potential.

Thus, on the base of above-mentioned it is possible to conclude that under the current conditions of functioning and development of domestic trade enterprises it is necessary and possible to develop efficient scientific and methodological method for the definition and quantitative measurement (quantitative assessment) of the competitiveness potential of trade enterprise, with taking into account the features management of modern enterprises of the trade industry, which are the objects of economic research and management. The use of such scientific and methodological 
methods in practice should help to improve the quality of management decisions in the system of adaptive management, which are aimed at strengthening the competitive positions of trade enterprises in the market in the strategic perspective.

\subsection{Methodological approach to integrated assessment of the trade enterprise competitiveness potential}

The activity of each economic entity, in particular the trade enterprise is aimed at obtaining certain results. However, some enterprises confidently achieve their goals, while others work less successfully. The activity success is connected with the right choice of its tendencies, resource availability, ability to navigate in rapid competitive environment and the ability to quickly adaptation to changes. In addition, the trade enterprise management, in particular, adaptation management, in the conditions of economic unexpectedness and competition, plays a significant role.

With taking into account that the current business environment of the trade enterprises is characterized by particularly high dynamism and constantly increasing competition (this fact is confirmed by the results of the diagnostics of the modern business environment of trade enterprises) and the study of the influence of factors of the environment on the formation of strategic objectives of business entities in the field of trade and the search for ways to increase the level of implementation of the competitiveness potential of the trade enterprises becomes one of the key problems of the economic entities of the trade field in the adaptation management system.

In this case, we consider that it is necessary to note that under the competitiveness potential of trade enterprise is understood dynamic, systemic set of its capabilities to provide competitiveness in the field of trade activity, which is formed by transforming the potential of the enterprise into the competitiveness potential under the influence of competition and determined by the presence and level of use actual and potential competitive advantages of the enterprise [253].

The enterprise's competitiveness potential is characterized by certain features, which are grounded by its specific characteristics. These characteristics are presented in Figure 3.2. 
FEATURES OF THE TRADE ENTERPRISE COMPETITIVENESS POTENTIAL

Increased adaptability to consumer market changes

Adaptation flexibility to changing conditions of trade activity because of variability of preferences, needs and demand of consumers

Self-regulation and self-development of the internal environment of trade enterprise, which is oriented on stable long-term relations with counteragents

Relative stability which is caused by the speed of commodity resources business turnover and the formation of income from their implementation

Stable orientation towards growth which is caused by the growth of sales as a result of the increasing of population purchasing power.

Figure 3.2. Features of the trade enterprise competitiveness potential [253]

The competitiveness potential of trade enterprise is complex multicomponent system which is characterized by the internal structure and has certain characteristics. At the same time, the structure of competitive potential is the main factor which characterizes the enterprise and takes into account its specificity, affects not only on the current activity of the trade enterprise, but also on the formation of the strategy for its development.

The structure of the competitiveness potential of the trade enterprise will be considered as the set of components of technical and technological, commercial, marketing, customer and business potential with taking into account the specifics of the trade sector and the features of the competitiveness potential of trade enterprises [253].

The technical and technological potential of trade enterprises forms the opportunities and competencies concerning the technologies of the trade and technological process of customer service, as well as the management technologies which are not stable. The motive for their improvement is the growth of customers' needs, the expansion of the range of goods and services, best practices of competitors, and so on.

Trade service technologies which are used by trade enterprises determine the content and effectiveness of their trading activities, which requires the segregation of commercial potential, which covers the scope of establishing business relationships 
with suppliers (producers and dealers), the organization of goods' purchasing and selling processes, the formation of financial and economic results of economic activity, etc.

Obtaining of these results, in turn, requires the establishment of the system of sustainable marketing communication interconnections and relationships between the trade enterprises and all counterparties in terms of commodity and money exchange, which are realized through marketing potential. The fact that the trade is faster than production reacts to the changes in consumer demand is particularly important in this context [263]. In this regard, the marketing potential is of particular importance in terms of establishing stable relationships with buyers in order to influence on buyers' behavior by providing information about products, services and retailers, as well as stimulating buyers to make decisions about goods and services purchasing. Marketing potential in today's conditions plays leading role in promoting goods and services on the market, as well as identifies trends of the consumer market development and the most important resources and competencies for meeting customers' (consumers') needs, namely, trade enterprise customers.

On this base it is logical to distinguish from the competitive potential of the trade enterprise of customer potential, which characterizes the target contingent of consumers (buyers) of goods and services which are loyal to this enterprise and have stable positive perception to this trade enterprise, the trust and commitment to it; it, of course, depends on the entrepreneurial potential of the business entity.

The business potential of trade enterprise has connection not only with the client's potential. It is interconnected with the technological, commercial and marketing potential of trade enterprise. This correlation can be argued by the presence of reverse signals of the consumer market about the degree of satisfaction of the customers' (consumers') demand for goods and services. The trade enterprise is forced to make changes in the trade process, change the technology of customer service, make adjustments in the organization of commercial activity of trade enterprise, improve the ways of marketing influence on the target contingent of buyers (consumers) of goods and services, and also in general, support and strengthen customer loyalty in case of deterioration of the buyers demand satisfaction level. Entrepreneurial potential directly influences on the technology potential in the field of generation and offering of new ideas about improvement of trade and technological processes of trade enterprise, on the marketing potential as a source of new creative solutions in the field of communication policy, ways of promoting goods and services, forming long-term relationships with customers and consumers of goods and services of trade enterprise [263].

It should be noted when speaking about the formation of the system of adaptive management of trade enterprises that the integrated assessment of the competitiveness potential on the base of integrated assessment methods application as integral part of the enterprise business management system becomes of paramount importance in the system of adaptive management of trade enterprises. Assessment of the competitiveness of trade enterprise on the base of integrated assessment methods use is one of the most effective methods of adaptation management, the main element of substantiation of managerial decisions in the system of adaptive management of industry enterprises [253]. 
As it is noted above, the problems of the enterprise's assessing are considered in the works of a great number of scholars, in particular: A. E. Voronkova [264], O. S. Makovoz [265], N. Krasnokutskaya [266-267], O. I. Oleksuk, I. Repin, O. S. Fedonin [268] and others. At the same time, the problem of integrated assessment of the competitiveness of trade enterprises remains largely unexplored.

In this regard, improvement of the methodological principles of the integrated assessment of trade enterprises competitiveness potential which are based on the complex assessments method is one of the prerequisites which allows increasing the efficiency of the adaptive management system of economic subjects of the industry, in particular of the decisions substantiation.

Comprehensive assessment of the trade enterprise competitiveness potential involves comprehensive study of the components of the competitiveness potential of the economic entity and determination of the level of its implementation. It is important management function and based on the systematic approach, comprehensive accounting of different factors, the qualitative selection of reliable information.

Under considering the assessment of the level of implementation of the trade enterprise competitiveness potential it is possible to mark out six main scientific approaches which are base for it. They are structural and logical, program and target, normative, control and regulating, systemic and complex. The manifestation of each from the approaches is realized through its main properties, principles and is determined by the content, methodology and assessment stages.

The structural and logical approach to assessment of the level of implementation of the trade enterprises competitiveness potential is one of the main approaches. In our opinion, its basic properties should include hierarchy, subordination, morphology and balance. The set of listed properties provides the basis not only for research, but also for new branches of knowledge, in particular, forms morphological analysis, which is used not only in complex assessment, but also in forecasting and managerial decisions developing in the trade enterprises adaptive management system.

Structural balance is particularly important property in the process of integrated assessment of the level of implementation of the trade enterprises competitiveness potential. This property allows regulation of financial and economic proportions in the economic entities of the industry activities.

The problem of the disproportions analysis was brewing over a long period. Attempts to solve it implicitly are taken by different scientists. In particular, Ya. Kornai in the process of studying the problems of the deficit in economic entities approaches to study the enterprise adaptability, its «vegetative mechanisms which regulate simple, elementary, trivial adaptations of real economic processes» [269, p. 167].

Samochkin V. M. pays attention to the study of this problem from the standpoint of research «flexible enterprise development». The scientist considers the flexibility of the object «as an inherent ability to react to an external action (environment) without radical structural changes» [270, p. 11].

It is accepted to mean by adaptability, which is inextricably connected with the study of imbalances «the process of purposeful change of parameters, structure, properties of an object in response to changes which occur» [271, p. 25]. It should be noted that adaptation is «process of adapting the structure and functions of the system to any environment conditions» [272, p. 14]. A. V. Shabarov in the process of 
adaptability problem (the ability to adapt) studying (in relation to management) notes that «adaptability is the level of the organization sensitivity to the necessary changes according to the organization theory» [272, p. 137].

The change in structural balance is directly related to the study of the development of both the system itself and the laws of its development. At the same time, the time factor becomes very important.

According to L. A. Didov, the structural dynamics theory subject is the study of the interconnections between the processes of economic growth and the structural changes which take place in the economic system, which is the enterprise [273]. At the same time, according to the author's point of view, the structural and dynamic approach emphasizes the comparison of structures of the economic system in dynamics, identifies of their similarity or difference, as a result the economic development features are studied, and, in turn, it creates the basis for comparative assessment.

The implementation of the normative approach is also closely related to the structural and logical and control and regulate components of one of the balance features, which is possible in the presence of commensurability in the financial and economic processes of economic activity, that is, under measure establishing (explicit or implicit, full or part measured, substantiated by the development of the enterprise and the conditions of its functioning). Measure determining leads to the formation of norms in accordance with the values, and, as a result, to the standards development.

The use of normative approach is carried out in the process of manifestation of the properties of control and regulatory and program and targeted approaches: planning, subordination, coordination, regulation, consistency.

The systematic approach is one of the most difficult. The peculiarities of its use in the field of integrated assessment of the implementation level of the trade enterprises competitiveness potential are determined, first of all, by the study subject. The base of the systematic approach is such specific properties as integrity, structure, interdependence of the system and the environment, autonomy, adaptability, hierarchy, uniqueness, plurality of descriptions.

The scientific literature analysis shows that success is achieved by those enterprises which apply the systematic approach to integrated potential assessment, in particular competitiveness potential assessment, and consider the enterprise as the single system. We share the point of view of the systematic approach supporters and consider that it is expedient to highlight the following key propositions.

1. Any system can not exist in isolation without exchange with the general system, which is the external environment relative to this system. That is, complete and consistent description of the system behavior can not exist, since its state depends on another system and it is an integral part of that system.

2. The systematic approach use allows identifying alternatives for goals achieving and it is characterized by complexity, implementation terms, scale and effects.

3. The openness of the trade enterprise system, as its main feature under market conditions, and direct dependence on the interaction of supply and demand, stipulates the necessity of forming the adaptive management system for economic entities and their activities in general, which can quickly and effectively respond to market needs. 
The manifestation of comprehensive approach to assessment the level of the trade enterprises competitiveness potential implementation is traced in its main properties, which include integrity, divisibility, isolation, identity, complexity, documentary validity [271]. In our opinion, it is advisable to supplement them with such properties of integrated approach as stage, sequence and interconnection of elements.

Thus, the study of modern methodological approaches to the comprehensive assessment of the implementation level of the trade enterprises competitiveness potential provides grounds for formulating the general requirements for this process organization:

1) interpretation uniqueness. The selection of assessment criteria should not be doubtful according to their further interpretation by the target audience, which will use the existing database during making managerial decisions about the trade enterprises competitiveness potential;

2) the possibility of dynamic picture constructing. Determination of the effectiveness of the adaptive management system activity of trade enterprises is carried out under mandatory monitoring of development indices in the dynamics. Consequently, the need to periodically update the basis of these indices and integral indices which are determined on their base is undoubted;

3 ) the formation of database indices according to the principle of «reasonable sufficiency». It is necessary to avoid of maximizing use of the entire statistical database which is available to the researcher, since a significant number of these data are interdependent with multicollinearity phenomenon between them. Only the most important indicator-indices should be selected, which can maximally describe the qualitative characteristics of the state of certain sphere of enterprise activity, in our case it is the level of the trade enterprise competitiveness potential realization.

The requirements for the complex assessment process organizing of the implementation level of competitiveness potential on the base of the systematic approach are the bases which form the construction of the method's specific characteristics [274].

Under current conditions, objective integrated assessment of the implementation level of the trade enterprises competitiveness potential becomes of special importance. There is a plurality of methods and assessment criteria on the base of the use of various indices system for its determining. Such methods provide opportunities to identify problem areas in the enterprise's activities regarding its competitiveness potential and to investigate the reasons which cause them, but do not provide an opportunity to make substantiated conclusions about the state and implementation level of the competitiveness potential as a whole. At the same time a lot of situations arise when comprehensive assessment of the enterprise's competitiveness potential is desirable, namely: the need for generalization of information about the state and implementation level of the competitiveness potential, the solution of problems of enterprise's effective management and the search for business development reserves, adaptation to existing environmental trends, etc.

In this regard, an important stage of the implementation level assessment of the trade enterprise competitiveness potential is the synthesis of uncoordinated results through the integrated assessment methodology. Such assessment is characteristic of the 
competitiveness potential level, which is the result of comprehensive study of the set of indices which present all aspects of the trade enterprise competitiveness potential. It should be noted that obtaining general conclusion regarding the implementation level of the enterprise's competitiveness potential is carried out on the base of identifying quantitative and qualitative differences from the comparison base (plan, norms, previous periods, achievements of similar objects, etc.) [275].

The task of complex assessment is enough simple under a small number of assessment parameters and objects. The task complication occurs with increasing of objects' number, in particular, indices and (or) assessment criteria. Theoretically, the problem lies in the fact that it is necessary to assess the level of trade enterprise competitiveness by one indicator, which synthesizes all aspects of its competitiveness potential. However, the complexity of the trade enterprise competitiveness potential category does not allow distinguishing among the generalized effective indices any one as the main one.

The task comes to the comprehensive assessment of the implementation level of trade enterprise competitiveness potential on the base of indices system with aggregation of various methods of quantitative and qualitative analysis. At the same time, the level of competitiveness potential of one business object should be compared with the level of competitiveness potential of other objects (competitors- enterprises). In addition, it provides real opportunity for dynamic picture construction of the competitiveness potential level of industry's economic entities.

With taking into account all above-mentioned, we substantiate the system of indices for assessment the components of the trade enterprises competitiveness potential: technical and technological, commercial, marketing, client and business components (potentials) with the object of solving certain problem and quantify assessment the selected components of the competitiveness potential.

The developed system of indices for assessment of the components of trade enterprises competitiveness is presented in table 3.1, and meets all requirements which are formed by us above and also adheres to the general requirements of complexity, sufficiency and consistency. In addition, it takes into account the trade enterprises specifics. 
Table 3.1

The system of indices of the components assessment of the trade enterprises competitiveness potential (author's development)

\begin{tabular}{|c|c|c|c|}
\hline $\begin{array}{l}\text { Components of } \\
\text { competitiveness } \\
\text { potential }\end{array}$ & $\begin{array}{l}\text { Assessment } \\
\text { indices }\end{array}$ & $\begin{array}{l}\text { Algorithm of } \\
\text { indices } \\
\text { calculation } \\
\end{array}$ & Legend \\
\hline 1 & 2 & 3 & 4 \\
\hline \multirow{3}{*}{$\begin{array}{l}\text { Technical and } \\
\text { technological } \\
\text { potential }\end{array}$} & $\begin{array}{l}\text { Fixed assets } \\
\text { profitability }\end{array}$ & $\mathrm{P}_{\mathrm{FA}}=\frac{\mathrm{FR}_{\mathrm{OA}}}{\overline{\mathrm{FA}}}$ & $\begin{array}{l}P_{F A}-\text { fixed assets profitability, } \\
\text { fraction units; } \\
F R_{O A}-\text { operational activity } \\
\text { financial result for the period, } \\
\text { money unit; } \\
F A-\text { the average cost of fixed } \\
\text { assets for the period, monetary } \\
\text { units }\end{array}$ \\
\hline & $\begin{array}{l}\text { Profit per } 1 \mathrm{~m}^{2} \\
\text { of sales area }\end{array}$ & $\mathrm{P}_{\mathrm{SA}}=\frac{\mathrm{FR}_{\mathrm{OA}}}{\mathrm{S}_{\text {sales }}}$ & $\begin{array}{l}P_{S A}-\text { profit per } 1 \mathrm{~m}^{2} \text { of sales area, } \\
\text { money unit } / \mathrm{m}^{2} ; \\
S_{\text {sales }}-\text { sales area, } \mathrm{m}^{2}\end{array}$ \\
\hline & $\begin{array}{l}\text { Capital } \\
\text { productivity } \\
\text { rate of growth }\end{array}$ & $\begin{aligned} \mathrm{CP}_{\mathrm{RG}} & =\frac{\mathrm{CP}_{1}}{\mathrm{CP}_{0}}, \\
\mathrm{CP} & =\frac{\mathrm{T}}{\overline{\mathrm{FA}}}\end{aligned}$ & $\begin{array}{l}C P_{R G}-\text { capital productivity rate of } \\
\text { growth, fraction units; } \\
C P_{1}, C P_{0}-\text { capital productivity in } \\
\text { the reporting and base periods, } \\
\text { respectively, fraction units; } \\
T-\text { goods turnover for the period, } \\
\text { monetary units }\end{array}$ \\
\hline \multirow{3}{*}{$\begin{array}{l}\text { Commercial } \\
\text { potential }\end{array}$} & $\begin{array}{l}\text { Liquid assets } \\
\text { profitability }\end{array}$ & $\mathrm{P}_{\mathrm{LA}}=\frac{\mathrm{FR}_{\mathrm{OA}}}{\overline{\mathrm{LA}}}$ & $\begin{array}{l}P_{L A}-\text { liquid assets profitability, } \\
\text { fraction units; } \\
L A-\text { the average cost of liquid } \\
\text { assets, monetary units }\end{array}$ \\
\hline & $\begin{array}{l}\text { Goods } \\
\text { turnover net } \\
\text { profitability }\end{array}$ & $\mathrm{P}_{\text {net }}=\frac{\mathrm{FR}_{\text {net }}}{\mathrm{T}}$ & $\begin{array}{l}\mathrm{P}_{\text {net }}-\text { net profitability of goods } \\
\text { turnover, fraction units; } \\
F R_{n e t}-\text { net financial result for the } \\
\text { period, monetary units }\end{array}$ \\
\hline & $\begin{array}{c}\text { Goods } \\
\text { turnover } \\
\text { operational } \\
\text { profitability }\end{array}$ & $\mathrm{P}_{\mathrm{O}}=\frac{\mathrm{FR}_{\mathrm{OA}}}{\mathrm{T}}$ & $\begin{array}{l}P_{O}-\text { goods turnover operational } \\
\text { profitability, fraction units }\end{array}$ \\
\hline \multirow{2}{*}{$\begin{array}{l}\text { Marketing } \\
\text { potential }\end{array}$} & $\begin{array}{l}\text { Stock of } \\
\text { goods } \\
\text { turnover }\end{array}$ & $\mathrm{S}_{\mathrm{GT}}=\frac{\mathrm{T}}{\overline{\mathrm{S}}}$ & $\begin{array}{l}S_{G T}-\text { stocks of goods turnover, } \\
\text { turnovers; } \\
S-\text { the average for the period stock } \\
\text { of goods cost, monetary units }\end{array}$ \\
\hline & $\begin{array}{l}\text { Stock of } \\
\text { goods } \\
\text { profitability }\end{array}$ & $\mathrm{P}_{\mathrm{GS}}=\frac{\mathrm{FR}_{\mathrm{OA}}}{\overline{\mathrm{S}}}$ & $\begin{array}{l}P_{G S}-\text { stock of goods profitability, } \\
\text { fraction units }\end{array}$ \\
\hline
\end{tabular}




\begin{tabular}{|c|c|c|c|}
\hline 1 & 2 & 3 & 4 \\
\hline & $\begin{array}{l}\text { Sales costs } \\
\text { profitability }\end{array}$ & $\mathrm{P}_{\mathrm{SC}}=\frac{\mathrm{FR}_{\mathrm{OA}}}{\mathrm{SC}}$ & $\begin{array}{l}P_{S C}-\text { sales costs profitability, fraction } \\
\text { units; } \\
S C \text { - sales costs for the period, monetary } \\
\text { units }\end{array}$ \\
\hline \multirow{3}{*}{$\begin{array}{l}\text { Client } \\
\text { potential }\end{array}$} & $\begin{array}{l}\text { Growth } \\
\text { rates of } \\
\text { goods } \\
\text { turnover }\end{array}$ & $\mathrm{T}_{\mathrm{T}}=\frac{\mathrm{T}_{1}}{\mathrm{~T}_{0}}$ & $\begin{array}{l}T_{T}-\text { growth rates of goods turnover, } \\
\text { fraction units; } \\
T_{1}, T_{0}-\text { goods turnover volume for the } \\
\text { reporting and base periods, respectively, } \\
\text { monetary units }\end{array}$ \\
\hline & $\begin{array}{l}\text { Growth rate } \\
\text { of the } \\
\text { market } \\
\text { share }\end{array}$ & $\begin{aligned} \mathrm{T}_{\mathrm{MS}} & =\frac{\mathrm{MS}_{1}}{\mathrm{MS}_{0}} \\
\mathrm{MS} & =\frac{\mathrm{T}}{\mathrm{RT}}\end{aligned}$ & $\begin{array}{l}T_{M S}-\text { growth rate of the market share, } \\
\text { fraction units; } \\
M S_{I}, M S_{0} \text { - market share in the reporting } \\
\text { and base periods, respectively, fraction } \\
\text { units; } \\
R T \text { - retail goods turnover of trade } \\
\text { enterprises, monetary units }\end{array}$ \\
\hline & $\begin{array}{l}\text { The growth } \\
\text { rate of } \\
\text { goods } \\
\text { turnover } \\
\text { per } 1 \mathrm{~m}^{2} \text { of } \\
\text { sales area }\end{array}$ & $\begin{aligned} \mathrm{T}_{\mathrm{TSA}} & =\frac{\mathrm{TSA}_{1}}{\mathrm{TSA}_{2}} \\
\mathrm{TSA} & =\frac{\mathrm{T}}{\mathrm{S}_{\text {sales }}}\end{aligned}$ & $\begin{array}{l}T_{T S A}-\text { growth rate of goods turnover per } \\
1 \mathrm{~m}^{2} \text { of sales area, fraction units; } \\
T S A_{1,} T S A_{0}-\text { goods turnover volume per } \\
1 \mathrm{~m}^{2} \text { of sales area in the reporting and } \\
\text { base periods, respectively, monetary } \\
\text { units } / \mathrm{m}^{2}\end{array}$ \\
\hline \multirow{3}{*}{$\begin{array}{c}\text { Entrepreneuria } \\
\text { potential }\end{array}$} & $\begin{array}{c}\text { Profitability } \\
\text { of capital }\end{array}$ & $P_{c}=\frac{F R_{\operatorname{tax}}}{\bar{C}}$ & $\begin{array}{l}P_{C}-\text { profitability of capital, fraction } \\
\text { units; } \\
F R_{\text {tax }}-\text { financial result before taxation } \\
\text { for the period, monetary units; } \\
\text { - the average cost of capital for the } \\
\text { period, monetary units }\end{array}$ \\
\hline & $\begin{array}{l}\text { Capital } \\
\text { turnover }\end{array}$ & $\mathrm{C}_{\mathrm{T}}=\frac{\mathrm{T}}{\overline{\mathrm{C}}}$ & $\mathrm{C}_{\mathrm{T}}-$ capital turnover, turnovers \\
\hline & $\begin{array}{l}\text { The growth } \\
\text { rate of labor } \\
\text { productivity }\end{array}$ & $\begin{aligned} \mathrm{LP}_{\mathrm{GR}} & =\frac{\mathrm{LP}_{1}}{\mathrm{LP}_{0}} \\
\mathrm{LP} & =\frac{\mathrm{T}}{\mathrm{E}}\end{aligned}$ & $\begin{array}{l}\mathrm{LP}_{\mathrm{GR}}-\text { growth rate of labor productivity, } \\
\text { fraction units; } \\
\mathrm{LP}_{1} \text {, } \mathrm{LP}_{0}-\text { labor productivity in the } \\
\text { reporting and base periods, respectively, } \\
\text { monetary units / person; } \\
\mathrm{E}-\text { average number of employees, } \\
\text { person }\end{array}$ \\
\hline
\end{tabular}


Thus, we propose to use the following partial indices, which in our opinion, with sufficient objectivity degree and completeness, make it possible to assess the level of technical and technological trade enterprises potential: the fixed assets profitability, profit from $1 \mathrm{~m}^{2}$ of sales area and growth rate of assets return for assessment of the technical and technological component of the trade enterprises competitiveness potential.

The indicator of fixed assets profitability is the ratio of the amount of profit (financial result of operating activity) to the average cost of fixed assets of the enterprise for the period and characterizes the amount of profit per unit of fixed assets. This indicator characterizes the efficiency level of fixed assets use. With taking into account the trade enterprises specifics, it should be noted that fixed assets of trade industry, mainly are intended to create conditions for the goods' storage and sale. In this regard, the fixed assets profitability indicator is not directly related to the generation of profits and has auxiliary character [275].

We propose to calculate the profit indicator (financial result from operating activity for the period) per $1 \mathrm{~m}^{2}$ of sales area for assessment the technical and technological component of the industry enterprises competitiveness with taking into account the direct dependence of the volumes and results of the trade enterprises activity on the availability of their sales areas. This indicator is recognized in the trade practice basis for comparing the effectiveness of the use of technical and technological capabilities of economic entities.

The third indicator of the technical and technological component of the trade enterprises competitiveness potential assessment is the growth rate of assets return. The value of this indicator is more than $100 \%$ means the economic activity of the enterprise in the implementation of its competitive efforts in the trend of efficient use of technical and technological capabilities.

As for the interpretation of the results of calculations of these indices, it should be noted that the increasing of their value in the dynamics is illustration of increased efficiency of the technical and technological enterprise's potential implementation.

It should be noted that some indices describe only certain aspect of the assessment object and do not allow general assessment obtaining. In this regard, there is the need for aggregating local indices for assessment the overall level of enterprise's competitiveness potential and final conclusions formulation. For this purpose, it is proposed to determine the complex integrated indicator of the implementation level of trade enterprises competitiveness potential on the base of the calculated partial indices of the competitiveness potential components assessment. The complex integrated indicator of the implementation level of trade enterprises competitiveness potential is the base for conclusions about the general level of their competitiveness potential substantiation.

We consider using the matrix method, which allows obtaining more objective results of the assessment for the goal achieving. The essence of the matrix method is determining the quantitative value of the integral rating indicator of the implementation level of certain enterprise competitiveness potential in the matrix of competitiveness under certain parameters. 
Common matrix method is scoring method, the application of which involves the implementation of successive stages, which are described by N.S. Krasnokutska [276]:

1. Formation of the original assessment indices matrix, which includes $m$ key indices of the competitive potential for $n$ objects. Each $i$ index $(1 \leq i \leq m)$ on the $j$ object $(1 \leq j \leq n)$ is given by the value of the corresponding coefficient $K i j$. As a result, we obtain the matrix with series which characterize aspects of the competitiveness of the object according to $m$ different indices:

$$
X=\left[\begin{array}{cccc}
K_{11} & K_{12} & K_{13} & K_{1 n} \\
K_{21} & K_{22} & K_{23} & K_{2 n} \\
\cdots & \ldots & \ldots & \ldots \\
K_{m 1} & K_{m 2} & K_{m 3} & K_{m n}
\end{array}\right]
$$

2. Ranking of assessment indices according to degree of importance.

The result of this stage is the construction of the vector $\left(k_{1}, k_{2}, \ldots, k_{m}\right)$, where $k_{i}$ is the importance factor of each index.

In this case, it is advisable to use the results of the ranking of competitiveness potential components according to their importance for the formation and implementation of trade enterprises competitiveness potential which were defined by the group of authors Hrosul V. A., Afanasieva M. V., Yanchev A. V. [253] according to the study results.

3. Construction of vector, which consists of the maximum values according to each of the $m$ indices, and forms an additional row of numbers $\left(K_{\max _{i}}\right)$ which are indices of the enterprise-standard, where

$$
K_{\max _{i}}=\max K j(1 \leq i \leq n)
$$

4. Formation of the normalized matrix $X^{\prime}$ by standardizing the indices of the initial matrix (Kij) relative to the corresponding index of the enterprise-standard:

$$
K_{i j}{ }^{\prime}=\frac{K_{i j}}{K_{\max _{i}}}
$$


Standardization allows avoiding of the implicit ranking of indices, when small variation of the index may affect on the assessment results [276].

5. The calculation of scores which are obtained by enterprises according to certain assessing index, by comparing their actual values with the best values in the aggregate:

$$
S_{i j}=K_{i j}^{\prime} \times 5 \max _{i}
$$

where Бmaxi - the maximum ascertained point of individual index assessment.

6. Obtaining of generalized point assessment of the competitiveness potential (Ккп) and ranking of enterprises in order of integral index growth with use of the following formula:

$$
K \kappa n_{j}=\sum_{j=1}^{n} B_{i j} \times k_{i}
$$

We consider adding one more stage on the base of developments of the group of authors (N.O. Vlasova, N.S. Krasnokutska, O.V. Nosova, O.S. Makovoz [275]).

7. Assessment of the implementation level of competitiveness potential. Adherence to the general approach to assessing the level of competitiveness potential calls for the assignment of each of the enterprises to specific group which meets high, medium and low levels of competitive potential.

For this purpose the integral index and the ranges of its values are determined on the base of the results of the competitiveness potential integrated indices.

Determination of the integral index range of the competitiveness potential is calculated by the formula [275, p. 103]:

$$
\mathrm{X}_{\mathrm{av}}=\frac{\mathrm{X}_{\max }-\mathrm{X}_{\min }}{3}
$$

where Xav - average value of the index (assessment range);

$\mathrm{Xmax}$, Xmin - respectively, the maximum and minimum values of the index. 
Accordingly: the value of the index from Xmin to $\mathrm{X} 1$ (where $\mathrm{X} 1=\mathrm{Xmin}+\mathrm{Xav}$ ) corresponds to the low level of competitiveness potential; the value of the index from $\mathrm{X} 1$ to $\mathrm{X} 2$ (where $\mathrm{X} 2=\mathrm{X} 1+\mathrm{Xav}$ ) corresponds to the average level of competitiveness potential; the value of the index from X2 to Xmax (where $\mathrm{Xmax}=\mathrm{X} 2+\mathrm{Xav}$ ) corresponds to high level of competitiveness potential.

The following should be taken into account during calculating the integral index of the competitiveness potential: in the case when calculated individual partial indices of the competitiveness potential components assessment have negative values, it may cause «significant spread between the minimum and the maximum values» $[275 ; 277]$. In this regard, there is the need for updating the values of such indices and using nonactual, but corrected, partial indices [275]. For this purpose, we consider for calculation of the integral index of the enterprises competitiveness potential to take negative values of the partial indices at zero level, and as a result it will allow obtaining of wellgrounded results of the enterprises competitiveness potential integrated assessment.

The practical use of this method allows not only to identify the main competitors and the competitiveness potential position of each trade enterprise which is assessed in the competition (on the base of the maximum score criterion), but also quantitatively assess the lagging from the enterprise with the highest level of competitiveness potential.

Thus, the results of the integrated assessment of the trade enterprises competitiveness potential are the bases for the adoption of grounded management decisions in the adaptive management system of trade enterprises for increasing of the competitiveness level of industry's economic entities and strengthening of their competitive positions in the market, as well as the formation of trade enterprises adaptation strategy.

\subsection{The methodology of the trade enterprise financial potential assessing during adaptation management system formation}

The objective basis for the formation of the adaptation management system is the financial potential created at trade enterprises, the study of which allows determining the range of available financial support opportunities for the adaptation process and investment. The formation of the adaptive management system of trade enterprises requires the use of integrated assessment methods, which in the context of this study involves obtaining of generalizing characteristic (magnitude) of financial opportunities with use of specially developed methodology.

It should be noted that in general, the assessment of the financial potential of any enterprise is analytical procedure which involves determining the value of its financial potential under different conditions of comparison. Such conditions, in our opinion, are determined by the range of tasks which are solved during the assessment [278]:

1) the identification of financial possibilities for operation and development from different sources of financing; 
2) determining of the level of available financial possibilities for realization of current or strategic goals;

3) study of the completeness of the existing financial possibilities implementation;

4) determining of the realization balance of enterprise's financial possibilities with other components of its potential;

5) measuring the effectiveness of the financial potential implementation.

According to our point of view, the first two objectives mostly answer to the formation goals of the adaptation management system, the solution of which will allow coordinating of the adaptation objectives with available resources. The problems of the completeness, balance and effectiveness of the financial potential implementation are although important for goals achievement monitoring, but they should be considered during assessment of the adaptation strategy implementation, rather than during its formation.

With taking into account the range of above-mentioned tasks, the study of analytical systems indices requires particular considering because they can be used as assessment indicators of financial potential availability and sufficiency. In economic literature, during the development of such systems, researchers tend to choose traditional financial indicators which are grouped according to such tendencies: indices of structure and capital dynamics, solvency, financial sustainability, business activity and profitability indices [279-284]. From our point of view, this approach does not differentiate between the assessment of the financial state of the enterprise and the assessment of its financial potential, which are differed, first of all, with the time orientation of results. The assessment of the financial state should characterize the financial activity of the enterprise from the standpoint of achieved results per the valuation date. The assessment of financial potential should identify existing and latent financial opportunities which will provide future results.

The range of financial opportunities, according to the research of M. V. Kudina is determined by «the existence and availability of financial resources, which are funding sources» [285, p. 178]. N. S. Krasnokutska has another point of view and proposes to mark out two basic components of financial potential: financial resources and financial competencies [267]. Financial resources can be represented «in the form of cash, funds in payments and financial investments and are formed from different sources (equity and loan capital) and with use of different technologies and financing mechanisms» [289, p. 32]. The use of these technologies and mechanisms depends on the level of capabilities and competencies of financial managers and determines a certain level of business activity and profitability.

Because of the heterogeneity of financial potential, its assessment for the purposes of the adaptive management system developing for trade enterprises in our opinion should be done in two ways [278]:

1) assessment of the availability and adequacy of financial resources;

2) level of financial competencies development. 
The main criterion for the availability of financial resources is their value, the increasing of which, under other equal conditions, indicates the financial potential resource component accretion. The most comprehensive system of valuation assessment of financial potential is presented in research papers [267] and covers the definition of the value of cash and cash equivalents, short-term financial investments and funds in the calculations at the valuation date. From our point of view, such system of indices although describes the available financial resources of the enterprise, should be supplemented by indices of capital structure and financial sustainability for determining the priority sources of funding for the enterprise and the prospects for their attraction. Indeed, if the available financial resources are formed mainly from accounts payable and bank loans, and net income is not sufficient for development purposes but also for functioning, then the development of, for example, the conservative adaptation strategy will not have sound basis.

With taking into account the above-mentioned we consider that it is necessary for the trade enterprises to form the assessment indices system of the financial potential resource component state, these indices characterize its existence and availability of funding sources and are presented in table 3.2.

As it is stated above, the second area of financial potential assessment for the purposes of the adaptive management system developing for trade enterprises is its competent component. In our opinion, although the nature of this component is intangible and its characteristics (capabilities and competencies of financial managers) do not have direct cost measurement, but result approach can be applied for its assessment. Financial managers provide different results by identifying financial abilities (capital attraction, investing, financial stability providing, solvency, etc.).

The presence of powerful financial competencies will be confirmed by the stable solvency of the trade enterprise, its high business activity and equity capital profitability increasing. Instead, the low level of experience and knowledge of financial professionals will invariably lead to settlement problems, inconsistencies between operational and investment needs and existence (or available) sources of funding.

Table 3.2

System of indices of the resource component state of trade enterprises financial potential assessment (author's development)

\begin{tabular}{|c|c|c|}
\hline Index & $\begin{array}{l}\text { Method of calculation / conventional } \\
\text { signs }\end{array}$ & Information support \\
\hline \multicolumn{3}{|c|}{ Indices of financial resources availability } \\
\hline $\begin{array}{l}\text { The cost of available } \\
\text { financial resources } \\
\left(R F_{a}\right)\end{array}$ & $\begin{array}{l}R F_{a}=F E+F I+R+B R, \\
\text { where } R F_{a}-\text { cost of available } \\
\text { financial resources; } F E-\text { balance of } \\
\text { funds and thier equivalents at the } \\
\text { valuation date; } F I \text { - financial } \\
\text { investments at the valuation date; } R- \\
\text { the value of receivables, real to } \\
\text { repayment; } B R-\text { the value of }\end{array}$ & $\begin{array}{l}\text { F. № } 1 \text { (annex 1, } \\
\text { National Statute } \\
\text { (Standard) of } \\
\text { Accounting 1); f. } \\
\text { № } 5 \text { «Notes } \\
\text { to the financial } \\
\text { statements» }\end{array}$ \\
\hline
\end{tabular}




\begin{tabular}{|c|c|c|}
\hline & received bills & \\
\hline $\begin{array}{l}\text { Share of available } \\
\text { financial resources in } \\
\text { the total amount of } \\
\text { capital }\left(\mathrm{S}_{\mathrm{FRa}}\right)\end{array}$ & $\begin{array}{l}\mathrm{S}_{\mathrm{FRa}}=\frac{\mathrm{FR}_{\mathrm{a}}}{\mathrm{C}}, \\
\text { where } C-\text { cost of capital at the } \\
\text { valuation date }\end{array}$ & \\
\hline \multicolumn{3}{|c|}{ Indices of financial potential support with funding sources } \\
\hline $\begin{array}{l}\text { The coefficient of } \\
\text { autonomy }\left(\mathrm{C}_{\mathrm{a}}\right)\end{array}$ & $\begin{array}{l}\mathrm{C}_{\mathrm{a}}=\frac{\mathrm{C}_{\mathrm{e}}}{\mathrm{C}} \\
\text { where } C_{e}-\text { cost of equity capital at } \\
\text { the valuation date }\end{array}$ & \\
\hline $\begin{array}{l}\text { Coefficient of } \\
\text { dependence on bank } \\
\text { lending }\left(C_{1}\right)\end{array}$ & $\begin{array}{l}\mathrm{C}_{1}=\frac{\mathrm{L}_{\mathrm{b}}}{\mathrm{C}} \\
\text { where } L_{b}-\text { the value of bank loans at } \\
\text { the valuation date }\end{array}$ & \\
\hline $\begin{array}{l}\text { Equity working capital } \\
\text { (EWC) }\end{array}$ & $\begin{array}{l}\text { EWC }=\mathrm{C}_{\mathrm{e}}^{\prime}-\mathrm{NA} \text {, } \\
\text { where } \mathrm{C}_{\mathrm{e}}{ }^{\prime}-\text { equity capital (with } \\
\text { taking into account long-term } \\
\text { liabilities); NA - nonliquid assets }\end{array}$ & \multirow[t]{2}{*}{$\begin{array}{l}\text { F. № } 1 \text { (annex 1, } \\
\text { National Statute } \\
\text { (Standard) of } \\
\text { Accounting 1) }\end{array}$} \\
\hline $\begin{array}{l}\text { Maneuverability } \\
\text { coefficient of equity } \\
\text { capital }\left(\mathrm{C}_{\mathrm{m}}\right)\end{array}$ & $\mathrm{C}_{\mathrm{m}}=\frac{\mathrm{EWC}}{\mathrm{C}_{\mathrm{e}}}$ & \\
\hline $\begin{array}{l}\text { Coefficient of financial } \\
\text { resources supporting } \\
\text { with equity working } \\
\text { capital }\left(\mathrm{C}_{\mathrm{rf}}\right)\end{array}$ & $\mathrm{C}_{\mathrm{rf}}=\frac{\mathrm{EWC}}{\mathrm{RF}_{\mathrm{a}}}$ & $\begin{array}{l}\text { F. № } 1 \text { (annex 1, } \\
\text { National Statute } \\
\text { (Standard) of } \\
\text { Accounting 1); f. } \\
\text { № } 5 \text { «Notes } \\
\text { to the financial } \\
\text { statements» }\end{array}$ \\
\hline
\end{tabular}

It allows stating that the assessment of financial competencies requires the use not only expert methods (for example, the use of the relational matrices system [267]), but also the systems of static (financial coefficients) and dynamic (indices) indicators. We propose to use for the financial competencies assessment indices which are grouped according to 4 areas of financial competences (table 3.3) because of the construction of any assessment system requires not all possible indices, but only the most relevant to tasks assessment: 
Table 3.3

System of indices of financial competencies assessment of trade enterprises (on the base of the resulting approach)

\begin{tabular}{|c|c|c|}
\hline $\begin{array}{l}\text { The tendency of } \\
\text { financial } \\
\text { competencies } \\
\text { assessment }\end{array}$ & Indices & Information support \\
\hline Solvency assurance & $\begin{array}{l}\text { Total coverage coefficient; } \\
\text { intermediate coverage coefficient; } \\
\text { absolute liquidity coefficient; } \\
\text { dynamics of coefficients }\end{array}$ & $\begin{array}{l}\text { F. №1 (annex 1, } \\
\text { National Statute } \\
\text { (Standard) of } \\
\text { Accounting 1) }\end{array}$ \\
\hline $\begin{array}{l}\text { Increasing of } \\
\text { business activity }\end{array}$ & $\begin{array}{l}\text { Assets turnover; turnover of accounts } \\
\text { receivable; turnover of accounts } \\
\text { payable; the ratio of payables and } \\
\text { receivables turnover; the dynamics of } \\
\text { turnover indices }\end{array}$ & $\begin{array}{l}\text { F. №1, f. №2 (annex } \\
\text { 1, National Statute } \\
\text { (Standard) of } \\
\text { Accounting 1); } \\
\text { f. № } 5 \text { «Notes } \\
\text { to the financial } \\
\text { statements» }\end{array}$ \\
\hline $\begin{array}{l}\text { Profitability } \\
\text { assurance }\end{array}$ & $\begin{array}{l}\text { The value and dynamics of net profit; } \\
\text { profitability of invested capital; } \\
\text { profitability of equity capital; the } \\
\text { dynamics of profitability indices }\end{array}$ & $\begin{array}{l}\text { F. №1, f. №2 (annex } \\
\text { 1, National Statute } \\
\text { (Standard) of } \\
\text { Accounting) }\end{array}$ \\
\hline Costs management & $\begin{array}{l}\text { Economic added value; a point of } \\
\text { strategic value destruction; the size } \\
\text { and growth rate of the net cash flow; } \\
\text { the rate of sustainable growth }\end{array}$ & $\begin{array}{l}\text { F. №1, f. №2 (annex } \\
\text { 1, National Statute } \\
\text { (Standard) of } \\
\text { Accounting); } \\
\text { f. № } 5 \text { «Notes } \\
\text { to the financial } \\
\text { statements»; } \\
\text { management } \\
\text { accounting materials }\end{array}$ \\
\hline
\end{tabular}

* - author's development; the methodology for indices calculating is presented in the works [284; 286-287].

1) solvency assurance, the lack or low level of which in the long-term perspective will lead to problems with repayment of debts and lack of sources of activity financing;

2) business activity increasing, which is considered one of the important reserves of financing needs reduction due to accelerated release of funds from turnover [288290];

3) profitability assurance, the negative or low level of which is evidence of low investment return and may lead to the withdrawal of business owners; 
4) business value management, which allows to reconcile the interests of owners and managers, to orientate themselves in making decisions on the criterion of increasing the value of invested capital, and always has strategic orientation through the time gap in the implementation of costs and obtaining real investment return.

It should be noted that such traditional indices for trade enterprises financial analysis as goods stocks turnover and goods turnover profitability are not included in the author's system of financial competences assessment because of their greater dependence on the development level of the potential operational component. And operational profit and goods turnover, and goods stocks are determined primarily by the operating conditions of trade enterprises: goods supply, its flexibility, the demand on range which is formed by operational managers, conditions of cooperation with suppliers, etc. Financial managers even at high level of competence haven't levers of influence on these indices, and therefore from our point of view it is incorrect to apply them during financial potential assessment.

Theoretical and methodological issues of complex assessment of financial potential of enterprises were considered in the works of domestic and foreign scientists I. Blank, H. Blakyta, P. Fomin, M. Starovoitov, S. Zenchenko, V. Berezhnoi, I. Yarotskyi, I. Yakovleva and others [284; 286; 291-300]. Despite the presence of certain interest of scientists in the problems of determining the generalized value (level) of financial potential, the needs of practice today are ahead of the scientific thought development in this issue.

In our opinion, the developments of I.O. Blank are the most methodologically weighed and consistent, who not only introduced the concept of «strategic financial position» into the scientific circle, but also proposed sequence of its definition, taking into account external financial opportunities, threats and internal financial potential [300]. With taking into account the achievements of I.O. Blank, it should be noted, however, that his financial potential vision is somewhat different from the author's position, which involves the allocation of resources and competencies. In addition, I.O. Blank does not specify the methods for financial potential components definition, but only notes the need for the use of matrix methods and provides the recommended form of the SWOT-matrix for their consideration although he proposes the possibility of attracting own and borrowed financial resources, successfully carrying out financial sanation in crisis situation, characteristics of the financial activity quality management as components of financial potential.

Numerous methodological approaches to the financial potential assessment of enterprises of various spheres of economic activity and regions which base on the use of integrated assessment methods are formulated in the works of I. V. Yarotskyi, S. V. Zenchenko, H. K. Dzhurabaieva, O. O. Chaliiev [293-294; 298; 301-302]. Although the composition of partial indices for constructing of generalizing integral indicator of the financial potential level in each of the approaches is different, but they all involve simulating the synthetic indicator with the help of measurement and standardization methods (on the base of standard or average values) or the additive model construction (with use of correlation or regression dependencies or ratings). Each of the author's approaches has limited scope of use because of the specificity of the research focus within which they were developed. 
From the point of practical application view, rating approach is characterized by the greatest specificity to the financial potential assessment of industrial enterprise; it is proposed in the works of P. Fomin, M. Starovoitov [284]. The authors propose for each coefficient, determine the high, average or low level of financial opportunities, and generalized assessment should be carried out expertly for taking away of boundary values of financial potential partial indices. In addition, the author's achievement, in our opinion, is an attempt to combine quantitative assessments of financial potential with qualitative characteristics of commercial reputation, which in total allows determining the enterprise's prospects for additional capital attracting. Despite a number of innovative and interesting ideas, the research [284] is aimed at solving the tasks of financial potential assessment without its connection with the objectives of enterprise development. Therefore, the results of such assessment, although develop methodological approaches to the study of the potential, but don't have direct connection with the formation of enterprise's adaptation management system.

In our opinion, it is advisable to systematize the methods, the use of which allows solving the problem of comprehensive assessment on the base of summarizing the experience about comprehensive assessment of the enterprise's financial potential which is accumulated by modern economic science. First of all, it should be noted that, according to the theory of economic analysis, all methods of integrated assessment are divided into descriptive and calculation [303]. Accepting the accepted approach, however, we consider that it is necessary to point out that the basic principle of such distribution is generalization method (linguistic or numerical), therefore, in order to adhere to the requirement of exhaustive classification, it is expedient to add to these two groups the group of graph-analytic methods which provide representation of the assessment results graphically.

Descriptive methods are based on the definition of the qualitative characteristics of the assessment object and are distinguished by subjectivity, blurred wording, and ambiguity in assigning the object to particular class. At the same time, they can be useful in the preliminary determination of strategic development priorities and their financial support. The application of the descriptive method during the financial potential assessment was developed in the research of P. Fomin, M. Starovoitov; they recommend determining the level of financial potential according to the scale «high medium - low» with use such linguistic features as the availability of profit as the results of enterprise's activity and stability of its financial state [284]. From our point of view, such features don't fully describe the available financial opportunities, since such assessment doesn't include the possibility of bank financing for development, competences of business value increasing through the implementation of financial strategy, etc.

In our view it is advisable to develop more detailed questionnaire, with unambiguous and independent of the respondent's perception answers for avoiding subjectivity during methodological approaches development on the base of descriptive method. With taking into account, for example, the characteristic of «financial state stability» it is impossible to determine it unambiguously, because the financial state itself is generalized characteristic, which in one direction (for example, solvency) can be defined as stable, and for another (for example, business activity) can be defined as variable. 
Calculating methods of integrated assessment base on quantitative indices and provide their generalization by constructing of additive, multiplicative, rating models. The study of possible approaches and the content of financial potential integrated assessment allows distinguishing of such calculation methods as rating (predominantly pointed method), distance method, integral method.

The pointed rating assessment of the financial potential is in conversion of actual values of the indices which characterize the state of financial resources and competencies to the points according to the defined assessment scale. In this case, range of changes and the scale corresponding to each interval must be defined for each index which is selected for the integrated system. Despite of use simplicity, pointed assessment requires grounded approach to the development of the assessment scale which must objectively describe the difference in the levels of indices. In our opinion, it is advisable to apply the method of fuzzy sets in the situation where it is difficult to uniquely determine which level of the indicator is considered high, middle and low with the corresponding points.

It is recommended to use the measurement and standardization methods, which, by their nature, are variants of the distance method for taking into account the differences in the indices of financial potential assessment of the region by the group of comparable objects in the works [293-296]. The basis of comparison under such conditions may be the group of average, minimum or maximum indices, the comparison with which of actual values allows taking into account the differences between them for different objects. From our point of view, both measurement and standardization for the purpose of the financial potential assessment of enterprise during the formation of the adaptation management system should not be based on comparison with the indices of similar enterprises (average group, maximum or minimum), but only on the comparison with the target (standard) their level. The distance from the standard allows formulating of the conclusion about certain level of financial potential of particular trade enterprise.

In our view, the integral method for carrying out of complex assessment of financial potential has subsidiary character and consists in aggregating of obtained by the distance method results by constructing integral (as a rule, additive) model. Such model, for example, in the work of I. V. Yarotskyi includes solvency, financial stability and profitability coefficients, which at the first stage are standardized by the meansquare deviation and at the second stage by use the «maximizing» criterion [299]. The obtained integral indices are proposed by the author to convert into percentage scale, where $100 \%$ means high level of financial potential. The close approach is described in the work of K. M. Khaustova, who, in addition to indices' standardizing according to the «maximizing» criterion, also proposes taking into account the tendentious nature of the indices' changes and calculate it by adding of additional points to the classical additive model with use Harrington point scale [304].

From our point of view, the unconditional advantage of the integral method is the visibility of the results and the possibility of taking into account large number of factors. At the same time, its application introduces increased requirements to selecting the maximum (minimum) values of the assessment indices, the overrated or understated level of which may lead to an inadequate assessment of the actual situation [278]. 
The graph-analytical methods can be used in addition to descriptive and calculation methods for the purposes of comprehensive assessment of the financial potential of trade enterprises; they require the construction of the assessment object profile on the base of actual data (or pointed assessments) and differ in the results visuality. In our opinion, the independence of this group of methods is debatable, since they cannot be applied without, firstly, grounded and calculated indices of financial potential, and, secondly, determined standard levels of indices.

The use of the matrix method is perspective, in our opinion, in the context of this study; this method receives the greatest popularity in the field of strategic analysis, and provides pairwise comparison of various criteria for financial potential assessment in terms of identifying the associated opportunities or threats. In our view, it is logical to consider matrix methods in the group of graph-analytic ones with taking into account the compulsory construction of the matrix, which is essentially the graphic model, and positioning in certain coordinate system. As it is noted above, such method of strategic financial position choosing is developed in the research of I.O. Blank [300], who proposes the construction of $3 \times 2$ matrix according to the criteria «the position of the internal (financial) environment - the impact of the financial (external) environment». In addition, H. V. Blakyta formulated quite interesting proposals for the use of matrix methods [291-292], but because of the innovative nature of ideas, this approach was considered predominantly at the theoretical level without specifying the definition of criteria and the scale of their possible assessments.

In our opinion, it should be noted that all of considered methods of financial potential integrated assessment during the trade enterprise's adaptive management system formation (table 3.4) have certain limitations and advantages and can not be applied as self-contained. Complexity of the assessment object requires the simultaneous application of several methods which provide the result which is the most relevant to the assessment objectives [278].

We propose scientific methodological approach on the based of the achievements of modern scholars and the results of studying the methodology of enterprise's financial potential assessment. This approach combines pointed, integral and matrix methods and allows, on the base of comparison of available financial resources and established financial competences, defining the vector of financial development of trade enterprises with taking into account possibilities and threats of the external financial environment. The content and sequence of the application of this approach are described in the following provisions (fig. 3.3):

1. Choosing of assessment indices of the financial potential of trade enterprises in the adaptive management system according to the criteria «availability of financial resources and their supporting with financing sources» and «level of financial competencies development».

We propose to include the index of financial resources availability share to the list of indices according to the criteria of financial resources availability in the resource potential value, the coefficient of financial resources supporting with equity working capital with taking into account that the main requirements for the selection of such indices are informality, avoidance of duplication, completeness of the description of the assessment object. 
Table 3.4

Methods of integrated assessment of trade enterprises financial potential

(author's development)

\begin{tabular}{|c|c|c|c|}
\hline Method & $\begin{array}{c}\text { Characteristics and range } \\
\text { of application }\end{array}$ & Advantages & Restrictions \\
\hline $\begin{array}{l}\text { 1. Descriptive } \\
\text { (expert) }\end{array}$ & $\begin{array}{l}\text { It allows obtaining of } \\
\text { qualitative characteristics } \\
\text { of financial potential; it is } \\
\text { appropriate under } \\
\text { strategic alternatives } \\
\text { choosing }\end{array}$ & $\begin{array}{l}\text { They can be used } \\
\text { in cases when it } \\
\text { is impossible to } \\
\text { get quantitative } \\
\text { assessments }\end{array}$ & $\begin{array}{l}\text { Subjectivity; } \\
\text { ambiguity of } \\
\text { assigning an } \\
\text { object to certain } \\
\text { class; lack of } \\
\text { clear fixation of } \\
\text { the result }\end{array}$ \\
\hline $\begin{array}{l}\text { 2. Calculating: } \\
\text { 2.1. Pointed } \\
\text { (rating) }\end{array}$ & $\begin{array}{l}\text { It assumes the use of the } \\
\text { point scales of assessment } \\
\text { and bases on quantitative } \\
\text { indices; It is expedient } \\
\text { during generalization of } \\
\text { various characteristics of } \\
\text { an object }\end{array}$ & $\begin{array}{l}\text { It allows bringing } \\
\text { different } \\
\text { measurement } \\
\text { scales to single } \\
\text { measurement } \\
\text { scale }\end{array}$ & $\begin{array}{l}\text { It doesn't take } \\
\text { into account } \\
\text { differentiation } \\
\text { in limiting values } \\
\text { indices; } \\
\text { subjectivity under } \\
\text { determining the } \\
\text { point scales }\end{array}$ \\
\hline $\begin{array}{l}\text { 2.2. Distance } \\
\text { method }\end{array}$ & $\begin{array}{l}\text { It assumes fixing of actual } \\
\text { values indices relative to } \\
\text { their standard level with } \\
\text { the subsequent } \\
\text { construction of additive } \\
\text { models; is used } \\
\text { in order to maximize the } \\
\text { differences in the level of } \\
\text { financial potential }\end{array}$ & $\begin{array}{l}\text { It is the most } \\
\text { formalized; } \\
\text { allows including } \\
\text { to the system of } \\
\text { indices of any } \\
\text { dimension and } \\
\text { orientation }\end{array}$ & $\begin{array}{l}\text { Complexity of } \\
\text { the standard level } \\
\text { determining; } \\
\text { indices with } \\
\text { larger variation of } \\
\text { values have a } \\
\text { greater impact on } \\
\text { the overall } \\
\text { assessment }\end{array}$ \\
\hline 2.3. Integral & $\begin{array}{l}\text { It is generalization of the } \\
\text { distance method and } \\
\text { construction of additive } \\
\text { model of financial } \\
\text { potential (according to } \\
\text { standard values of } \\
\text { indices); is used for } \\
\text { interim assessment results } \\
\text { aggregating }\end{array}$ & $\begin{array}{l}\text { It allows to get } \\
\text { clear assessment } \\
\text { of the financial } \\
\text { potential level }\end{array}$ & $\begin{array}{l}\text { Conclusions are } \\
\text { indicative; the } \\
\text { possibility of } \\
\text { obtaining } \\
\text { calculated high } \\
\text { level of financial } \\
\text { potential under } \\
\text { low level of } \\
\text { partial indices }\end{array}$ \\
\hline $\begin{array}{l}\text { 3. Graphologic } \\
\text { and analytic }\end{array}$ & $\begin{array}{l}\text { It assumes construction of } \\
\text { graphic model of financial } \\
\text { potential; it is used for the } \\
\text { visual synthesis of the } \\
\text { results of descriptive or } \\
\text { calculation methods }\end{array}$ & $\begin{array}{l}\text { Visibility of } \\
\text { results; allows } \\
\text { determining the } \\
\text { degree of } \\
\text { deviation from } \\
\text { the target state }\end{array}$ & $\begin{array}{l}\text { It is not } \\
\text { independent; has } \\
\text { low calculated } \\
\text { accuracy }\end{array}$ \\
\hline
\end{tabular}




\begin{tabular}{|c|c|c|c|}
\hline including matrix & $\begin{array}{l}\text { It assumes the } \\
\text { development of the } \\
\text { financial potential } \\
\text { assessments matrix } \\
\text { according to several } \\
\text { criteria; it is oriented to } \\
\text { determining of the } \\
\text { strategic financial position }\end{array}$ & $\begin{array}{l}\text { Possibility of } \\
\text { results } \\
\text { generalization } \\
\text { according to } \\
\text { different criteria; } \\
\text { perspective } \\
\text { orientation }\end{array}$ & $\begin{array}{l}\text { Subjectivity of } \\
\text { choice of } \\
\text { criterion limits } \\
\text { for assessment } \\
\text { results } \\
\text { classification }\end{array}$ \\
\hline
\end{tabular}




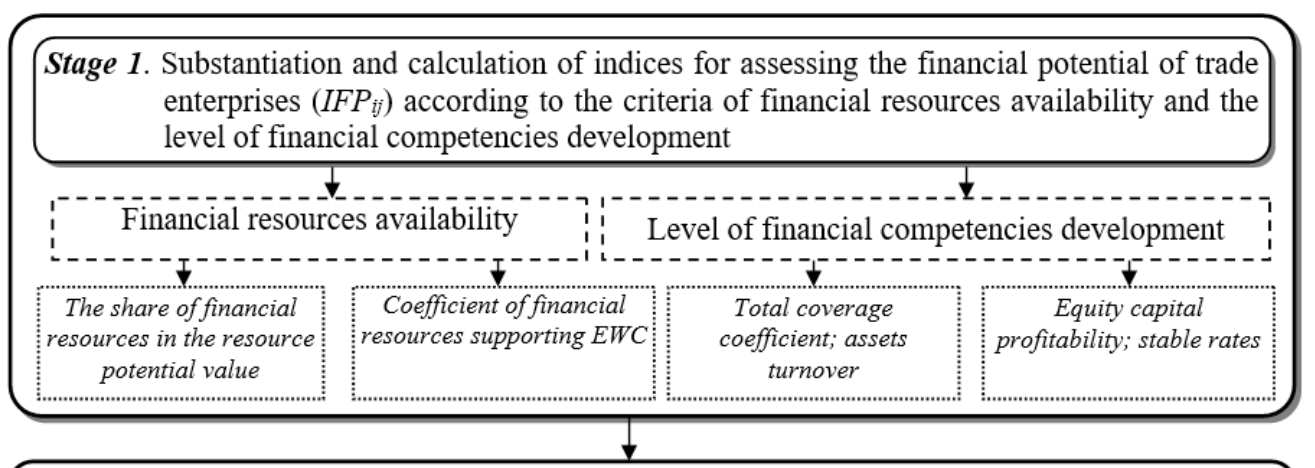

Stage 2. Substantiation of standard values of indices for trade enterprises' financial potential assessment (maximum $\left(I F P_{\max }\right)$ and minimal $\left.\left(I F P_{\min }\right)\right)$

Stage 3. Standardization of indices for trade enterprises' financial potential assessment with use of linear scaling:

$\mathrm{IFP}^{\prime}{ }_{\mathrm{ij}}=\frac{\mathrm{IFP}_{\mathrm{ij}}-\mathrm{IFP}_{\min j}}{\mathrm{IFP}_{\max \mathrm{j}}-\mathrm{IFP}_{\min j}}$, де IFP' ${ }_{i j}^{\prime}-$ standard value of $j$ indicator of financial potential assessment in $i$ period

Stage 4. Conversion of standardized indices to the pointed measurement system (pointed method) according to 10 -point scale: $B_{I F P} i j=\operatorname{IFP}^{\prime}{ }_{i j} \times 10$

Stage 5. Determination of integral indices of financial potential assessment $\left(I I_{F P}\right)$ according to the established criteria with use of the additive model: $\mathrm{II}_{\mathrm{FP}}=\sum_{\mathrm{j}=1}^{\mathrm{n}} \mathrm{B}_{\mathrm{IFP} \mathrm{ij}}$

Stage 6. Positioning of the obtained integral assessments in the matrix «availability of financial resources - the level of trade enterprises' financial competences development» for ranking the obtained assessments by the levels:

- low level of financial potential $-B_{\min } \leq I_{F P} \leq \mathrm{B}_{1}$, (де $\left.\mathrm{B}_{1}=\mathrm{B}_{\min }+B_{a v}\right)$;

- average level of financial potential $-\mathrm{B}_{1} \leq I_{F P} \leq \mathrm{B}_{2}$ (де $\mathrm{B}_{2}=\mathrm{B}_{1}+B_{a v}$ );

- high level of financial potential $-\mathrm{B}_{2} \leq I_{F P} \leq \mathrm{B}_{\max }\left(\right.$ де $\left.\mathrm{B}_{\max }=\mathrm{B}_{2}+B_{a v}\right)$.

Figure 3.3. Structural and logical sequence of trade enterprise's financial potential assessment in the adaptation management system (author's development)

We proposed to choose for quantify assessment of the financial potential according to the criterion «level of financial competencies development» the general coverage coefficient (which is more informative in terms of strategic perspective than the intermediate coefficient of coverage or the absolute liquidity coefficient); the 
coefficient of assets turnover (which, on the one hand, generalizes competencies in order to increase the efficiency of investment, and on the other allows to determine the strategic reserves of the financial resources releasing); profitability equity capital (as the index of internal investment opportunities); the steady growth for internal sources cost (as the index of the increasing potential of invested capital value for internal sources cost).

It should be noted that important indices such as economic added value and point of value strategic degradation are not included in the integrated assessment system due to the impossibility of identifying single standard which should be the base of comparison. Meanwhile, if the enterprise implements the cost management system, it must monitor such indices and their target values will be determined separately for each enterprise by their financial management.

2. Substantiation of the standard values for each selected index of the financial potential of trade enterprises. Typically, in the practice of economic analysis and integrated assessment, minimum, maximum or medium-scale indices are used as such standard values. With taken into account that the financial potential value is function of the available financial resources and the level of financial competences development, we propose to consider that the standard level is the maximum values of selected indices. It is necessary to determine the minimum level of the indicator for identification of approximation degree to the maximum value.

If mathematically, there are no difficulties here, then from an economic point of view, the definition of such maximizing values is ambiguous. The author's suggestions on their choice and the logic of their substantiation are as follows:

- $\quad$ since the higher cost of financial resources unambiguously indicates powerful financial potential, the maximum value of the share of financial resources in the total cost of resource potential can be taken at the level of $100 \%$, respectively, the minimum $-0 \%$. Although such maximum exists only theoretically, it does not rule out the informality of its comparison with the actual values of the coefficients. Choosing as the maximum of medium-sized values or values which are sufficient in terms of management (for example, $40-50 \%$ ) will not provide realistic assessment of the resource component capacity of financial opportunities;

- the coefficient of financial resources support with its equity working capital is significantly dependent on the cost of financial resources, under decreasing of which the actual value of the coefficient may acquire any absolute values. That is why, in our opinion, it is advisable during determining its standard value, to rely not on the retail trade practice (according to the results of the previous study), but on the values of related coefficients of the availability of equity working capital of reserves and in general liquid assets which are recommended by the normative documents and scientists [305]. In accordance with the Regulation of the procedure for conducting an analysis of the financial condition of enterprises which are subjects of privatization, the recommended value of the support coefficient of liquid assets should be not less than 0,1 [289; 306], and according to researches of scientists, the marginal value of coefficient of financial resources providing is 0,6 [289; 305-306]. With taking into account that the valuation of financial resources (excluding long-term financial investments) is equal to the difference between liquid assets and stock value, 
the recommended level of financial resources availability (with use of mathematical reductions) should be not less than 0,12 . It is logical that the minimum level of the index in the presence of own equity working capital should be 0 , and under its absence this index will be equal to the actual value of the coefficient at the enterprise;

- in our view it is advisable to recommend as standard (maximum) the total coverage coefficient value at the level of 1,5 , which corresponds to the requirements to the equity working capital availability and sufficient level of solvency of retail trade enterprises with taking into account that below recommended value of the total coverage coefficient is 1 [305]. The theoretical minimum limit of the coefficient is 0 if there are no liquid assets at the enterprise at the time of assessment. Of course, it's hard to imagine such situation in practice, therefore, we accept the minimum limit of the coefficient at the level of 0,1 for calculations on the base of existing practice in the industry (for example, the coverage coefficient value is decreased to 0,12 for some periods for selection retail trade enterprises which are studied in the previous chapters of this work);

- the assets turnover coefficient, as a rule, is not included in the list of indices for which normative values are developed at the state level, since its value essentially depends on the sphere of enterprise's activity. With taking into account that the index increasing is considered the best, its maximum level at the enterprise of retail trade for $3-5$ preceding periods can be accepted as standard. If this maximum level is lower than the average industry value, then the maximum can be taken as the average industry index. The minimum limit of the coefficient of assets turnover is selected on the base of the results of business activity retrospective study;

- in accordance with the normative documents, the marginal value of the equity capital profitability is its positive level, which indicates the effective use of owners' capital. From another point of view, it is not enough to get net profit for owners' stimulation; it is necessary to provide profitability, more than under alternative ways of own capital investing. Therefore, from our point of view, the bank interest rate on deposit contributions can be considered as the standard level equity capital profitability. The minimum level of profitability, in our opinion, for enterprises with positive its value should be taken at zero level, and for unprofitable enterprises - at the level of its actual value;

- the rate of sustainable growth is computational value which is determined by the reinvestment policy, operating profitability, assets turnover and the structure of trade enterprise capital. Therefore, its maximum value depends on the accepted standard levels of the variables which describe it. For example, the maximum value of the reinvestment coefficient in any case is 1 , the standard level of turnover assets is 3 , profitability is $10 \%$, the coefficient of dependence is 0,5 . Under such conditions, the maximum (standard) value of the rate of sustainable growth is $17,6 \%$, which is determined by the following formula: 


$$
\mathrm{q}=\frac{\mathrm{r} \times \mathrm{C}_{\mathrm{op}} \times \mathrm{C}_{\mathrm{ta}} \times \mathrm{C}_{\mathrm{d}}}{1-\mathrm{r} \times \mathrm{C}_{\mathrm{op}} \times \mathrm{C}_{\mathrm{ta}} \times \mathrm{C}_{\mathrm{d}}}
$$

where $\mathrm{q}$ - the coefficient of sustainable growth rates providing through internal reserves;

$\mathrm{r}$ - profit reinvestment coefficient;

Cop - operational profitability coefficient (it is calculated on the base of net profit);

$\mathrm{Cta}$ - assets turnover coefficient;

$\mathrm{Cd}$ - financial dependence coefficient.

Therefore, it is impossible to establish integrated recommended value of the sustainable growth rate with taking into account of the individual peculiarities of business activity and operational profitability of trade enterprises. We propose to take the minimum limit for the sustainable growth rate for enterprises with internal reserves at zero level (for other cases, the calculation of such rates does not make sense).

3. Standardization of indices for the financial potential of retail trade enterprises assessment with use of linear scale method for indices, the trend of which desired changes has rising nature:

$$
\mathrm{IFP}_{\mathrm{ij}}^{\prime}=\frac{\mathrm{IFP}_{\mathrm{ij}}-\mathrm{IFP}_{\min \mathrm{j}}}{\mathrm{IFP}_{\operatorname{maxj}}-\mathrm{IFP}_{\min \mathrm{j}}}
$$

where IFP' $\mathrm{ij}$ - standardized value of $\mathrm{j}$ indicator of financial potential assessment in the i period;

IFPij - actual value of $\mathrm{j}$ indicator of financial potential assessment in the i period;

IFPmaxj, IFPminj - respectively, maximum and minimum values of $j$ indicator of financial potential assessment in the i period.

4. Conversion of standardized indices to point measurement system (pointed method) according to 10-point scale:

$$
\mathrm{BIFPij}=\mathrm{IFP}^{\prime} \mathrm{ij} \times 10,
$$

where BIFPij - pointed assessment of $\mathrm{j}$ indicator of financial potential assessment in the i period.

5. Integral indices determining of financial potential assessment (IIFP) according to established criteria with the additive model use: 


$$
\mathrm{II}_{\mathrm{FP}}=\sum_{\mathrm{j}=1}^{\mathrm{n}} \mathrm{B}_{\mathrm{IFPij}}
$$

6. Positioning of the obtained integral assessments in the matrix «financial resources availability - level of financial competencies development», which allows making approximate choice of the strategic position of trade enterprise in the adaptation management system with taking into account of internal financial forces and weaknesses.

For construction such matrix, we propose to rank the value of integral indices at intervals «high», «average» and «low» level with use of the scale:

$$
\mathrm{B}_{\mathrm{av}}=\frac{\mathrm{B}_{\max }-\mathrm{B}_{\min }}{3},
$$

where $B_{a v}, B_{\max }, B_{\min }-$ respectively, the average (assessment range), the maximum and minimum number of points.

Accordingly, the linguistic characteristics of the obtained point assessment ranges have the following form:

low level of financial potential according to $k$ criterion - the value of the integral index is in the range $B_{\text {min }} \leq \mathrm{II}_{\mathrm{FP}} \leq \mathrm{B}_{1}$, (where $\left.\mathrm{B}_{1}=\mathrm{B}_{\text {min }}+B_{a v}\right)$;

average level of financial potential according to $k$ criterion - the value of the integral index is in the range $\mathrm{B}_{1} \leq \mathrm{II}_{\mathrm{FP}} \leq \mathrm{B}_{2}$ (where $\mathrm{B}_{2}=\mathrm{B}_{1}+B_{a v}$ );

high level of financial potential according to $k$ criterion - the value of the integral index is in the range $\mathrm{B}_{2} \leq \mathrm{II}_{\mathrm{FP}} \leq \mathrm{B}_{\max }$ (where $B_{\max }=\mathrm{B}_{2}+B_{a v}$ ).

We select two indices of financial potential assessment according to the criterion of financial resources availability (the proportion of financial resources and their availability with equity working capital), the maximum number of points is equal to 20 ; according to the criterion of the level of financial competences development the maximum possible number of points is 40 (because of 4 assessment indices are taken into account during calculation). The matrix of strategic position choosing of trade enterprise on the based of financial potential assessment in the adaptation management system is presented in Figure 3.4. 


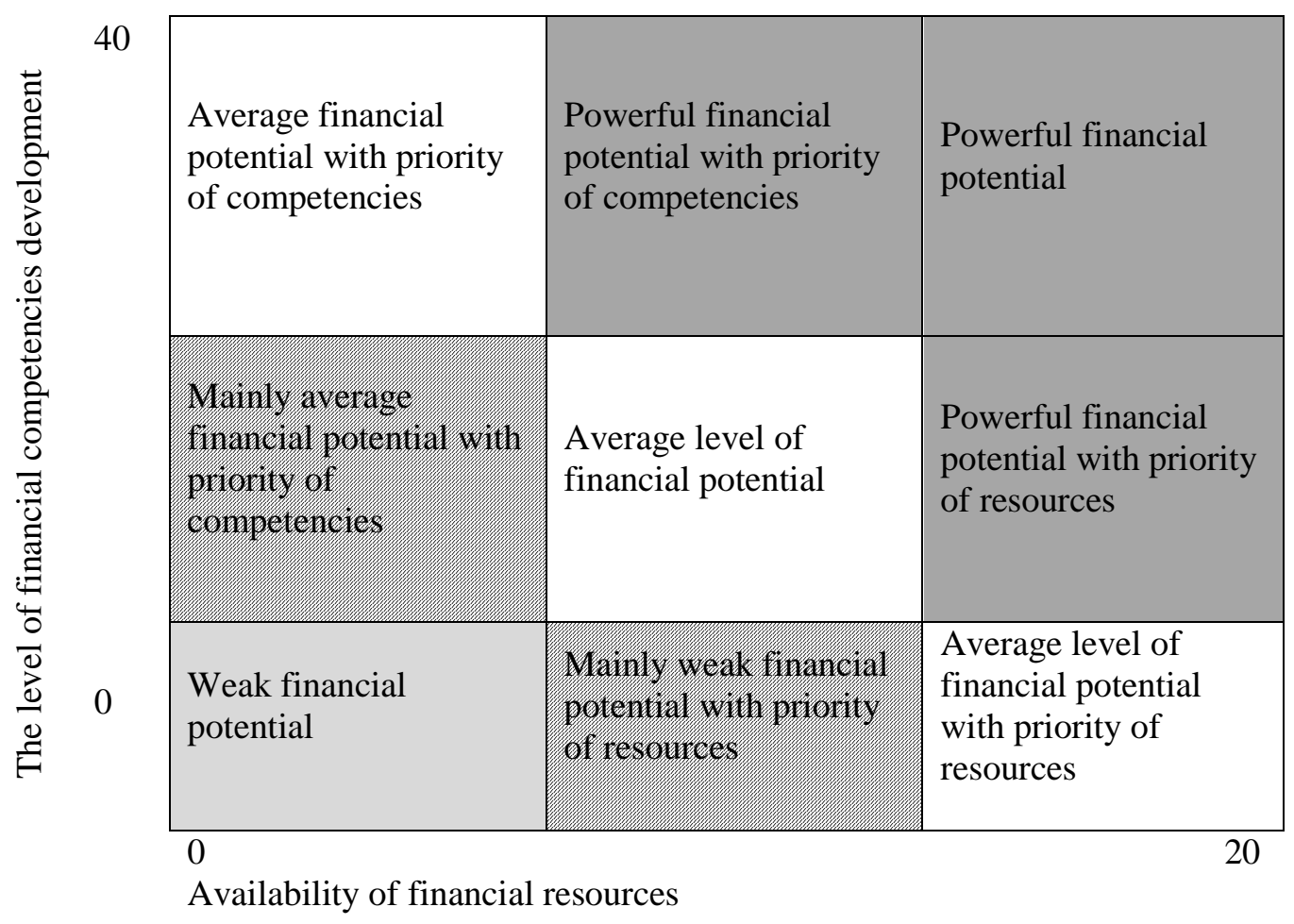

Figure 3.4. The matrix of trade enterprise's strategic position choosing in the
adaptation management system on the base of financial potential (author's development)

Thus, the proposed scientific and methodical approach to trade enterprise financial potential assessment under the adaptation management system formation has the basis of the formed at the enterprise financial potential, provides use of a number of integrated assessment methods and allows determining the vector of financial development of enterprises with taking into account the possibilities and threats of the external environment, on the base of comparison of available financial resources and existing financial competencies. 


\section{Conclusions to chapter 3}

1. Competition between enterprises is the main driving force of market economy. Market competition is objective law of the modern economy, which is expressed in the struggle of sellers of goods and services for economically advantageous conditions of economic activity and sales of goods for meeting the needs of consumers, obtaining the greatest profits and strengthening their market positions. Competitive relations are characterized by double: it is constant competitiveness in the markets, and the need to compete, which is base for the economy development. The double essence of competition manifests in the most important characteristic - competitiveness. There is need for the development of methodical methods for integrated assessment of the competitiveness potential and trade enterprises financial potential with taking into account that one of the criteria for the adaptation of trade enterprises is the level of their competitiveness potential, and the other is the level of enterprise's financial potential.

2. Taking into account that the current business environment of the trade enterprises' activity is characterized by high dynamism and competition, the search for ways of increasing the competitiveness of trade enterprises is becoming one of the key problems of economic entities in the adaptive management system formation. Taking into account the necessity of quantify assessment of the trade enterprises competitiveness, the system of indices for assessment of its individual components (technical, technological, commercial, marketing, client and entrepreneurial), which meets the requirements of complexity, sufficiency, consistency and sectoral specificity is developed.

3. The expediency of use the pointed method for comprehensive integrated assessment of the level of trade enterprise competitiveness potential implementation is substantiated. The application of the proposed approach in the trade enterprises allows determining of the main competitors and the place of competitiveness potential of each enterprise in the competition, as well as quantifies the lagging behind the enterprise with the highest level of competitiveness potential.

4. Important trend of the adaptive management system formation of trade enterprises is the assessment of the financial potential of enterprises in the sector, which is proposed to implement according to two aspects: determining the availability and adequacy of financial resources; analysis of the level of financial competencies development. The system of indices was developed for studying the state of financial resources availability. The main components of the financial competencies of the trade enterprises which should be taken into account during the adaptation management system formation are the competences for solvency providing, business activity and profitability increasing, cost management competences. The system of assessment indices is proposed for determining of their level in the industry.

5. As the development of the methodology of the trade enterprises adaptive management system the scientific methodological approach which combines the pointed method, the method of linear scaling, integral and matrix methods is developed. It allows on the base of positioning of enterprises in the matrix «the financial resources availability - the level of financial competences development» determining their level 
of the financial potential, the coordination of which with the opportunities and threats of the external financial environment can ground the priority vector of development in the adaptation management system of industry enterprises. 


\section{CONCLUSIONS}

1. Key accents about the interpretation of enterprise adaptation essence are established according to the results of the existing approaches study to the definition of enterprise adaptation, and its definition is formulated as systematic process of the enterprise's adaptation to the variability of environmental conditions, which is implemented through the set of targeted adaptation measures and changes (reactions), has strategic character, accompanies the entire life cycle of the enterprise and aims at providing the efficiency of its operation and development.

2. Taking into account the modern requirements and content of the management process, the basic principles of the trade enterprises' adaptation management are formulated and it is determined that the main among them are the principles of uniform structural integrity, permanence, differentiation of strategic and tactical levels of adaptation management, organizational planning, economic efficiency, professional competence, hierarchical subordination and the formation of corporate culture management of the enterprise's adaptation. Structural and logical scheme of trade enterprise adaptation management at the strategic and operational and tactical levels is developed for providing of adaptation management effectiveness and achievement of trade enterprise's stable functioning.

3. The peculiarities of the adaptation strategy are determined on the based of the study of strategic management theory genesis and the results of the approaches' analysis to the «strategy» concept interpretation. It is proposed to understand under which the combination of the planned goals, actions and solutions of long-term and short-term nature according to enterprise adaptation to new opportunities of competitive advantages obtaining and new threats of its competitive position weakening in the existing business environment.The adaptation strategic direction is providing the viability and efficiency of the operation of the enterprise in the long-term perspective on the base of dynamic balance with the business environment with taking into account the essential characteristics of the adaptation strategy. The system of goals and objects of the adaptation strategy is developed; it gives comprehensive idea of the directions of adaptation solutions adoption and is the base for determining the complex of measures for influencing on the adaptive management objects.

4. The model of the integrated system of trade enterprises adaptive management is substantiated: it creates the conceptual preconditions of the adaptation management system development, and it is the only ordered set of elements and actions which form the self-contained management system. The model of the organizational and economic mechanism of the adaptive management system is developed in compliance with the conceptual principles of adaptive management which are grounded by its properties and scope, as well as the principles of construction and functioning of the adaptive management system. The scientific base of the development's grounds is on the combination of systematic, functional, process, integration, marketing, dynamic and 
integrated approaches and it provides the efficiency of implementation of the adaptive management system.

5. The task of the enterprise's adaptation in dynamic external conditions is the formation of flexible management system which is able to self-organization and restructuring. The developed structure of the organizational and economic mechanism of trade enterprises' adaptive management is hierarchy of circulation circuits and information transformations during the process of management concept implementation and is able to adapt to specific organizational and legal forms, types of economic activity and enterprises' specifics. Implementation of it in to the practice of trade enterprises provides survival, stability, efficiency of functioning, improves the macroeconomic status and ensures of macroeconomic stability.

6. Adaptive management is effective and resulting under systematical monitoring of «weak signals» of the destabilizing influence of external environment and immediate, adequate response to these signals. The use of management methods according to «weak signals» in the system of adaptive management of trade enterprises is aimed at the rapid response to the dangerous changing realities of the market, and also allows organizational, financial and psychological preparation of enterprises to their perceiving.

7. Scientific and practical recommendations for the complex of calculation and analytical tools for the trade enterprises' adaptive management system formation are substantiated on the base of the study of scientific research conducting methods. It is recommended to use modern management tools: proactive management, balanced system of operational efficiency indices, benchmarking, customer relationship management, time savings, growth strategies, knowledge management, analysis of opportunities for changing market trends, business processes reengineering, scenario planning, etc. for increasing the effectiveness of analytical procedures of adaptation management.

8. Competition between enterprises is the main driving force of market economy. Market competition is objective law of the modern economy, which is expressed in the struggle of sellers of goods and services for economically advantageous conditions of economic activity and sales of goods for meeting the needs of consumers, obtaining the greatest profits and strengthening their market positions. Competitive relations are characterized by double: it is constant competitiveness in the markets, and the need to compete, which is base for the economy development. The double essence of competition manifests in the most important characteristic - competitiveness. There is need for the development of methodical methods for integrated assessment of the competitiveness potential and trade enterprises financial potential with taking into account that one of the criteria for the adaptation of trade enterprises is the level of their competitiveness potential, and the other is the level of enterprise's financial potential.

9. The system of indices for assessment of competitiveness potential components, which meets the requirements of complexity, sufficiency, consistency and sectoral specificity is developed with taking into account the necessity of quantify assessment of the trade enterprises' competitiveness in the adaptive management system of trade sector enterprises. The expediency of use the pointed method for comprehensive integrated assessment of the level of trade enterprise competitiveness potential implementation is substantiated. The application of the proposed approach in the trade enterprises allows determining of the main competitors and the place of 
competitiveness potential of each enterprise in the competition, as well as quantifies the lagging behind the enterprise with the highest level of competitiveness potential as the base for the trade enterprises' adaptive management system formation.

10. The analytical system of indices for financial resources availability assessment and their financing sources supporting is elaborated for developing the methodology for financial potential assessment in the trade enterprises' adaptive management system. Study of the competence of trade enterprises' financial potential component is proposed according to 4 spheres of financial competences (solvency, business activity increasing, profitability and cost management providing). The system of analytical indices of the competences' development level is elaborated for each sphere of competences.

11. It is proved that solving the problem of strategic position choosing in the system of adaptive management of trade enterprises requires obtaining of general characteristic (value) of financial opportunities with the use of integrated assessment methods, the systematization of which, by generalization, allows forming of the portfolio of methods (descriptive, computational and graph-analytic), determining the scope of their application, benefits and limitations. As the development of the methodology of the trade enterprises adaptive management system the scientific methodological approach which combines the pointed method, the method of linear scaling, integral and matrix methods is developed. It allows on the base of positioning of enterprises in the matrix «the financial resources availability - the level of financial competences development» determining their level of the financial potential. 


\section{APPENDICES}




\section{APPENDIX A}

Table A.1

Systematization of the definitions of the economic category "adaptation of the enterprise" the main key points in the writings of scientists (developed by the author on the basis of [11-33; 41; 47; 52-67])

\begin{tabular}{|c|c|c|}
\hline Author & Definition & Reference \\
\hline 1 & 2 & 3 \\
\hline \multicolumn{3}{|c|}{ Adaptation of the enterprise as a process } \\
\hline Rastryhin L.A. & $\begin{array}{l}\text { The process of purposeful change of parameters and } \\
\text { structure of the system in order to determine the } \\
\text { criteria for its effective functioning }\end{array}$ & {$[53$, p. 127] } \\
\hline Tsypkin Ya.Z. & $\begin{array}{l}\text { The process of changing the parameters and structure } \\
\text { of the system, and possibly of managerial actions on } \\
\text { the basis of current information for the achievement } \\
\text { of a certain, usually optimal, state of the system } \\
\text { under initial uncertainty and changing conditions. }\end{array}$ & {$[61$, p. 58] } \\
\hline Chyzhenkova Ye.V. & $\begin{array}{l}\text { The process of adjusting parameters of the enterprise } \\
\text { to uncertain environmental conditions, which ensures } \\
\text { an increase in the efficiency of its operation } \\
\text { throughout its life cycle. }\end{array}$ & {$[11$, p. 5$]$} \\
\hline Biloshkurska N. V. & $\begin{array}{l}\text { The process of adapting the enterprise and its } \\
\text { activities to the external environment, and effective } \\
\text { use of its production potential }\end{array}$ & {$[23$, p. 102] } \\
\hline $\begin{array}{l}\text { Kozachenko G. V., } \\
\text { Ponomaryov V. P., } \\
\text { Lyashenko A. N. }\end{array}$ & $\begin{array}{l}\text { The process of purposeful change of parameters, } \\
\text { structure and properties of any object in response to } \\
\text { changes occurring both in the external environment } \\
\text { of the object's activity and inside it }\end{array}$ & {$[24$, p. 176] } \\
\hline $\begin{array}{l}\text { Yachmenyova V. } \\
\text { M., Osmanova Z. O. }\end{array}$ & $\begin{array}{l}\text { The process of adapting the parameters of economic } \\
\text { entities and systems in general to new, uncertain } \\
\text { conditions of the environment, which provides an } \\
\text { increase in the efficiency of their functioning }\end{array}$ & {$[54$, p. 350] } \\
\hline Melnyk A. O. & $\begin{array}{l}\text { Management process aimed at developing and } \\
\text { implementing a system of anti-crisis measures that } \\
\text { would ensure effective operation of the enterprise in a } \\
\text { crisis management process, aimed at developing and } \\
\text { implementing a system of anti-crisis measures that } \\
\text { would ensure ffective operation of the enterprise in a }\end{array}$ & {$[25$, p. 32] } \\
\hline
\end{tabular}




\begin{tabular}{|c|c|c|}
\hline & crisis & \\
\hline $\begin{array}{l}\text { Minko I. S., } \\
\text { Shamina L. K. }\end{array}$ & $\begin{array}{l}\text { The process of forced adaptation of an enterprise to } \\
\text { changes in the conditions of its existence that can } \\
\text { occur in the external (at macro and micro levels) and } \\
\text { in the internal environment of the enterprise }\end{array}$ & {$[12$, p. 15] } \\
\hline Kulikov P. M. & $\begin{array}{l}\text { The process of the system adaptation to the } \\
\text { variability of the environment, which accompanies } \\
\text { the entire life cycle of the enterprise }\end{array}$ & {$[26$, p. 56] } \\
\hline Markovska O. I. & $\begin{array}{l}\text { The process of adapting economic system to the } \\
\text { changes that arise in the external and internal } \\
\text { environment of its functioning, through the } \\
\text { development of special adaptation mechanisms }\end{array}$ & {$[35$, p. 64] } \\
\hline Otenko I. P. & $\begin{array}{l}\text { The process of adapting the enterprises' parameters to } \\
\text { changing environmental conditions, aimed at } \\
\text { increasing the level of efficiency and stability of } \\
\text { activity throughout its life cycle }\end{array}$ & {$[64$, p. 86] } \\
\hline $\begin{array}{l}\text { Kovalenko N. V., } \\
\text { Hontova N. V. }\end{array}$ & $\begin{array}{l}\text { Continuous process of purposeful structural and } \\
\text { functional adaptation of the enterprise to the } \\
\text { conditions of existence, which are formed under the } \\
\text { influence of factors of the external and internal } \\
\text { environment, manifested through the set of adaptive } \\
\text { responses (adaptation changes) of the enterprise in } \\
\text { response to the impact on it. }\end{array}$ & {$[41$, p. 151] } \\
\hline Pastukhova Ye. A. & $\begin{array}{l}\text { The process of adapting the economic system, its } \\
\text { subsystems and individual elements to changing } \\
\text { conditions of the external or internal environment in } \\
\text { order to ensure survival of the system, providing } \\
\text { stability and establishing dynamic equilibrium } \\
\text { between the system and the environment. }\end{array}$ & {$[13$, p. 79$]$} \\
\hline $\begin{array}{l}\text { Turylo A. M., } \\
\text { Bohachevska K. V. }\end{array}$ & $\begin{array}{l}\text { The process of adapting the enterprise to the } \\
\text { conditions of the external and internal environment, } \\
\text { based on the assessment of all subjective and } \\
\text { objective factors of enterprise development, aimed at } \\
\text { ensuring its strategic competitive functioning. }\end{array}$ & {$[23$, p. 30] } \\
\hline \multicolumn{3}{|c|}{ Adaptation of the enterprise as a capability } \\
\hline Krysko Zh. L. & $\begin{array}{l}\text { Ability to make adequate changes in time to correct } \\
\text { the enterprise activities according to the } \\
\text { requirements of the environment. }\end{array}$ & {$[27$, p. 38] } \\
\hline Popova L. F. & $\begin{array}{l}\text { Ability of the system to adapt to changing } \\
\text { environmental conditions, interfering from the } \\
\text { environment and affect the system. }\end{array}$ & {$[55$, p. 67] } \\
\hline
\end{tabular}




\begin{tabular}{|c|c|c|}
\hline $\begin{array}{l}\text { Postolova M. A., } \\
\text { Hryaznova N. L. }\end{array}$ & $\begin{array}{l}\text { Ability of the system to detect purposeful adapted } \\
\text { behavior in complex environments. }\end{array}$ & {$[56$, p. 65] } \\
\hline Tymokhyn V. N. & $\begin{array}{l}\text { Ability of the system in the development process to } \\
\text { maintain essential parameters unchanged in certain } \\
\text { limits of their variation, despite the variety of } \\
\text { environmental actions. }\end{array}$ & {$[28$, p. 172] } \\
\hline Dorofeeva V. V. & $\begin{array}{l}\text { Ability of the enterprise to adapt to the variability of } \\
\text { the external environment to ensure survival, stable } \\
\text { position of the enterprise in the market, achieve } \\
\text { sustainable development. }\end{array}$ & {$[63$, p. 280] } \\
\hline \multicolumn{3}{|c|}{ Adaptation of the enterprise as an activity } \\
\hline Benyk N.G. & $\begin{array}{l}\text { Adequate formation of the company's activities aimed } \\
\text { at improving its competitiveness in the future when } \\
\text { changing the competitive environment. }\end{array}$ & {$[58$, p. 3] } \\
\hline Alekseev S. B. & $\begin{array}{l}\text { Development and implementation of actions aimed at } \\
\text { changing the internal environment of the enterprise in } \\
\text { accordance with the requirements of the environment. }\end{array}$ & {$[14$, p. 6$]$} \\
\hline Shershnyova Z.Ye. & $\begin{array}{l}\text { Realization of new methods of production and } \\
\text { financial activity of the enterprise in the external } \\
\text { environment. }\end{array}$ & {$[57$, p. 238] } \\
\hline Demyaova O. V. & $\begin{array}{l}\text { The totality of actions aimed at adapting the } \\
\text { enterprise to changes in environmental factors based } \\
\text { on the use of available resources for the prevention of } \\
\text { the deterioration of the results of its activities, } \\
\text { development and improvement. }\end{array}$ & {$[16$, p. 74$]$} \\
\hline Kucherenko O. O. & $\begin{array}{l}\text { Ordered in some way toltality of changes made to the } \\
\text { strategy of the enterprise development and internal } \\
\text { systems of its activities, the implementation of which } \\
\text { provides an effective business in a changed } \\
\text { environment. }\end{array}$ & {$[31$, p. 67] } \\
\hline Sokolova L. V. & $\begin{array}{l}\text { Bringing the enterprise possibilities in compliance } \\
\text { with changes in the business environment in order to } \\
\text { ensure the efficiency of life and sustainable } \\
\text { development, justifying expectations of its owners } \\
\text { regarding the growth of market value of business and } \\
\text { improving the quality of life of its employees. }\end{array}$ & {$[65$, p. 10] } \\
\hline Lushchikov Yu. A. & $\begin{array}{l}\text { A certain direction of the economic activity of the } \\
\text { enterprise, which is to find and implement measures } \\
\text { that are adequate to changes in the sphere of }\end{array}$ & {$[66$, p. 8] } \\
\hline
\end{tabular}




\begin{tabular}{|c|c|c|}
\hline & $\begin{array}{l}\text { exchange, that is, market conditions, and the } \\
\text { directions of the state economic policy, for obtaining } \\
\text { sufficient profit for simple and expanded } \\
\text { reproduction. }\end{array}$ & \\
\hline Wou Thieu Zang & $\begin{array}{l}\text { Changes in the activities of an enterprise related to } \\
\text { the objectives of the activity or tactics of their } \\
\text { achievement, accompanied by changes in the internal } \\
\text { systems and units of the enterprise in response to } \\
\text { changes in the environment. }\end{array}$ & {$[67$, p. 9] } \\
\hline \multicolumn{3}{|c|}{ Adaptation of the enterprise as a phenomenon (reaction) } \\
\hline Akoff R. L. & $\begin{array}{l}\text { Reaction to changing conditions that counteract } \\
\text { actual or possible decrease in the effectiveness of } \\
\text { system behavior; system feedback that prevents its } \\
\text { weakening. Changes may be internal or external. }\end{array}$ & {$[59$, p. 139] } \\
\hline $\begin{array}{l}\text { Econoic } \\
\text { Encyclopedic } \\
\text { Dictionary }\end{array}$ & $\begin{array}{l}\text { Adaptation of the economic system and its individual } \\
\text { subjects, workers to the conditions of the changing } \\
\text { environment, production, labor, exchange, life needs } \\
\text { of the population. }\end{array}$ & {$[60$, p. 43] } \\
\hline $\begin{array}{l}\text { Tsarehorodtsev G. I., } \\
\text { Georgiyevskii O. } \\
\text { Petlenko V. P., } \\
\text { Sahno A. V. }\end{array}$ & $\begin{array}{l}\text { An integral set of system reactions, which is the basis } \\
\text { of the mechanism of its adaptation to changing } \\
\text { environment and aims not only to maintain dynamic } \\
\text { equilibrium of the system in these environmental } \\
\text { conditions, but also provide the possibility of the } \\
\text { system evolution when they are changed. }\end{array}$ & $\begin{array}{l}{[47, \mathrm{p} .42-} \\
43]\end{array}$ \\
\hline $\begin{array}{l}\text { Kulyk N. M., } \\
\text { Sokolenko T. M. }\end{array}$ & $\begin{array}{l}\text { Adoption of the changes in the socio-economic } \\
\text { environment and interaction with them that leads to } \\
\text { the coordination of interests of both parties. }\end{array}$ & {$[30$, p. 99] } \\
\hline Hrechko M. V. & $\begin{array}{l}\text { Adaptation of the system to change conditions, that } \\
\text { is, the reaction of the system to external disturbances. }\end{array}$ & {$[18$, p. 20] } \\
\hline Vynohradsky S.B. & $\begin{array}{l}\text { Reaction of the system to changes of the activity } \\
\text { conditions, which counteracts the existing or possible } \\
\text { decrease in the efficiency of the system functioning. }\end{array}$ & {$[33$, p. 7] } \\
\hline Kapitanets Yu. O. & $\begin{array}{l}\text { The form of enterprise development, characterized by } \\
\text { rapid response and flexible adaptation of internal } \\
\text { capabilities of the enterprise to future changes in the } \\
\text { external environment of its functioning. }\end{array}$ & {$[29$, p. 11] } \\
\hline Dubchak V. V. & $\begin{array}{l}\text { Type of interaction between the entity or a group of } \\
\text { entities with socio-economic environment in which } \\
\text { the requirements are met for the expectations of its } \\
\text { participants. }\end{array}$ & {$[20$, p. 7] } \\
\hline $\begin{array}{l}\text { Halushko Ye. S., } \\
\text { Halushko S. A., } \\
\text { Lopatiev P. S. }\end{array}$ & $\begin{array}{l}\text { Comprehensive phenomenon of the company's } \\
\text { response to changes in the internal and external } \\
\text { environment for the achievement of the cascade of } \\
\text { goals. }\end{array}$ & {$[21$, p. 247] } \\
\hline
\end{tabular}




\begin{tabular}{|c|c|c|}
\hline Pashnyuk L. O. & $\begin{array}{l}\text { Complex phenomenon that includes the variety of } \\
\text { conditions that a system can adapt to; and the ability to } \\
\text { survive, that is, strength of the system, which is to } \\
\text { preserve certain stable characteristics during the } \\
\text { restructuring; and directly the process of adaptation. }\end{array}$ & {$[22$, p. 79] } \\
\hline $\begin{array}{l}\text { Mamiy Ye. A., } \\
\text { baryshev V. A. }\end{array}$ & $\begin{array}{l}\text { The company's response to permanent changes in the } \\
\text { environment }\end{array}$ & {$[19$, c. 4$]$} \\
\hline \multicolumn{3}{|c|}{ Adaptation of the enterprise as a method } \\
\hline Kravchenko S. A. & $\begin{array}{l}\text { Totality of forms and methods of survival of } \\
\text { enterprises in a competitive environment; subsystem } \\
\text { of economic mechanism of the state; component of } \\
\text { the economic policy of the state }\end{array}$ & {$[15$, p. 125] } \\
\hline Budnik M. M. & $\begin{array}{l}\text { The set of complexes, rules and procedures that are } \\
\text { used to adapt elements of the internal environment of } \\
\text { the enterprise and connections between them, to the } \\
\text { influence of a certain factor of the external } \\
\text { environment }\end{array}$ & {$[17$, p. 9] } \\
\hline Kolodina O. M. & $\begin{array}{l}\text { Complex of purposeful measures of the management } \\
\text { of the enterprise in response to the influence of } \\
\text { environmental factors that affect life-sustaining } \\
\text { processes of the enterprise for the increase of the } \\
\text { efficiency of the activities occurring through balanced } \\
\text { regrouping of the joints, flows, elements in the } \\
\text { internal environment of the enterprise during the } \\
\text { exchange of the environment }\end{array}$ & {$[52$, p. 208] } \\
\hline Khanaliev G. I. & $\begin{array}{l}\text { Mechanism of economic and social regulation that } \\
\text { allows the system to maintain (change) the direction } \\
\text { and pace of development regardless of the influence } \\
\text { of external factors }\end{array}$ & {$[62$, p. 121] } \\
\hline
\end{tabular}


Table A.2

Genesis of the notion "strategy» (developed by the author based on [120; 179; 268; 330-335])

\begin{tabular}{|c|c|c|c|}
\hline № & Author & Definition & Essential features \\
\hline 1 & 2 & 3 & 4 \\
\hline 1 & $\begin{array}{l}1962 \\
\text { A. Chandler } \\
{[330]}\end{array}$ & $\begin{array}{l}\text { Method for setting } \\
\text { long-term goals of a } \\
\text { company, programs of } \\
\text { its actions and priority } \\
\text { directions on allocation } \\
\text { of resources }\end{array}$ & $\begin{array}{l}\text { Long-term goals are developed once } \\
\text { and not subject to significant } \\
\text { changes in the conditions of the } \\
\text { external and internal environment in } \\
\text { which the company operates. }\end{array}$ \\
\hline 2 & $\begin{array}{l}1965 \\
\text { Harvard } \\
\text { Business School } \\
\text { (K. Andrews) } \\
\text { [331] }\end{array}$ & $\begin{array}{l}\text { Method of determining } \\
\text { the company's } \\
\text { competitive goals }\end{array}$ & $\begin{array}{l}\text { The strategy defines the main } \\
\text { business areas that are most } \\
\text { attractive to the company's } \\
\text { development (existing and new } \\
\text { ones) }\end{array}$ \\
\hline 3 & $\begin{array}{l}1965 \\
\text { I. Ansoff [332] }\end{array}$ & $\begin{array}{l}\text { Method of setting goals } \\
\text { for corporate, } \\
\text { functional, business } \\
\text { management levels of } \\
\text { the company }\end{array}$ & $\begin{array}{l}\text { During the development of the } \\
\text { strategy it is necessary to allocate } \\
\text { corporate, functional, business goals } \\
\text { from the point of view of their } \\
\text { various influence on the processes of } \\
\text { management of the company. }\end{array}$ \\
\hline 4 & $\begin{array}{l}1977 \\
\text { D. Stainder, } \\
\text { P. Lorange } \\
\text { [333] }\end{array}$ & $\begin{array}{l}\text { Further development of } \\
\text { I. Ansoff ideas }\end{array}$ & $\begin{array}{l}\text { Further development of I. Ansoff } \\
\text { ideas }\end{array}$ \\
\hline 5 & $\begin{array}{l}\text { 1980-1985 } \\
\text { M. Porter [268] }\end{array}$ & $\begin{array}{l}\text { Method of responding } \\
\text { to external opportunities } \\
\text { and threats, internal } \\
\text { strengths and } \\
\text { weaknesses }\end{array}$ & $\begin{array}{l}\text { The strategy is designed to achieve } \\
\text { long-term competitive advantages } \\
\text { over other market players in each of } \\
\text { the business spheres. }\end{array}$ \\
\hline 6 & $\begin{array}{l}1987 \\
\text { G. Mintsberg, } \\
\text { B. Alstrend, } \\
\text { G. Lempel [179] }\end{array}$ & $\begin{array}{l}\text { Consistent, coordinated } \\
\text { and integrated } \\
\text { management decision } \\
\text { making }\end{array}$ & $\begin{array}{l}\text { When designing a strategy, the focus } \\
\text { should be on developing plans that } \\
\text { serve to control the effectiveness of } \\
\text { the achievement of established } \\
\text { strategic objectives. }\end{array}$ \\
\hline 7 & $\begin{array}{l}1987 \\
\text { K. Stern } \\
\text { J. Stock [334] }\end{array}$ & $\begin{array}{l}\text { Method of achieving } \\
\text { the main economic and } \\
\text { non-economic benefits } \\
\text { that the company plans } \\
\text { to provide to key } \\
\text { stakeholders. }\end{array}$ & $\begin{array}{l}\text { Social orientation of the strategy is } \\
\text { considered from the point of view of } \\
\text { passing corporate philosophy and } \\
\text { organizational culture of the } \\
\text { company }\end{array}$ \\
\hline
\end{tabular}




\begin{tabular}{|c|l|l|l|}
\hline 8 & $\begin{array}{l}1989 \\
\text { M. Hamel, } \\
\text { K. Prakhalad } \\
{[335]}\end{array}$ & $\begin{array}{l}\text { Method of developing } \\
\text { the company's main } \\
\text { competitive advantages }\end{array}$ & $\begin{array}{l}\text { Competitiveness is based on special } \\
\text { (unique) abilities, competencies of } \\
\text { the company, its internal resources }\end{array}$ \\
\hline 9 & $\begin{array}{l}1995 \\
\text { A. Thomson, } \\
\text { G. Strickland } \\
{[120]}\end{array}$ & $\begin{array}{l}\text { A set of actions and } \\
\text { approaches to achieve } \\
\text { the specified } \\
\text { performance indicators }\end{array}$ & $\begin{array}{l}\text { The strategy is both preactive } \\
\text { (preventing) and reactive (adaptable) } \\
\text { to the external environment }\end{array}$ \\
\hline 10 & $\begin{array}{l}2008 \\
\text { G. B. Kleyner } \\
{[329]}\end{array}$ & $\begin{array}{l}\text { A rather complete, but } \\
\text { not contradictory, } \\
\text { complex of } \\
\text { interconnected strategic } \\
\text { decisions }\end{array}$ & $\begin{array}{l}\text { Competitiveness is based on } \\
\text { corporate knowledge, internal } \\
\text { institution institutes, cultural } \\
\text { resources and other non-material } \\
\text { factors of enterprise activity. }\end{array}$ \\
\hline
\end{tabular}




\section{LIST OF REFERENCES}

1. Чистий прибуток (збиток) велики та середніх підприємств за видами економічної діяльності // Державна служба статистики України // http://www.ukrstat.gov.ua.

2. Ансофф И. Новая корпоративная стратегия / И. Ансофф. - СПб, 1999. - 416 c.

3. Алєксєєв С. Б. Формування адаптивного управління підприємствами вугільного машинобудування : автореф. дис. ... канд. ек. наук / С. Б. Алєксєєв. - Донецьк, 2003. - 23 с.

4. Крисько Ж. Л. Адаптація підприємства до зовнішнього середовища через механізм реструктуризації / Ж. Л. Крисько // Галицький економічний вісник. - 2009. - № 2. - С. 38-42.

5. Клейнер Б. Г. Стратегия предприятия / Б. Г. Клейнер. - Москва, 2008. - 568 c.

6. Малярчук О. Г. Визначення характеру та параметрів адаптації підприємств залежно від умов зовнішнього середовища / О. Г. Малярчук // Стратегія економічного розвитку України.- Вип. 24-25. - К., 2009. - С. 97-103.

7. Мельник А. О. Адаптація вітчизняних підприємств в умовах світової економічної кризи / А. О. Мельник // Бізнес Інформ. - 2012. - № 10. - С. 30 32.

8. Отенко I. П. Стратегічні пріоритети підприємства / I. П. Отенко. - Харків, 2008. - $180 \mathrm{c}$.

9. Ячменьова В. М. Сутність понять «адаптація» та «адаптивність» / В. М. Ячменьова // Вісник Національного університету «Львівська політехніка». - 2010. - № 684. - С. 346-353.

10. Гросул В. А. Формування стратегії адаптації підприємств торгівлі : монографія / В. А. Гросул, О. Д. Рачкован. - Харків : Видавництво Іванченка I.C., 2016. - 304 с.

11. Чиженькова Е. В. Формирование экономического механизма адаптации хозяйствующего субъекта к рыночной среде : автореф. канд. экон. наук. M., 2006. $-20 \mathrm{c}$.

12. Минко И. С. Адаптивность и инновации в экономических системах [Електронний ресурс] / И. С. Минко, Л. К. Шамина // Электронный научный журнал СПбГУНиПТ : Экономика и экологический менеджмент. 2011. - № 1. - Режим доступу : http://economics.openmechanics. com/articles/295.pdf

13. Пастухова Е. А. Адаптация экономической системы к изменениям среды / Е. А. Пастухова // Современные наукоемкие технологии. - 2006. - № 5. - С. 77-80.

14. Кравченко С. А. Адаптация экономического механизма функционирования сельскохозяйственных предприятий к условиям рынка : монография / С. А. Кравченко. - К. : ННЦ ИАЭ, 2008. - 444 с.

15. Демьянова Е. В. Принципиальные основы адаптивного управления предприятием / Е. В. Демьянова // Вестник ВНУ им. В. Даля. - № 10 (116). - Луганск : ВНУ им. В. Даля, 2007. - С. 70-75. 
16. Буднік М. М. Адаптація промислових підприємств до ринкових умов господарювання : Автореф. дис. канд. ек. наук : 08.06.01 / М. М. Буднік / ХДЕУ. - Харків, 2002. - 14 с.

17. Гречко М. В. Адаптация как ключевое свойство эволюции экономических систем / М. В. Гречко // Наука и мир : Международный научный журнал. 2015. - № 4 (20). - Т. 3. - С. 20-23.

18. Мамий Е. А. Теоретические аспекты управления реакцией предприятия на изменения рыночной среды [Електронний ресурс] / Е. А. Мамий, В А. Барышев // Научный журнал НИУ ИТМО. Серия «Экономика и экологический менеджмент». - 2014. - №1 (16). - Режим доступу : http://economics.ihbt.ifmo.ru/file/article/8838.pdf

19. Дубчак В. В. Теоретико-методологические аспекты формирования системы адаптивного управления промышленными предприятиями : автореферат дис. канд. экон. наук / Дубчак В. В. - Ростов-на-Дону, 2006. - 23 с.

20. Галушко С. С. Сутність механізму адаптації промислового підприємства / Є. С. Галушко, С. А. Галушко, П. С. Лопатьєв // Розвиток фінансових методів державного управління національною економікою : зб. наук. праць. - Донецьк : ДонДУУ. - 2012. - С. 245-250.

21. Пашнюк Л. О. Теоретичні аспекти адаптації підприємства до ринкових умов господарювання / Л. О. Пашнюк // Актуальні Проблеми Економіки. 2007. - № 1(67). - С. 76-81.

22. Білошкурська Н. В. Моделі адаптивної поведінки та їх роль у формуванні економічної безпеки підприємства / Н. В. Білошкурська // Актуальні проблеми економіки. - 2010. - № 12 (114). - С. 101-105.

23. Козаченко Г. В. Економічна безпека підприємства: сутність та механізм забезпечення : монографія / Г. В. Козаченко, В. П. Пономарьов, О. М. Ляшенко. - К. : Лібра, 2003. - 280 с.

24. Куліков П. М. Теоретичні основи адаптації підприємства до мінливості оточуючого середовища / П. М. Куліков // Бізнес-інформ. - 2010. - Т. 1. - № 5. - C. 56-58.

25. Тимохин В. Н. Методология моделирования экономической динамики : монография / В. Н. Тимохин. - Донецк : Юго-Восток, Лтд, 2007. - 271 с.

26. Капітанець Ю. О. Визначення та забезпечення конкурентоспроможності підприємства : автореф. канд. екон. наук / Ю. О. Капітанець. - Тернопіль, 2009. $-20 \mathrm{c}$.

27. Кулик Н. М. Технологія адаптації у системі управління підприємством / Н. М. Кулик, Т. М. Соколенко // Економічний аналіз : зб. наук. праць ТНЕУ. Тернопіль : Економічна думка, 2013. - Т. 14. - № 3. - С. 96-100.

28. Кучеренко А. А. Адаптивная реакция как элемент адаптации предприятия к изменениям условий внешней среды / А. А. Кучеренко // Бизнес-Информ. 2008. - № 10. - С. 66-68.

29. Турило А. М. Теоретико-методичні засади визначення сутності економічної категорії «адаптаційний потенціал підприємства» / А. М. Турило, К. В. Богачевська // Актуальні проблеми економіки. - 2014. - № 2 (152). - С. 2632.

30. Виноградський С. Б. Організація системи адаптивного менеджменту фірми: 
автореф. дис. канд. екон. наук: 08.06.02 / С. Б. Виноградський; Донец. нац. ун-т. - Донецьк, 2001. - 19 с.

31. Шевченко В. В. Место адаптации в системе экономических понятий / В. В. Шевченко // Научные труды ДонНТУ. Серия : Экономическая. - 2015. - № 1. - C. 78-88.

32. Марковская Е. И. Институциональные основы адаптации экономических субъектов / Е. И. Марковская // Развитие современной науки: теоретические и прикладные аспекты : сборник научных статей. В 2 ч. Ч. 2. Вып. 3. Пермь, 2016. - С. 61-69.

33. Писанко А. I. Адаптивне управління підприємством у сучасному середовищі / Писанко А. I. // Економічні науки. Серія : Економіка та менеджмент : зб. наук. праць. Луцький національний технічний університет. - Вип. 9 (34). Ч. 2. - Луцьк, 2012. - С. 35-41.

34. Галушко Е. С. Обоснование организационно-экономического механизма адаптации предприятия / Е. С. Галушко, С. А. Галушко // Вестник СевНТУ. - Сер. Экономика и финансы. - Сб. 130. - 2012. - С. 43-47.

35. Глаголев С. Н. Развитие организационно-экономического механизма управления адаптацией промышленного предприятия: теория, оценка, практика : автореф. дис. д-ра экон. наук / С. Н. Глаголев. - Саратов, 2009. 42 c.

36. Деркач М. Н. Адаптационный механизм институциональных изменений экономичекой системы / М. Н. Деркач // Бізнес-інформ. - 2011. - № 1. - С. 133-135.

37. Литературный словарь терминов - [Електронний ресурс]. - Режим доступу : http://www.litdic.ru/adaptaciya/

38. Коваленко Н. В. Сутність поняття «адаптація» в контексті інноваційного розвитку підприємства / Н. В. Коваленко, Н. В. Гонтова // Економічний вісник Донбасу. - 2012. - № 2 (28). - С. 147-154.

39. Ожегов С. И. Словарь русского языка / Под ред. Н. Ю. Шведовой. - 20-е изд., стереотип. - М. : Рус. яз., 1989. - 750 с.

40. Райзберг Б. А. Современный экономический словарь / Б. А. Райзберг, Л. Ш. Лозовский, Е. Б. Стародубцева. - 2-е изд., испр. - М. : ИНФРА-М, 1999. 479 c.

41. Экономико-математический энциклопедический словарь / Гл. ред. В. И. Данилов-Данильян. - М. : ИНФРА-М, 2003. - 688 с.

42. Социологический справочник / Под ред. В. И. Воловича. - К. : Изд-во политической литературы Украины, 1990. - 382 с.

43. Корель Л. В. Социология адаптаций: вопросы теории, методологии и методики : монография / Л. В. Корель. - Новосибирск : Наука, 2005. - 424 с.

44. Философские проблемы теории адаптации / А. Б. Георгиевский, В. П. Петленко, А. В. Сахно, Г. И. Царегородцев ; под ред. Г. И. Царегородцева. - М. : Мысль, 1975. - 277 с.

45. Урманцев Ю. А. Природа адаптации (системная экспликация) / Ю. А. Урманцев // Вопросы философии. - 1998. - № 12. - С. 21-36.

46. Эфендиев Б. А. Разработка и функционирование адаптивных систем управления организацией / Б. А. Эфендиев // Российское предпринимательство. - 2008. - № 11. - Вып. 1 (22). - С. 21-25.

47. Desai M. The finance function in the global corporation / M. Desai // Harvard 
Business Review. - July - August. - 2008. - P. 108-112.

48. Organization \& Management Theory : Conference Paper Abstracts. - Academy of Management Annual Meeting Proceedings. - 2010. - 133 p.

49. Колодіна О. М. Економічний зміст адаптації підприємства / О. М. Колодіна // Вісник СумДУ. Серія : Економіка. - Суми : СумДУ, 2010. - № 1. - С. 200210.

50. Растригин Л. А. Адаптация сложных систем / Л. А. Растригин. - Рига : Знание, 1981. - $375 \mathrm{c}$.

51. Попова Л. Ф. Адаптационный механизм управления организационной структурой в системе устойчивого развития промышленного предприятия / Л. Ф. Попова // Вестник Саратовского государственного социальноэкономического университета. - 2013. - № 4 (48). - С. 64-69.

52. Постолова М. А. Организация произвоства на предприятиях отрасли / М. А. Постолова, Н. Л. Грязнова. - 2-е изд., перераб. и доп. - Кемерово, 2008. $248 \mathrm{c}$.

53. Шершньова 3. Є. Стратегічне управління : підручник / 3. Є. Шершньова. 2-ге вид., перероб. і доп. - К. : КНЕУ, 2004. - 399 с.

54. Беник Н. Г. Поняття і сутність категорії «адаптація підприємств» / Н. Г. Беник // Водний транспорт. - 2012. - Вип. 3. - С. 85-89.

55. Акофф Р. Акофф о менеджменте / Р. Акофф. - Пер. с англ., под ред. Л. А. Волковой. - СПб. : Питер, 2002. - 448 с.

56. Економічний енциклопедичний словник : У 2 т., Т. 1 / С. В. Мочерний, Я. С. Ларіна, О. А. Устенко, С. І. Юрій; за ред. С. В. Мочерного. - Львів : Світ, 2005. $-616 \mathrm{c}$.

57. Цыпкин Я. 3. Адаптация и обучение в автоматических системах / Я. 3. Цыпкин. - М. : Наука, 1988. - 274 с.

58. Ханалиев Г. И. Развитие системы сбалансированного управления предприятием автомобильного транспорта в условиях изменяющейся экономической среды / Г. И. Ханалиев // Известия высших учебных заведений. Поволжский регион. Общественные науки. - 2010. - № 3 (15). C. 118-125.

59. Дорофеева В. В. Реформирование предприятий как способ их адаптации к новым макроэкономическим условиям существования / В. В. Дорофеева // European Social Science Journal. - 2011. - № 3. - C. 278-285.

60. Соколова Л. В. Організаційно-економічне забезпечення адаптації підприємств до невизначеності бізнес-середовища : автореф. дис. д-ра екон. наук : 08.06.01 / Л. В. Соколова. - Донецьк, 2006. - 44 с.

61. Лущиков Ю. А. Адаптация сельскохозяйственных предприятий к рыночным условиям хозяйствования : автореф. дис. канд. экон. наук : 08.00.05 / Ю. А. Лущиков. - Воронеж, 2001. - 26 с.

62. Ву Тхієу Занг. Організація управління процесом адаптації підприємства : автореф. дис. канд. екон. наук : 08.06.01 / Ву Тхієу Занг. - Луганськ, 1999. $23 \mathrm{c}$.

63. Гросул В.А.Формування стратегії адаптації підприємств торгівлі : монографія / В.А. Гросул, О.Д. Рачкован. - Х. : Видавництво Іванченка I.C., 2017. - 304 c. 
64. Авраамова Е. Адаптация промышленных предприятий к рыночным условиям / Е. Авраамова, И. Гурков // Вопросы экономики. - 1997. - № 11. - C. 145-149.

65. Глаголев С. Н. Методологические основы формирования механизма адаптации промышленных предприятий в условиях меняющейся рыночной среды : монография / С. Н. Глаголев. - Белгород : БГТУ, 2007. - 163 с.

66. Глаголев С. Н. Факторы, влияющие на возможность адаптации промышленных предприятий к современным условиям / С. Н. Глаголев // Экономический анализ: теория и практика. - 2009. -№ 25. - С. 63-66.

67. Дібніс Г. І. Фактори, що визначають адаптивні можливості підприємства до змін кон'юнктури ринку / Г. І. Дібніс, Є. В. Дем'янова // Управління проектами та розвиток виробництва : зб. наук. пр. - Луганськ : СНУ ім. В. Даля, 2008. - № 3 (27). - С. 153-161.

68. Рачкован О. Д. Фактори, що впливають на адаптивність підприємств торгівлі / О. Д. Рачкован // Науковий вісник Полтавського університету економіки та торгівлі. - Полтава : ПУЕТ, 2014. - С. 108-115.

69. Степанова Ю. Л. Класифікація адаптації підприємства в залежності від прогнозованості виникнення змін у зовнішньому середовищі підприємства. - [Електронний ресурс] / Ю. Л. Степанова. - Режим доступу: http://www.nbuv.gov.ua/old_jrn/Soc_Gum/VSUNU/2010_2_2/Stepanova.pdf

70. Рачкован О. Д. Внутрішні фактори, що впливають на адаптивність підприємств торгівлі / О. Д. Рачкован : тези допов. Міжнар. наук.-практ. конф. [«Розвиток харчових виробництв, ресторанного та готельного господарств і торгівлі: проблеми, перспективи, ефективність»], (Харків, 14 травня 2015 р.). - Харків : ХДУХТ, 2015. - Ч. 2. - С. 375-376.

71. Рачкован О. Д. Теоретичний базис системи адаптаційного управління підприємств торгівлі / О. Д. Рачкован // Науковий вісник Херсонського державного університету. Серія «Економічні науки». - Херсон : ХДУ, 2015. - Вип 12. - Ч. 1. - С. 122-125.

72. Гончаров В. Н. Система адаптации и организация сборочного производства : монография / В. Н. Гончаров, А. М. Зинченко, С. В. Автономов, Н. В. Зинченко. - Луганск : Книжковий світ, 2002. - 136 с.

73. Капітанець Ю. О. Стратегічна адаптація підприємства до зовнішнього середовища / Ю. О. Капітанець // Науковий вісник Національного університету «Львівська політехніка». - Львів. - 2007. - №5 99. - С. 257261.

74. Ландіна Т. В. Організаційно-економічні механізми адаптації підприємства до умов ринку / Т. В. Ландіна. - К. : Наукова думка, 1994. - 283 с.

75. Степанова Ю. Л. Результативність адаптації підприємства / Ю. Л. Степанова // Економіка. Менеджмент. Підприємництво. Зб. наук. праць Східноукраїнського національного університету ім. В. Даля. Вип. 24. Ч. 1. - Луганськ : СНУ ім. В. Даля, 2012. - С. 156-162.

76. Стец I. Адаптивне управління потенціалом підприємства / I. Стец // Українська наука : минуле, сучасне, майбутнє. - 2013. - Вип. 18. - С. 154162.

77. Ткаченко Ю. В. Адаптация предприятий к условиям функционированияв период кризисна / Ю. В. Ткаченко // Бізнес Інформ. - 2012. - № 2. - С. $194-$ 196. 
78. Рачкован О. Д. Деякі аспекти адаптації торговельних підприємств до зміни середовища функціонування / О. Д. Рачкован : матеріали VII Міжнар. наук.практ. конф. [«Тренди та інновації в сучасній економіці»], (Харків, 23-24 квітня 2015 р.). - Харків : ХНУБА, 2015. - Ч. 3. - С. 158-160.

79. Рачкован О. Д. Принципи формування системи адаптаційного управління підприємств торгівлі / О. Д. Рачкован : тези допов. міжн. наук.-практ. конф. [«Розвиток національної економіки України: нові реалії і можливості в умовах започаткованих змін»], (Львів, 21 жовтня 2015 р.) - Львів : ЛКА, 2015. - С. 170-172.

80. Рачкован О. Д. Сутнісні характеристики адаптації підприємства / О. Д. Рачкован : тези допов. III міжнар. наук.-практ. конф. [«Актуальні проблеми та перспективи розвитку економіки в умовах глобальної нестабільності »], (Кременчук, 10-12 грудня 2015 р.). - Кременчук, КрНУ, 2015. - C.247-248.

81. Міценко Н. Г. Розвиток роздрібного товарообороту споживчої кооперації України як результат адаптації торговельної мережі до умов конкурентного середовища / Н. Г. Міценко // Науковий вісник : зб. наук.-техн. праць. Львів: НЛТУУ, 2011. Вип. 21.15. - С. 230-236.

82. Міценко Н. Г. Створення інтегрованих систем як шлях адаптації підприємств до змін у ринковому середовищі / Н. Г. Міценко // Механізми стабілізації й розвитку діяльності підприємств : монографія / Під ред. О. О. Шубіна, Л.В. Фролової. - Донецьк : вид-во «Ноулідж» (донецьке відділення), 2013. - 513с. - С. 458-468.

83. Линькова Е. Ю. Особенности менеджмента в условиях кризиса / Е. Ю. Линькова // Символ науки. - Уфа. 2015. № 6. - С. 132-134.

84. Карлофф Б. Деловая стратегия / Б. Карлофф; пер. с англ., науч. ред. и авт. послесл. В. А. Приписной. - М. : Экономика, 2008. - 239 с.

85. Минцберг Г. Стратегический процесс / Г. Минцберг, Дж. Б. Куинн, С. Гошал. - СПб. : Питер, 2011. -688 с.

86. Мескон М. Х. Основы менеджмента: Пер. с англ. / М. Х. Мескон, М. Альберт, Ф. Хедоури. - М . : Дело, 1992. - 702 с.

87. Хасси Д. Стратегия и планирование: Пер. с англ. / Д. Хасси. - СПб : Питер, 2001. $-384 \mathrm{c}$.

88. Боумен К.Основы стратегического менеджмента / К. Боумен. - М. : ЮНИТИ, 1997. - 177 с.

89. Виханский О. С. Менеджмент: учебник / О. С. Виханский, А. И. Наумов. 4-е изд., перераб. и доп. - М. : Экономистъ, 2006. - 670 с.

90. Циба Т. С. Особливості і механізм стратегічного планування / Т. С. Циба // Актуальні проблеми економіки. - 2006. - No 2 (56). - С. 159-172.

91. Фатхутдинов Р. А. Стратегический менеджмент / Р. А. Фатхутдинов. - 7-е изд., испр. и доп. - М. : Дело, 2005. - 448 с.

92. Управление организацией: Учебник / Под ред. А. Г. Поршнева, 3. П. Румянцевой, Н. А. Саломатина. - М. : ИНФРА-М, 2008. - 735 с.

93. Туленков Н. В. Введение в теорию и практику менеджмента : Учебное пособие / Н. В. Туленков. - К. : ЦУЛ, 1998. - 133 с.

94. Kenichi O. The Mind of the Strategist / O. Kenichi. - New York : Mc Graw-Hill, 
1982. -304 p.

95. Kay J. Foundations of Corporate Success / J. Kay. - Oxford : Oxford Press, 1993. $-416 \mathrm{p}$.

96. Нємцов В. Д. Стратегічний менеджмент / В. Д. Нємцов, Л. Є. Довгань. - К. : ТОВ «УВПК ЕксОб», 2001. - 560 с.

97. Экономическая стратегия фирмы / Под ред. А. П. Градова - СПб. : Специальная Литература, 1995. - 184 с.

98. Ігнатьєва І. А. Корпоративне управління : підручник. / I. А. Ігнатьєва, О. І. Гарафонова - К.: «Центр учбової літератури», 2013. - 600 с.

99. Клівець П. Г. Стратегія підприємства / П. Г. Клівець. - К. : Академвидав, 2007. $-320 \mathrm{c}$.

100. Джонсон Дж. Корпоративная стратегия: теория и практика: Пер. с англ. / Дж. Джонсон, К. Шоулз, Р. Уиттингтон. - М.: ООО «И.Д. Вильямс», 2007. $800 \mathrm{c}$.

101. Уткин Е.А. Управление фирмой / Э. А. Уткин. - М.: Акалис, 1996. - 516 с.

102. Hofer C. W. Strategy Formulation: Analytical Concept / C. W. Hofer, D. Schendel. - New York : West Publishing Company, 1978.

103. Glueck W. L. Business Policy and Strategic Management / W. L. Glueck, L. R. Jauch. - New York : McGraw Hill, 1988.

104. Henderson B. D. The origin of strategy / B. D. Henderson // Harvard business review. - 1989. - Nov.-Dec. - P.139-143.

105. Каплан Р. С. Стратегические карты. Трансформация нематериальных активов в материальные результаты / Р. С. Каплан, Д. П. Нортон; Пер. с англ. - М. : ЗАО «Олимп-Бизнес», 2005. - 512 с.

106. Фаэй Л. Курс МВА по стратегическому менеджменту / Л. Фаэй, Р. Рэнделл; пер. с англ. - М . : Альпина Паблишер, 2002. - 608 с.

107. Міщенко А. П. Стратегічне управління / А. П. Міщенко. - Дн-ськ : Вид-во ДУЕП, 2007. - 332 с.

108. Miles R. E. Organizational strategy, structure and process / R. E. Miles, C. C. Snow. - N. Y. : McGraw-Hill, 1978. - 391 c.

109. Шарапудинов Г. М. Механизмы адаптации предприятия в условиях перехода к рыночной экономике : дис. канд. экон. наук : 08.00 .05 / Г. М. Шарапудинов; Ин-т соц.-экон. исслед. Дагестанского науч. центра РАН. - Махачкала, 2000. - 148 с.

110. Маслодудов Ю. А. Формирование организационно-экономического механизма адаптивного управления машиностроительным предприятием : автореф. дис. канд. экон. наук : 08.00.05 / Ю. А. Маслодудов; ННОУ ВПО «Московский гуманитарный университет». - М., 2010. - 25 с.

111. Таранова Е. В. Стратегии адаптации предприятий легкой промышленности к инновационным изменениям : [Электронный ресурс] /

E. B.

Таранова // Социологические исследования. - 2008. - № 9. - С. 47-52.

112. Сірик I. П. Обгрунтування управлінських рішень в умовах адаптації підприємства до змін ринкового середовища : автореф. дис. канд. екон. наук : 08.00.04 / І. П. Сірик; Сумський державний университет. - Суми, 2012. $20 \mathrm{c}$.

113. Орлова К. Є. Стратегія адаптації промислових підприємств до умов овнішнього середовища: динамічний аспект / К. Є Орлова // Інноваційний розвиток та конкурентоспроможність підприємств і секторів економіки. - 
Житомир, 2014. - С. 80-81.

114. Янченко Н. В. Стратегічні аспекти адаптивного управління на підприємствах залізничного транспорту / Н. В. Янченко // Вісник Хмельницького національного університету. Економічні науки. -2011. - № 6, T. 1. - C. 44-46.

115. Томпсон А.А. Стратегический менеджмент: концепции и ситуации для анализа. / А. А. Томпсон, А. Дж. Стрикленд. - 12-е изд. Пер. с англ.. - М. : Вильямс, 2007. - 928 с.

116. Петров, А.Н. Стратегический менеджмент: учебник для вузов / А. Н. Петров. - СПб. : Питер, 2008. - 496 с.

117. Румянцева 3. П. Общее управление организацией: теорія и практика / 3. П. Румянцева. - М . : ИНФРА-М, 2007. - 304 с.

118. Власова Н. О. Економічний механізм регулювання підприємницької діяльності в роздрібній торгівлі : монографія / Н. О. Власова, М. В. Чорна, М. В. Бєляєва. - Харків : ХДУХТ, 2013. - 157 с.

119. Друкер П. Ф. Управление, нацеленное на результаты / П. Ф. Друкер ; [пер с англ.]. - М. : Технол. шк. бизнеса, 1994. - 200 с.

120. Кристенсен К. Дилемма инноватора. Как из-за новых технологий погибают сильные компании [Електронний ресурс]. - Режим доступу: http://www.yakaboo.ua/the-innovators-dilemma-when-new-technologies-causegreat-firms-to-fail.html?utm_source=salesdoubler\&medium =cpa\&term $=$ 018759\&aff_sub =147474849\#media_popup_fragment

121. Лігоненко Л. О. Антикризова діяльність підприємством: теоретикометодологічні засади та практичний інструментарій: монографія / Л. О. Лігоненко. - К. : КНТЕУ, 2004. - 580 с.

122. Петрович Й. М. Удосконалення управління процесом адаптації підприємства до ринкових умов господарювання [Електронний ресурс] / Петрович Й. М., Грибик I. I. - Режим доступу: http://ena.lp.edu.ua:8080/bitstream/ntb/19227/1/23-Petrovich-110-117.pdf

123. Терещенко О. О. Антикризове фінансове управління на підприємстві : монографія / О. О. Терещенко. - К. : КНЕУ, 2004. - 268 с.

124. ТРИЗ: меньше проблем, больше жизни [Електронний ресурс]. - Режим доступу: http://triz.iatp.by/ trizba-1-00.php3

125. Фомин В. Н. Некоторые общие принципы построения адаптивных систем управления / В. Н. Фомин // Соросовский образовательный журнал. - 1996. - № 368. - С. 102-109.

126. Хаммер М. Реинжиниринг корпорации: манифест революции в бизнесе: пер. с англ. / М. Хаммер, Дж. Чам- пи; пер. с англ. Ю. Е. Корнилович. - М.: Манн, Иванов и Фербер, 2006. - 287 с.

127. Харченко В. Принципи формування системи стратегічного управління розвитком промислового підприємства [Електронний ресурс] / В. Харченко. - Режим доступу: http: // ea.dgtu.donetsk.ua : 8080/bitstream/123456789/28462/3/5.Принципи\%20стаття\%20Харченко1.pdf

128. Холл Р. Х. Организации: Структуры, процессы, результаты / Р. Х. Холл. СПб. : Питер, 2001. - 512 с.

129. Черниш I. В. Обгрунтування принципів і функцій антикризової політики 
держави у туристичній галузі / I. В. Черниш // Проблеми економіки. - 2014. - № 1. - С. 173-179.

130. Шеер А. Бизнес-процессы: основные понятия, теория, методы: пер. с англ. / А. Шеер. - 2-е изд., пере- раб. и доп. - М. : Просветитель, 1999. - 154 с.

131. Соломаха С. А. Моделі і методи адаптивного управління виробничоекономічними системами в умовах нестабільного попиту : автореф. дис. ... канд. екон. наук / С. А. Соломаха. - Донецьк : ДНУ, 2006. - 19 с.

132. Стасюк В. П. Моделі адаптивного управління підприємством у нестабільному економічному середовищі : автореф. дис. ... д-ра екон. наук / В. П. Стасюк. - Донецьк : ДНУ, 2003. - 32 с.

133. Фаерман М. И. Комплексный социально-психологический подход к предупреждению сопротивлений нововведениям персонала: на примере организаций малого и среднего бизнеса : автореферат дис. ... кандидата психологических наук : 19.00.05, 19.00.03 / М. И. Фаерман ; Ярослав. гос. ун- т им. П. Г. Демидова. - Ярославль, 2007 - 24 с.

134. Burrow J. L. Business Principles and Management / J. L. Burrow, B. Kleindl, K. E. Everard. - South-Western Educational Pub, 2007. - 723 p.

135. Certo S. C. Modern Management : Concepts and Skills / S. C. Certo, T Certo. Prentice Hall, 2011. - 600 p.

136. Daft R. L. Management / R. L. Daft ; 12th ed. - Cengage Learning, 2015. - 784 p.

137. Taylor F. W. Introduction to Management / F. W. Taylor. - Science Prentice Hall, 2013. - $841 \mathrm{p}$.

138. Герчикова И. Н. Менеджмент / И. Н. Герчикова. - М. : Банки и биржи, ЮНИТИ, 1995. - 480 с.

139. Друкер, Питер, Ф. Энциклопедия менеджмента : пер. с англ. - М. : Вильямс, 2004. - 432 c.

140. Економічна енциклопедія, у 3. т. Т. 2 / Редкол.: С. В. Мочерний (відп. ред.) та ін. - К. : Академія, 2001. - 848 с.

141. Основи менеджменту А. А. Мазаракі, С. І. Бай, В. Я.Брич, О. А. Гавриш, С. О.Гуткевич та ін. / за ред. А. Мазараки. - Фолио, 2014. - 848 с.

142. Саймон Г. А. Менеджмент в организациях / Г. А. Саймон, Д. У. Смитбург, В. А. Томпсон. - М. : РАГС «Экономика», 1995. - 337 с.

143. Тейлор Ф. У. Менеджмент / Ф. У. Тейлор. - М. : Контроллинг, 1992. - 137 c.

144. Янчева Л. М. Інформаційні системи управління товарорухом в роздрібній торгівлі : монографія / Л. М. Янчева, А. С. Крутова, О. О. Нестеренко. - Х. : ХДУХТ, 2012. - $271 \mathrm{c.}$

145. Тейлор Ф. У. Принципы научного менеджмента / Ф. У. Тейлор. - М. : Кон $\urcorner$ троллинг, 1991. - 104 с

146. Taylor F. W. Scientific Managment / Taylor F. W. - N. Y: Harper and Brothers, 1947.

147. Принципи управління Файоля Електронний ресурс. - Режим доступу: http://allendy.ru/teoruprav/122-princip-fajol.pdf

148. Принципи управління [Електронний ресурс]. - Режим доступу: http://svitohlyad.com.ua/biznes/anri-fajol-pryntsypy-upravlinnya/

149. Кунц Г. Управление: системный и ситуационный анализ управленческих функций / Г. Кунц, С. О’Доннел ; пер. с англ., ред. Д. М. Гвишиани. - М. : 
Прогресс, 1981. - 250 с.

150. Кнорринг В. И. Теория, практика и искусство управления [Електронний peсурс]. - Режим доступу: http://polbu.ru/knorring_management/ch38_i.html

151. Maslow A. N. Motivation and Personality / A. N. Maslow. - N. Y. : Harper and Row, 1957.

152. Mayo E. The Social Problems of an Industrial Civilization / E. Mayo. Cambrige, Mass. : Harvard University, 1945.

153. Яка система відносин склалася на підприємстві [Електронний ресурс]. Режим доступу: http://www.frontmanagement.org/fomants-227-1.html

154. Харчишина О. В. Вплив наукових шкіл менеджменту наформування теорії організаційної культури / О. В. Харчишина [Електронний ресурс]. - Режим доступу: http://eprints.zu.edu.ua/8328/1/10kovtok.pdf.

155. Філософські проблеми сучасного управління складними системами: ідеї, принципи і моделі : монографія / Ю. В. Бех, А. І. Слєпцов ; Мін-во освіти і науки, молоді і спорту ; Нац. пед. ун-т імені М. П. Драгоманова. - К. : Видво НПУ імені М. П. Драгоманова,2012. - 405 с.

156. Градов А. П. Стратегия и тактика антикризисного управления фирмой : монография / А. П. Градов, Б. И. Кузин, А. В. Федотов, Г. В. Слабиков и др. - СПб. : Специальная литература, 1996. - 510 с.

157. Питерс Т. В поисках эффективного управления / Т. Питерс, Р. Уотермен. М.: Прогресс, 1986. - 254 c.

158. Hubner W. F. Reviews the book "The Structure of Organizations," by Peter M. Blau and Richard A. Schoenherr // Industrial and Labor Relations Review. 1972. - C. 286-287.

159. Papworth M. A. An exploratory content analysis of situational leadership / M. A. Papworth, D. Milne, G. Boak // Journal of Management Development. - 2009. T. 28. - №. 7. - C. 593-606.

160. Porter M. E. Competitive Advantages: Creating and Sustaining Superior Performance / M. E. Porter. - New York : Free Press, 1985. - 252 p.

161. Davenport T. H. Business Innovation, Reengineering Work through Information Technology / T. H. Davenport. - Boston : Harvard Business School Press, 1993. $-364 \mathrm{p}$.

162. Безгін К. С. Порівняльний аналіз процесного та функціонального підходів до управління підприємством / К. С. Безгін, I. В. Гришина // Вісник економічної науки України. - 2009. - № 2. - С. 3-7.

163. ISO 31000:2009, ISO/IEC 31010:2009, СТБ ISO/IEC 31010, COSO, [Електроннй pecypc]. - Режим доступу: http://www.dvbi.ru/risk_management/library/tabid/213/Token/ViewInfo/ItemId/1 4/language/ru-RU/Default.aspx

164. Татеиси К. Вечный дух предпринимательства. Практическая философия бизнесмена / К. Татеиси. - К. : Укрзакордонвизасервис, 1992. - 206 с.

165. Хойер В. Как делать бизнес в Европе / В. Хойер. - М. : Прогресс, 1992. $256 \mathrm{c.}$

166. Минцберг Г. Школы стратегий / Минцберг Г., Альстренд Б., Лэмпел Дж. СПб : Питер, 2001. - 512 с.

167. Конкурентная стратегия: Методика анализа отраслей и конкурентов / 
Майкл Портер ; Пер. с англ. - 4-е изд. - М. : Альпина Паблишер, 2011. $453 \mathrm{c}$.

168. Мартиненко М. М. Стратегічний менеджмент / М. М. Мартиненко, І. А. Ігнатьєва. - К. : Каравела, 2006. - 320 с.

169. Лепейко Т. I. Механізм формування конкурентної стратегії підприємства / Т. І. Лепейко, Д. В. Кіпа // Академічний огляд. - 2014, № 2 (41). - С. 64-69.

170. Павлова В. А. Конкурентоспроможність підприємства: управління, оцінка, стратегія: монографія / В. А. Павлова, О. В. Кузьменко, В. М. Орлова, Г. А. Рижкова. - Дніпропетровськ : ДУЕП імені Альфреда Нобеля, 2011. - 352 с.

171. Стратегия предприятия: теория, методология, практика: монография / Л. В. Кривенко, В. М. Милашенко, С. В. Кривенко; Гос. вуз «Укр. акад. банк. дела Нац. банка Украины». - Полтава : ПУЭТ, 2012. - 256 с.

172. Животенко В. О. Принципи формування ефективної системи антикризового управління підприємствами [Електронний ресурс]. - Режим доступу: http://www.dspace.puet.edu.ua/bitstream/123456789/2315/1/

Животенко\%20B.Pdf.

173. Harrald J. R. A Strategic Framework for Corporate Crisis Management: Proceeeding of the fifth tiems conference held in Washington D. C., 19-22 May, 1998, P. 389-397.

174. Лук'янихін В. О. Принципи антикризового управління територіальними одиницями [Електронний ресурс] / В. О. Лук'янихін, О. О. Мельник, Мін Лi. - - Режим доступу: http://essuir.sumdu.edu.ua/bitstream/123456789/36884/1/crisis_management.pdf

175. Осадча О. А. Сутність, принципи, функції та методи антикризового управління підприємствами машинобудування / О. А. Осадча // Актуальні проблеми економіки. - 2010. - № 11 (113)- С. 149-155.

176. Функції і принципи антикризового управління [Електронний ресурс]. Режим доступу: http://www.frontmanagement.org/fomants-1871-1.html

177. Сш С. М. Досконала технологія антикризового управління як фактор успіху господарюючих суб'єктів [Електронний ресурс]. - Режим доступу: http://dspace.nuft.edu.ua/jspui/bitstream/123456789/16330/1/5.pdf

178. Обгрунтування господарських рішень та оцінка ризиків : Навчальний посібник / Балджи М. Д., Карпов В. А., Ковальов А. І., Костусєв О. О., Котова І. М.,Сментина Н. В. - Одеса : ОНЕУ, 2013. - 670 с.

179. Сутність та принципи аналізу господарських рішень [Електронний ресурс]. - Режим доступу: http://www.uaeconomic.com/ulens-29-1.html

180. Burns T. The Management of innovation / T. Burns, G. Stulker. - L. : Tavistock, 1961.

181. Саломатіна Л. М. Адаптаційні механізми в управ- лінні розвитком промислових підприємств / Л. М. Саломатіна [Електронний ресурс]. Режим доступу : д nbuv.gov.ua/portal/soc_gum/eprom/2011_54/st_54_10

182. Аубакирова Г. М. Становление и развитие адаптивного управления промішленнім предприятием / Г. М. Аубакірова // Вестник КАСУ. - 2007. № 4. - C. 87-93.

183. Лупак Р. Л., Романюк В. О. Запровадження адаптаційних процесів на підприємстві у конкурентному середовищі [Електронний ресурс]. - Режим доступу: 
http://www.rusnauka.com/2_KAND_2014/Economics/10_154750.doc.htm

184. Фесік Л. І. Адаптивне управління: еволюція поняття та сутнісна характеристика [Електронний ресурс]. - Режим доступу: http://tme.umo.edu.ua/docs/5/11fescec.pdf

185. Кемерон Э. Управление изменениями: Модели, инструменты и технологии организационных изменений / Э. Кемерон, М. Грин. - М. : Добрая книга, 2006. -360 c.

186. Арутюнян Т. Что вам делать со стратегией? Руководство по стратегическому развитию компании / Т. Арутюнян. - М. : Манн, Иванов и Фебер, 2013. - 368 c.

187. Чорна М. В. Управління конкурентоспроможністю підприємств роздрібної торгівлі: теоретико-методологічні засади та практичний інструментарій : монографія / М. В.Чорна. - Х. : ХДУХТ, 2010. - 421 с.

188. Леви М. Основы розничной торговли / М. Леви, Б. А. Вейтц; пер. с англ. Ю. Н. Каптуревского. - СПб. : Питер, 1999. - 448 с.

189. Джонс Р. Оздоровлення роздрібної торгівлі: як налаштувати успішні стратегічні взаємовідносини / Р. Джонс, Д. Мерфі ; пер. 3 англ. Дніпропетровськ : Баланс Бізнес Букс, 2005. - 288 с.

190. Краснокутська Н. С. Управління діловою репутацією торговельного підприємства : монографія / Н. С. Краснокутська, О. А. Товма. - Харків : Видавництво Іванченка I. С., 2016. - 140 с.

191. Торговельне підприємництво: теорія та практика : монографія / за ред. Л. О. Лігоненко. - К. : Київ. нац. торг-екон. ун-т, 2012. - 304 с.

192. Дядюк М. А. Ризикостійкість підприємства як складова інтегрованої системи ризик менеджменту / М. А. Дядюк // Економічна стратегія i перспективи розвитку сфери торгівлі та послуг. - Х. : ХДУХТ, 2014. - с. 150-158.

193. Мишин В., Асташкина И. Стадии и этапы исследования систем управления [Електронний ресурс]. - Режим доступу: http://www.inventech.ru libanalis/analis0025/

194. Функции управления [Електронний ресурс]. - Режим доступу: http://www.btraining.ru/function/

195. Mintzherd H. The nature of managerial work / H. Mintzherd. - Englewood Cliffs, N. J.: Prentice Hall, 1980.

196. Senge P. The fifth discipline the art and practice of the learning organization [Електронний pecypc]. - Режим доступу: http://lib100.com/book/wealth/fifth_discipline/Пятая_дисциплина Теория_и_практика_самообучаюшихся_организаций.pdf

197. Ансофф $\bar{И}$. Стратегическое управление / И. Ансофф ; пер. с англ. под ред. Евенко Л. И. - М. : Экономика, 1989. - 519 с.

198. Руденский Р. А. Антисипативное управление сложными экономическими системами: модели, методы, инструменты [Текст] : монография / Р. А. Руденский. - Донецк : Юго-Восток, 2009. - 257 с.

199. Ashley W. C. Anticipatory Management: Tools for Better Decision Making / William C. Ashley, James L. Morrison // The Futurist. - 1997. - Septemberoctober (№ 31). - P. 47-50. 
200. Дядюк М. А. Управління за слабкими сигналами в системі адаптаційного управління підприємств торгівлі / М. А. Дядюк // Економічна стратегія і перспективи розвитку сфери торгівлі та послуг : зб. наук. праць ХДУХТ. Харків, 2015. - Вип. 2 (22). - С. 1-10.

201. Ямпольская Д. О. Менеджмент / Д. О. Ямпольская, М. М. Зонис. - Спб : Нева. - 2005. - 488 с.

202. Старик Р. Я. Управління змінами як фактор зміцнення ринкової позиції підприємства / Р. Я. Старик // Науковий вісник НЛТУ України. - 2011. Вип. 21.14 - С. 297-303.

203. Попов В. Ю. Удосконалення управлінського процесу на базі функціонально-вартісного аналізу: автореф. дис. ... канд. екон. наук: спец. 08.06.01 / В. Ю. Попов ; Національний аграрний університет. - К., 2002. $19 \mathrm{c.}$

204. Гуржій Н. М. Механізм проактивного управління стратегічною маркетинговою стійкістю / Н. М. Гуржій // Вісник ОНУ ім. І. І. Мечникова. - 2013, Т. 18, Вип. 2. - С. 110-119.

205. Гайдукович Д. С. Характеристика інструментів маркетингового аналізу в сфері банківських послуг [Електронний ресурс]. - Режим доступу: http://dspace.oneu.edu.ua/jspui/bitstream/123456789/948/1/Гайдукович\%20Д.С .\%20Характеристика\%20інструментів\%20маркетингового\%20аналізу\%20в \%20сфері\%20банківських\%20послуг.pdf

206. Коэн Д. С. Суть перемен: путеводитель. Инструменты и тактика руководства преобразованиями в компании : пер. с англ. / Д. Коен, Дж. Коттер. - М. : Олимп-Бизнес, 2007. - 320 с.

207. Куликов П. М. Методичний підхід і оцінювання готовності підприємства до організаційних змін / П. М. Куликов, Н. Е. Беляева // Экономика Менеджмент и Маркетинг. - 2009. - № 5. - С. 130-136.

208. Усик С. П. Вибір стратегії розвитку з урахуванням ступеня готовності підприємства до стратегічних змін / С. П. Усик // Актуальні проблеми економіки. - 2009. - № 6 (96). - С.142-151.

209. Павлова А. В. Позиционирование машиностроительного предприятия относительно успеха реализации изменений в условиях инновационнотехнологической модернизации его производства / А. В. Павлова // Современная экономика: проблемы, тенденции, перспективы. - 2011. - № 5. - C. 2-20.

210. Ермоленко Л. И. Формирование методики оценки готовности предприятия к организационным изменениям / Л. И. Ермоленко // Вестник СамГУ. - № 3 (84). - 2011. - C. 86-92.

211. Гусєва О. Ю. Управління стратегічними змінами: теорія і прикладні аспекти : монографія / О. Ю. Гусєва. - Донецьк: Вид-во «Ноулідж», 2014. 395 c.

212. Метод и инструмент менеджмента [Електронний ресурс]. - Режим доступу: http://allendy.ru/teoruprav/148-method-i-instrument-menegmenta.html

213. Жигало I. I. Економічний інструментарій в системі управління підприсмством http://www.vuzllib.su/articles/961Економічний_інструментарій_в_системі_управління_підприємством/1.html

214. Загорная Т. $\bar{O}$. Управление предприятием на основе системного использования экономических методов / Т. О. Загорная, Ф. А. Шаповалов // 
Прометей. - 2007. - № 2 (23). - С. 251-256.

215. Гейтс Б. Бизнес со скоростью мысли. Изд. 2-е, исправленное - М. : ЭКСМО-Пресс, 2001. - 480 с.

216. Ньюстром Дж. Организационное поведение / Дж. Ньюстром, К. Дэвис. СПб : Питер., 2000. - 448 с.

217. Держак Н. О. Управління реакціями підприємства на ринкові зміни [Електронний ресурс]. - Режим доступу: http://essuir.sumdu.edu.ua/bitstream/ 123456789/24133/1/mmi2011_3_1_106_110.pdf

218. Краснокутська Н. С. Стратегічні завдання розвитку потенціалу торговельних підприємств в Україні в умовах глобалізації / Н. С. Краснокутська // Вісник Хмельницького національного університету. Економічні науки. - Хмельницький : ХмНУ. - 2012. - Т. 3. - С. 77-86.

219. Сгорова Л. І. Стратегія антикризового проактивного управління підприємством : дис... канд. екон. наук за спеціальністю 08.06.01 Економіка, організація і управління підприємствами ; Донецький національний університет. - Донецьк, 2003.

220. Штангрет А. М. Окремі аспекти використання проактивного антикризового управління на поліграфічних підприємствах [Електронний ресурс]. - Режим доступу: http://nz.uad.lviv.ua/static/media/1-11/16.pdf

221. Черняк О. I. Концепція моделювання проактивного механізму прийняття управлінських рішень на базі інструментарію інтелектуального аналізу даних [Електронний ресурс] / О. І. Черняк, Г. О. Чорноус, Я. Стрік. - Режим доступу: http://irh.inf.unideb.hu/ jsztrik/publications/papers/Kiev_011.pdf

222. Ітченко Д. М. Аналіз підходів до проактивного управління в контексті їх застосування при реалізації проектів і програм АПК [Електронний ресурс]. - Режим доступу:

http://vestnik.kpi.kharkov.ua/files/Наукова_періодика/vestnik/Стратегічне\%20 управління,\%20управління\%20портфелями,\%20програмами\%20та\%20прое ктами/2015/2/АНАЛІ3\%20ПІДХОДІВ\%20ДО\%20ПРОАКТИВНОГО\%20УП РАВЛІННЯ.pdf

223. Чорноус Г. О. Методологія проактивного управління соціальноекономічними системами / Г. О. Чорноус // Теоретичні та прикладні питання економіки. - 2012. - Вип. 27, Т.3 - С. 62-70.

224. Чорноус Г. О. Інформаційне забезпечення проактивного управління [Електронний ресурс]. http://visnik.knteu.kiev.ua/files/2012/05/10.pdf

225. Вертакова Ю. В. Упреждающее управление на основе новых информационных технологий [Текст] / Ю. В. Вертакова, Э. Н. Кузьбожев. - Курск : Курск. гос. техн. ун-т, 2001. - 150 с.

226. Большаков А. С. Антикризисное управление на предприятии: финансовый и системный аспекты [Текст] / А. С. Большаков. - СПб. : Изд-во СанктПетербургского гуманитарного ун-та профсоюзов, 2010. - 488 с.

227. Клебанова Т. С. Механизмы и модели управления кризисными ситуаци-ями / Т. С. Клебанова (ред.), В. И. Грачев, Е. В. Раевнева, Л. С. Гуحрьянова, О. Ю. Полякова. - Х. : Инжэк, 2007. - 200 с.

228. Електронний peсурс. - Режим доступу: http://www.klubok.net/ 
article1487.html

229. Larissa T. M. Business Intelligence Roadmap: the complete project lifecycle for decision-support applications / Larissa T. M., Shaku Atre. - Pearson Education, 2003. $-576 \mathrm{p}$.

230. Ситник В. Ф. Інтелектуальний аналіз даних (дейтамайнінг): навч. посіб. / В. Ф. Ситник, М. Т. Краснюк. - К. : КНЕУ, 2007. - 376 с.

231. Балабанов А. С. Выделение знаний из баз данных - передовые компьютерные технологии интеллектуального анализа данных / А. С. Балабанов // Математичні машини і системи. - 2001. - № 1-2. - С. 4054.

232. Бондаренко М. В. Сближение Business Process Management и Business Intelligence: тенденции в 2009 году [Електронний ресурс] / M. В. Бондаренко, С. Н. Тихонов. - Режим доступу : http://journal.itmane.ru/node/49.

233. Бушуєва Н. С. Матричні технології проактивного управління програмами організаційного розвитку : автореф. дис... д-ра техн. наук : 05.13.22 Київ. нац. ун-т будівництва і архітектури. - К., 2008.

234. Darrell Rigby Management Tools 2003 [Електронний ресурс]. - Режим доступу: http://www.management.com.ua/strategy/str097.html.

235. Уотермен Р. Фактор обновления: как сохраняют конкурентоспособность лучшие компании : пер. с англ. / Р. Уотермен. - М. : Прогресс, 1988. - 364 с.

236. Львов Д. С. Эффективное управление техническим развитием / Д. С. Львов. - М. : Экономика, 2000. - 255 с.

237. Словарь современной экономической теории Макмиллана; общ. ред. Д.У. Пирса. - М. : ИНФРА-М, 2003. - 608 с.

238. Эшби У. Р. Введение в кибернетику / У. Р. Эшби. - М. : Иностр. лит., 1959. $-432 \mathrm{c}$.

239. Эванс Дж. Маркетинг : пер. с англ. / Дж. Эванс, Б. Берман. - М. : Экономика, 1990. - 352 с.

240. Лунёв В. Л. Тактика и стратегия управления фирмой : учеб. пособие / В. Л. Лунёв. - М. : Финпресс, НГАЭиУ, 1997. - 356 с.

241. Азоев Г. Л. Конкуренция: анализ, стратегия и практика / Г. Л. Азоев. - М. : Центр экономики и маркетинга, 2003. - 374 с.

242. Амоша А. И. Каноны рынка и законы экономики. - Кн. 8: Экономи-ческое проектирование / А. И. Амоша и др. - Донецк : ИЭП НАН Украины, 2005. $548 \mathrm{c}$.

243. Гусев Ю. В. Стратегическое управление : учеб. пособие / Ю. В. Гусев. Новосибирск : Изд-во НГАЭиУ, 1995. - 211 с.

244. Соловьев Б. А. Управление маркетингом. Модуль 13 / Б. А. Соловьев. - М. : ИНФРА-М, 2000. - 288 с.

245. Федоренко Н. П. О целях и стратегии социально-экономического раз-вития России / Н. П. Федоренко // Экономика и математические методы. - 2003. Т. 39. - № 2. - С. 3-13.

246. Селезнев А. Инфраструктура рынка и конкурентоспособность продукции / А. Селезнев // Экономист. - 2009. - № 2. - С. 9-24.

247. Портер М. Стратегія конкуренції. Пер. з англ. / М. Портер. - К. : Основи, 1998. - $390 \mathrm{c}$.

248. Соколова Л. В. Адаптация предприятий к условиям рынка / Л. В. Соколова. 
- Харьков : ФОРТ, 2006. - 246 с.

249. Васильева 3. А. Иерархия понятий конкурентоспособности субъектов рынка / 3. А. Васильева // Маркетинг в России и за рубежом. - 2006. - № 2.

250. Компанец И. Н. Управление конкурентоспособностью предприятия на основе организации предпринимательской деятельности : Автореф. дис. на соиск. учен. степ. канд. экон. наук : (08.00.05) / Компанец Илья Николае ᄀвич ; [С.-Петерб. гос. инженер.-экон. ун-т]. - СПб., 2003. - 16 с.

251. Мілаш I. В. Стратегічне управління витратами підприємств роздрібної торгівлі : монографія / І. В. Мілаш, А. В. Красноусов. - Х. : ХДУХТ, 2015. $286 \mathrm{c}$.

252. Grosul V. A. Structuring of the basic concepts of categorical apparatus of the theory of competition / V. A. Grosul, M. V. Afanasieva // The Advanced Science Journal. - Unated State. - 2014. - P. 94-97.

253. Гросул В. А. Управління конкурентним потенціалом підприємств роздрібної торгівлі : монографія / В. А. Гросул, М. В. Афанасьєва, А. В. Янчев. - Х. : Видавництво Іванченка І.С., 2016. - 244 с.

254. Сімех Ю. А. Оцінка конкурентостійкості підприємств роздрібної торгівлі: автореф. дис. на здобуття наук. ступеня канд. екон. наук: спец. 08.00.04 «Економіка та управління підприємствами (за видами економічної діяльності)». - Харків : ХДУХТ. - 2009. - 16 с.

255. Кулиняк Ю. І. Проблеми визначення сутності конкурентної стратегії організації / Ю. І. Кулиняк // Менеджмент та підприємництво в Україні: етапи становлення і проблеми розвитку. - 2011. - № 714. - С. 87-96.

256. Котлер Ф. Основы маркетинга / Ф. Котлер, Г. Армстронг, Дж. Сондерс, В. Вонг; пер. с англ. - 2-е европ. изд. - М. : Вильямс, 1999. - 1152 с.

257. Конкуренція і конкурентна політика: категорія та поняття / В. Д. Лагутін, О. О. Бакалінська, О. В. Вертелєва та ін.; за заг. ред. В. Д. Лагутіна. - К. : КНТЕУ, 2009. - $320 \mathrm{c}$.

258. Войцеховская И. А. Потенциал предприятия как основа его конкурентоспособности / И. А. Войцеховская // Проблемы современной экономики. - 2006. - № 1/2 (17/18). - С. 152-154.

259. Ерохин Д. В. Теоретические основы оценки конкурентного потенциала промышленной фирмы / Д. В. Ерохин, Д. В. Галушко // Вестник Брянского государственного технического университета. - 2006. - № 4 (12). - С. 76 81.

260. Гольдштейн Г. Я. Стратегический менеджмент : конспект лекций / Г. Я. Гольдштейн. - Таганрог, 1995. - 93 с.

261. Баринов В. А. Развитие организации в конкурентной бреде / В. А. Баринов, А. В. Синельников // Менеджмент. - 2000. - № 6. - С. 3-13.

262. Кристенсен К. М. Решение проблемы инноваций в бизнесе. Как создать растущий бизнес и успешно поддерживать его рост / К. М. Кристенсен, М. Е. Рейнор; пер. с англ. - М. : Альпина Бизнес Букс, 2004. - 290 с.

263. Афанасьєва М. В. Концептуальна модель конкурентного потенціалу підприємства роздрібної торгівлі / М. В. Афанасьєва // Розвиток національної економіки: теорія і практика : Матеріали міжнар. наук.-практ. конф. (Івано-Франківськ, 3-4 квітня 2015 р.); ДВНЗ «Прикарпатський 
національний університет імені Василя Стефаника». - Тернопіль : Крок, 2015. - Ч. 2. - C. 19-20.

264. Воронкова А. Э. Стратегическое управление конкурентоспособным потенциалом предприятия: диагностика и организация : монография; 2-е изд. / А.Э. Воронкова. - Луганск : ВНУ им. В. Даля, 2004. - 320 с.

265. Маковоз О. С. Методичний підхід до оцінки ресурсного потенціалу підприємств роздрібної торгівлі / О. С. Маковоз // Економіка: проблеми теорії та практики: зб. наук. пр. - Дніпропетровськ: ДНУ, 2009. - Вип. 247, т. III. - C. 736-744.

266. Краснокутська Н. С. Потенціал торговельного підприємства: теорія та методологія дослідження : монографія / Н. С. Краснокутська. - Х. : ХДУХТ, 2010. - 247 c.

267. Краснокутська Н. С. Управління потенціалом торговельного підприємства: монографія / Н. С. Краснокутська. - Х. : ХДУХТ, 2012. - 322 с.

268. Федонін О.С. Потенціал підприємства: формування та оцінка: навч. посібник / О.С. Федонін, І.М. Репіна О.І. Олексюк . - К. : КНЕУ, 2004. - 316 c.

269. Корнаи Я. Дефицит / Я. Корнаи. - М. : Наука, 1990. - 607 с.

270. Самочкин В. Н. Гибкое развитие предприятия: анализ и планирование / В. Н. Самочкин. - М. : Дело, 2000. - 376 с.

271. Каледин С. В. Актуальные проблемы оценки деятельности и инвестирования субъектов хозяйствования : монография / С. В. Каледин. Челябинск, 2004. - 256 с.

272. Шабаров А. В. Об одной модели экономического равновесия в менеджменте горизонтальных структур. Моделирование процессов обработки информации и управления / А. В. Шабаров. - М. : МФТИ, 1997. - $167 \mathrm{c}$.

273. Дедов Л. А. Структурно-динамический анализ в экономике : монография / Л. А. Дедов. - Ижевск : ИжГТУ, 1995. - 159 с.

274. Гросул В. А. Методичні підходи до комплексного оцінювання конкурентного потенціалу торговельного підприємства / В. А. Гросул, М. В. Афанасьєва // Актуальні проблеми економіки. - 2015. - № 5(167). - С. 176-183.

275. Власова Н. О. Оцінка економічного потенціалу підприємств роздрібної торгівлі: монографія / Н. О. Власова, О. В. Носова, Н. С. Краснокутська, О. С. Маковоз. - Харків : ХДУХТ, 2011. - 230 с.

276. Краснокутська Н. С. Потенціал підприємства: формування та оцінка : навч. посіб. / Н. С. Краснокутська. - К. : Центр навчальної літератури, 2005. - 352 c.

277. Адаптивные модели в системах принятия решений / ред. Н. А. Кизима. - Х. : ИНЖЭК, 2007. - 364 с.

278. Гросул В. А. Формування фінансової стратегії підприємств роздрібної торгівлі : монографія / В. А. Гросул, Т. С. Колєснік. - Харків : Іванченко І. С., 2015. - 239 c.

279. Кайгородов А. Г. Финансовый потенциал как критерий целесообразности финансового оздоровления предприятия / А. Г. Кайгородов, А. А. Хомякова // Аудит и финансовый анализ. - 2007. - № 4 [Электронный ресурс]. Режим доступа: http://www.auditfin.com/fin/2007/4/Homyakova/ 
Homyakova\%20.pdf.

280. Маслак О. I. Особливості оцінювання фінансового потенціалу промислового підприємства / О. І. Маслак // Вісник КрНУ ім. М. Остроградського. - 2012. - № 6. - С. 124-129.

281. Николаевская О. А. Оценка фінансового потенциала промышленного предприятия / О. А. Николаевская // Управление экономическими системами. - 2013. - № 4 [Електронний ресурс]. - Режим доступу: http://uecs.ru/teoriya-upravleniya/item/2092-2013-04-16-06-06-18.

282. Сердюк-Копчекчи Ю. В. Модель діагностики финансового потенциала промышленных предприятий / Ю. В. Сердюк-Копчекчи // Финансы, учет, банки. - 2011. - Вып. 13. - С. 92-102.

283. Толпежников Р. А. Оценка и прогнозирование финансового потенциала предприятия / Р. А. Толпежников, Л. Ш. Маматова // Ефективна економіка [Електронний ресурс]. - Режим доступу: http://www.economy.nayka.com.ua/ ?op=1\&z=1639.

284. Фомин П. А. Особенности оценки производственного и финансового потенциала промышленных предприятий / П. А. Фомин, М. К. Старовойтов // Среднее профессиональное образование. - 2002. - № 11. - С. 25-35.

285. Кудина М .В. Теория стоимости компании / М. В. Кудина. - М. : ФОРУМ : ИНФРА-М, 2010. - 368 с.

286. Блакита Г. В. Фінансова стратегія торговельних підприємств: методологічні та прикладні аспекти : монографія / Г. В. Блакита. - К. : Київ. нац. торг.екон. ун-т, 2010. - 244 с.

287. Павлова Л. Н. Финансовый менеджмент / Л. Н. Павлова. - М. : ЮнитиДана, 2003. - 269 с.

288. Абрютина М. С. Фианнсовый анализ / М. С. Абрютина. - М. : Дело и сервис, 2011. - 192 с.

289. Азаренкова Г. М. Фінанси підприємств / Г. М. Азаренкова, Т. М. Журавель, Р. М. Михайленко. - К. : Знання-Прес, 2006. - 287 с.

290. Брег С. Настольная книга финансового директора / С. Брег. - М. : Альпина Бизнес Букс, 2007. - 397 с.

291. Блакита Г. В. Систематизація видів фінансової стратегії торговельних підприємств / Г. В. Блакита // Вісн. КНТЕУ. - 2009. - № 6. - С. 67-77.

292. Блакита Г. Методологія вибору виду фінансової стратегії на торговельному підприємстві / Г. Блакита // Вісник КНТЕУ. - 2010. - № 6. - С. 48-60.

293. Зенченко С. В. Система интегральной оценки финансового потенциала региона и методика ее формирования / С. В. Зенченко, В. И. Бережной // Региональные проблемы преобразования экономики. - № 2 (15). - 2008. C. 22-30.

294. Зенченко С. В. Формирование и оценка финансового потенциала региона: монография / С. В. Зенченко. - Ставрополь : СевКавГТУ, 2007. - 211 с.

295. Кунцевич В. О. Поняття фінансового потенціалу розвитку підприємства та його оцінки / В. О. Кунцевич // Актуальні проблеми економіки. - 2004. - № 7 (37). - C. 123-130.

296. Сорокина Н. А. Финансовый потенциал коммерческой организации как элемент стратегического управления / Н. А. Сорокина // Власть и 
управление на Востоке России. - 2009. - № 1 (46). - С. 57-66.

297. Яковлева И. Н. Влияние внешней и внутренней финансовой среды при разработке финансовой стратегии / И. Н. Яковлева // Справочник экономиста. - 2010. - № 10. - С. 5-11.

298. Яковлева И. Н. Справочник по финансовой стратегии и тактике / И. Н. Яковлева. - М. : Профессиональное издательство, 2009. - 336 с.

299. Яроцкий И. В. Методический подход к оценке финансового потенциала страховой организации / И. В. Яроцкий // Вестник ТГЭУ, серия «Экономика и управление». - 2012. - № 3. - С. 55-63.

300. Бланк И. А. Финансовая стратегия предприятия / И. А. Бланк. - К. : НикаЦентр ; Эльга, 2004. - 720 с.

301. Джурабаева Г. К. Интегральная оценка экономического потенциала организации / Г. К. Джурабаева, В. О. Шаланов // Сибирская финансовая школа. - 2009. - №3. - С. 135-138.

302. Чалиев А. А. Совершенствование методологии оценки финансовоэкономического потенциала жилищно-коммунальных предприятий : автореф. дисс. к.э.н. : 08.00.10 / А. А. Чалиев. - Нижний Новгород, 2007. $19 \mathrm{c}$.

303. Шеремет А. Д. Теория экономического анализа / А. Д. Шеремет. - М. : Инфра-М, 2008. - 429 с.

304. Хаустова К. Методика стратегического позиционирования предприятий на основе интегральной оценки инвестиционно-инновационного потенциала / К. М. Хаустова // Проблемы современной экономики. - 2013. - № 2 (46). C. $108-110$.

305. Положення про порядок здійснення аналізу фінансового стану підприємств, що підлягають приватизації / Наказ Міністерства фінансів України № 221 від 8.02.2001 зі змінами та доповненнями [Электронный ресурс]. - Режим доступа: http://zakon4.rada.gov.ua/laws/show/z0121-01.

306. Власова К. Э. Финансовая стратегия: теоретические основы и методика разработки / К. Э. Власова, Е. В. Кырова // Современный менеджмент: проблемы и решения: материалы Междунар. заочной научно-практической конференции, 1 февраля 2010 года. - Новосибирск, 2010. - С. 62-71.

307. Chandler A. D. Strategy and Structure; Chapters in the History of the Industrials Enterprises / A. D. Chandler. - Cambridge, Mass: MIT Press, 1962. - 256 p.

308. Andrews K. R. The Concept of Corporate Strategy / K.R. Andrews. - Dow Jones-Irwin: Homewood, IL, 1971. - 160 p.

309. Лоранж П. Новый взгляд на управленческое образование: задачи руководителей / П. Лоранж. - М.: Олимп-Бизнес, 2004. - 388 с.

310. Сток Дж. Стратегии, которые работают: подход BCG: сб. ст.: пер. с англ. / сост. К. Штерн и Дж. Сток-мл.; [под.общ. ред. И. В. Лазуковой]. - 2-е изд. М.: Манн, Иванов и Фербер, 2007. - 496 с.

311. Хамел Г. Конкурируя за будущее. / Г. Хамел, К. Прахалад. - Олимп-Бизнес, 2002. -288 c. 
ADAPTIVE MANAGEMENT OF TRADE ENTERPRISES:

THEORY AND PRACTICE

The Monograph 